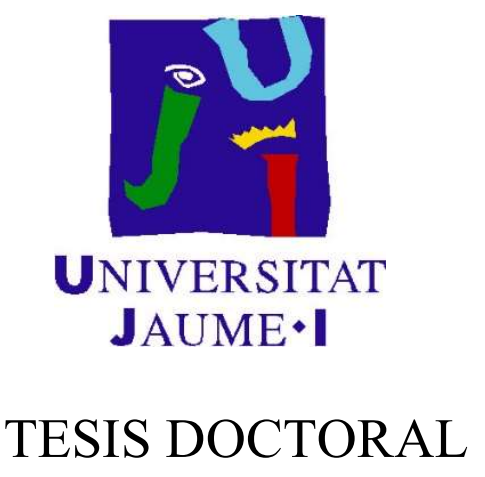

Facultad de Ciencias Jurídicas y Económicas

Departamento de Administración de Empresas y Marketing

Doctorado en Administración de Empresas y Marketing

\title{
MOTIVACIÓN DE COMPRA: UN ESTUDIO COMPARATIVO ENTRE EL PEQUEÑO COMERCIO Y LOS GRANDES CENTROS COMERCIALES
}

\author{
Autora: \\ Sandra Tena Monferrer \\ Directores: \\ Dr. Juan Carlos Fandos Roig \\ Dr. Javier Sánchez García
}

Castellón de la Plana, septiembre de 2016 

A mis padres.

A Isaac. 



\section{AGRADECIMIENTOS}

Es difícil alcanzar a entender la relevancia de los agradecimientos en una tesis doctoral hasta que no se ha finalizado. Es en ese instante cuando te das cuenta de cuánto tienes que agradecer a tanta gente. Intentaré plasmar en las próximas líneas la gratitud que siento hacia todas las personas que han estado presentes durante esta etapa, de una manera $\mathrm{u}$ otra, haciendo posible que deje de ser un sueño y pase a ser una realidad.

Sin duda, a mis directores de tesis. A Juan Carlos Fandos, por sus aportaciones, su apoyo moral y humano, su paciencia y consejos. Por su incansable respaldo desde antes de que comenzase este proyecto. A Javier Sánchez, por su amabilidad, su contagiosa energía y afán de superación.

A mis compañeros de departamento y del grupo de investigación IMK con quien he compartido proyectos e ilusiones durante los últimos años.

A Isaac, por ser y estar. Por ayudarme a cambiar el color del cristal con que se mira.

A mis padres, por su incondicional apoyo. Pues este logro es en gran parte gracias a vosotros.

A todos, muchas gracias. 



\section{RESUMEN}

El objetivo general de esta investigación se centra en el análisis de la motivación de compra del consumidor a través de la utilización de la variable moderadora tipo de centro o establecimiento en el que se realizaron las compras, distinguiendo entre los compradores del pequeño comercio urbano y los compradores de los grandes centros comerciales. Esta clasificación se realiza con el objetivo de detectar diferencias y aspectos significativos o característicos que permitan el desarrollo de estrategias diferenciales para estos pequeños formatos minoristas tradicionales. Este último, un grupo que ha sido a menudo ignorado en contextos generales de la investigación del comercio minorista (Cadeaux y Dubelaar, 2012). Un hecho sorprendente cuando los pequeños comerciantes urbanos son considerados como contribuyentes clave para la economía y el empleo, y catalizadores para la ciudad y la regeneración de la misma (Dixon, 2005).

Al mismo tiempo, también analizar los efectos que la motivación de compra puede generar sobre el valor percibido por el consumidor, la satisfacción o la lealtad. Con el fin último de realizar aportaciones significativas para los gerentes de los pequeños comercios no sólo desde una perspectiva más psicológica o abstracta, sino también con implicaciones en la gestión diaria.

El estudio empírico realizado para confirmar el modelo teórico planteado, se ha realizado sobre una muestra de 516 compradores recientes de moda y complementos de la Comunidad Valenciana.

Las principales conclusiones que hemos obtenido han sido la existencia de dos planos de trabajo diferenciados; por un lado la relación entre la motivación que desencadena o da inicio al proceso de compra y el valor percibido en la experiencia de compra propiamente dicha; y por otro lado, la influencia que ejerce cada una de las dimensiones afectivas y cognitivas del valor percibido sobre la satisfacción. Pues pese a 
que son los motivos éticos o morales que rodean la compra aquellos que desencadenan la selección del pequeño comercio urbano, es el valor hedónico/emocional aquel que mayor influencia tiene en la satisfacción del consumidor y por ende, en la obtención de resultados comerciales a través de la lealtad del consumidor. En este sentido, es esencial que la gerencia de estos pequeños formatos sea capaz de trabajar en ambos planos para así conseguir desarrollar su actividad en una industria altamente competitiva.

Consideramos que, pese a las limitaciones, tanto el modelo teórico propuesto como los resultados obtenidos, estos suponen una contribución relevante a diversas líneas de investigación en el campo de la distribución comercial minorista. El presente trabajo contribuye a una mejor comprensión del comportamiento de compra del consumidor del pequeño comercio urbano tradicional, así como de las peculiaridades de la naturaleza de este formato comercial. En conclusión, consideramos pensamos que los resultados pueden tener implicaciones en la segmentación de los consumidores por parte de los gerentes, así como la definición de acciones de marketing encaminadas a fomentar dichos valores en el camino hacia la obtención de buenos resultados comerciales que aseguren la supervivencia en un entorno altamente competitivo. 


\section{ÍNDICE DE CONTENIDOS}

CAPÍTULO 1. INTRODUCCIÓN ..............................................................................3

1.1. JUSTIFICACIÓN DE LA INVESTIGACIÓN .....................................................

1.2. OBJETIVOS DE LA INVESTIGACIÓN.........................................................

1.3. CONTRIBUCIONES DE LA INVESTIGACIÓN ............................................6

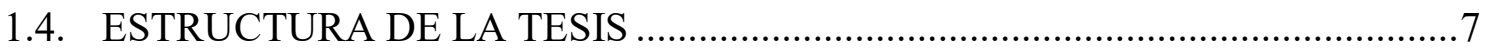

CAPÍTULO 2. EL MARKETING RELACIONAL .........................................11

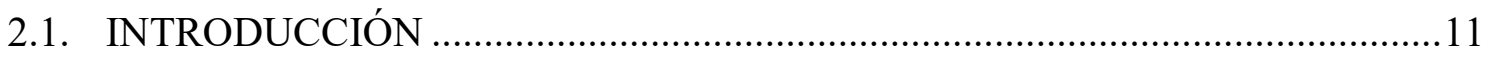

2.2. FUNDAMENTOS TEÓRICOS DEL MARKETING RELACIONAL..................12

2.2.1. Concepto y orígenes del marketing relacional ....................................... 14

2.3. FACTORES FAVORECEDORES DEL DESARROLLO DEL MARKETING

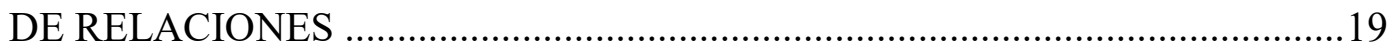

2.4. ENFOQUE RELACIONAL FRENTE AL TRANSACCIONAL .......................27 
3.2.1. Definición y evolución del concepto de motivación .38

3.2.2. Teoría de la autodeterminación . .43

3.2.3. Dimensionalidad de la motivación de compra del consumidor .46

3.2.3.1 Motivación utilitarista y motivación hedónica: la investigación tradicional

3.2.3.2 Motivación ética: la aparición del enfoque moral 55

\section{CAPÍTULO 4. EFECTOS DE LA MOTIVACIÓN DE COMPRA DEL CONSUMIDOR}

4.1. INTRODUCCIÓN 63

4.2. EL VALOR PERCIBIDO POR EL CONSUMIDOR .65

4.2.1. Concepto de valor percibido: definición y evolución 67

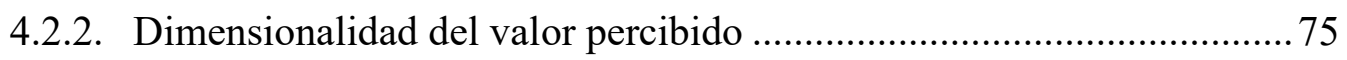

4.2.3. Relación entre motivación y valor percibido 84

4.3. LA SATISFACCIÓN 87

4.3.1. Concepto de satisfacción: definición y evolución 88

4.3.2. Relación del valor percibido y la satisfacción 92 


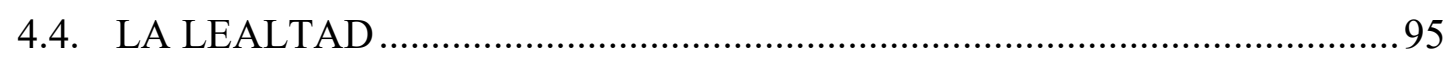

4.4.1. Concepto de lealtad: definición y evolución ............................................95

4.4.2. Definición y evolución del concepto de lealtad .....................................97

4.4.3. Relación entre la satisfacción y la lealtad .............................................107

4.5. MODELO GENERAL PROPUESTO DE LA MOTIVACIÓN DE COMPRA Y SU PAPEL EN LA OBTENCIÓN DE RESULTADOS COMERCIALES EN EL PEQUEÑO COMERCIO................................................................... 109

4.6. EL TIPO DE COMERCIO: VARIABLE MODERADORA .112

CAPÍTULO 5. METODOLOGÍA DE LA INVESTIGACIÓN .121

5.1. OBJETIVO DE LA INVESTIGACIÓN 121

5.2. DESCRIPCIÓN DEL SECTOR OBJETO DE ESTUDIO 122

5.2.1. Sector de la moda y complementos 128

5.3. DISEÑO DEL CUESTIONARIO .131

5.4. SELECCIÓN DE LA MUESTRA Y TRABAJO DE CAMPO 134

5.5. TÉCNICAS ESTADÍSTICAS UTILIZADAS 139 
6.1. DIMENSIONALIDAD, FIABILIDAD Y VALIDEZ DE LAS ESCALAS DE MEDICIÓN

6.2. ANÁLISIS DESCRIPTIVO.

6.2.1. Descripción del perfil de la muestra.

6.2.2. Análisis descriptivo de los datos obtenidos.

6.3. ANÁLISIS DE LAS RELACIONES CAUSALES DEL MODELO ESTRUCTURAL Y CONTRASTE DE LAS HIPÓTESIS 186

6.3.1. Modelo estructural: pequeño comercio urbano. 190

6.3.2. Modelo estructural: gran centro comercial. 194

CAPÍTULO 7. CONCLUSIONES .201

7.1. CONCLUSIONES 201

7.2. IMPLICACIONES PARA LA GESTIÓN .214

7.3. LIMITACIONES Y FUTURAS LINEAS DE INVESTIGACIÓN 217 
Figura 2.1 Fundamentos teóricos del marketing de relaciones ........................... 15

Figura 2.2 Orígenes del marketing relacional ............................................... 17

Figura 3.1 Teoría de la autodeterminación: taxonomía motivacional.................45

Figura 4.1 Teoría de la autodeterminación: taxonomía motivacional................ 111

Figura 5.1 Diferencia gasto medio en subgrupos .......................................... 125

Figura 5.2 Evolución densidad comercial ..................................................... 126

Figura 5.3 Evolución de la facturación del comercio textil en España ...............128

Figura 5.4 Densidad comercial de la Comunidad Valenciana ........................... 136

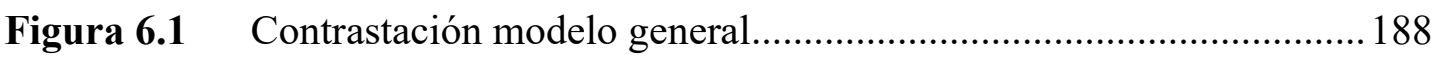

Figura 6.2 Contrastación modelo pequeño comercio urbano ............................. 192

Figura 6.3 Contrastación modelo gran centro comercial ................................... 196 



\section{ÍNDICE DE TABLAS}

Tabla 2.1. Elementos favorecedores desarrollo del marketing relacional ..........20

Tabla 2.2. Diferencias entre marketing transaccional y relacional ....................28

Tabla 2.3. Evolución de la definición de marketing (AMA) ................................31

Tabla 3.1. Definiciones del concepto de motivación .......................................... 41

Tabla 3.2. Investigaciones sobre las motivaciones hedónicas y utilitaristas .......50

Tabla 3.3. Investigación incluyendo dimensiones morales................................57

Tabla 4.1. Definiciones de valor percibido por el consumidor ........................... 71

Tabla 4.2. Trabajos sobre la multidimensionalidad del valor percibido ...............78

Tabla 4.3. Trabajos sobre la relación del valor percibido con la satisfacción .....992

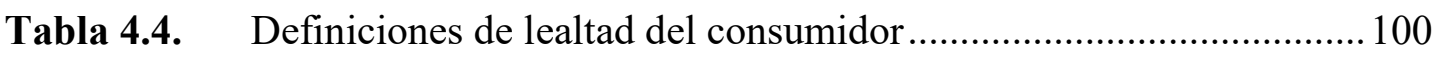

Tabla 5.1. Resumen de las hipótesis planteadas ............................................. 121

Tabla 5.2. Índices de ventas corregidos por formatos comerciales ................... 123

Tabla 5.3. Gasto medio por hogar y por grupo en euros año $2015 \ldots \ldots \ldots \ldots \ldots \ldots \ldots . . . . .124$

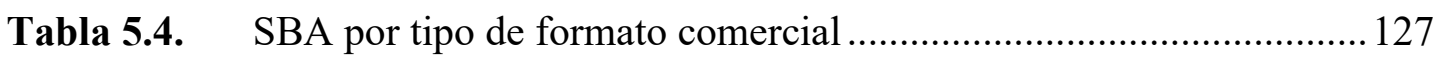

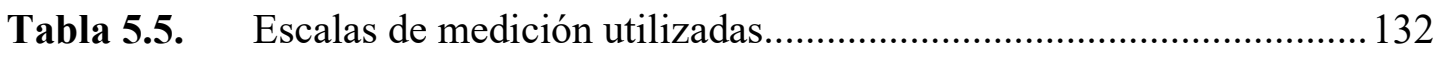

Tabla 5.6. Distribución de la muestra por ciudad, edad y sexo. ......................... 134

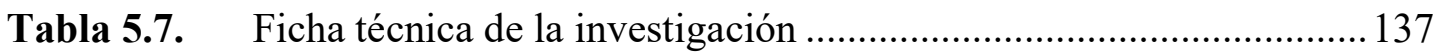

Tabla 6.1. Análisis de las escalas de medida (I) ........................................... 151

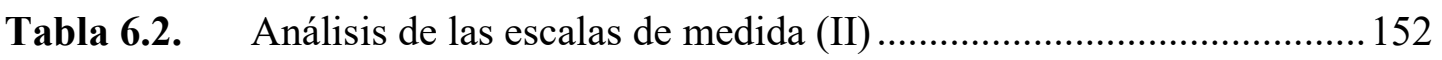

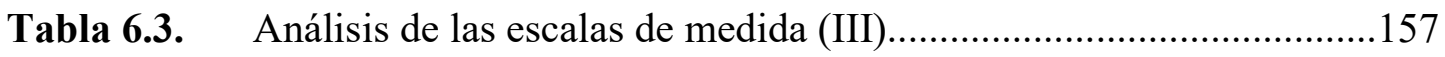

Tabla 6.4. Análisis de las escalas de medida (IV) ............................................ 160 
Tabla 6.5. Análisis de las escalas de medida (V)

Tabla 6.6. Reparto de la muestra según el tipo de comercio en el que se realizó la compra. 163

Tabla 6.7. Tipo de establecimiento en el que se realizó la compra en función de la provincia

Tabla 6.8. Distribución de encuestados por tramos de edad y tipo de comercio en el que realizó la compra

Tabla 6.9. Distribución de encuestados por género y tipo de comercio en el que se realizó la compra.

Tabla 6.10. Distribución de encuestados por ocupación principal y tipo de establecimiento en el que se realizó la compra

Tabla 6.11. Distribución de encuestados según su nivel de estudios superado y el tipo de establecimiento en el que realizó la compra

Tabla 6.12. Distribución de encuestados por nivel de ingresos totales mensuales y tipo de establecimiento 168

Tabla 6.13. Distribución de encuestados por número de miembros en el hogar y tipo de establecimiento

Tabla 6.14. Distribución de encuestados con niños en el hogar y tipo de establecimiento en el que realizó la compra

Tabla 6.15. Distribución de encuestados por tamaño de la población de residencia y tipo de establecimiento

Tabla 6.16. Distribución de encuestados por gasto mensual medio en moda y complementos y tipo de establecimiento 172

Tabla 6.17. Motivación utilitarista de compra por tipo de establecimiento 174

Tabla 6.18. Motivación ética de compra por tipo de establecimiento 175

Tabla 6.19. Motivación hedónica de compra por tipo de establecimiento 176 
Tabla 6.20. Valor utilitarista percibido por tipo de establecimiento.

Tabla 6.21. Valor ético percibido por tipo de establecimiento 179

Tabla 6.22. Valor emocional percibido por tipo de establecimiento 180

Tabla 6.23. Satisfacción por tipo de establecimiento 182

Tabla 6.24. Lealtad por tipo de establecimiento 183

Tabla 6.25. Relaciones causales y contraste de hipótesis I (modelo general) ..... 189

Tabla 6.26. Relaciones causales y contraste de hipótesis II (modelo pequeño comercio urbano)

Tabla 6.27. Relaciones causales y contraste de hipótesis III (modelo gran centro comercial) 

CAPÍTULO 1. INTRODUCCIÓN 



\section{CAPÍTULO 1. INTRODUCCIÓN}

\subsection{JUSTIFICACIÓN DE LA INVESTIGACIÓN}

La intensidad de la competencia para los pequeños comercios urbanos tradicionales ${ }^{1}$ continúa su escalada mientras los grandes formatos minoristas a nivel regional, nacional o internacional se expanden (Noble, Griffith y Adjei 2006; Cadeaux y Dubelaar 2012). Sin embargo, pese al creciente interés que genera el estudio de este tipo comercio detallista en concreto entre académicos y profesionales del sector, existe en general cierta falta de investigación, y una necesidad de profundizar en el conocimiento de las particularidades de estos pequeños comercios. Y en la búsqueda de aquellos factores que mueven al consumidor a decidir realizar sus compras en un determinado tipo de establecimiento entre el amplio abanico de opciones existentes nos encontramos antes la variable motivación de compra.

La motivación de compra es definida como un proceso o condición interna que activa o desencadena el comportamiento, dándole dirección hacia un objetivo $\mathrm{y}$ manteniendo su intensidad a lo largo del tiempo (Atkinson 1964; Kleinginna y Kleinginna 1981; Park y Mittal 1985; Robbins 2003, Solomon y Rabolt 2006; Franken 2006; Schunk et al. 2008; Schiffman y Kanuk 2009; Devesa et al. 2010; Reeve 2010; Solomon et al. 2013, Reeve 2014; Evans 2014; Hoffman 2015).

La motivación varía en su intensidad pero también lo hace en su dirección. La dirección de la motivación hace referencia a los factores subyacentes que dan origen a ese determinado comportamiento. Por un lado, la motivación intrínseca es una motivación natural que surge de manera espontánea, es una propensión inherente. Cuando los

\footnotetext{
${ }^{1}$ Pequeño comercio urbano: aquel comercio tradicional independiente, de tamaño pequeño por el número de puntos de venta con que cuenta, en el que generalmente el papel de la gerencia coincide con la propiedad.
} 
individuos actúan en su propio interés, "porque es divertido", y debido a la sensación que causan dicha actividad, se dice que su motivación es intrínseca. ¿Qué hace tan importante este origen de motivación? La facilidad de lograr continuidad en el tiempo a través de persistencia en las tareas. Con la estimulación adecuada, la motivación continúa de manera constante y reduce la variabilidad en el tiempo, con sus respectivas repercusiones a nivel comercial.

Por otro lado, la motivación extrínseca es aquella que proviene de incentivos y consecuencias externas (dinero, alabanza, atención, aprobación, premios...). En lugar de realizar una actividad con el objetivo de experimentar una satisfacción intrínseca, la motivación extrínseca surge de consecuencias independientes de la propia actividad. Reeve (2010, p.84) afirma que la motivación extrínseca deriva del contrato de comportamiento "hacer esto y conseguir aquello." Por ello es muy importante tener en cuenta este origen de motivación y promover con incentivos y recompensas. Reforzarlo con actos o iniciativas que atraigan a los individuos a seguir realizando una acción en particular.

Llegados a este punto, ese evidente desde un punto de vista práctico orientado a la obtención de resultados comerciales, que la motivación intrínseca representa un factor clave, pues el nivel de esfuerzo necesario para su activación por parte de la empresa es nulo o inexistente. En contraposición, aquella motivación extrínseca que es guiada por incentivos, requieres de planes de acción y estrategias encaminadas a la atracción más específica del consumidor.

En este sentido, y en base a las últimas líneas, en el presente trabajo utilizaremos el tipo de establecimiento (pequeño comercio urbano o gran centro comercial) como variable moderadora con el objetivo no solo de conocer los factores que llevan a comprar en el pequeño comercio, sino también aquellos que hacen ir a comprar a los grandes centros comerciales. Con el fin último de comparar resultados y proponer estrategias de actuación más adecuadas. 


\subsection{OBJETIVOS DE LA INVESTIGACIÓN}

El objetivo general de esta investigación se centra en el análisis de la motivación de compra del consumidor en los dos tipos de comercio establecidos (pequeño comercio urbano y gran centro comercial), con el objetivo de detectar diferencias y aspectos significativos o característicos que permitan el desarrollo de estrategias diferenciales para estos pequeños formatos minoristas. Al mismo tiempo, también analizar los efectos que la motivación de compra puede generar sobre el valor percibido por el consumidor, la satisfacción o la lealtad.

Con el objetivo de alcanzar este objetivo general, se ha llevado a cabo un estudio entre compradores recientes de moda y complementos en la Comunidad Valenciana, en las provincias de Castellón, Valencia y Alicante. A partir de una muestra compuesta por 516 compradores, se ha realizado el estudio comparativo motivacional entre aquellos clientes del pequeño comercio urbano y del gran centro comercial.

El objetivo general puede ser concretado en tres objetivos específicos. El primer objetivo específico estudia las relaciones entre el constructo multidimensional de la motivación de compra y el valor percibido tras la compra por el consumidor. En el segundo objetivo específico tratamos la relación del valor percibido por el consumidor y sus efectos sobre la satisfacción de compra. Y finalmente, el tercer objetivo analiza la relación de la satisfacción y la lealtad. 


\subsection{CONTRIBUCIONES DE LA INVESTIGACIÓN}

De lo expuesto en los apartados anteriores se desprende la relevancia del presente trabajo tanto para el ámbito empresarial como para el académico.

En el ámbito empresarial, nuestro estudio permitirá a los pequeños comercios principalmente conocer en mayor profundidad aquellos valores o aspectos a la naturaleza de su oferta que son valorados por los consumidores. Con esta información, estos detallistas podrán segmentar sus mercados, siendo capaces de aumentar la lealtad de sus clientes a través del desarrollo de acciones de marketing que hagan hincapié en los motivos de compra de cada uno de los diferentes segmentos.

En el ámbito académico, nuestro trabajo no únicamente contribuye a ampliar la escasa literatura existente acerca de las particularidades y especificidades del pequeño comercio urbano. Además representa un estudio comparativo innovador que proporciona una visión completa de la motivación de compra del consumidor. Además el análisis de relaciones establecido entre el valor percibido por el consumidor y la satisfacción aporta información interesante acerca cómo las condiciones internas conducen hacía un tipo de valores asociados a la compra que posteriormente no son aquellos más directamente relacionados con la variable afectiva. 


\subsection{ESTRUCTURA DE LA TESIS}

El trabajo se ha estructurado en siete capítulos. El primero de ellos presenta la justificación de la investigación, sus objetivos y las principales contribuciones del mismo.

El segundo capítulo presenta enfoque del marketing relacional frente al tradicional enfoque transaccional. Son los pequeños negocios, más tradicionales generalmente en esencia, aquellos que evolucionan gradualmente y a lento paso hacia un marketing relacional, centrado en la atracción de clientes y en el aporte de un valor añadido (Badi, Wang y Prike 2016).

En el tercer capítulo se presenta la variable motivación de compra como el punto de partida del proceso de toma de decisiones de compra (Caber y Albayrak 2016), lo que constituye un elemento clave en el proceso de comprensión del comportamiento del consumidor. Se presenta una revisión histórica de la variable, así como su dimensionalidad y principales estudios relativos a la misma.

En el capítulo 4 se exponen los efectos de la variable motivación de compra sobre el valor percibido por el consumidor, la satisfacción y la lealtad como variable que representa el mejor predictor que podemos utilizar a la hora de analizar los posibles comportamientos de recompra por parte del consumidor final (Burnham et al., 2003; Aydin y Özer, 2005; Lin y Ding, 2005; Johnson, Herrmann y Huber, 2006). Al mismo tiempo se presenta la variable moderadora, la tipología de formato comercial como herramienta que los permitirá realizar la comparación de resultados entre el pequeño comercio urbano y el gran centro comerciales

Los capítulos quinto y sexto recogen la metodología de la investigación llevada a cabo, así como los principales análisis de resultados. Finalmente, en el capítulo 8 se recogen las conclusiones obtenidas del estudio, las conclusiones generales de la tesis, las recomendaciones para la gestión, así como las limitaciones y futuras líneas de trabajo. 

CAPÍTULO 2. EL MARKETING RELACIONAL 



\section{CAPÍTULO 2. EL MARKETING RELACIONAL}

\subsection{INTRODUCCIÓN}

El marketing transaccional tradicional, con su perspectiva cortoplacista y su enfoque centrado en las características del producto y las transacciones individuales, es cada vez más discordante con el entorno altamente competitivo en el que hoy en día se mueven las empresas (De Wulf. et al. 2001, Christopher, Payne y Ballantyne 2002, Zineldin y Philipson 2007, Palmatier et al. 2009, Alrubaiee y Al-Nazer 2010, Hau y Ngo 2012, Huang 2015, Yoganathan, Jebarajakirthy y Traichon 2015).

$\mathrm{Y}$ este hecho es particularmente importante para las pequeñas y medianas empresas (PYME), teniendo en cuenta la competitividad de los mercados y los nuevos formatos comerciales con agresivas políticas de precios, se hace cada vez más necesario implantar estrategias que añadan valor a los productos y servicios más allá de su naturaleza misma, con el fin de conseguir diferenciarse (De Wulf. et al. 2001, Christopher, Payne, y Ballantyne 2002, Palmatier et al. 2009, Ndubisi y Matanda 2011, Badi, Wang y Prike 2016).

Estos pequeños negocios, más tradicionales, están evolucionando gradualmente y a lento paso hacia un marketing relacional, centrado en la atracción de clientes y en el aporte de un valor añadido (Badi, Wang y Prike 2016). El marketing relacional, por lo tanto, se centra en mantener relaciones a largo plazo mutuamente beneficiosas entre compradores y vendedores (Spekman y Carraway 2006). De hecho, en este sentido, un número creciente de investigadores en marketing han llamado a un "cambio de paradigma" con las relaciones y redes que se consideran las piedras angulares de la comercialización (Gummesson 1999).

Como una primera aproximación, podemos definir la orientación del marketing relacional como aquel enfoque centrado en la creación y el mantenimiento de la relación 
entre las dos partes que componen todo intercambio, es decir, el proveedor y el consumidor, a través del desarrollo del deseo de ser mutuamente empático, recíproco, y con el objetivo último de confiar y formar vínculos de lealtad a largo plazo (Callaghan et al. 1995, Morgan y Hunt 1994, Yau et al. 2000, Sin et al. 2005, Barroso et al. 2015).

En base a estas líneas, el principal objetivo de este capítulo es realizar una revisión del concepto de marketing relacional, su definición, su origen y su posición como enfoque consolidado en el campo del marketing. Con el fin último de poder reconocer su relevancia en el entorno del pequeño comercio tradicional, en contraposición a su lento proceso de implantación en el mismo (Badi, Wang y Prike 2016).

\subsection{FUNDAMENTOS TEÓRICOS DEL MARKETING DE RELACIONES}

Desde una óptica académica, el marketing relacional es el resultado de un proceso evolutivo que ha surgido fruto del desarrollo de diferentes perspectivas sectoriales, orientaciones y escuelas académicas, y a partir de reflexiones precedentes de distintas extensiones del marketing. El interés por el marketing relacional ha evolucionado a lo largo del tiempo y ha resultado en una proliferación tanto de investigación conceptual como empírica.

Prueba de ello son las publicaciones de libros sobre el marketing de relaciones como los de Hennig-Thurau y Hansen (2000), Sheth y Parvatiyar (2000), Gummesson (2008), Buttle (2008), Kostojohn y Paulen (2011), Baran y Galka (2013) y Chorianopoulos (2016) a nivel internacional, y Martínez-Ribes, Borja y Carvajal (1999), Barroso y Martín (1999), Reinares y Ponzoa (2004), Gómez (2006), Burgos (2007), Barquero y Barquero (2010), Rosendo y Laguna (2014) y Zuluaga (2014) a nivel nacional. 
Respecto a las orientaciones académicas, Payne (1995) y Hart et al. (1999), identifican cuatro escuelas de pensamiento o grupos de investigación que trabajan en el campo del marketing de relaciones.

El primer grupo inició sus investigaciones en la Cransfield School Management en 1988. Este grupo estaba formado por investigadores como Sweeney, Soutar, Ulaga y Eggert, entre otros, cuyos trabajos actualmente se encuentran integrados dentro de la escuela Anglo-Australiana de marketing de relaciones.

El segundo grupo lo encontramos en Europa y está integrado por un equipo de profesores escandinavos, dentro de los cuales se incluyen Grönroos, Evert, Gummesson y otros colegas que desarrollan sus investigaciones tanto en la Escuela Sueca de Economía y Administración de Empresas en Finlandia, como en la Universidad de Estocolmo. La Escuela Nórdica comienza su investigación a raíz del hallazgo de diferencias específicas de los servicios, enfatizando la naturaleza relacional en la preocupación por la calidad del servicio. Grönroos (1984) y Gummeson (1987), así como Christopher, Payne y Ballantyne (1994) han realizado numerosas aportaciones que ayudaron en la comprensión de la integración de calidad, servicio al cliente y marketing.

El tercer grupo de investigadores también se encuentra ubicado en Europa y lo integran los investigadores de la Industrial Marketing Purchasing Group (IMP). Desde finales de la década de los ochenta, se centra en una aproximación al marketing industrial desde la perspectiva del paradigma de redes. Se trata de una concepción del marketing basada en el establecimiento y gestión de las relaciones, bajo el objetivo intrínseco de la fidelización de los clientes, propugnando, en todo caso, la consolidación del enfoque relacional. La investigación realizada por esta escuela se basa en descripciones conceptualmente profundas diseñadas desde una perspectiva relativista.

Por último, el cuarto grupo tiene sus raíces en Norte América, donde el desarrollo del marketing de relaciones puede seguirse a partir de los trabajos de Levitt y Jackson en la Harvard Business School en los mercados industriales, y de Berry y sus compañeros 
de la Texas A\&M University en el campo del marketing de servicios. Más recientemente, Sheth y sus compañeros de la Universidad de Emory en Atlanta, han constituido el Centro para el Marketing de Relaciones. La Escuela Norteamericana está más en la línea del realismo científico o empirismo moderno. En este sentido esta corriente propugna que conceptos tales como la confianza o el compromiso necesitan ser testados en el mercado para establecer su validez. Es por ello, que se tiende a buscar la confirmación o desaprobación de modelos objetivos a través de rigurosos análisis estadísticos de datos cuantitativos.

\subsubsection{Concepto y orígenes del marketing relacional}

El marketing de relaciones sigue cobrado gran interés tras los últimos 20 años, convirtiéndose en uno de los enfoques predominantes en marketing y ampliado sus ámbitos de aplicación (Baker 1995a; Baker 1995b; Buttle 1996; Peck et al. 1999; Gummeson 1999; Sheth y Parvatiyar 2000; Gómez 2006; Burgos, 2007; Gummesson 2008; Buttle 2009). Así, en este punto se analizan los fundamentos teóricos, así como las principales corrientes de investigación que convergen en este enfoque relacional de marketing.

De este modo, al hablar de marketing de relaciones, nos referimos a las actividades de marketing orientadas a establecer, desarrollar y mantener relaciones con los consumidores. Así, el marketing de relaciones es resultado de actividades relacionales de marketing, que no necesariamente tienen que ser actividades realizadas de forma consciente o activa. Desde esta perspectiva, el marketing de relaciones recoge relaciones diádicas y multilaterales, así como redes de relaciones, y comparte con otras disciplinas un claro interés por las alianzas estratégicas, asociaciones así como por sistemas de redes estratégicas. Abarca relaciones intra-organizacionales e inter-organizacionales, así como relaciones entre organizaciones e individuos clientes (Morgan y Hunt 1994; Sheth y Parvatiyar 2000; Gómez 2006; Burgos 2007; Gummesson 2008; Buttle 2009). 
La preocupación por las relaciones y por las redes no es algo nuevo. Aunque sólo a partir de la década de los 70 es cuando la literatura de organización de empresas comienza a destacar su importancia, existen muchos trabajos previos en disciplinas como economía, ciencias políticas, sociología, psicología social y derecho que ya demostraron interés por las relaciones y las redes (Eiriz y Wilson 2006). La figura 2.1 muestra un punto de vista general de cómo el marketing relacional se ha desarrollado desde éstas disciplinas.

Figura 2.1 Fundamentos teóricos del marketing de relaciones

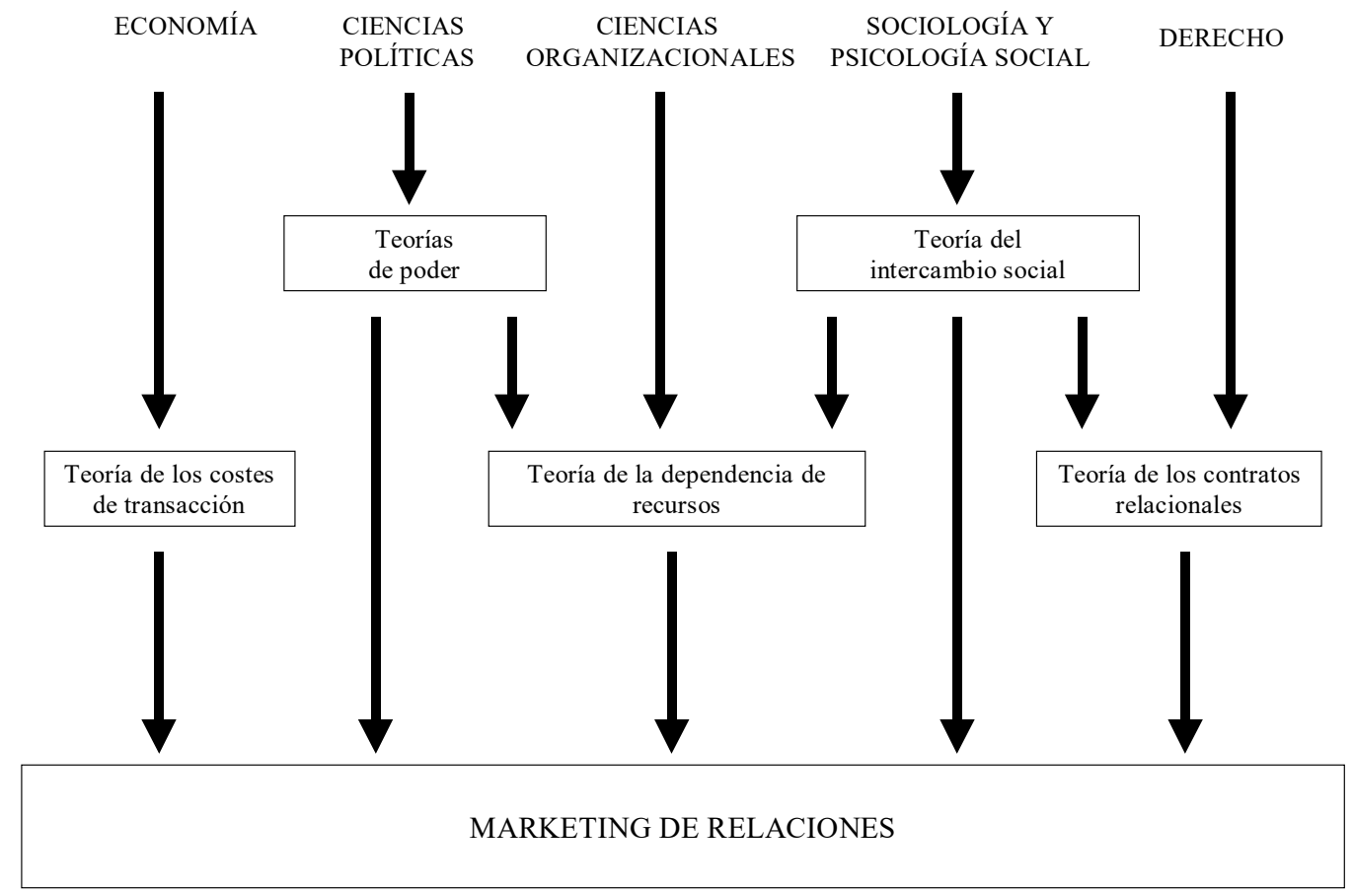

Fuente: Eiriz y Wilson (2006). 
Barbara Bund Jackson, fue la primera en acuñar el concepto de marketing de relaciones en un proyecto de marketing industrial a finales de los años 70. Desde el ámbito de los servicios, Berry (1983) es el primer académico en utilizar y definir formalmente el término de marketing de relaciones (Gummesson 1997). Esta definición es bastante limitada ya que contempla únicamente las relaciones con el cliente final. En trabajos posteriores, se amplía el tipo de relaciones que pueden afectar a la interacción con la empresa (Berry y Parasuraman 1993; Morgan y Hunt 1994; Berry 1995). Asimismo, Jackson (1985) proporciona una definición inicial del concepto de marketing de relaciones desde la perspectiva del marketing industrial.

Aunque las primeras referencias del término de marketing de relaciones se encuentran en Berry (1983) en el ámbito de los servicios, y en Jackson (1985) bajo la óptica del marketing industrial, el concepto de marketing de relaciones no se utiliza de forma general hasta la década de los noventa (Gummesson 1996). De este modo, la mayor parte de las definiciones existentes pueden cubrir algunas situaciones específicas pero no todas, por lo que no es difícil encontrar diversas definiciones del concepto de marketing relacional desde diferentes perspectivas sectoriales. La complejidad de su conceptualización se reafirma con el trabajo de Coviello, Brodie y Grönroos (1998), quiénes después de una amplia revisión bibliográfica identificaron tres tipos de marketing inherentes al enfoque de marketing relacional: marketing de bases de datos -utilización de herramientas informáticas para segmentar y retener a los clientes-, marketing interactivo - desarrollo de relaciones interpersonales, relaciones individuales entre comprador y vendedor- y finalmente, el marketing de redes -posicionamiento de la organización en un conjunto conectado de interrelaciones entre organizaciones-. Ello se debe a las numerosas contribuciones teóricas en el desarrollo del concepto de marketing de relaciones, de forma que no existe un origen único en la formación de dicho concepto.

Los motivos o razones que dieron lugar al nacimiento y posterior desarrollo del concepto marketing de relaciones, pueden ser múltiples y variados, convergiendo la mayoría de ellos en la propia evolución del concepto de marketing, con la introducción 
del concepto de marketing social, en los años setenta y posteriormente con la evolución del marketing de servicios y el industrial en la década de los ochenta (Kotler 1995 y 2000; Grönroos 1989; 1994, 1995 y 2000; Gummesson 1987 y 1994; Alet 1994; Payne et al. 1997; Barroso y Martín 1999; Ambler y Styles 2000; Küster et al. 2000; Healy et al. 2001), convirtiéndose actualmente en el centro de atención de muchos investigadores desde la década de los noventa (Cravens 1992; Berry 1995; Henning-Thurau y Hansen 2000; Healy et al. 2001; Wong y Sohal 2002; Fullerton 2005; Gómez 2006; Suh, Janda y Seo 2006; Burgos 2007; Gummesson 2008; Buttle 2009).

Möller y Halinen (2000) proponen como raíces del marketing de relaciones el marketing industrial, el marketing aplicado a los canales de distribución, el marketing de servicios y el marketing directo o marketing de bases de datos, teniendo en cuenta que mientras los dos primeros enfoques se centran en las relaciones entre empresas, los dos últimos hacen referencia a las relaciones de las empresas con el cliente final (Figura 2.2).

Figura 2.2 - Orígenes del marketing relacional

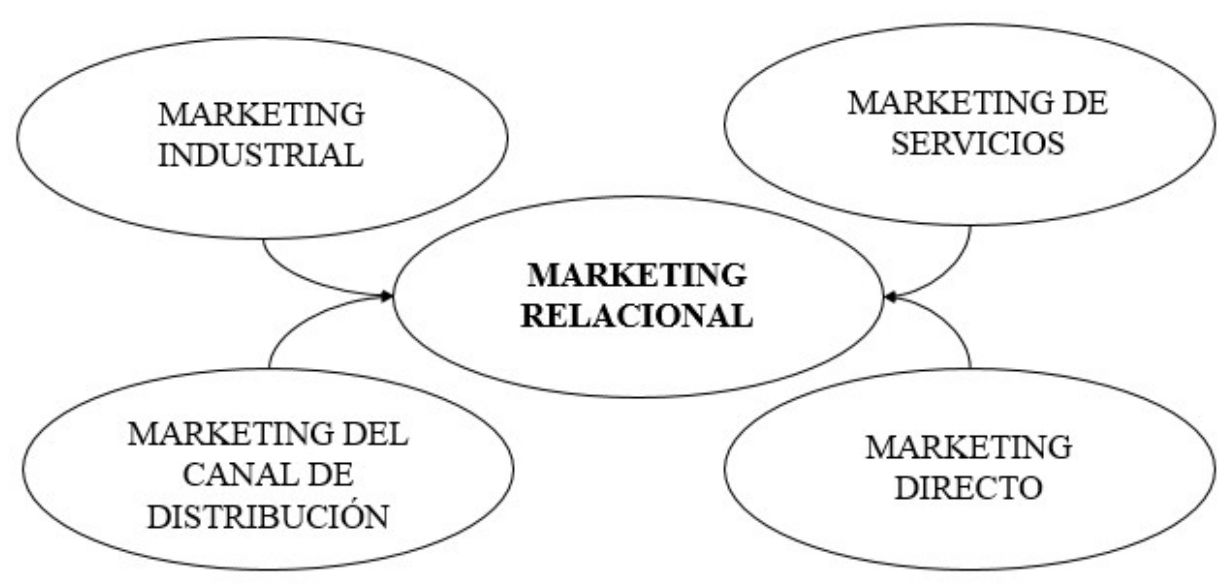

Fuente: Möller y Halinen (2000). 
Concretamente, el marketing en los canales de distribución, presentó en su momento una importante novedad. Las relaciones diádicas entre empresas del canal, en contraposición a la aportación del marketing mix realizada por el marketing transaccional. De este modo, también dentro del canal, el centro de interés pasó del análisis de los mecanismos de control en los sistemas integrados de marketing, a estudiar las relaciones dentro del canal, teniendo un fuerte arraigo en las teorías socio-económicas en el momento de suministrar implicaciones normativas para la adecuada gestión del canal (Bonona y Johnston 1978; Frazier 1983; Anderson y Narus 1984; Frazier, Speckman y O’Neal 1988; Heide y John 1998; Nevin, 1995; Frazier y Antia 1995; Weitz y Jap 1995). Este enfoque explica las estructuras de gobierno y la naturaleza del comportamiento diádico en el contexto de la distribución, en base a una metodología de razonamiento hipotético-deductivo. En él, se analizan las relaciones organizacionales, en el intercambio económico y en su eficiencia, de forma que las relaciones se conciben con un alto grado de interdependencia y reciprocidad. De hecho, la propia literatura ha aportado distintas perspectivas teóricas sin que exista un marco teórico unificador. Por ejemplo, para Stern y Reve (1980), el análisis de los canales de distribución de marketing se basa en el paradigma económico y el paradigma del comportamiento -junto con el paradigma de la política económica, que analiza ambos-. Aunque con posterioridad han venido cobrando interés nuevos paradigmas y teorías -algunos provenientes de otras áreas de investigación-, como la teoría de la dependencia de recursos, la teoría de los costes de transacción, hasta llegar a la teoría del intercambio relacional.

La aplicación de las nuevas tecnologías de la información al marketing, desde mediados de los años ochenta, ha facilitado también el desarrollo del marketing de relaciones (Hart et al. 1999; Zablah, Johnston y Bellenger 2005). Como consecuencia de ello, ha surgido un nuevo tipo de literatura basada en la relación de clientes de una forma más aplicada. De este modo, conceptos como marketing de base de datos, marketing uno a uno, marketing directo o marketing interactivo pueden recogerse en la literatura de marketing (Mckenna 1991; Peppers y Rogers 1993 y 1997; Sheppard 1995; Berger y Nasr 1998; Alet 1994 y 2001). No obstante, estas denominaciones tienen un punto común que 
es la comunicación interactiva como máximo exponente del mantenimiento de la relación (Nickels y Wood 1997; Möller y Halinen 2000; Lindgren 2004).

De este modo, expondremos las diferentes aportaciones teóricas que han influido en la generación del concepto de marketing relacional en base a la clasificación de Möller y Halinen (2000).

\subsection{FACTORES FAVORECEDORES DEL DESARROLLO DEL MARKETING DE RELACIONES}

En el punto anterior hemos analizado los fundamentos del marketing de relaciones y la evolución del concepto a un nivel más académico. Sin embargo, además de los elementos conceptuales estudiados, existen una serie de factores provenientes de la realidad empresarial, de tipo macroeconómico, microeconómico y social, cuya evolución ha favorecido la transición al marketing de relaciones. Tras la revisión bibliográfica realizada (Berry 1995 y 2002; Kotler 1995 y 2000; Grönroos 1989, 1994, 1995 y 2000; Gummesson 1987, 1994, 1996 y 2002; Barroso y Martín 1999; Sheth y Parvatiyar 2002; Eiriz y Wilson 2006; Leverin y Lijander 2006; Palmatier, Dant, Grewal y Evans 2006), se identifican una serie de elementos favorecedores del desarrollo del marketing de relaciones (Tabla 2.1).

En primer lugar, un incremento de la oferta que conlleva a una excedencia productiva que ha dado lugar a un mayor desfase entre oferta generada y demanda existente. En ello ha influido, notablemente, la aplicación de las nuevas tecnologías, que permiten una mayor informatización y automatización de los procesos productivos, aumentando así la productividad de los mismos. El exceso de oferta comporta un mayor abanico de posibilidades de elección por parte de los consumidores, y ante esta situación las empresas necesitan crear vínculos con sus clientes para mantenerlos como tales a lo largo del tiempo (Barroso y Martín 1999). 
Por otro lado, como factores favorecedores del desarrollo del marketing relacional, se encuentran una mayor intensidad y globalización de la competencia (Mckenna 1994; Sheth y Parvatiyar 1995b; Newell 1997; Barroso y Martín 1999; Santesmases 1999; Wong y Sohal 2002) y un incremento de la fragmentación de los mercados (Buttle 1999; Reinares y Ponzoa 2002; Wong y Sohal 2002) en la mayoría de los negocios, tanto de bienes de consumo, como de bienes industriales y servicios. Estas circunstancias han dado lugar a una mayor proliferación de productos y servicios en el mercado, y como consecuencia de ello, una mayor confusión en el consumidor ante un número creciente de productos y servicios semejantes (Fullerton 2005; Gómez 2006; Suh, Janda y Seo 2006; Burgos 2007; Gummesson 2008; Buttle 2009).

Tabla 2.1 - Elementos favorecedores del desarrollo del marketing de relaciones

\begin{tabular}{|l|l|}
\hline \multicolumn{1}{|c|}{ Factores } & \multicolumn{1}{c|}{ Autores } \\
\hline La excelencia productiva. & Barroso y Martín, 1999; Reinares y Ponzoa, 2002 \\
\hline $\begin{array}{l}\text { Una mayor intensidad y } \\
\text { globalización de la competencia. }\end{array}$ & $\begin{array}{l}\text { Mckenna, 1994; Sheth y Parvatiyar, 1995b; } \\
\text { Newell, 1997; Barroso y Martín, 1999; Buttle, } \\
\text { 2002; Wontesmases, 1999; Reinares y Ponzoa, }\end{array}$ \\
\hline $\begin{array}{l}\text { La creciente inquietud por parte } \\
\text { de las empresas en la mejora de } \\
\text { la calidad global. }\end{array}$ & $\begin{array}{l}\text { Gummesson, 1994 y 2002; Sheth y Parvatiyar, } \\
\text { 1995b; Reinares y Ponzoa, 2002 }\end{array}$ \\
\hline $\begin{array}{l}\text { El cambio en los hábitos de vida } \\
\text { y consumo de loso individuos. }\end{array}$ & $\begin{array}{l}\text { Mckenna, 1991; Alet, 1994; Berry, 1995; Magrath, } \\
\text { Newell, 1997; Buttle, 1999; Santesmases, 1999; } \\
\text { Reinares y Ponzoa, 2002; Wong y Sohal, 2002 }\end{array}$ \\
\hline $\begin{array}{l}\text { La evolución del poder de la } \\
\text { marca. }\end{array}$ & $\begin{array}{l}\text { Reinares y Calvo, 1999; Kotler, 2000; Reinares y } \\
\text { Ponzoa, 2002 }\end{array}$ \\
\hline $\begin{array}{l}\text { La evolución en los medios de } \\
\text { comunicación. }\end{array}$ & $\begin{array}{l}\text { Mckenna, 1991; Alet, 1994 y 2000; Hart el al., } \\
1999 ; \text { Kotler, 2000; Reinares y Ponzoa, 2002; } \\
\text { Sheth y Parvatiyar, 2002 }\end{array}$ \\
\hline Los avances tecnológicos. & $\begin{array}{l}\text { Band, 1991; Mckenna, 1991; Peppers y Rogers, } \\
1993 \text { y 1997; Sheppard, 1995; Sheth y Parvatiyar, } \\
1995 b ; \text { Berger y Nasr, 1998; Alet, 1994 y 2001; } \\
\text { Hart el al., 1999; Kotler, 2000; Berry, 2002; } \\
\text { Gummesson, 2002; Reinares y Ponzoa, 2002 }\end{array}$ \\
\hline
\end{tabular}




\begin{tabular}{|c|c|}
\hline Factores & Autores \\
\hline $\begin{array}{l}\text { La evolución en las técnicas de } \\
\text { ventas y canales de distribución }\end{array}$ & $\begin{array}{l}\text { Frazier, 1983; Anderson y Narus, 1984; Frazier, } \\
\text { Speckman y O’Neal, 1988; Ballantyne, 1994; } \\
\text { Sheth, 1994; Nevin, 1995; Weitz y Jap, 1995; } \\
\text { Newell, 1997,; Heide y John, 1998; Buttle, 1999; } \\
\text { ong y Sohar, 2002; Reinares y Ponzoa, 2002 }\end{array}$ \\
\hline $\begin{array}{l}\text { Inadecuación del enfoque } \\
\text { transaccional para el marketing } \\
\text { industrial y de servicios }\end{array}$ & $\begin{array}{l}\text { Zeithaml, Parasuraman y Berry, 1985; Donaldson, } \\
\text { 1996; Grönroos, 1990; Morgan y Hunt, 1994; } \\
\text { Berry, 1995 y 2002; Sheth y Parvatiyar, 2002 Eiriz } \\
\text { y Wilson, 2006; Leverin y Lijander, 2006; } \\
\text { Palmatier, Dant, Grewal y Evans, } 2006\end{array}$ \\
\hline
\end{tabular}

Fuente: Adaptado de Callarisa (2004).

Si además tenemos en cuenta el bajo crecimiento demográfico en los países desarrollados, con el consiguiente estancamiento de la demanda, dicho efecto intensificador de la demanda se acentúa (Band 1991). Para las empresas va a suponer tener que adecuar sus productos y servicios a las necesidades reales de los clientes, integrándolos en el propio proceso de diseño, producción, prestación del servicio y adecuación del precio (Alet 1994; Morgan y Hunt 1994; Payne et al. 1997). En dicho contexto, la creación de valor para el cliente como elemento central de la estrategia competitiva de la empresa, adquiere especial relevancia. Y el concepto de orientación al mercado se convierte en el eje de la política organizativa.

Conjuntamente, también se da una creciente inquietud por parte de las empresas en la mejora de la calidad global de los productos, de los procesos productivos así como de las relaciones con sus clientes y proveedores (Gummesson 1994 y 2000; Sheth y Parvatiyar 1995b; Reinares y Ponzoa 2002) con la intención de diferenciarse de sus competidores inmediatos y de buscar una mayor eficiencia en la aplicación de los recursos disponibles en los procesos productivos. La intensificación de la competencia obliga a las empresas a buscar nuevos sistemas de producción que permitan optimizar los costes, así como buscar ventajas de las relaciones con proveedores y clientes. De esta forma, se han implantado nuevas formas de organización empresarial como el Just In Time (Bello y 
Gómez 1997) o los sistemas de calidad que permitan certificar la organización y la normalización de sus procesos productivos y de la prestación de los servicios (Implantación de los planes de calidad total -Total Quality Management- y de los círculos de calidad y los CTC -Control de la Calidad Total-, así como las nuevas normativas ISO). Del mismo modo, las nuevas tendencias en la certificación medioambiental, y de nuevas prácticas productivas y comerciales socialmente más responsables, se convierten en nuevas herramientas de demostración de la calidad de vida y de sensibilidad social, e influyen también en el proceso de percepción de calidad global de las empresas. En este sentido, va a ser necesario por parte de las empresas, el disponer de las herramientas y habilidades necesarias para comunicar dicha mejora en la calidad a los clientes y proveedores (Woodruff 1997), siendo el marketing de relaciones uno de los instrumentos clave ante este propósito.

Se observa, además, un cambio en los hábitos de vida y consumo de los individuos (Alet 1994; Grönroos 1997; Newell 1997; Buttle 1999; Wong y Sohal 2002) como consecuencia de la aplicación de los avances tecnológicos (Mckenna 1991; Alet 1994; Berry 1995; Magrath 1995; Sheth y Parvatiyar 1995b; Santesmases 1999; Reinares y Ponzoa 2002) tanto a su vida laboral como familiar y social, dotándoles de más tiempo libre, mayor accesibilidad a la información y más posibilidades para ocupar el tiempo de ocio. Ello ha comportado la existencia de consumidores más sofisticados y exigentes en su toma de decisiones de los procesos de compra y en el uso o consumo, lo cual requiere un mayor esfuerzo por parte de las empresas para adaptarse a este creciente nivel de exigencia.

La evolución del poder de la marca (Reinares y Ponzoa 2002), con un aumento de marcas privadas del distribuidor y un consiguiente descenso en el consumo del fabricante, con lo que el poder del canal de distribución pasa a ser mayor. Esto es consecuencia, en parte, de una creciente percepción por parte del consumidor de una semejanza en la calidad de los productos con marca blanca o del distribuidor pero a un menor precio debido a unos menores gastos en comunicación de éstos últimos (Kotler 
2000). Ante esta situación, los establecimientos distribuidores, aplicando políticas de merchandising, modifican su estrategia de marca en el lineal. Así, es cada vez más frecuente que el establecimiento minorista incorpore una marca líder del fabricante, mientras que el resto de marcas de los fabricantes van perdiendo espacio en el lineal, a favor las marcas blancas del distribuidor, convirtiéndose las primeras en elementos de reclamo, imagen o referencia del establecimiento en cuestión. Por lo tanto, es prioritario para las empresas fabricantes conseguir la lealtad de los consumidores a sus marcas, a través de la creación de valor futuro para el cliente mediante técnicas de marketing de relaciones (Alet 1994).

Se observa, también, una evolución en los medios de comunicación (Mckenna 1991; Alet 1994 y 2000; Hart el al. 1999; Kotler 2000; Reinares y Ponzoa 2002; Sheth y Parvatiyar 2002). En los últimos años, han aparecido nuevos medios y como consecuencia de ello, también han aparecido nuevos soportes, tanto en prensa, como en radio, televisión o internet, con la consiguiente dispersión del público objetivo y por lo tanto con una disminución de la efectividad de las campañas de publicidad y de los medios de comunicación masivos convencionales, como soporte de las mismas (Kotler 2000; Reinares y Ponzoa 2002; Sheth y Parvatiyar 2002). Esto provoca dos nuevas situaciones: por una parte existe una menor efectividad del medio en cuestión como elemento comunicador del mensaje frente al público en general, lo cual provoca a su vez una pérdida de cotización del mismo. Por otra parte, dicha situación obliga a las empresas anunciantes a diversificar los distintos medios a través de los cuales va a desarrollar su campaña. Por lo tanto, este doble movimiento convergente provoca una disminución de las tarifas de los medios de comunicación, como es el caso de las televisiones, y por otra parte un aumento de las necesidades de buscar nuevas formas de comunicación más directas, que aumenten la efectividad de las mismas. Así, medios como el correo postal, el correo electrónico, el fax o la televisión por cable ganan protagonismo, en un intento por buscar una comunicación más personalizada. 
A la vez, también es necesario destacar el papel de los avances tecnológicos (Band 1991; Mckenna 1991; Peppers y Rogers 1993 y 1997; Sheppard 1995; Sheth y Parvatiyar 1995b; Berger y Nasr 1998; Alet 1994 y 2001; Hart el al. 1999; Kotler 2000; Berry 2002; Gummesson 2002; Reinares y Ponzoa 2002), que permiten la aplicación de tecnología informática, tanto a los procesos productivos como a los relacionados con la comunicación. Con respecto a los primeros, permite una mejora continua de los procesos, de los productos y de los servicios, adecuándose a las necesidades de los consumidores y a los cambios en el mercado. En cuanto a la aplicación en los procesos de comunicación, facilita el acceso y la utilización de información, permite darle forma, archivarla de forma rápida, dando lugar a una herramienta muy poderosa dentro del marketing de relaciones, como puede ser la base de datos (Möller y Halinen 2000). Todo ello permite la realización de una comunicación personalizada, y por lo tanto más efectiva (Santesmases 1999). La tecnología permite generar una retroalimentación, integrando al cliente en la empresa, posibilitando que ésta se comunique con el mercado y que trabaje según las necesidades del cliente.

Además, el acortamiento del ciclo de vida de los productos (Wong y Schoal 2002), dificulta el mantenimiento de las ventajas competitivas de las organizaciones, por lo que toma cada vez más relevancia el concepto de ciclo de vida del cliente en detrimento del ciclo de vida del producto, para lo cual será necesario saber adaptarse al cliente según el ciclo en que se encuentre (Band 1991). En definitiva, los cambios en la tecnología tienen implicaciones sobre la concepción de la empresa, lo que provoca un cambio en el paradigma de marketing vigente (Aijo 1996)

Otro elemento favorecedor del desarrollo del marketing de relaciones es la evolución en las técnicas de ventas y canales de distribución (Nevell 1997). La causa la encontramos en la existencia de una mayor diversidad de productos, unido a una mayor complejidad técnica de los mismos en unos mercados cada vez más fragmentados (Buttle 1999; Wong y Sohar 2002). Ante esta situación, las empresas necesitan contar con una fuerza de ventas cada vez más cualificada. Este nexo entre tecnología y marketing, ha 
alterado la relación entre cliente y empresa, convirtiendo al personal de contacto en consultores de marketing que asesoran, aconsejan y educan a los clientes (Mckenna 1991). Ello posibilita la explotación de la información sobre el mercado, permitiendo a la empresa mejorar la interacción con el cliente de forma individualizada, según sus características demográficas, psicográficas, estilos de vida y patrones de consumo, apareciendo conceptos como el marketing uno a uno, marketing interactivo o marketing de base de datos.

A su vez, la evolución tecnológica también ha provocado modificaciones importantes dentro del canal (Alet 1994; Mckenna 1994), como es el caso de la aparición de las autopistas de la información, lo que a su vez conduce a la aparición de nuevos competidores, motivando la necesidad de cambiar la filosofía de búsqueda de control y poder dentro del canal por compromiso y coordinación entre sus miembros (Ballantyne 1994; Sheth 1994; Weitz y Jap 1995).

Por otra parte, la creciente importancia del distribuidor como elemento comunicador y transmisor de la propiedad o uso de los bienes del fabricante al consumidor final, ha incrementado el poder del mismo. Además, el distribuidor dispone de información sobre los hábitos y comportamientos del consumidor. Por lo tanto, las empresas fabricantes deben de esforzarse por trabajar de forma conjunta con el distribuidor en la comunicación y merchandising. Cada vez es más habitual la colaboración entre los distintos integrantes del canal de distribución, con el objeto de crear un valor común. El concepto del Just In Time está ligado al de una perfecta integración logística entre proveedor y cliente, y la necesaria reducción de conflictos entre ellos (Reinares y Ponzoa, 2002).

La inadecuación del enfoque transaccional al marketing de servicios y al marketing industrial también apoyó el desarrollo del marketing de relaciones. Una característica propia del marketing de servicios es su heterogeneidad (Zeithaml, Parasuraman y Berry 1985), que junto con otras particularidades como la intangibilidad, 
la caducidad y la adaptabilidad de la oferta a cada individuo, unido al hecho de la necesaria inseparabilidad del servicio en relación a quien lo presta y quien lo recibe, propician el desarrollo de la relación proveedor-cliente, elemento esencial para el marketing de relaciones (Berry 1995 y 2002; Morgan y Hunt 1994). De hecho, para algunos autores los servicios son procesos, no objetos, de ahí que entiendan que una empresa de servicios no tiene productos, sino procesos interactivos (Grönroos 2001; Berry 2002). La influencia del marketing de servicios en el marketing de relaciones queda patente en conceptos como el marketing interactivo y ciclo de vida del cliente, que provienen de la Escuela Nórdica de Servicios. O incluso el propio concepto de marketing de relaciones realizado por Berry en 1983, que representa a la Escuela Americana, y que lo realiza desde la literatura del marketing de servicios, donde propone un continuo de marketing de relaciones en función del tipo de vínculo existente entre las partes, desde la relación financiera a la estructural pasando por la social.

En definitiva, todos estos factores analizados y la interrelación que se ha producido entre ellos, han dado lugar a que a partir de la última década del siglo XX, el marketing de relaciones se haya convertido en un área del máximo interés dentro de la economía (Christopher et al. 1991; Berry 1995 y 2002; Payne et al. 1997; Sheth y Parvatiyar 2002). Su concurrencia e interrelación ha determinado dos aspectos fundamentales, por una parte, ha ampliado una vez más el concepto de marketing con una nueva gama de actividades como son las relaciones de la empresa con los mercados de consumidores, con los empleados, los mercados de referencias y con los mercados de los influyentes. Por otra, de todo ello implícitamente se deriva un cierto reconocimiento de que las relaciones de las empresas con los clientes y el entorno están cambiando y por lo tanto es muy importante poder controlarlas. 


\subsection{ENFOQUE RELACIONAL FRENTE AL ENFOQUE TRANSACCIONAL}

En definitiva, podemos afirmar que, a nivel general, la disciplina de marketing ha experimentado un cambio de enfoque. En parte debido a la evolución de aspectos de índole académica y en parte debido a las fuerzas naturales del mercado. Se ha pasado de un enfoque eminentemente transaccional a otro fundamentalmente relacional (Barroso y Martín 1999; Bigné, Moliner y Callarisa 2000; Sheth y Parvatiyar 2002). Los aspectos más significativos de este cambio se analizarán en este punto.

El término marketing de relaciones ha tenido varias interpretaciones en la literatura de marketing. Para algunos autores ha sido considerado una táctica de marketing, cuyo objetivo es atraer y retener clientes (Jackson 1985; Doyle y Roth 1992). Para otros, se ha planteado si ha sido o es un cambio de enfoque (Day y Wensly, 1983; Grönroos 1990 y 1994; Aijo 1996; Robicheaux y Coleman 1995; Gummesson 1997a y 1997b; Harker 1999; Gomez, Bello y Cervantes 2000) o por el contrario, se trata de una elección estratégica (Berry 1983; Kotler 1991; Mudambi y Mudambi 1995; Chrysty, Oliver y Penn 1996; Morris, Bruyne y Page 1998; Li y Nicholls 2000).

En este sentido, pueden identificarse varias diferencias entre el enfoque transaccional y el relacional (Grönroos 1994; Berry 1995; Barroso y Martín 2000). Efectivamente, el enfoque relacional del intercambio ha supuesto un cambio, tanto a nivel académico como profesional. A nivel general, existen diferencias tanto en la duración del proceso completo de intercambio con el cliente, como en el compromiso tomado por parte de la empresa (Christopher, Payne y Ballantyne 1991; Grönroos 1995; Payne Christopher et al. 1997). El enfoque transaccional, al basarse en un acto puntual que es la venta (Sheth y Parvatiyar 1995a), persigue el intercambio a corto plazo, mientras que el enfoque relacional se basa en un trato que se prolonga en el largo plazo, cuyo objetivo es la lealtad y la creación de relaciones con el cliente (Gummesson 1994; Sheth y Parvatiyar 1995a; Peterson 1995). De este modo, en el enfoque relacional el cliente se ha convertido en el 
elemento clave de la disciplina (Brodie et al. 1997; Coviello y Brodie 1998; Grönroos 1994 y 1995; Gummesson 1987 y 1994).

Si observamos la Tabla 2.2, podemos apreciar que el enfoque transaccional considera que el contacto con el cliente está guiado por la rentabilidad inmediata y que las dos partes persiguen su propio beneficio, mientras que el enfoque relacional supone que ambas partes buscan el beneficio de la relación (Jüttner y Wehrli 1994; Weitz y Jap 1995). De hecho el enfoque tradicional del marketing pone mucho énfasis en el producto, al que se considera la variable fundamental del marketing (Lambin 1995), mientras que el enfoque relacional pone mucho más énfasis en los recursos y capacidades y en los procesos, por lo que el marketing de masas tendrá una aplicación limitada (Grönroos 1990 y 1996; Bitner 1995).

Tabla 2.2 - Diferencias entre el marketing de relaciones y el marketing de transacciones

\begin{tabular}{|c|l|l|}
\hline & Marketing transaccional & \multicolumn{1}{|c|}{ Marketing relacional } \\
\hline 1 & $\begin{array}{l}\text { Se centra en las ventas o transacciones } \\
\text { individuales. }\end{array}$ & $\begin{array}{l}\text { Se centra en el mantenimiento e } \\
\text { intensificación y mejora de las } \\
\text { relaciones con valor para los clientes. }\end{array}$ \\
\hline 2 & $\begin{array}{l}\text { Orientado a las características de los } \\
\text { productos. Escasa diferenciación. }\end{array}$ & $\begin{array}{l}\text { Orientado hacia los beneficios de los } \\
\text { productos para los clientes y } \\
\text { consumidores. }\end{array}$ \\
\hline 3 & $\begin{array}{l}\text { Rentabilidad del producto. (Ciclo de vida del } \\
\text { producto). }\end{array}$ & $\begin{array}{l}\text { Rentabilidad del cliente. (Ciclo de } \\
\text { vida del cliente). }\end{array}$ \\
\hline 4 & $\begin{array}{l}\text { Visión a corto plazo. Obtención de } \\
\text { beneficios a corto plazo. } \\
\text { Óptica del intercambio como proceso } \\
\text { discreto. }\end{array}$ & $\begin{array}{l}\text { Óptica del intercambio como un de la empresa a largo plazo. } \\
\text { proceso continuo. }\end{array}$ \\
\hline 6 & $\begin{array}{l}\text { Óptica del marketing de bienes de consumo. } \\
\text { Óptica del marketing de servicios y } \\
\text { marketing industrial. }\end{array}$ \\
\hline 7 & $\begin{array}{l}\text { Exige un nivel bajo o moderado de } \\
\text { compromiso y de contactos con los clientes. }\end{array}$ & $\begin{array}{l}\text { Exige un elevado nivel de compromiso } \\
\text { y contacto con los clientes. }\end{array}$ \\
\hline
\end{tabular}




\begin{tabular}{|c|c|c|}
\hline & Marketing transaccional & Marketing relacional \\
\hline 8 & $\begin{array}{l}\text { Política diferenciadora entre empresa y } \\
\text { cliente. }\end{array}$ & $\begin{array}{l}\text { Política integradora del cliente en la } \\
\text { empresa, en el diseño de sus productos } \\
\text { y servicios. }\end{array}$ \\
\hline 9 & Necesidad de intermediarios. & $\begin{array}{l}\text { Comprador y vendedor asumen } \\
\text { funciones normalmente desarrolladas } \\
\text { por los intermediarios. }\end{array}$ \\
\hline 10 & $\begin{array}{l}\text { La función de marketing dominante es el } \\
\text { marketing mix. Tiene en cuenta sólo al cliente } \\
\text { como público objetivo. }\end{array}$ & $\begin{array}{l}\text { La función de marketing dominante es } \\
\text { el marketing interactivo. Amplitud de } \\
\text { públicos a los que se dirige. }\end{array}$ \\
\hline & Clientes muy sensibilizados al precio. & Clientes menos sensibles al precio. \\
\hline 12 & $\begin{array}{l}\text { Estrategias de comunicación de masas } \\
\text { dirigidas al mercado, basadas principalmente } \\
\text { en la publicidad y promoción de ventas. }\end{array}$ & $\begin{array}{l}\text { Estrategias de comunicación } \\
\text { segmentadas a partir de la observación } \\
\text { del mercado, basadas principalmente } \\
\text { en el marketing directo y la } \\
\text { recomendación (boca-oreja). }\end{array}$ \\
\hline 13 & \begin{tabular}{|lrr} 
Estrategia & comercial & basada \\
fundamentalmente en la obtención de nuevos & \\
clientes. &
\end{tabular} & $\begin{array}{l}\text { Estrategia comercial } r \text { basada } \\
\text { fundamentalmente en } r \text { el } \\
\text { mantenimiento de clientes satisfechos } \\
\text { y leales. }\end{array}$ \\
\hline 14 & Escaso énfasis en los costes de cambio. & $\begin{array}{l}\text { Especial interés en la creación de } \\
\text { elevados costes de cambio. }\end{array}$ \\
\hline 15 & $\begin{array}{l}\text { La calidad centrada fundamentalmente en el } \\
\text { producto (calidad endógena). }\end{array}$ & $\begin{array}{l}\text { La calidad como preocupación de todos } \\
\text { los integrantes de la empresa (calidad } \\
\text { exógena). }\end{array}$ \\
\hline 16 & $\begin{array}{l}\text { Ventaja competitiva de la empresa basada en } \\
\text { los aspectos tangibles. }\end{array}$ & $\begin{array}{l}\text { Transmisión de valor de la empresa } \\
\text { basada en los aspectos intangibles. }\end{array}$ \\
\hline 17 & $\begin{array}{l}\text { Estrategia de empresa con carácter seguidor, } \\
\text { reactiva. }\end{array}$ & $\begin{array}{l}\text { Estrategia de empresa con carácter } \\
\text { innovador, proactiva. }\end{array}$ \\
\hline 18 & $\begin{array}{l}\text { Objetivo de la empresa basado en términos } \\
\text { económicos y de mejora de la cuota de } \\
\text { mercado. }\end{array}$ & $\begin{array}{l}\text { Objetivo de la empresa basado en } \\
\text { térmicos de aumentar la satisfacción, el } \\
\text { valor y la fidelidad del cliente con la } \\
\text { relación. }\end{array}$ \\
\hline 19 & $\begin{array}{l}\text { Presunción del mercado con cambios lentos o } \\
\text { estables. }\end{array}$ & $\begin{array}{l}\text { Presunción del mercado en constante y } \\
\text { rápido cambio. }\end{array}$ \\
\hline 20 & $\begin{array}{l}\text { Las tareas de marketing se desarrollan dentro } \\
\text { del departamento de marketing. }\end{array}$ & $\begin{array}{l}\text { Las tareas de marketing son } \\
\text { desarrolladas por todos los integrantes } \\
\text { de la empresa. }\end{array}$ \\
\hline
\end{tabular}




\begin{tabular}{|c|l|l|}
\hline & Marketing transaccional & \multicolumn{1}{|c|}{ Marketing relacional } \\
\hline 21 & $\begin{array}{l}\text { Filosofía de rivalidad y conflicto con los } \\
\text { proveedores, competidores y distribuidores. }\end{array}$ & $\begin{array}{l}\text { Filosofía de relaciones y cooperación } \\
\text { mutua entre organizaciones. }\end{array}$ \\
\hline 22 & El marketing como estrategia. & El marketing como filosofía. \\
\hline
\end{tabular}

Fuente: Adaptado de Callarisa (2004).

Otro cambio fundamental es que las actividades de marketing no estarán centradas únicamente en el departamento de marketing, sino que estarán presentes en toda la empresa, y sobre todo en el personal de contacto (Webster 1992; Gummesson, 1987, 1991 y 1994; Grönroos 1995 y 2000; Reinares y Calvo 1999; Kotler 2000; Barroso y Martín 2000). También es necesario destacar la importancia del marketing interno (Shapiro 1989; Trespalacios 1993). Si el marketing externo tiene como función hacer promesas sobre lo que los clientes pueden esperar de la empresa, el marketing interno permite que esas promesas se lleven a la práctica dotando a los empleados y a los sistemas de servicio con las habilidades, capacidades, herramientas y motivación necesarias (Bitner 1995; Gómez, Bello y Cervantes 2000; Kuster 2000).

Por otro lado, el enfoque relacional deja de centrarse en la óptica de los mercados de consumo. Así se da cabida a otras extensiones del marketing como el caso de los mercados de servicios, mercados industriales o aspectos relacionados con el marketing social. Todo ello ha tenido como consecuencia que el enfoque transaccional sólo ha fomentado la tarea de atraer consumidores, considerándose que el marketing se preocupa de forma específica de cómo se crean, se facilitan y se valoran las transacciones (Kotler 1972). En cambio, con el enfoque relacional tienen cabida las tareas de mantenimiento de la relación en el tiempo y por lo tanto, los procedimientos y procesos, elementos tan importantes para el marketing de servicios o el marketing industrial. De hecho en la propia evolución de la definición del concepto de marketing de la AMA (Tabla 2.3) se constata la influencia del enfoque relacional. En la primera de las definiciones se entiende que las 
tareas dirigidas a crear intercambios son las tradicionales de los mercados de consumo, centradas en atraer consumidores, no recogiéndose las labores dirigidas a mantener e intensificar las relaciones con la otra parte del intercambio (Moliner y Callarisa 1997). Tampoco recoge el establecimiento de vínculos con el cliente que incrementasen el posible coste del cambio por otro proveedor, tales como vínculos de carácter personal (afectivos o emocionales, ventajas económicas asociadas a la lealtad, etc.) o asociados al producto (de formación y aprendizaje, de rediseño o reformulación, o de riesgo de fracaso por la nueva elección, entre otros). La última definición introduce ya el valor percibido, las relaciones e incluso otras partes interesadas que pueden ser diferentes al consumidor y a la propia organización pero que también hay que tener en cuenta. Vemos que en la línea más relacional la definición de marketing se ha ido completando y ampliando cada vez más contemplando incluso beneficios para la sociedad en general.

Tabla 2.3 - Evolución de la definición de marketing (AMA)

\begin{tabular}{|c|l|}
\hline AÑO & \multicolumn{1}{c|}{ DEFINICIÓN } \\
\hline 1960 & $\begin{array}{l}\text { Marketing es la ejecución de actividades empresariales que dirigen el flujo } \\
\text { de bienes y servicios de productores a consumidores. }\end{array}$ \\
\hline 1985 & $\begin{array}{l}\text { Marketing es una función de la organización y una serie de procesos para } \\
\text { crear y distribuir valor a los consumidores y para gestionar las relaciones } \\
\text { con clientes de forma que beneficien a la organización y a sus grupos de } \\
\text { interés. }\end{array}$ \\
\hline 2004 & $\begin{array}{l}\text { Marketing es el proceso de planificar y ejecutar la concepción, precio, } \\
\text { promoción y distribución de ideas, bienes y servicios que creen } \\
\text { intercambios que satisfagan los objetivos individuales y organizacionales. }\end{array}$ \\
\hline 2013 & $\begin{array}{l}\text { Marketing es la actividad, grupo de instituciones y procesos para crear, } \\
\text { comunicar, distribuir e intercambiar ofrecimientos que tengan valor para } \\
\text { los consumidores, clientes, partners y sociedad en general. }\end{array}$ \\
\hline $\begin{array}{l}\text { Marketing es la actividad, conjunto de instituciones y procesos para crear, } \\
\text { comunicar, distribuir, y el intercambio de ofertas que tienen valor para los } \\
\text { consumidores, clientes, socios y la sociedad en general. }\end{array}$ \\
\hline
\end{tabular}

Fuente: AMA. 
Dentro de esta línea puede apuntarse también que, en el marketing transaccional, la calidad está centrada básicamente en el producto, en sus especificaciones técnicas y en su proceso productivo, muy en la línea con la orientación de las empresas hacia la consecución de la normalización de la calidad de sus productos y procesos (calidad endógena). Por su parte el marketing de relaciones, va más allá, y persigue la calidad en todos los procesos y en todos los integrantes de la empresa, y que esa filosofía pueda ser transmitida al exterior (Nickels y Wood 1997). De ahí que su interés esté centrado en que la calidad sea entendida como algo interno y externo (calidad exógena), y que recoja aquellos aspectos que el cliente realmente valora. Por ejemplo, cada vez los clientes valoran más los aspectos relacionados con la responsabilidad social de la empresa, sobre todo en aspectos medioambientales y aspectos relacionados con las condiciones de trabajo y su relación con la sociedad en general. De este modo, lo que distingue a una empresa de otra es la calidad entendida desde el punto de vista del cliente, es decir, la calidad percibida, de forma que, lo que permita ofrecer y mantener una ventaja competitiva superior sean los aspectos intangibles (difíciles de identificar, copiar o reproducir) y no los aspectos tangibles asociados al producto o servicio (Gummesson 1994; Grönroos 1995; Woodruff 1997; Sheth y Parvatiyar 2002). En esa capacidad de distinguirse las empresas unas de otras, en esa transmisión de valor superior en base a los intangibles, van a radicar el éxito de las empresas.

Otro elemento diferencial reside en que identificar intercambio con transacción supone centrarse en el intercambio de valores entre las partes (Kotler 1972), mientras que la relación se define en términos de trato o amistad, con un elevado componente afectivo (Horovitz 2000). De este modo, el enfoque relacional hace hincapié en lo continuo mientras que el marketing transaccional se fija en lo discreto (Grönroos 1995). Desde una perspectiva transaccional, la relación con el cliente termina con la venta, mientras que con una perspectiva relacional, con la primera venta comienza la relación con el cliente. 
En este sentido se están realizando muchos esfuerzos para conocer qué elementos son los que determinan la lealtad del consumidor. Es decir, cuando un cliente vuelve a nuestra empresa y se inicia una relación de intercambio duradera, ¿por qué lo ha hecho? Y en el caso de que otro cliente no quiera seguir con nosotros y no quiera volver más o sólo de forma esporádica, ¿qué es lo que le lleva a realizar ese comportamiento? ¿Nuestro producto? ¿Nuestro servicio? ¿Las acciones de la competencia? ¿Su propia personalidad? o ¿las modas u otros aspectos de aceptación social? A tenor de estas dudas que hemos planteado y de muchas otras, bastante más concretas, la línea de investigación sobre la lealtad del consumidor final es una de las más importantes en la actualidad en el campo del marketing de relaciones tanto a nivel académico como en el campo profesional.

De este modo, y a nivel general, se considera que la lealtad es el corazón de la gestión de las relaciones con el cliente (Oliver 1999; Rust, Zeithaml y Lemon 2000; Reichheld 2001; Kivetz y Simonson 2002, 2003; Van Heerde y Bijmolt 2005; Melnik, Van Osselaer y Bijmolt 2009; Yuping y Yang 2009). En este sentido, son muchas las investigaciones publicadas sobre la lealtad en los últimos años (Van Heerde y Bijmolt 2005; Melnik; Kim, Morris y Swait 2008; Brakus, Schmitt y Zarantonello 2009; Fosch, Schloffer, Maloles y Chia 2009; Jamal y Anastasadou 2009; Martínez y Martínez 2009; Melnik, Van Osselaer y Bijmolt 2009; Ponder y Lueg 2009; Wagner, Hennig-Thurau y Rudolph 2009; Yuping y Yang 2009). En esta dirección proponemos el presente trabajo, planteado desde el enfoque del marketing relacional, y donde pretendemos presentar un modelo de formación de la lealtad del consumidor.

Así, hemos visto que el marketing relacional apareció como resultado de un proceso evolutivo. Fundamentalmente la gran idea subyacente y diferencial del marketing relacional es establecer, desarrollar y mantener relaciones con los clientes a largo plazo (Morgan y Hunt 1994). Sin embargo, este enfoque relacional ha tomado elementos de varias disciplinas como la propia economía, las ciencias políticas, las ciencias organizacionales, el derecho y como no, la sociología y la psicología social. Se han combinado ciencias, de alguna manera, más formales y estructuradas que estudian 
esencialmente aspectos cognitivos con otras ciencias que son capaces de trabajar con emociones y afectos. Éstas últimas son necesarias y complementan a la perfección a las primeras si tenemos en cuenta que vamos a trabajar con personas.

De este modo, el marketing de relaciones apareció a partir de las aportaciones del marketing industrial, del marketing aplicado a los canales de distribución, del marketing de servicios y del marketing directo. Además, convergieron una serie de factores económicos y sociales, como el incremento de la competencia, las nuevas tecnologías o la globalización, que favorecieron el desarrollo del enfoque relacional. Desde el marketing relacional se busca mantener relaciones con los clientes a largo plazo, viendo el proceso de intercambio con el cliente como algo continuo. Se trata de conseguir que los clientes estén satisfechos para alcanzar, por un lado su fidelidad y por otro sus recomendaciones a otros clientes potenciales. De este modo, podemos concluir que la lealtad del consumidor es el objetivo principal del marketing de relaciones, ya que un cliente fiel, no sólo volverá a comprarnos la próxima vez que necesite un producto, sino que además hablará bien de nosotros en su entorno. En este sentido, y con el objetivo de contextualizar el presente estudio y las relaciones entre las variables que conducen a la lealtad del consumidor, presentamos el siguiente capítulo. 
CAPÍTULO 3. LA MOTIVACIÓN DE COMPRA DEL CONSUMIDOR 



\section{CAPÍTULO 3. LA MOTIVACIÓN DE COMPRA DEL CONSUMIDOR}

\subsection{INTRODUCCIÓN}

La palabra motivación deriva del término latín "movere", cuyo significado es movimiento. El estudio de la motivación de compra del consumidor representa el punto de partida del proceso de toma de decisiones de compra (Caber y Albayrak 2016), lo que constituye un elemento clave en el proceso de comprensión del comportamiento del consumidor. Por ello, podemos delimitar el estudio de la motivación del consumidor como aquella investigación encaminada a profundizar y definir aquellos factores que conducen a los consumidores a llevar cabo determinado comportamiento encaminado a la compra.

La comprensión de las motivaciones de compra de los consumidores es una tarea esencial si deseamos llevar a cabo un estudio en profundidad del proceso de compra. Ribeiro y Carvalho (2010) afirman que "este conocimiento puede ser interesante para el comercio minorista de pequeño y medio tamaño, ya que puede proporcionar información valiosa para el desarrollo de estrategias de marketing y atraer compradores". Entre las muchas acciones que pueden realizarse en el comercio urbano, los minoristas pueden obtener información y orientación acerca de aquello que los consumidores valoran en la naturaleza de su oferta. La importancia de la estimulación de la experiencia social, el atractivo de la decoración, la facilidad para las comparaciones de productos o el precio son algunas de las líneas de actuación que pueden ponerse de manifiesto.

Por lo tanto, no es sorprendente que este concepto esté generando interés entre tanto académicos como profesionales del comportamiento del consumidor. Sin embargo, la investigación sobre la motivación hasta hace escasos años ha sido campo de trabajo de psicólogos con el objetivo de entender, explicar, predecir y controlar el comportamiento (Hardeep 2010). Es por ello que la mayor parte de la base teórica del concepto contiene 
un gran trasfondo psicológico que se expresará en el presente trabajo desde el punto de vista más práctico con el fin de obtener resultados de utilidad para el comercio minorista.

En esta sección vamos a analizar las diferentes definiciones que se han hecho del concepto de la motivación del consumidor, al mismo tiempo que se llevará a cabo una revisión de las investigaciones anteriores realizadas en la materia. A continuación se estudiará en profundidad la evolución de las dimensiones utilizadas a lo largo de los años para definir la variable.

\subsection{CONCEPTO DE MOTIVACIÓN DE COMPRA DEL CONSUMIDOR}

\subsubsection{Definición y evolución del concepto de motivación}

A través de la comprensión de las motivaciones y valores de los individuos, mayor conocimiento puede ser alcanzado acerca de por qué los individuos se comportan de la manera en que lo hacen (Solomon et al. 2013). Y con el objetivo de contribuir a su comprensión, se llevará a cabo a continuación una revisión conceptual de la variable motivación. Haciendo hincapié en la evolución del concepto a lo largo de la historias y de cómo las antiguas definiciones fueron reemplazadas por nuevas teorías, y finalmente, el modo en el que se expandió su utilización en gran variedad de disciplinas que envuelven la psicología (Bolles 1975).

La definición del concepto de la motivación posee orígenes filosóficos. Desde los antiguos pensadores griegos como Aristóteles, Platón y Sócrates hasta el Renacimiento europeo, la motivación ha sido entendida dentro de dos dimensiones o apartados. Por un lado los aspectos intangibles (es decir, la voluntad) y por otro lado los aspectos impulsivos y biológicos (es decir, los deseos básicos humanos). El estudio filosófico de la voluntad y los impulsos no constituyó el camino correcto, aportaba más cuestiones a debate de las que conseguía resolver con su formulación. 
En consecuencia, la fisiología comenzó a desarrollar nuevos análisis y conceptualizaciones, centrándose en esta ocasión en el concepto mecanicista de la herencia genética (impulsos biológicos dirigidos). En esta etapa se debe destacar el determinismo biológico de Charles Darwin, ya que su concepto de motivación fue capaz de explicar lo que "la voluntad" de los filósofos no podía hacer; conocer el origen de la motivación primaria (Beach 1955).

Como resultado, William James (1890) fue el primer psicólogo que popularizó una teoría de motivación basada en el instinto. James fue significativamente influenciado por Darwin, la asociación con los seres humanos un gran número de instintos mentales y físicas. Todo lo requerido para desarrollar un comportamiento motivado era la presencia de un estímulo.

Woodworth (1918) sustituyó al instinto e introdujo la pulsión en el nuevo concepto de motivación. El deseo se origina de la biología funcional; la función del comportamiento es satisfacer las necesidades del cuerpo. Cuando aparecen los desequilibrios biológicos, el cuerpo del animal experimenta deficiencias, en términos psicológicos llamados pulsiones. Las pulsiones deben ser lo suficientemente fuertes como para buscar cubrir las necesidades. Las dos teorías más aceptadas en lo relativo a las pulsiones como desencadenantes motivacionales fueron las de Freud (1915) y Hull (1943).

La década de 1960 desencadenó la etapa de las mini teorías; la pulsión fue reemplazada por los incentivos y la activación. Pero las mini teorías tenían una limitación, eran capaces de explicar una parte, pero no toda la conducta motivada. Atkinson (1964) fue uno de los principales exponentes de las mini teorías y, como consecuencia, surgió la primera publicación dedicada exclusivamente a la motivación, Motivación y Emoción (1977).

Fue a finales del siglo XX, principios del XXI, cuando las investigaciones dieron un gran salto tras la sustitución de la cuestión principal a investigar. Estar vivo conlleva 
estar activo, por lo que no hay momentos temporales en el que un cuerpo no esté activo, simplemente hay momentos en el que un determinado organismo vivo no muestra evidencias de energía y dirección. Las dos cuestiones principales a investigar a partir de este momento son:

- ¿Por qué varía el comportamiento en su intensidad?

- ¿Por qué una persona se inicia una actividad determinada y no otra?

Este nuevo paradigma de la motivación no sólo se es activado y dirigido por una sola y única causa, sino por una multitud de influencias relacionadas entre sí.

Existen grandes diferencias entre los conceptos, definiciones y las evaluaciones realizadas por diferentes autores en el campo de la motivación. Destaca la cuestión acerca de las diferencias existentes entre aquellos factores que activan o energizan un determinado comportamiento y aquellos factores que proporcionan la persistencia (mantenimiento) en el mismo. Tal y como destaca Huitt (2011), cada una de estas situaciones requiere una medida diferente de los factores.

Además, la existencia de los diferentes conceptos mencionados pone de manifiesto la dificultad de comprensión de la motivación de los individuos, dado que nos estamos refiriendo a un proceso interno. Los investigadores en el campo de la psicología son muy conscientes de esta situación; es una tarea muy compleja explicar el comportamiento humano en toda su complejidad.

Con el fin de presentar y precisar los diferentes puntos de vista sobre el concepto de motivación, en la Tabla 3.1 se recogen algunas de las definiciones que se han utilizado en la literatura, con el objetivo último de proponer una definición de la motivación de compra del consumidor. 
Tabla 3.1 -Definiciones del concepto de motivación.

\begin{tabular}{|c|c|}
\hline AUTOR & DEFINICIÓN \\
\hline Atkinson (1964) & $\begin{array}{l}\text { El concepto de motivación hace referencia a la generación de } \\
\text { una tendencia a actuar, a desencadenar una o más } \\
\text { consecuencias. }\end{array}$ \\
\hline $\begin{array}{ll}\text { Kleinginna } & y \\
\text { Kleinginna }(1981) & \end{array}$ & $\begin{array}{l}\text { La motivación es una condición interna o estado (en ocasiones } \\
\text { descrita como una necesidad o deseo) que activa y genera un } \\
\text { comportamiento dirigido a la consecución de un determinado } \\
\text { objetivo. }\end{array}$ \\
\hline Park y Mittal (1985) & $\begin{array}{l}\text { La motivación se define como aquella activación del } \\
\text { comportamiento hacia la consecución de un determinado } \\
\text { objetivo. }\end{array}$ \\
\hline Robbins (2003) & $\begin{array}{l}\text { La motivación se puede conceptualizar como un proceso que } \\
\text { influye en la orientación y la intensidad de los esfuerzos de los } \\
\text { individuos en la consecución de las metas. }\end{array}$ \\
\hline $\begin{array}{l}\text { Solomon y Rabolt } \\
(2006)\end{array}$ & $\begin{array}{l}\text { Motivación hace referencia a los procesos que llevan a los } \\
\text { individuos a actuar de un modo particular. }\end{array}$ \\
\hline Franken (2006) & $\begin{array}{l}\text { La motivación es la aparición, dirección y persistencia de un } \\
\text { determinado comportamiento. }\end{array}$ \\
\hline Schunk et al. (2008) & $\begin{array}{l}\text { El proceso mediante el cual una actividad intencionada es } \\
\text { activada y sostenida. }\end{array}$ \\
\hline $\begin{array}{l}\text { Schiffman y Kanuk } \\
(2009)\end{array}$ & $\begin{array}{l}\text { La motivación hace referencia a las fuerzas que conducen a } \\
\text { determinados comportamientos. }\end{array}$ \\
\hline Devesa et al. (2010) & $\begin{array}{l}\text { La motivación representa las fuerzas internas que llevan a los } \\
\text { individuos a actuar. }\end{array}$ \\
\hline Reeve (2010) & $\begin{array}{l}\text { El estudio de la motivación hace referencia a aquellos procesos } \\
\text { que impulsan y dan dirección al comportamiento. }\end{array}$ \\
\hline $\begin{array}{l}\text { Solomon et al., } \\
\text { (2013) }\end{array}$ & $\begin{array}{l}\text { Las motivaciones son los procesos que provocan que la gente } \\
\text { se comporte de la manera que lo hace, que además se producen } \\
\text { cuando surge una necesidad que el consumidor desea } \\
\text { satisfacer. }\end{array}$ \\
\hline Reeve (2014) & $\begin{array}{l}\text { La motivación representa la aparición o la generación de un } \\
\text { comportamiento dirigido a la consecución de un objetivo o de } \\
\text { un estado ideal. }\end{array}$ \\
\hline Evans (2014) & $\begin{array}{l}\text { El estudio de la motivación tiene como objetivo definir las } \\
\text { razones que llevan a un organismo, en un determinado } \\
\text { momento, a actuar de la manera en que lo hace. }\end{array}$ \\
\hline
\end{tabular}




\begin{tabular}{|l|l|}
\hline \multicolumn{1}{|c|}{ AUTOR } & \multicolumn{1}{c|}{ DEFINICIÓN } \\
\hline Hoffman (2015) & $\begin{array}{l}\text { El grado de esfuerzo e intensidad dirigido hacia la consecución } \\
\text { de un objetivo conductual o de aprendizaje. }\end{array}$ \\
\hline
\end{tabular}

Fuente: elaboración propia.

Tras analizar las anteriores definiciones del concepto de la motivación (Atkinson 1964; Kleinginna y Kleinginna 1981; Park y Mittal 1985; Robbins 2003, Solomon y Rabolt 2006; Franken 2006; Schunk et al. 2008; Schiffman y Kanuk 2009; Devesa et al. 2010; Reeve 2010; Solomon et al. 2013, Reeve 2014; Evans 2014; Hoffman 2015) se presentan las siguientes conclusiones:

- La motivación es un proceso interno o condición (Kleinginna y Kleinginna 1981, Devesa et al 2010).

- Que activa o desencadena el comportamiento (Atkinson 1964, Kleinginna y Kleinginna 1981, Park y Mittal 1985, Solomon y Rabolt 2006, Reeve 2010).

- Le da dirección hacia un objetivo (Kleinginna y Kleinginna 1981, Park y Mittal 1985, Reeve 2014, Hoffman 2015).

- Al mismo tiempo que instiga o mantiene el mismo (Franken, 2006).

En el presente trabajo se utilizará esta definición de la variable motivación, desarrollada en su concepto esencial por Kleinginna y Kleinginna (1981), que incluye la aportación adicional de Franken (2006). Se trata de la definición más completa, por lo que nos ayudará a desarrollar un mejor estudio en profundidad del comportamiento de los consumidores y sus motivaciones de compra hacia el comercio minorista. 


\subsubsection{Teoría de la autodeterminación: motivación extrínseca e intrínseca.}

Habiendo definido la motivación como un proceso interno o condición que activa o desencadena el comportamiento, le da la dirección hacia una meta e instiga o mantiene el mismo (Kleinginna y Kleinginna 1981; Franken 2006), presentamos a continuación la teoría de la autodeterminación o teoría TAD (en inglés, SelfDetermination Theory (SDT)). Que sin formar del principal objetivo a investigar del presente trabajo debemos destacar su relevancia en comprensión del comportamiento motivado en la literatura.

La motivación varía en su intensidad pero también lo hace en su dirección. La dirección de la motivación hace referencia a los factores subyacentes que dan origen a ese determinado comportamiento. Por ejemplo, un estudiante puede estar altamente motivado a hacer sus deberes debido a su interés y curiosidad en la materia, o en cambio, porque él o ella deseen conseguir la aprobación por parte del profesor o de sus padres. En nuestro campo, un consumidor puede estar motivado a realizar su compra en un determinado tipo de área comercial debido a los factores ambientales y de disfrute que lo rodean, o en cambio, por el reconocimiento social que genera el realizar las compras en ese determinado lugar. En estos ejemplos la intensidad de la motivación no necesariamente tiene que variar, pero la naturaleza y el enfoque de la motivación ciertamente sí lo hacen.

En la teoría de la autoderminación de la motivación podemos diferenciar, en su nivel más básico, entre motivación intrínseca y motivación extrínseca (Pittman et al. 1982; Ryan y Deci 2000; Lutz et al. 2008; Lee et al. 2015; Friederichs et al. 2016). Por un lado, la motivación intrínseca es una motivación natural que surge de manera espontánea, es una propensión inherente. Cuando los individuos actúan en su propio interés, "porque es divertido", y debido a la sensación que causan dicha actividad, se dice que su motivación es intrínseca. ¿Qué hace tan importante este origen de motivación? La facilidad de lograr continuidad en el tiempo a través de persistencia en las tareas. Con la 
estimulación adecuada, la motivación continúa de manera constante y reduce la variabilidad en el tiempo.

Por otro lado, la motivación extrínseca es aquella que proviene de incentivos y consecuencias externas (dinero, alabanza, atención, aprobación, premios...). En lugar de realizar una actividad con el objetivo de experimentar una satisfacción intrínseca, la motivación extrínseca surge de consecuencias independientes de la propia actividad. Reeve (2010, p.84) afirma que la motivación extrínseca deriva del contrato de comportamiento "hacer esto y conseguir aquello." Por ello es muy importante tener en cuenta este origen de motivación y promover con incentivos y recompensas. Reforzarlo con actos o iniciativas que atraigan a los individuos a seguir realizando una acción en particular

En la literatura clásica, la motivación extrínseca ha sido siempre caracterizada como tenue y empobrecida en comparación con la motivación intrínseca (Ryan y Deci 2000). Sin embargo, tal y como podemos apreciar en la Figura 3.1, existen diferentes tipos de motivación extrínseca algunas de las cuales representan tenues fuerzas motivacionales, mientras que otras no lo son, representando agentes activos de cambio direccional (DeCharms 1968). 
Figura 3.1 Teoría de la autodeterminación: taxonomía motivacional

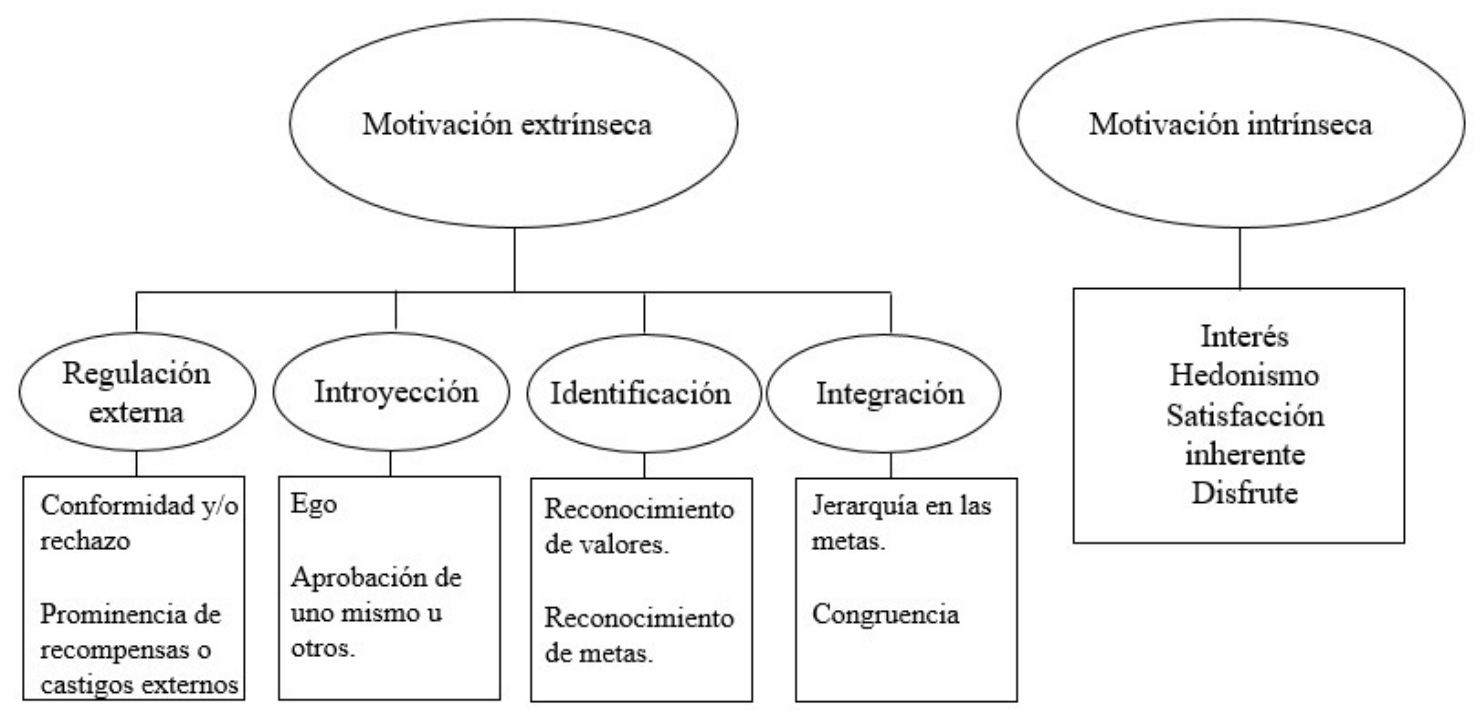

Fuente: adaptación de Ryan y Deci (2000).

Si analizamos la motivación extrínseca, en primer lugar encontramos la categoría de regulación externa. En este caso, los comportamientos de los individuos son llevados a cabo con el objetivo de recibir una recompensa o evitar un castigo. A continuación, la introyección describe comportamientos motivados con el objetivo de promover o incentivar la aprobación de uno mismo de acuerdo con las conductas realizadas, el orgullo o el ego son elementos que aparecen en esta categoría. En tercer lugar aparece la identificación, una forma más autónoma que motivación que las anteriores, en la cual los individuos reconocen la relevancia de la conducta motivada en relación a sus objetivos personales y/o metas establecidas. Finalmente encontramos la integración, una forma más evolucionada y autónoma que la regulación anterior. En esta ocasión, el individuo alcanza no solo a reconocer dichas metas o valores, sino que también es capaz de jerarquizarlas y ordenarlas en función de sus preferencias. Como podemos apreciar, a medida que los desplazamos hacia la derecha, las categorías motivacionales extrínsecas ganan en complejidad y asimilación por parte del individuo. 
Por otro lado, la motivación intrínseca es en su esencia un factor que activa el comportamiento de manera "natural", dando dirección hacia la satisfacción y el disfrute. Un gran número de autores se refieren a este tipo de motivación como la verdadera esencia desencadenante de comportamientos, ya que la disposición del individuo no requiere del uso de refuerzos o recompensas (White 1959; Ryan 1982; Schwartz y Waterman 2006; Wang et al. 2016).

En este sentido, y tras analizar la taxonomía de la motivación propuesta y ampliamente aceptada por Ryan y Deci (2000), podemos concluir que si bien aquellos aspectos hedónicos y de disfrute son considerados como la forma más esencial de motivación no debemos olvidar que los factores extrínsecos cuya integración en la estructura conductual del individuo representan una no menos importante formula motivacional. Si bien en nuestro trabajo se presentan aspectos utilitaristas, hedónicos y éticos, algunos de ellos están compuestos por tanto aspectos extrínsecos como intrínsecos por lo que su análisis se trabajará desde una perspectiva única global.

\subsubsection{Dimensionalidad de la motivación de compra consumidor}

En lo que respecta a la dimensionalidad de la motivación de compra del consumidor, en las últimas décadas la investigación tradicional sobre las motivaciones de compra examina la experiencia de compra en perspectivas tanto utilitaristas como hedónicas (Batra y Ahtola 1991; Babin, Darden y Griffin 1994; Bardhi y Arnould 2005). La investigación tradicional en este campo ha estudiado la motivación como un constructo compuesto por dos dimensiones, una más racional y otra más emocional.

Sin embargo, en los últimos años ha aumentado la importancia de una nueva perspectiva relativa a la moralidad que envuelve la compra. Esta nueva dimensión ha sido añadida en varios estudios (Freestone y McGoldrick 2008; Bezençon y Blili 2009; Guiot y Roux 2010) a las dimensiones tradicionales ya conocidas (hedónica y utilitarista). Los 
autores previamente mencionados consideran que la inclusión de una dimensión ética mejora el resultado del estudio motivacional de compra del consumidor. Por ello, en los siguientes apartados se presentarán las dos líneas de investigación con sus respectivas conceptualizaciones y trabajos más relevantes: la investigación tradicional y la aparición del enfoque moral.

\subsubsection{Motivación utilitarista y motivación hedónica: la investigación}

\section{tradicional}

La dimensión utilitarista representa la parte más racional de la variable motivación, recogiendo los aspectos cognitivos y funcionales del comportamiento del consumidor. Por lo tanto, el comportamiento del consumidor utilitarista puede ser descrito como un enfoque racional que implica o se relaciona con una compra que se realiza de manera eficiente, incluso si la realización de la misma no proporciona ninguna diversión (Babin et al., 2004).

La investigación tradicional entre las motivaciones utilitaristas examina las compras desde un enfoque orientado a la tarea (Batra y Ahtola 1991; Babin, Darden y Griffin 1994). La dimensión utilitarista del comportamiento del consumidor está enfocada hacia la satisfacción de una necesidad funcional o económica (Babin, Darden \& Griffin 1994), y las compras se comparan con la realización de una tarea, siendo su valor representado por el éxito o la finalización de la misma (Hirschman y Holbrook 1982).

En el utilitarismo, un individuo es visto como un "solucionador de problemas" (Hirschman y Holbrook 1982). Es por ello que Babin et al. (1994), Kim (2006) y Ribeiro y Carvalho (2010) establecen en sus trabajos dos dimensiones dentro de la motivación de compra utlitarista: el logro y la eficiencia. El logro hace referencia a una orientación comercial relacionada con la consecución de una meta, donde el éxito se obtiene mediante la obtención de aquellos productos o servicios específicos que se plantearon para esa determinada compra. Mientras que la eficiencia hace referencia a las necesidades del 
consumidor por ahorrar tiempo y recursos en el proceso de compra. El logro representa el cumplimiento del objetivo, mientras que la eficiencia se describe cómo se cumple el objetivo

Las dos dimensiones que componen la motivación utilitarista han sido utilizadas en diversas investigaciones durante los últimos años. Sin embargo, y debido a que la escala es relativamente reciente, algunos de los estudios se desarrollan para confirmarla en diferentes ambientes, situaciones o culturas.

Por otro lado, durante las últimas décadas, los investigadores también han desarrollado la comprensión de la experiencia de compra desde una perspectiva más emocional; la motivación hedónica de compra (Bardhi y Arnould 2005).

El consumo hedónico se ha definido como aquellas facetas del comportamiento humano que se relacionan con lo multisensorial, la fantasía y los aspectos emotivos de la compra (Hirschman y Holbrook 1982; Kang y Park-Poaps 2010). Los motivos de compra hedónicos son similares a los utilitaristas, la diferencia se presenta en la naturaleza de la "tarea" a realizar. En esta ocasión, el objetivo es experimentar diversión, fantasía y estimulación sensorial, en lugar de una consecución eficiente y rápida de la meta en cuestión (Babin et al., 1994).

Los investigadores han centrado su atención a los aspectos emocionales de las compras y la necesidad de profundizar en su comprensión. El componente hedónico o emocional de las compras es visto como una experiencia positiva donde los consumidores pueden disfrutar y sentirse satisfechos con una experiencia relacionada con la actividad comercial, independientemente de si finalmente se realiza la transacción comercial o no. La dimensión hedónica de la motivación de compra se ha analizado y definido como la emoción, la excitación, la alegría, lo festivo, el escapismo, la fantasía, o la aventura (Babin et al. 1994; Bloch y Richins 1983; Sherry 1990; Fischer y Arnold 1990; Hirschman y Holbrook 1982). 
Los avances de la investigación del comportamiento del consumidor parecen indicar que cualquier tipo de compra puede ser placentera, aunque sí es cierto que algunos grupos de consumidores están más interesados en los resultados placenteros de las compras que otros, y que ciertos ambientes producen emociones más placenteras que podrían relacionarse con los diferentes comportamientos de compra. La motivación hedónica se basa en gratificaciones afectivas (Batra y Ahtola 1991). Ir de compras puede representar o puede no representar un placer o actividad recreativa, pero en esta investigación no se va a evaluar la moralidad o inmoralidad de esta cuestión.

El hedonismo, "el lado festivo o incluso epicúreo" (Sherry 1990), está motivado por el deseo de divertirse y experimentar sensaciones positivas. Por lo tanto, la compra hedónica refleja los valores experimentales de las compras que incluyen la fantasía, la excitación, la estimulación sensorial, el disfrute, el placer, la curiosidad (Scarpi 2006; Hirschman y Holbrook 1982). A medida que se han ido confirmado los valores hedónicos asociados a las compras como una nueva dimensión del constructo motivacional, los investigadores han comenzado a reconocer múltiples razones que varían dentro de los motivos hedónicos de compra entre los diferentes individuos (por ejemplo, el disfrute, el placer, la experiencia social y otros valores relacionados con aspectos hedónicos de compra) (Babin et al. 1994; Hirschman y Holbrook 1982; Scarpi 2006).

Los investigadores, por lo tanto, han abandonado la perspectiva unidireccional en la que las compras sólo son una actividad cognitiva y han añadido los factores hedónicos como uno de los motivos para ir de compras. El ocio y la recreación, o las funciones emocionales del estado de ánimo y el placer deben complementar los aspectos más funcionales y cognitivos (Hirschman y Holbrook 1982; Havlena y Holbrook 1986; Bagozzi y Heatherton 1994; Hoffman y Novak 1996).

De acuerdo con ello, autores como Tauber (1972) comenzaron a tratar la motivación como un constructo multidimensional (Tabla 3.2 - Investigaciones más relevantes sobre las motivaciones hedónicas y utilitaristas), su investigación revela que las personas no van de compras sólo porque necesitan un producto. Pueden ir de compras, 
ya que necesitan distracción, la auto-gratificación o conocer gente con intereses similares. El autor realizó un estudio exploratorio, basado en entrevistas en profundidad e identificó once motivos, divididos en dos categorías: los motivos personales y motivos sociales para ir de compras.

Westbrook y Black (1985) sugieren que la motivación de compra está formada por tres dimensiones: el deseo de adquirir un producto, el deseo de satisfacer necesidades no vinculadas con el producto, y el objetivo de lograr ciertos fines independientes de la compra en sí. A continuación, los autores desarrollan las siete dimensiones que encuentran más relevantes en la comprensión de los motivos por los que compran los individuos: la utilidad esperada, adquisición de roles, la negociación, la optimización de la elección, afiliación, poder y autoridad, y la estimulación.

En un trabajo posterior, Babin et al. (1994) desarrollaron una escala para medir las motivaciones hedónicas y utilitaristas de compra del consumidor. El estudio identificó dos dimensiones y mostró que los consumidores perciben las compras tanto en términos utilitarios como hedónicos. También se reconoce que no todos los comportamientos del consumidor implican el cumplimiento de las necesidades funcionales, sino también implica motivaciones emocionales. Pero el hecho más importante es que los autores identificaron dos dimensiones dentro la motivación utilitarista (logro y eficiencia) que fueron utilizados posteriormente en gran variedad de investigaciones.

Tabla 3.2 - Investigaciones más relevantes sobre las motivaciones hedónicas y utilitaristas.

\begin{tabular}{|l|c|}
\hline AUTOR & \multicolumn{1}{c|}{ MEDICIÓN } \\
\hline Tauber (1972) & $\bullet$ Motivación personal \\
& - Juego de roles \\
& - Diversión \\
& - Auto gratificación \\
\hline
\end{tabular}




\begin{tabular}{|c|c|}
\hline AUTOR & MEDICIÓN \\
\hline & $\begin{array}{c}\text { - } \text { Mantenerse al día en nuevas tendencias } \\
\text { - } \quad \text { Actividad física } \\
\text { - } \text { Estimulación sensorial } \\
\text { - Motivación social } \\
\text { - } \text { Experiencias sociales } \\
\text { - } \quad \text { Comunicación } \\
\text { - Atención cara a cara. } \\
\text { - Estatus y autoridad } \\
\text { - Placer y negociación. }\end{array}$ \\
\hline Westbrook y Black (1985) & $\begin{array}{l}\text { - } \text { Utilidad esperada } \\
\text { - Adquisición de roles. } \\
\text { - Negociación } \\
\text { - Optimización de decisiones. } \\
\text { - Afiliación. } \\
\text { - } \\
\text { - } \\
\text { - } \text { Estimulación y autoridad }\end{array}$ \\
\hline Babin et al. (1994) & $\begin{array}{l}\text { - Motivación hedónica. } \\
\text { - Motivación utilitarista. } \\
\text { - } \text { Logro } \\
\text { - Eficiencia }\end{array}$ \\
\hline Arnold y Reynolds (2003) & $\begin{array}{l}\text { - } \\
\text { - } \text { Adventure shopping } \\
\text { - } \quad \text { Role shopping } \\
\text { - } \text { Value shopping } \\
\text { - } \quad \text { Social shopping } \\
\text { - } \quad \text { Idea shopping }\end{array}$ \\
\hline
\end{tabular}




\begin{tabular}{|c|c|}
\hline AUTOR & MEDICIÓN \\
\hline Haanpää (2005) & $\begin{array}{l}\text { - Motivación hedónica } \\
\text { - Motivación recreacional } \\
\text { - Motivación económica } \\
\text { - Motivación de conveniencia }\end{array}$ \\
\hline Kim (2006) & 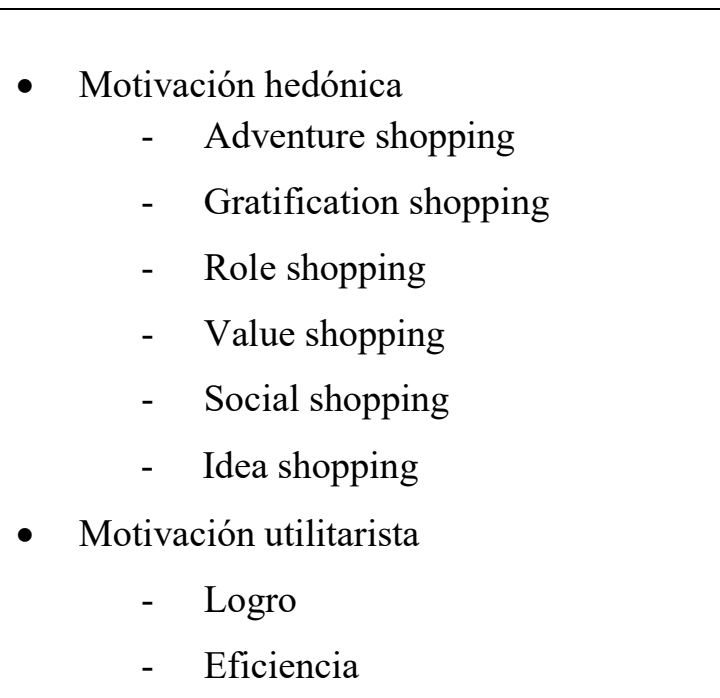 \\
\hline Noble et al. (2006) & $\begin{array}{l}\text { - Obtención de información } \\
\text { - Comparación de precios } \\
\text { - Búsqueda de productos o servicios únicos } \\
\text { - Búsqueda de amplitud de surtido } \\
\text { - Conveniencia } \\
\text { - Interacción social } \\
\text { - Explorar }\end{array}$ \\
\hline Ribeiro y Carvalho (2010) & $\begin{aligned} & \text { Motivación hedónica } \\
- & \text { Pleasure shopping } \\
\text { - } & \text { Idea shopping } \\
- & \text { Social shopping } \\
- & \text { Role shopping }\end{aligned}$ \\
\hline
\end{tabular}




\begin{tabular}{|c|c|}
\hline AUTOR & MEDICIÓN \\
\hline & $\begin{array}{c}\text { - } \quad \text { Value shopping } \\
\text { - Motivación utilitarista } \\
\text { - } \quad \text { Logro } \\
\text { - } \quad \text { Eficiencia }\end{array}$ \\
\hline Kim et al. (2013) & $\begin{array}{l}\text { - Motivación utilitarista } \\
\text { - Motivación social } \\
\text { - Motivación hedónica }\end{array}$ \\
\hline $\begin{array}{l}\text { Chang y Chen (2015) } \\
\text { Chung (2015) }\end{array}$ & 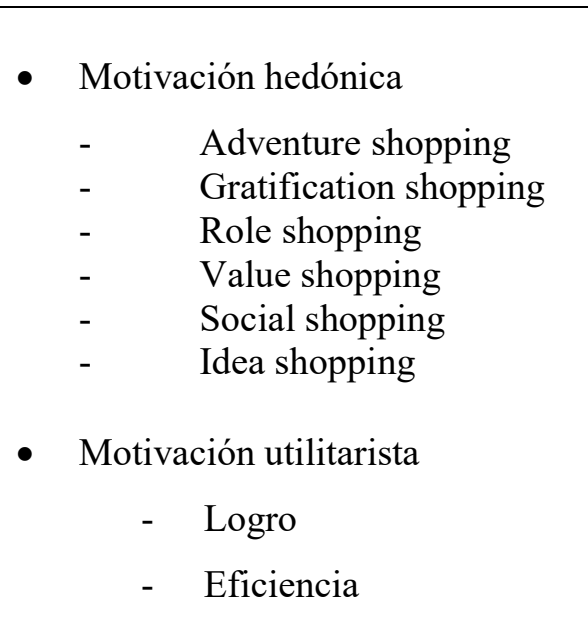 \\
\hline
\end{tabular}

Fuente: elaboración propia.

En 2003, Arnold y Reynolds desarrollaron una escala compuesta por 18 ítems en la que se identificaron seis dimensiones de motivaciones de compra, todas ellas hedónicas. Sobre la base de las motivaciones hedonistas, los autores hicieron un análisis de conglomerados y se identificaron cinco segmentos comerciales que eran realmente útiles para desarrollar estrategias de venta al por menor.

Haanpää (2005) estudió los motivos de compra entre los consumidores finlandeses. El análisis mostró cuatro dimensiones de motivos comerciales, "hedónicos" 
y "recreacionales" conectados con un comportamiento más emocional, y "de conveniencia" y "económicos", más relacionados con los aspectos utilitarios.

Kim (2006) desarrolló una investigación entre los consumidores del centro urbano de una conocida ciudad de Estados Unidos a través del examen de sus motivaciones hedónicas y utilitarias de compra. Se llevó a cabo un estudio entre aquellos habitantes que residían habitualmente en el centro de la ciudad y aquellos que lo hacían en zonas más periféricas con el fin último de comparar sus motivaciones de compra. Kim valida correctamente la escala utilizada por Arnold y Reynolds (2003) para medir las seis dimensiones hedónicas propuestas y también las dos dimensiones utilitarias (Babin et al. 1994): logro y eficiencia.

En 2010, Ribeiro y Carvalho desarrollaron un estudio entre los consumidores jóvenes portugueses con la intención de confirmar los resultados obtenidos en estudios previos llevados a cabo en EE.UU. (Kim 2006; Babin et al. 1994). Su investigación cuantitativa validó los dos factores principales que explican la motivación de compra (motivaciones hedónicas y utilitarias) e identificó siete variables que se muestran en la tabla anterior.

En 2015, dos investigaciones utilizan de nuevo escalas bidimensionales para la medición y estudio de la motivación de compra del consumidor. Chung lleva a cabo un análisis de las motivaciones de compra de los viajeros en los aeropuertos, haciendo hincapié en las relaciones de factores hedónicos e utilitaristas con la satisfacción y lealtad. Entre las conclusiones de su investigación destaca la superioridad de los aspectos multisensoriales y hedónicos a la hora comprar artículos en los aeropuertos frente a los aspectos utilitaristas (duty free). Paralelamente, en ese mismo año, Chang y Chen llevan a cabo una investigación acerca de las motivaciones hedónicas y utilitaristas en la participación en subastas y apuestas online y de cómo la presión temporal en las mismas se relaciona con cada una de dichas dimensiones en cada tipo de usuario. En ambos casos se hace uso de las escalas desarrolladas por los autores Arnold y Reynolds en 2003 y Babin et al. 1994. 


\subsubsection{Motivación ética: la aparición del enfoque moral}

Sin embargo, en los últimos años ha aumentado la notoriedad de una nueva dimensión relacionada con la ética que rodea la decisión de compra (Freestone y McGoldrick 2008). Esta nueva dimensión tiene como objetivo aumentar la comprensión de la compleja serie de variables que influyen en la motivación del consumidor a la hora de desarrollar las compras. Por eso creemos que la inclusión de esta dimensión mejorará el resultado de la investigación motivacional y contribuirá a una más profunda comprensión y análisis de la variable.

El concepto de consumo ético (de la raíz griega ethikos, cuyo significado es "moral") es concebido como una consecuencia del movimiento por el medio ambiente y el consumo verde. La distinción entre el consumo verde y el consumo ético es importante debido a que las preocupaciones éticas representan una gama más amplia de temas y por tanto un proceso más complejo de toma de decisiones para los consumidores (Shaw y Shiu 2002). Las cuestiones éticas incluyen asuntos de conciencia como el comercio justo, las normas laborales, las condiciones de trabajo, las condiciones económicas y de salud o el bienestar animal.

La motivación ética de compra, por lo tanto, hace referencia además las personas que han intervenido o intervendrán en que ese producto o servicio llegue a manos del consumidor (Strong 1996). Los consumidores éticamente motivados tienen en cuenta si el negocio promueve la inclusión de empleados que pertenecen a minorías étnicas o grupos desfavorecidos, como las personas mayores o las personas con discapacidad.

La motivación ética, en su búsqueda de un sentido o sensación de logro, nos redirige a los objetivos de Maslow de la auto-realización y la realización personal (Solomon et al. 2013); los compradores éticos solo están dispuestos a poner su dinero donde también está su moral. 
De acuerdo con Harper y Makatouni (2002, p.289), ser un consumidor ético significa "la compra de productos que no son tan perjudiciales para el medio ambiente y la sociedad, y esto puede ser tan simple como comprar huevos de corral o tan complejo como boicotear los bienes producidos por trabajo infantil”.

No se trata únicamente de productos o servicios éticos; se trata de la compra aquello que se produce éticamente por negocios que también actúan éticamente. Una situación que afecta especialmente al comercio minorista, ya que su actitud y comportamiento puede ser determinante en la decisión de compra.

Se puede decir que el siglo XXI marca la emancipación del consumidor ético (Nicholls 2002), este mercado en crecimiento, donde los consumidores compran intangibilidad, justicia y tal vez la conciencia, está desafiando las teorías comunes de la racionalidad del consumidor. Es por ello que vale la pena preguntarnos sobre las motivaciones de consumo y comportamientos éticos

De acuerdo con ello, autores como Freestone y McGoldrick (2008, p.445) afirman que "existen fuertes indicios de que muchos consumidores están cambiando hacia productos y servicios más responsables social y ambientalmente, lo que refleja un cambio en los valores de consumo indicados en varios países". Es por eso que desarrollan y estudio en profundidad sobre las motivaciones que rodean a los consumidores éticos (Tabla 3.3 - Investigación más reciente de la variable motivación incluyendo dimensiones morales). Los autores identifican cinco dimensiones, tanto en el bienestar personal y social utilizado en sus aspectos positivos y negativos, pero también los aspectos monetarios relacionados con el acto de compra. Los autores también remarcan la importancia de continuar con el estudio de los motivos que impulsan hacia este tipo de compra, o aquellos motivos que disuaden a otros de realizar compras con una mayor carga ética en su motivación esencial. 
Tabla 3.3 Investigación más reciente de la variable motivación incluyendo dimensiones morales.

\begin{tabular}{|c|c|}
\hline AUTOR & MEDICIÓN \\
\hline $\begin{array}{l}\text { Freestone y McGoldrick } \\
(2008)\end{array}$ & 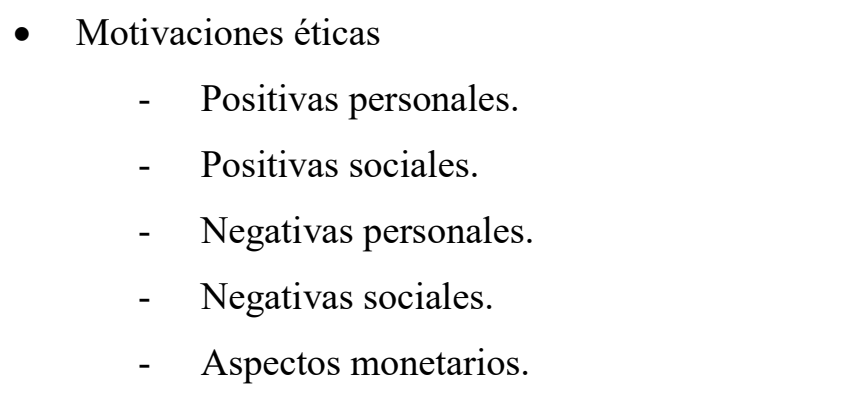 \\
\hline Bezençon y Blili (2009) & $\begin{array}{l}\text { - Implicación decisiones éticas. } \\
\text { - Valor ético. } \\
\text { - Valor hedónico de lo ético. } \\
\text { - Riesgo ético. } \\
\text { - Adhesión ética. }\end{array}$ \\
\hline Guiot y Roux (2010) & $\begin{array}{l}\text { - Motivación crítica } \\
\text { - } \quad \text { Distanciamiento del sistema. } \\
\text { - } \quad \text { Ética y ecología. } \\
\text { - Motivaciones experimentales relacionados con la } \\
\text { naturaleza de la oferta y las características del } \\
\text { canal } \\
\text { - Originalidad } \\
\text { - Búsqueda de tesoros } \\
\text { - } \quad \text { Contacto social } \\
\text { - Placer nostálgico } \\
\text { Motivación económica } \\
\text { - Papel gratificativo del precio. } \\
\text { - } \quad \text { Búsqueda del precio justo. }\end{array}$ \\
\hline
\end{tabular}




\begin{tabular}{|c|c|}
\hline Dowd y Burke (2013) & $\begin{array}{l}\text { - Motivación ética } \\
\begin{aligned}- & \text { Respeto al medio ambiente y entorno. } \\
- & \text { Valores políticos y sociales. } \\
- & \text { Aspectos religiosos. }\end{aligned}\end{array}$ \\
\hline $\begin{array}{l}\text { Barbopoulos y Johansson } \\
(2016)\end{array}$ & $\begin{array}{l}\text { - Motivación económica } \\
\text { - Motivación hedónica } \\
\text { - Motivación moral } \\
\text { - Motivación social } \\
\text { - Motivación de seguridad }\end{array}$ \\
\hline
\end{tabular}

Fuente: elaboración propia

En 2009, Bezençon y Blili estudiaron la implicación en el consumo de productos éticos a través de un análisis de sus precedentes; las motivaciones. Basado en un análisis en profundidad de la literatura y las especificidades de los productos éticos, se validó un modelo. Los autores confirman cinco dimensiones dentro de la motivación ética de compra: decisión ética, valores éticos, de valor hedónico de lo ético, riesgo ético y adhesión ética. El peso de la motivación hedónica y utilitarista en el consumo de productos éticos es estudiado en su trabajo, pero también se hace hincapié en el riesgo asociado al acto de compra y las cuestiones morales y éticas relacionados con la naturaleza del producto / servicio.

Guiot y Roux (2010) analizaron y midieron las motivaciones de compra en productos de segunda mano. Los autores identificaron tres dimensiones: motivaciones críticas, motivaciones hedónicas y motivaciones económicas. Las motivaciones críticas hacen referencia la posibilidad de evitar los canales comerciales convencionales, el apoyo y respaldo a cuestiones éticas y ecológicas, la lucha contra el gasto innecesario y evitando la ostentación. La motivación hedónica está vinculada con la naturaleza de la oferta 
(originalidad, el placer nostálgico o auto-expresión) y las características del canal (contacto social o estimulación). Por último, los factores económicos están relacionados con el precio: el deseo de pagar menos, la búsqueda de precio justo, la caza de gangas y el papel recompensativo del precio. La escala de medición de la motivación de compra en artículos de segunda mano compuesta por las anteriores tres dimensiones es validada y a lo largo de su trabajo los autores sugieren la necesidad de aplicar una nueva estrategia que se adapte a los cambios que se están produciendo en el comportamiento del consumidor.

Dowd y Burke en 2013, analizan las motivaciones de compra de alimentos orgánicos o de comercio justo. Los autores identifican un considerable aumento en el consumo de estos, y aunque existe una amplía literatura en lo relacionado con este aspecto, las motivaciones de compra de este tipo de productos van más allá de aquello que consigue sugerir la etiqueta "verde". Por ejemplo, el bienestar animal, los precios pagados a granjeros o agricultores son cuestiones que deben incluirse también en el estudio motivacional de este tipo de productos. Por ello, en la investigación se incluye una dimensión ética en el análisis de la motivación de compra de los productos que incluye aspectos relacionados con el entorno, la gente que rodea la producción y su bienestar, aspectos políticos, sociales y hasta religiosos. Los autores validan la escala motivacional y concluyen que el consumo de este tipo de productos se está postulando como una identidad propia entre los consumidores.

En 2016, Barbopoulos y Johansson llevan cabo una investigación en la que desarrollan una nueva escala de medición de la motivación de compra del consumidor basada en cinco dimensiones. El entorno cambiante y las nuevas opciones comerciales como los mercadillos o los comercios de segunda mano ponen de manifiesto la necesidad de actualizar los análisis de la motivación de compra del consumidor. Los autores identifican cinco dimensiones, pudiendo ser divididas en: aspectos económicos, hedónicos, normativos, morales y de seguridad. En este sentido, el objetivo del trabajo es demostrar la escasa homogeneidad de la motivación de compra (Lindenberg and Steg 
2007) y cómo los consumidores buscan satisfacer diversas motivaciones y necesidades simultáneamente (Kopetz 2007) en un entorno cada vez menos predecible y más cambiante.

De este modo y apoyándonos en las investigaciones que consideran la motivación de compra del consumidor un constructo multidimensional (Tauber 1972, Westbrook y Black 1985, Kim 2006, Bezençon y Blili 2009, Guiot y Roux 2010, Ribeiro y Carvalho 2010, Chung 2015, Barbopoulos y Johansson 2016) planteamos la siguiente hipótesis de trabajo:

H1: La motivación de compra del consumidor es un constructo multidimensional formado por tres dimensiones: motivación utilitarista, motivación ética y motivación hedónica. 
CA PÍTULO 4. EFECTOS DE LA MOTIVACIÓN DE COMPRA DEL CONSUMIDOR 



\section{CAPÍTULO 4. EFECTOS DE LA MOTIVACIÓN DE COMPRA DEL CONSUMIDOR}

\subsection{INTRODUCCIÓN}

En el presente capítulo vamos a estudiar las variables que suceden a la motivación de compra en el camino hacia la lealtad del consumidor con el tipo de comercio en el que decide realizar sus compras. Hemos visto en el capítulo anterior cómo la motivación de compra del consumidor se define como un proceso o condición interna que activa o desencadena un determinado comportamiento dándole dirección hacia un objetivo determinado. A continuación se pretende abordar todo el proceso desde que el consumidor realmente realiza la compra bajo un comportamiento motivado y realiza las primeras evaluaciones hasta la decisión de recompra y su posterior comportamiento. Para ello utilizaremos una variable resultante de la evaluación directa del individuo como es el valor percibido, una variable afectiva como es la satisfacción y finalmente la variable lealtad, ya que ésta representa el mejor predictor que podemos utilizar a la hora de analizar los posibles comportamientos de recompra por parte del consumidor final. Ya que, si bien todo comportamiento motivado no desencadena la consecución del objetivo, la variable motivación no sólo tiene en su esencia el energizar comportamientos, sino también mantenerlos hasta alcanzar etapas que se asimilan en cierto modo a un comportamiento leal (desde una perspectiva más afectiva y psicosocial).

El valor percibido por el consumidor es, de todas, la variable más cognitiva y experiencial ya que se basa en apreciaciones realizadas por el individuo del rendimiento que ha tenido el producto comprado. De dicha valoración va a depender en gran medida que un cliente vuelva a recomprar el mismo producto al mismo proveedor, es decir, su fidelidad. Sin embargo esa relación, aunque ampliamente demostrada, no es tan directa como pudiera parecer ya que hay toda una serie de factores y todo un proceso mental que determinan el comportamiento final del individuo. 
Con la finalidad de conocer mejor este proceso mental del que hablamos, analizaremos las variables motivación y valor percibido en base a las mismas dimensiones, con el objetivo de observar si coinciden los comportamientos motivados con las experiencias de compra. Además, incluimos una variable con mayor carga afectiva y que se forman en la mente del consumidor, ya no tan directamente desde la experiencia, sino con un mayor grado de información procesada. Es decir, después de la experiencia directa, se lleva a cabo una labor de razonamiento y asentamiento de la información obtenida a lo largo del tiempo que llevará al individuo a generar una determinada actitud general hacia el proveedor. Esta variable de la que hablamos es la satisfacción. La satisfacción referida a un estado placentero experimentado por el consumidor (Oliver, 1996).

Por otro lado, en el presente trabajo vamos a incluir una variable moderadora que nos diferenciará entre dos grupos de compradores: aquellos que realizaron sus compras en el pequeño comercio urbano y aquellos que las realizaron en grandes centros comerciales. Así, se buscarán las diferencias que pueden presentar estos grupos de clientes a la hora de realizar su procesamiento mental desde el desencadenante comportamiento motivado, pasando por la experiencia de compra, la satisfacción y la formación de la lealtad y estudiaremos el efecto moderador que puede realizar en nuestro modelo. De este modo, primero presentaremos las variables objeto de nuestro trabajo y posteriormente plantearemos las relaciones a estudiar en forma de hipótesis. 


\subsection{VALOR PERCIBIDO POR EL CONSUMIDOR}

El valor percibido por el consumidor centra desde hace más de tres décadas la atención de multitud de investigadores en marketing. Sin embargo, se trata de una variable en continua exploración y análisis desde nuevas perspectivas y ámbitos de aplicación. Este hecho radica en el importante papel que el valor percibido desempeña en el estudio de la decisión de compra del consumidor y en las posteriores intenciones de recompra. Por lo tanto, es relevante destacar su papel en la tarea de lograr una ventaja competitiva sostenible para los comercios (Chen y Dubinsky, 2003; Eid y El-Gohary, 2015).

Hoy en día los consumidores toman sus decisiones de compra basándose en los valores asociados a la misma. Dichos valores son cada vez más diversos y complejos, por lo que se convierte en una tarea esencial para los gerentes de los comercios entender aquello que los consumidores valoran y donde ellos mismos deberían centrar su atención para lograr y mantener su ventaja competitiva (Sweeney y Soutar, 2001; Diep y Sweeny, 2008).

Y en esta línea, retomamos el concepto de marketing relacional. En el camino de lograr la ventaja competitiva, las empresas han comenzado a preocuparse por desarrollar estrategias relacionales basadas en el valor de la compra que eviten la pérdida indiscriminada de clientes. Este cambio se ha apoyado en las múltiples ventajas que ofrece la retención de los clientes adecuados. Pero para implantar el marketing relacional en la práctica es necesario un cambio estratégico en el seno de la organización, orientando la gestión en torno al valor percibido por el cliente (Ravald y Grönroos 1996; Reichheld 1996; Weistein y Jonson 1999; Rust, Zeithaml y Lemmon 2000). El valor es una parte muy importante del marketing relacional, y la capacidad de la empresa para ofrecer un valor superior a sus clientes está considerada, a partir de la década de los 90, como una de las estrategias más exitosas. Esta capacidad se ha convertido en un medio de diferenciación clave para el logro de una ventaja competitiva sostenible (Ravald y Grönroos 1996). 
Woodruff (1997) afirma que la generación de valor superior para el cliente es la fuente de ventaja competitiva del siglo XXI, destacando además la carencia de herramientas operativas de gestión del valor que tienen actualmente las organizaciones. De este modo, el valor percibido por el consumidor es el eje sobre el que se mueven los planteamientos de gestión relacionales. Por ello esta variable ha adquirido una gran importancia en la gestión de cualquier tipo de negocio. Las empresas se han dado cuenta de la importancia que tiene coordinar sus actividades internas con la finalidad de crear las sinergias necesarias para la creación y distribución de valor a los consumidores de forma continuada. Por tanto el valor percibido, resultado esencial de las actividades de marketing, se perfila como un elemento de primer orden dentro del marketing de relaciones ya que de su evaluación dependerá la actitud generada en el individuo y su lealtad hacia la marca (Peterson 1995; Huber, Hermann y Morgan 2001; Callarisa, Moliner y Rodríguez 2002). El individuo necesita realizar toda una serie de evaluaciones cognitivas para formarse una opinión o sentimiento general hacia una empresa. De este modo, el cliente, a partir de su experiencia directa, realiza juicios del valor recibido en sus encuentros con la entidad y éstos serán los que a la postre determinarán si esta persona vuelve o no a recomprar al mismo proveedor.

Las organizaciones empresariales deben convertirse en proveedoras de valor y deben hacerlo de forma diferente unas de otras, puesto que esta habilidad les va a permitir diferenciarse, mejorar sus resultados y aumentar sus posibilidades de supervivencia futura (Christopher, Payne y Ballantyne 1994; Peterson 1995; Butz y Godstein 1996; Hunt 1997; Lapierre 2000; Callarisa, Moliner y Rodríguez 2002; Callarisa 2004).

En este punto vamos a presentar la variable de evaluación por parte del consumidor, resultado de la comparación de los beneficios recibidos con los sacrificios soportados (Zeithaml 1988; Monroe 1990; Lovelock 1991; Gale 1994; Bigné, Moliner y Callarisa 2000; Teas y Agarwal 2000; Ulaga y Eggert 2003; Sánchez et al. 2006). Para ello, en primer lugar analizaremos las diferentes definiciones propuestas en la literatura sobre el concepto de valor percibido por el consumidor y posteriormente pasaremos a 
estudiar la evolución del concepto a lo largo del tiempo. Finalmente, presentaremos la conceptualización de valor percibido que utilizaremos en este trabajo, justificando debidamente los motivos que nos han llevado a escoger esta opción.

\subsubsection{Concepto de valor percibido por el consumidor: definición y evolución}

Para que se inicie una relación han de existir al menos dos partes interesadas: proveedor y cliente. Además cada uno debe esperar obtener ciertas ventajas y beneficios con el desarrollo y transcurrir de la misma, que hacen que la relación tenga valor y, por lo tanto, se mantenga viva, (Gwinnner, Gremler y Bitner, 1998). Dentro de las distintas definiciones de marketing de relaciones un elemento fundamental común es el cumplimiento de los objetivos de las partes o los beneficios mutuos de la relación (Grönroos, 1997).

Sin embargo, es necesario tener en cuenta que no todos los clientes son iguales. Por lo tanto es fundamental centrarse en la generación de valor para los clientes adecuados (Jones y Sasser 1995; Reichheld 1996). Así, las empresas pueden obtener grandes beneficios del mantenimiento de las relaciones con sus clientes, siempre y cuando éstos sean adecuados.

Gassenheimer, Houston y Davis (1998) definen el valor de una relación, y por tanto, sus posibilidades de supervivencia, desde una doble perspectiva, tanto social como económica. Los elementos sociales son, al igual que los resultados económicos obtenidos, claves en el valor de una relación.

Desde la perspectiva del cliente, estos pueden apreciar beneficios económicos como motivo para formar parte de programas relacionales (Peterson, 1995). Otros clientes fieles desarrollan un comportamiento relacional simplemente porque de esta forma obtienen un mejor servicio, ya que dicha relación hace que los proveedores se adapten 
mejor a sus necesidades específicas, les dispensen un trato preferencial o incluyan servicios adicionales que serían inaccesibles de otra manera (Gwinner, Gremler y Bitner, 1998; Rust, Zeithaml y Lemmon, 2000).

Otro tipo de beneficios de gran importancia para el cliente son los beneficios sociales que se derivan de entablar una relación. En muchas ocasiones, de los encuentros entre proveedor y cliente surgen relaciones de amistad y confianza. En esos momentos se crean lazos afectivos que llegan a ser tan considerados como los aspectos profesionales (Berry, 1995). Pero no se tienen lazos afectivos con una empresa, sino con las personas. Los beneficios personales son aquellos relativos a la relación personal existente entre el cliente y la compañía, a través de los empleados de la misma (Reichheld, 1993).

Los beneficios que ofrecen las relaciones personales se han clasificado en dos tipos: funcionales y sociales. Los beneficios funcionales son aquellos que están más orientados a aspectos económicos, como por ejemplo: asesoramiento, ahorros de tiempo, mejores decisiones de compra, etc. Los beneficios sociales proceden de la relación de amistad, confianza, estatus y trato más personalizado que otorga la relación (Reynolds y Beatty, 1999). Gwinner, Gremler y Bitner (1998), señalan a la familiaridad, la fraternización, la amistad y el reconocimiento personal entre el empleado y el cliente como causas de la apreciación de estos beneficios sociales, más valorados que los beneficios económicos, especialmente en aquellos servicios cuya prestación incluye un alto grado de interacción entre el empleado y el cliente.

De este modo, una relación se mantendrá siempre y cuando las partes valoren lo que están recibiendo y lo que esperan recibir. La clave para la continuidad de la relación no sólo radica en el valor de la oferta actual que se le realiza al cliente, sino en las expectativas que éste tiene para la relación a largo plazo (Ravald y Grönroos, 1996). En este sentido la empresa debe de mantener la confianza de alcanzar las expectativas del cliente para que éste perciba que la relación va a seguir teniendo valor en el futuro. Además la empresa tiene que corresponder a dichas expectativas cumpliendo las promesas que realice, fomentando la confianza y el compromiso, buscando la 
reciprocidad de la relación. En definitiva los clientes inician y mantienen una relación de mercado porque esperan recibir un valor positivo como consecuencia de su participación (Peterson 1995).

Para implantar el marketing relacional es necesario un cambio estratégico en el seno de la organización orientando la gestión en torno al valor percibido por el cliente (Ravald y Grönroos, 1996; Reichheld, 1996; Weistein y Jonson, 1999; Rust, Zeithaml y Lemmon, 2000). Sin embargo, para poder llevar a cabo dicha tarea con garantías de éxito, se necesita conocer en profundidad la naturaleza de lo que se conoce como valor percibido por el cliente (Grönroos, 1997; Weistein y Jonson, 1999).

Porter (1985) fue el primero en indicar que la creación de valor para el cliente es una forma de lograr la ventaja competitiva, proponiendo el modelo conocido como "cadena de valor". Esta cadena de valor divide las acciones que realiza la empresa en actividades "primarias" y "de apoyo", descomponiendo las mismas en diferentes pasos, para que se facilite la creación de valor en cada uno de ellos. Para lograrlo propone dos vías: realizar las actividades de forma más eficiente (esto permitirá reducir los sacrificios del cliente) o realizarlos de una manera única en el mercado (aportando mayores beneficios al cliente).

Stabell y Fjelstand (1998) han ampliado la clasificación de los procesos de creación de valor y sus implicaciones estratégicas, en las que la cadena de valor precedente es sólo una de las tres configuraciones posibles, adecuada para empresas productivas. Según estos autores, las actividades primarias de las empresas de servicios especializados, la segunda configuración posible, no giran en torno a un producto, sino que contribuyen a solucionar un problema de un cliente. Para las empresas de servicios especializados, el coste y las economías de escala no tienen la importancia clave de una cadena de valor tradicional, ya que sólo afectan a cada proyecto individualmente. Lo esencial son los resultados que se consigan mediante un proyecto más o menos complejo. 
Por otra parte, la tercera configuración posible, la creación de valor en empresas mediadoras se materializa en la actividad de mediación entre los clientes a través de una red. Estas actividades se pueden clasificar en tres grupos: operaciones de infraestructura de la red, promoción de la red y gestión de contratos, y provisión de servicios a través de la red. Todas estas actividades se desarrollan en paralelo.

Según Woodruff (1997), existe consenso entre los defensores del valor como ventaja competitiva en que su gestión requiere dos cosas: una organización preparada para aprender y conocer en profundidad a sus mercados y clientes, y tener la capacidad para convertir este aprendizaje en resultados. En este sentido, también destaca la carencia de herramientas operativas de gestión del valor que tienen actualmente las organizaciones.

Christopher, Payne y Ballantyne (1994) opinan que para conseguir una gestión relacional adecuada hace falta establecer a priori cuál es el valor que hay que entregar a los clientes para iniciar y mantener relaciones con los mismos. En su trabajo, aportan un marco teórico que refleja el cambio de orientación que se está defendiendo y que llaman secuencia de entrega de valor. Dicha secuencia concibe a la empresa como un proceso generador de valor, compuesto por tres etapas. La primera de ellas consiste en elegir el valor que quieren los clientes. Para ello es fundamental comprender cuáles son sus necesidades y cómo cambian, así como hasta qué punto consiguen satisfacer dichas necesidades las ofertas que realizan los competidores (Butz y Godstein, 1996). El objetivo debe ser conocer qué es exactamente lo que quiere hacer el consumidor con la oferta de la empresa, en un momento y lugar determinados. De este modo para que la empresa pueda conseguir ventaja competitiva, las ofertas que propongan deben generar un valor neto superior a las ofertas de los competidores.

En una segunda etapa, la empresa debe suministrar el valor elegido al cliente. Es decir, componer una oferta que sea percibida como dotada de un valor superior por los clientes. Hay que tener en cuenta que la oferta de la empresa incluye tanto elementos tangibles -bienes- como intangibles -varios tipos de servicios- (Grönroos, 1997), y que 
cuando la competencia en estos servicios adicionales es la clave para triunfar en el sector entonces todos los negocios deben concebirse como un negocio de servicios (Grönroos, 1995).

Por último, una vez constituida la oferta hay que comunicar el valor que ésta aporta. Para ello hay que llevar a cabo actividades que consigan persuadir a los clientes adecuados de que el valor que les está siendo ofrecido es superior al que se les ofrece en el mercado, tomando como base para el mismo la prestación de un servicio de alta calidad.

Tal como se ha ido viendo a lo largo de este punto, el valor percibido por el cliente es el eje sobre el que se mueven los planteamientos de gestión relacionales. Pero para poder utilizarlo como herramienta de gestión es necesario, en primer lugar conocer su naturaleza en profundidad. Para ello, a continuación presentan las diferentes concepciones de valor percibido y los elementos que lo componen.

Con la intención de aclarar los distintos puntos de vista relativos al valor del cliente, en la Tabla 4.1, se recopilan algunas de las definiciones que se han empleado en la literatura para delimitar el concepto de valor percibido.

Tabla 4.1 - Definiciones de valor percibido por el consumidor.

\begin{tabular}{|l|l|}
\hline \multicolumn{1}{|c|}{ AUTOR } & \multicolumn{1}{c|}{ DEFINICIÓN } \\
\hline $\begin{array}{l}\text { Zeithaml } \\
(1988)\end{array}$ & $\begin{array}{l}\text { El valor es el juicio general que realiza el cliente sobre la utilidad } \\
\text { de un producto, basándose en las percepciones de lo que se recibe } \\
\text { y lo que se da. }\end{array}$ \\
\hline Monroe (1990) & $\begin{array}{l}\text { Las percepciones de valor de los compradores suponen un } \\
\text { intercambio entre la calidad y los beneficios que perciben en } \\
\text { relación con los sacrificios percibidos al pagar el precio. }\end{array}$ \\
\hline $\begin{array}{l}\text { Lovelock } \\
(1991)\end{array}$ & $\begin{array}{l}\text { El valor neto es la suma de todos los beneficios percibidos (valor } \\
\text { bruto) menos la suma de todos los costes percibidos. }\end{array}$ \\
\hline Albretch (1994) & $\begin{array}{l}\text { El valor del cliente es la percepción del cumplimiento de sus } \\
\text { necesidades específicas que es el resultado que buscan y no la cosa } \\
\text { o la experiencia por la que pagan. }\end{array}$ \\
\hline Gale (1994) & $\begin{array}{l}\text { El valor es la calidad percibida de mercado ajustada por el precio } \\
\text { relativo del producto. }\end{array}$ \\
\hline
\end{tabular}


AUTOR

DEFINICIÓN

\begin{tabular}{|l|l|}
\hline $\begin{array}{l}\text { Butz y Godstein } \\
(1996)\end{array}$ & $\begin{array}{l}\text { Por valor del cliente se entiende los lazos emocionales } \\
\text { establecidos entre un cliente y un productor, después de que el } \\
\text { cliente haya utilizado un producto o de servicio del productor y } \\
\text { haya encontrado en el mismo valor añadido. }\end{array}$ \\
\hline $\begin{array}{l}\text { Woodruff } \\
(1997)\end{array}$ & $\begin{array}{l}\text { El valor del cliente es una preferencia y evaluación percibida de } \\
\text { aquellos atributos del producto, atributos de sus resultados y } \\
\text { consecuencias que resultan del uso que permiten que el cliente } \\
\text { logre sus objetivos en las distintas situaciones de uso. }\end{array}$
\end{tabular}

Bigné, Moliner El valor percibido puede ser considerado como la valoración y Callarisa global que hace el cliente de la utilidad de una relación de (2000) intercambio, basada en las percepciones de lo que recibe y lo que da.

Teas y Agarwal Las percepciones de valor del consumidor se basan en la (2000) compensación entre los beneficios del producto y el sacrificio monetario.

Lapierre (2000) El valor percibido por el consumidor diferencia entre los beneficios y los sacrificios percibidos por los clientes en cuanto a sus expectativas (es decir, necesidades y deseos).

Hellier et al. El valor percibido puede ser descrito como la valoración global (2003) por parte del cliente del producto o servicio recibido sobre una base de coste/ beneficio. Los beneficios buscados por el cliente o consumidor y los gastos de adquisición y utilización del producto o servicio.

Ulaga y Eggert El valor percibido en los mercados de negocios es el equilibrio (2003) entre, por una parte, el producto, los servicios, el conocimiento, el tiempo adecuado, y los beneficios sociales, y por otra, el precio y los costes de proceso de las relaciones con el proveedor, que son tenidos en cuenta para la toma de decisiones clave por parte de la empresa del cliente, y considerando la posibilidad de establecer relaciones con otros proveedores.

Martin-Ruiz et El valor percibido se deriva de la relación entre lo que el sujeto al. (2008) $\quad$ recibe frente a lo que se da por invertido.

Moliner, Gil y El valor percibido por el consumidor refleja una evaluación Ruiz (2011) perceptiva de un intercambio entre lo que se consigue (resultados y beneficios deseados) y lo que se ha invertido (dinero, tiempo y esfuerzo). 


\begin{tabular}{|l|l|}
\hline \multicolumn{1}{|c|}{ AUTOR } & \multicolumn{1}{c|}{ DEFINICIÓN } \\
\hline $\begin{array}{l}\text { Chiu et al. } \\
(2014)\end{array}$ & $\begin{array}{l}\text { El valor percibido por el consumidor, por lo tanto, refleja los } \\
\text { beneficios y costes según la percepción de los clientes en relación } \\
\text { a los productos tangibles e intangibles junto con la combinación } \\
\text { de calidad, servicio y precio. }\end{array}$ \\
\hline $\begin{array}{l}\text { Rasoolimanesh, } \\
\text { Dahalan } \\
\text { Jaafar (2016) }\end{array}$ & $\begin{array}{l}\text { El valor percibido por el consumidor describe una opinión, una } \\
\text { evaluación mental o un juicio de valor emitido por el consumidor } \\
\text { en relación al valor de un producto o servicio que le han sido } \\
\text { prestados. }\end{array}$ \\
\hline
\end{tabular}

Fuente: Elaboración propia.

Analizando los puntos comunes de las definiciones, se observan dos características relevantes en el valor del cliente. En primer lugar, éste es inherente al uso del producto, circunstancia que lo diferencia de los valores personales u organizacionales. En segundo lugar, es percibido por los clientes, y no puede ser determinado objetivamente por el vendedor. Es el cliente el único capacitado para percibir si un producto o servicio ofrece valor o no.

Sin embargo también existen una serie de divergencias entre los conceptos e interpretaciones del valor del cliente. La primera de ellas es que no se apoyan en los mismos términos (utilidad, calidad, beneficios, valor económico, etc.), y esto hace que la comparación entre conceptos sea muy difícil. Otra divergencia es la consideración de diferentes contextos a la hora de estimar el valor percibido: en el momento de la compra, en el momento del uso y después del uso. En cada uno de estos momentos puede realizarse un juicio diferente (Oliver, 1997).

A nivel general el valor percibido es definido como un juicio o una valoración que realiza el cliente de la comparación entre los beneficios o utilidad obtenidos de un producto, servicio o relación y los sacrificios o costes percibidos (Zeithaml 1988; Monroe 1990; Lovelock 1991; Gale 1994; Bigné, Moliner y Callarisa 2000; Teas y Agarwal 2000). 
Ante la fragmentación de la investigación y el numeroso conjunto de divergencias relativas al concepto del valor, Woodruff (1997) propone y defiende una definición que incorpora tanto el valor recibido como el esperado, resaltando y diferenciando las percepciones del cliente sobre preferencias y evaluaciones.

Continuando con la problemática de la conceptualización del valor, Parasuraman (1997) señala que, si bien la definición que aporta Woodruff(1997) refleja la complejidad y riqueza del concepto, ésta no facilita la construcción de una escala psicométrica que haga operativa su utilización. La variedad de contextos (precompra y postcompra), las múltiples tareas cognitivas (preferencias, evaluaciones) y los distintos niveles abstractos en los criterios de juicio (atributos, consecuencias de uso y objetivos del consumidor) dificultan esta labor.

En esta línea, Albrecht (1994) y Butz y Godstein (1996) consideran una jerarquía de tres niveles en el concepto del valor percibido del cliente. En el primer nivel se encontraría el valor básico esperado, aquel que el cliente considera normal para la empresa y sus competidores; en el segundo nivel aparecería el valor deseado, formado por aquellas características añadidas que conoce y desea el cliente pero que no espera recibir, y finalmente, en el último nivel, el valor no anticipado, que son aquellas características que van más allá de las expectativas y deseos del cliente. 


\subsubsection{Dimensionalidad del valor percibido por el consumidor.}

A la hora de concretar y profundizar en la conceptualización y dimensionalidad del valor percibido, se pueden identificar dos grandes enfoques. El primer enfoque define el valor percibido como un constructo configurado por dos partes, una de beneficios recibidos (económicos, sociales y de la relación) y otra de sacrificios soportados (precio, tiempo, esfuerzo, riesgo y conveniencia) por el cliente (Doods, Monroe y Grewal, 1991; Rapp y Collins, 1991 y 1996; Grewal, Monroe y Krishnan, 1998; Cronin et al., 1997 y 2000; Bigné, Moliner y Callarisa, 2000).

El segundo enfoque se fundamenta en la concepción del valor percibido como un constructo multidimensional (Woodruff, 1997; De Ruyter et al., 1997 y 1998; Sweeney y Soutar, 2001; Sánchez et al., 2006). Esta perspectiva de valor, además de la dimensión funcional, incorpora una dimensión afectiva que recoge aspectos emocionales y sociales del individuo profundizando en temas relacionados con el comportamiento de compra del consumidor. El valor funcional viene definido por las valoraciones racionales y económicas de los individuos. La calidad del producto y del servicio formaría parte de esta dimensión. Respecto a la dimensión afectiva, recoge los sentimientos o emociones generados por los productos o servicios. Esta dimensión afectiva se divide en una dimensión emocional (relacionada con los sentimientos o emociones internas) y una dimensión social (relacionada con el impacto social de la compra realizada) (Sweeney, Soutar y Johnson, 1999; Sweeney y Soutar, 2001; Petrick, 2002; Sánchez et al., 2006).

En cuanto al primer enfoque, Zeithaml (1988) define el valor percibido por el cliente como el juicio general que éste realiza acerca de la utilidad de un producto basándose en las percepciones de lo que da y lo que recibe. El valor para el consumidor, de este modo, resulta de la comparación personal de los beneficios obtenidos con los sacrificios realizados. Por lo tanto se trata de un concepto altamente subjetivo y personal (Parasuraman, Zeithaml y Berry, 1985). Además comporta un componente de beneficios y otro de sacrificios, siendo una percepción del resultado esencialmente utilitarista. Se 
trata de una visión general aplicable tanto en el ámbito de los productos, de los servicios y de las relaciones.

Según Zeithaml (1988), el componente de beneficios, lo que recibe un consumidor con la compra, incluiría los atributos intrínsecos y extrínsecos al producto o servicio adquirido, su calidad percibida y una serie de beneficios psicológicos. La calidad percibida se define como el juicio sobre la superioridad o excelencia general de un producto que hace un cliente. Los beneficios psicológicos se aproximan a una especie de satisfacción.

El componente de sacrificios, lo que debe dar el consumidor, estaría formado por los precios monetarios y no monetarios, es decir, dinero y otra serie de recursos como tiempo, energía, esfuerzos, etc. Éstos dependen de la voluntad y situación del cliente.

La relación calidad-precio se suele confundir con el valor percibido (Sweeny et al., 1999). Esto es un error, ya que ni la calidad es el único beneficio que reciben los consumidores ni el precio pagado es único sacrificio. El tiempo, el esfuerzo y los costes psicológicos son algunos de los demás sacrificios (Zeithaml, 1988).

Spreng, Dixon y Olshavsky (1993) sugieren que las expectativas de los sacrificios a soportar antes de la compra de un producto están compuestas por los costes de compra, de utilización, reparación y psicológicos, así como el tiempo dedicado a la compra, utilización y reparación. Algunos de estos costes pueden ser evaluados en el momento de la compra, pero otros no.

Grewal, Monroe y Krishnan (1998) matizan el concepto de valor, y siguiendo la propuesta de Monroe (1990), diferencian dos componentes distintos y relacionados. A la relación entre los beneficios obtenidos sobre los sacrificios presentada por Zeithaml (1988) lo llaman valor de adquisición. El segundo componente es el valor de transacción, que definen como la satisfacción psicológica o placer que obtiene el cliente si percibe 
haber conseguido un "buen trato". La evaluación de la bondad de la transacción es realizada por el consumidor comparando el precio de venta del producto con su precio de referencia interno. Los resultados del trabajo indican que realizar la distinción entre los dos valores permite encontrar una relación directa y positiva entre el valor de adquisición percibido y las intenciones de compra posteriores del cliente, así como directa y negativa con la búsqueda de otras alternativas. Estas conclusiones confirman los resultados obtenidos por investigaciones previas (Dodds, Monroe y Grewal, 1991).

Butz y Godstein (1996) consideran que por valor del cliente se entienden los lazos emocionales establecidos entre un cliente y un productor, después de que el cliente haya utilizado un producto o servicio del productor y haya encontrado en el mismo valor añadido. Para el establecimiento de estos lazos se tiene que cumplir que los productos y servicios ofrecidos por la empresa superen regularmente las expectativas de los clientes y que los beneficios superen a los costes incurridos por el consumidor, teniendo como referencia a la competencia. Para ello es fundamental comprender las necesidades del cliente.

El concepto de valor percibido ha evolucionado a lo largo del tiempo. Partiendo de una perspectiva racional o cognitiva basada fundamentalmente en aspectos de carácter funcional, se ha pasado a contemplar también aspectos de carácter emocional y social.

En este sentido autores como Mattsson (1991) tratan la multidimensionalidad del valor percibido y ya recogen los aspectos cognitivos y afectivos del valor percibido (Tabla 4.2). En la misma dirección se plantean los trabajos de Sheth, Newman y Gross (1991a y 1991b), que llegaron a identificar hasta cinco dimensiones del concepto de valor (social, emocional, funcional, condicional y epistémico).

El valor funcional lo definen como una utilidad percibida de los atributos de los productos y servicios. El valor emocional, son los sentimientos o los estados afectivos que genera la experiencia de consumo. El valor social sería el grado de aceptación o 
utilidad a nivel de las relaciones del individuo con su entorno social. Por su parte el valor epistémico es la capacidad del producto o servicio para sorprender, despertar la curiosidad o satisfacer el deseo de conocimiento. Finalmente el valor condicional se refiere a los factores coyunturales o situacionales tales como enfermedades o situaciones sociales específicas (Sheth, Newman y Gross, 1991a).

Groth (1995a) también advierte que el concepto valor percibido tiene al menos dos dimensiones, una cognitiva y otra psicológica y que las denomina valor de utilidad percibida y valor psicológico. La primera representa la proyección futura que realiza el cliente antes de la compra sobre los beneficios futuros que va a representar la compra. La segunda, representa un conjunto de elementos percibidos y no percibidos. Estos a su vez pueden dividirse en función del nivel de influencia en factores de ámbito interno (aquellos que están por encima de las opiniones e influencias externas) y externo (opiniones, reflexiones, relaciones personales con terceros, etc.).

\section{Tabla 4.2 - Trabajos más relevantes sobre la multidimensionalidad del valor} percibido.

\begin{tabular}{|c|c|}
\hline AUTORES & DIMENSIONES \\
\hline Mattson (1991) & $\begin{array}{l}\text { - Emocional } \\
\text { - Práctica } \\
\text { - Lógica }\end{array}$ \\
\hline $\begin{array}{l}\text { Sheth, Newman y Gross (1991a y } \\
\text { 1991b) }\end{array}$ & $\begin{array}{l}\text { - } \quad \text { Valor social } \\
\text { - Valor emocional } \\
\text { - Valor funcional } \\
\text { - Valor epistémico } \\
\text { - }\end{array}$ \\
\hline Groth (1995a y 1995b) & $\begin{array}{l}\text { - Cognitivo: Utilidad percibida } \\
\text { - Psicológico } \\
\text { - Internos } \\
\text { - } \text { Externos }\end{array}$ \\
\hline Grönroos (1997) & $\begin{array}{l}\text { - } \text { Cognitivo } \\
\text { - Emocional (psicológico) }\end{array}$ \\
\hline
\end{tabular}




\begin{tabular}{|c|c|}
\hline De Ruyter et al. (1997) & $\begin{array}{l}\text { - Dimensión emocional o valor intrínseco } \\
\text { - Dimensión funcional o valor extrínseco } \\
\text { - Dimensión lógica }\end{array}$ \\
\hline Sweeney, Soutar y Johnson (1999) & $\begin{array}{l}\text { - Valor social (aceptabilidad) } \\
\text { - Valor emocional } \\
\text { - Valor funcional (precio/valor por dinero) } \\
\text { - Valor funcional (rendimiento/calidad) } \\
\text { - Valor funcional (versatilidad) }\end{array}$ \\
\hline Sweeney y Soutar (2001) & $\begin{array}{l}\text { - Dimensión funcional (económica y de calidad) } \\
\text { - Dimensión social } \\
\text { - Dimensión emocional }\end{array}$ \\
\hline Petrick (2002) & $\begin{array}{l}\text { - } \text { Calidad percibida } \\
\text { - Respuesta emocional } \\
\text { - Precio monetario } \\
\text { - Sacrificios no monetarios } \\
\text { - Reputación }\end{array}$ \\
\hline Sánchez et al. (2006) & $\begin{array}{l}\text { - Valor funcional de las instalaciones del } \\
\text { establecimiento } \\
\text { - Valor funcional del personal de atención } \\
\text { - Valor funcional del producto/ servicio } \\
\text { (Calidad) } \\
\text { - Valor funcional precio } \\
\text { - Valor social } \\
\text { - Valor emocional }\end{array}$ \\
\hline Wang y Wang (2010) & - Sacrificios percibidos \\
\hline Nikhashemi et al. (2016) & $\begin{array}{l}\text { - Valor funcional } \\
\text { - Valor simbólico }\end{array}$ \\
\hline $\begin{array}{l}\text { Rasoolimanesh, Dahalan y Jaafar } \\
\text { (2016) }\end{array}$ & $\begin{array}{l}\text { - Valor funcional } \\
\text { - Valor emocional } \\
\text { - Valor social }\end{array}$ \\
\hline $\begin{array}{l}\text { El-Adly y Eid (2015) } \\
\text { El-Adly y Eid (2016) }\end{array}$ & $\begin{array}{l}\text { - Hedónico } \\
\text { - Autosatisfacción } \\
\text { - Utilitarista } \\
\text { - Epistémico } \\
\text { - Interacción social }\end{array}$ \\
\hline
\end{tabular}




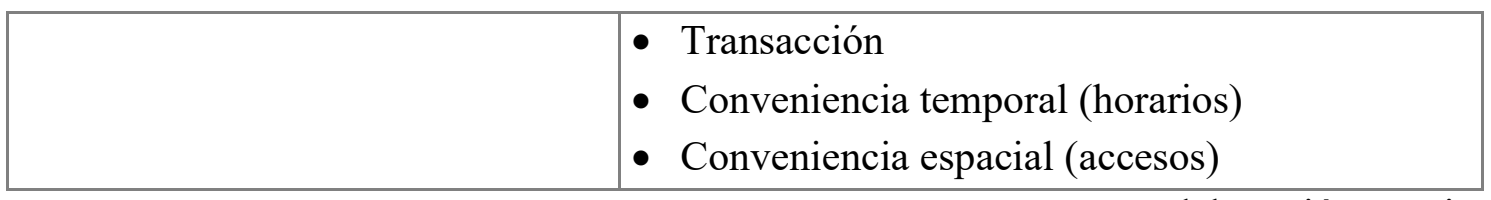

Fuente: Elaboración propia.

En la misma línea, De Ruyter et al. (1997) proponen un enfoque comprensivo del valor, que incorpora una respuesta cognitiva (valor por dinero) y componentes afectivos. Según estos autores, el valor percibido estaría compuesto por tres dimensiones: una emocional, otra funcional y otra lógica. La dimensión emocional muestra la evaluación afectiva del encuentro de servicio por parte del cliente; la dimensión funcional refleja aspectos prácticos del episodio de servicio y finalmente, la dimensión lógica está compuesta por la calidad de servicio y el precio, el mencionado valor por dinero. Cada fase del proceso de prestación del servicio es susceptible de ser evaluada según estas dimensiones.

En un trabajo posterior, Sweeney y Soutar (2001) no consideraron relevantes las dimensiones epistémica y condicional propuestas por Sheth, Newman y Gross (1991a y 1991b). Por lo tanto las cinco dimensiones iniciales se redujeron a tres: valor funcional, valor social y valor emocional. Estos autores diseñaron una escala de medición de valor conocida como PERVAL. Dentro de la dimensión funcional del valor, incluyen factores como el precio (relación calidad- precio, valor por dinero), la calidad (calidad percibida y rendimiento esperado del producto o servicio) y la versatilidad (adaptabilidad y practicidad del producto). La dimensión social y emocional, vienen representadas por el conjunto de intangibles que afectan a la relación.

Sánchez et al. (2006) desarrollan una escala de medición del valor global percibido postcompra de 24 ítems denominada GLOVAL. En este trabajo se identifican seis dimensiones de valor percibido. Cuatro de ellas corresponden a dimensiones de valor funcional: valor funcional del establecimiento (instalaciones), valor funcional del 
personal de contacto (profesionalidad), valor funcional del producto comprado (calidad) y valor funcional precio. Las dos dimensiones restantes van referidas a la dimensión afectiva del valor percibido, que son el valor emocional y el valor social.

Posteriormente, y en el contexto específico de las reservas hoteleras a través del teléfono móvil, Wang y Wang (2010) proponen una escala de medición del valor percibido por los usuarios en base a la relación coste-beneficio. Los clientes evalúan la utilidad de aplicar este método teniendo en cuenta todos los beneficios correspondientes y los factores de sacrificio. En este sentido los autores proponen las dimensiones de beneficios percibidos y sacrificios percibidos con la finalidad de realizar una valoración de experiencia de compra.

El-Adly y Eid (2015), proponen y validan en su trabajo una novedosa escala de medición del valor percibido por el consumidor en centros comerciales denominada MALLVALL. En este trabajo se identifican ocho dimensiones: valor hedónico, valor utilitarista, autosatisfacción, valor epistémico, valor transaccional, valor social, conveniencia espacial y conveniencia temporal. Aunque posteriormente, en el año 2016 los mismos autores presentan un nuevo trabajo en que relacionan el valor percibido por el consumidor en el contexto de los centros comerciales en relación con la satisfacción y la lealtad. Cabe destacar que los autores en esta ocasión reducen de ocho a seis dimensiones la escala de medición del valor percibido, eliminando la conveniencia espacial de la misma.

Nikhashemi et al. (2016) en su trabajo realizan una análisis multidimensional del valor percibido por el consumidor en el comercio minorista. Los autores ponen de manifiesto la necesidad de tratar esta variable como un constructo multidimensional y tras una amplia revisión de la literatura simplifican la medición en su trabajo a dos dimensiones básicas: valor funcional y valor simbólico. El valor funcional en este estudio hace referencia a la evaluación general de los consumidores sobre la calidad de los productos y el dinero que pagan por ellos (si consideran justo el precio). Mientras que el 
valor simbólico se refiere a la percepción general desde la perspectiva emocional, social, y la reputación.

En un trabajo posterior en el campo del turismo, Rasoolimanesh, Dahalan y Jaafar (2016) analizan el valor percibido por los turistas que se alojan en una casa familiar en su país de vacaciones. La variable fue estudiada desde una perspectiva formativa multidimensional que incluía tres dimensiones: valor funcional (precio, instalaciones...), valor emocional (hedonismo) y valor social (cultura, aprendizaje...).

En general los autores que trabajan el concepto de valor como un constructo multidimensional están de acuerdo en que se pueden diferenciar dos dimensiones: una con carácter funcional y otra de tipo emocional o afectivo. En la dimensión funcional se han identificado factores como relación valor/ precio (Sweeney, Soutar y Johnson, 1999), calidad del producto (Sweeney, Soutar y Johnson, 1999; Sweeney y Soutar, 2001; Petrick, 2002), versatilidad (Sweeney, Soutar y Johnson, 1999), calidad del servicio, sacrificios no monetarios (Sweeney, Soutar y Johnson, 1999; Petrick, 2002) y precio (Sweeney, Soutar y Johnson, 1999; Sweeney y Soutar, 2001; Petrick, 2002).

La dimensión afectiva recoge los sentimientos o emociones generados por los productos o servicios. Esta dimensión afectiva está formada por un componente emocional, relacionado con los sentimientos o emociones internas, y un componente social, relacionado con el impacto social de la compra realizada (Sánchez et al., 2006).

En definitiva, el enfoque cognitivo asume que la gente realiza sus acciones desde una perspectiva racional, mientras el enfoque afectivo considera que hay un buen número de reacciones no razonadas que se forman en el subconsciente del consumidor (Derbaix y Vanden Abeele, 1985; Derbaix y Pham, 1998; Sánchez et al., 2006).

Pero a pesar de esta diferenciación ambos sistemas no son independientes, sino que interaccionan entre sí influyéndose mutuamente. Es más, para tener una explicación completa de las actitudes y comportamientos de los consumidores es necesario tener en 
cuenta las respuestas cognitivas y afectivas (Hales, 1991; Derbaix y Pham, 1998; Peter y Olson, 1999; Sánchez et al., 2006). El enfoque multidimensional intenta explicar el concepto de valor percibido desde una perspectiva global, teniendo en cuenta tanto el sistema cognitivo como el afectivo (Sánchez et al., 2006).

El marco general de referencia que se ha presentado para el valor percibido es aplicable tanto en el ámbito de los servicios como de los productos. Es más, según Holbrook (1994), todos los productos potencialmente proveen servicios. De hecho, lo que los consumidores quieren son experiencias satisfactorias y no los medios que los producen.

En este apartado se han intentado exponer las distintas concepciones del valor percibido del cliente. Como resultado, se ha visto que existen dos grandes enfoques en cuanto a la naturaleza del valor, varios contextos significativos, distintos niveles de evaluación, diferencias relativas a los clientes, e influencias temporales que hacen del valor percibido un constructo dinámico y difícil.

En todo caso, el presente trabajo va a seguir el enfoque de Sweeney y Soutar (2001) y Sánchez et al. (2006), ya que permite recoger la perspectiva de los clientes en su dimensión racional, emocional y social o moral, y por ello pensamos que ofrece una aproximación más completa de aquello que ocurre en las mentes de los consumidores. Por ello, se va a tratar el concepto de valor desde la perspectiva multidimensional.

En el presente trabajo intentaremos profundizar en el conocimiento del valor percibido, tanto en el análisis de su dimensionalidad como en su relación con la motivación. Entendiendo esta última como una condición interna, fruto de un conjunto de valores relativos al individuo, sus preferencias y cultura. Y entendiendo la primera de ellas como el resultado de ese comportamiento motivado que finalmente desencadenó una compra con su correspondiente experiencia. Respecto a la dimensionalidad, se ha visto que las emociones juegan un papel muy importante en la percepción del valor de la mayoría de los consumidores (Sheth, Newman y Gross, 1991a y 1991b; Sweeney, Soutar 
y Jonson, 1999; Hay et al., 2000; Robinette et al., 2001; Sweeny y Soutar, 2001). De esta forma, analizar las dimensiones emocional social, o moral, además de la funcional o racional, es importante para tener una visión completa del concepto valor percibido.

\subsubsection{Relación entre el valor percibido por el consumidor y la motivación de compra.}

La motivación de compra ha sido definida en apartados anteriores como la fuerza o disposición interna que conduce o energiza un determinado comportamiento dándole un dirección hacia un objetivo, al mismo tiempo que instiga o mantiene el mismo (Atkinson 1964; Kleinginna y Kleinginna 1981; Park y Mittal 1985; Robbins 2003, Solomon y Rabolt 2006; Franken 2006; Schunk et al. 2008; Devesa et al. 2009; Schiffman y Kanuk 2009; Reeve 2010; Solomon et al. 2013; Reeve 2014; Evans 2014; Hoffman 2015). En este sentido, y teniendo en cuenta que podemos entender la motivación como el punto de partida que inicialmente hace desencadenarse un determinado comportamiento de compra, es razonable afirmar que la motivación de compra del consumidor pueda también afectar a la actitud general del consumidor y en otros aspectos destacables como pueden ser las percepciones, la implicación o la satisfacción (Fodness 1994; Gnoth 1997).

En el campo del turismo, Williams (2004) establece la denominada teoría del comportamiento turístico motivado. En su teoría se establece el "ciclo" del comportamiento de la estimulación, incluyendo la motivación y la formación de la intención, pasando por el comportamiento real y la experiencia $\mathrm{y}$, por último, la evaluación y las consecuencias relativas a la intención de recompra. Se trata de una herramienta de medición importante en la investigación de la motivación del turismo, basado en el constructo de actitud de Heider (1958) y la teoría de Kelley (1967) basada en la atribución. Este "ciclo" de comportamiento propuesto por Williams también incluye 
elementos de la línea de pensamiento conductista perteneciente a la tensión emocional y la reducción del impulso a través del turismo.

Duman y Mattila (2005), en su análisis del turismo de cruceros consideran la motivación el punto de partida previo a la situación experimental (valor percibido en la compra, o en este caso en la experiencia del crucero) y destacan la estrecha relación entre ambas variables. Consistentemente, apoya su argumento en Babinet al. (1994, quien propone que los aspectos afectivos de los consumidores están directamente relacionadas con sus percepciones de valor. $\mathrm{Y}$ aunque, si bien esta última afirmación no considera todas las dimensiones que se presentan en este trabajo para la medición de las variables, sí consideramos que tienen el mismo planteamiento téorico.

En 2012, Prebensen, Woo, Chen y Uysal realizan una investigación sobre turistas noruegos en la que destacan el papel de del valor de la experiencia como eje de las relaciones turísticas. Partiendo de esta premisa, el estudio ofrece un enfoque integrado para la comprensión de los valores de la experiencia de los turistas, la motivación, la satisfacción, y hay un resultado coherente para la trayectoria de la motivación y para la percepción de valor de la industria a través de contextos concretos.

Kim et al. 2013, llevan a cabo un trabajo sobre la implicación y las conductas de uso de dispositivos móviles. Los autores destacan que el uso continuado de sus teléfonos móviles conduce a los usuarios a alcanzar un comportamiento intrínsecamente muy motivado, haciéndolos muy sensibles a las valoraciones experimentales de uso de sus dispositivos y vinculando su experiencia con la satisfacción y la lealtad. Reconociendo y destacando el papel de la comprensión de las motivaciones de los usuarios de teléfonos inteligentes como una variable muy relacionada con la satisfacción en base a un uso continuado y un mayor compromiso con los smartphones.

De este modo y apoyándonos en los trabajos de Sweeney, Soutar y Jonson (1999), Sweeney y Soutar (2001) y Sánchez et al. (2006), quienes analizan el concepto de valor 
como un constructo multidimensional planteamos nuestra segunda proposición (H2): La motivación de compra del consumidor tiene un efecto positivo y directo sobre el valor percibido por el mismo (Fodness 1994, Gnoth 1997 Williams 2004, Duman y Mattila 2005, Prebensen et al. 2012 y Kim et al. 2013).

En nuestro trabajo establecemos tres dimensiones de valor percibido que coinciden con las planteadas en el apartado de la variable motivacional. Así, planteamos una hipótesis para la valoración de cada una de las relaciones. Con ello, podremos evaluar el efecto de cada dimensión de motivación en el resultado de la experiencia de compra en forma de valor percibido por el consumidor:

H2a: La motivación utilitarista de compra tiene un efecto positivo y directo sobre el valor utilitarista de la compra percibido por el consumidor.

H2b: La motivación ética de compra tiene un efecto positivo y directo sobre el valor ético de la compra percibido por el consumidor.

H2c: La motivación hedónica de compra tiene un efecto positivo y directo sobre el valor emocional de la compra percibido por el consumidor. 


\subsection{LA SATISFACCIÓN}

La satisfacción del consumidor se ratifica, pese al paso de los años, como uno de los constructos más relevantes e interesantes dentro del campo del marketing (Oliver 1999; Lombart y Louis 2012), tanto desde su vertiente más académica como desde la perspectiva más empresarial o de gestión. Lo cual no es un hecho sorprendente, pues la satisfacción del consumidor es un aspecto crítico para la longevidad de cualquier negocio, y por ello es también uno de los temas más investigados en el área de marketing (Grace y O’Cass 2005; Pappu y Quester 2006; El-Adly y Eid 2016).

Si tenemos en cuenta el entorno altamente competitivo en el que hoy en día desarrollan su actividad los comercios minoristas, son éstos mismos aquellos más interesados en conseguir que la satisfacción de consumidores. Centrar los esfuerzos en la consecución de relaciones satisfactorias y duraderas con los consumidores marca el camino hacia la obtención resultados comerciales positivos (Ailawadi y Keller 2004; Lombart y Louis 2012).

Según Theron y Terblanche (2010), la satisfacción de los consumidores con un determinado tipo de negocio depende positivamente del dinamismo y fortaleza de la relación entre el comprador y el vendedor. Y esta relación, juega un papel clave en la consecución de objetivos comerciales finales (Sarlak y Fard, 2009).

Sin embargo, tras la revisar la literatura existente, podemos afirmar que no existe un consenso universal en cuanto a la definición del concepto de satisfacción, así como tampoco en el modo de evaluación del mismo (Geyskens et al. 1999; Szymanski y Henard 2001; Giese y Cote 2002; Kesari y Atulkar 2016). En ese sentido, en el presente apartado se llevará a cabo una revisión de las definiciones propuestas por los autores a lo largo de los últimos años, la evolución del concepto de satisfacción del consumidor y se plantearán sus relaciones con el valor percibido en la compra. 


\subsubsection{Concepto de satisfacción: definición y evolución}

La satisfacción se ha concebido tradicionalmente como la confirmación de las expectativas, siguiendo el paradigma disconfirmatorio en la formación de la misma (Yi 1990; Fornell 1992; Oliver 1993; McKinney et al. 2001). Este paradigma dominante afirma que los consumidores tienen estándares de comparación previos al consumo, y que, observando el desempeño del mismo y comparándolo con dichos estándares, se forman las percepciones de conformidad o disconformidad que producen una evaluación de satisfacción. El estándar de comparación más común son las expectativas predicativas (resultado o reflejo de las experiencias positivas y/o negativas), aunque también se han propuesto otros estándares (Fournier y Mick 1999). De este modo, un consumidor estará satisfecho cuando su evaluación hacia un producto o servicio (las percepciones) confirme o exceda sus expectativas.

Sin embargo, además de este proceso cognitivo de disconformidad, debemos destacar la relevancia del componente afectivo de la satisfacción, ya que los consumidores se forman dos estados afectivos, uno basado en afecciones positivas, y otro basado en afecciones negativas, aunque estas puedan darse a la vez (Oliver 1993, 1996).

Con el objetivo de diferenciar la satisfacción de la calidad percibida se han realizado trabajos donde se afirma que las expectativas en la calidad se aplican al ideal o lo que esperaría un cliente de una empresa excelente, mientras que las expectativas en la satisfacción del servicio se refieren a aquello que los clientes creen que ocurrirá (Parasuraman et al. 1988; Bitner 1990; Boulding et al. 1993).

Por otro lado, las valoraciones sobre satisfacción precisan de la experiencia del cliente, mientras que para evaluar la calidad no es necesaria (Parasuraman et al. 1988; Bolton y Drew 1991; Cronin y Taylor 1992; Boulding et al. 1993; Oliver 1993). Operativamente, la satisfacción es similar a una actitud, de forma que puede ser evaluada como la suma de las satisfacciones con los diversos atributos del producto o del servicio 
(Churchill y Surprenant 1982). Sin embargo, mientras la actitud es una variable predecisión, la satisfacción es una experiencia post-decisión (LaTour y Peat 1979). La satisfacción puede considerarse a dos niveles: a nivel de la transacción o interacción y a nivel de satisfacción global (Bitner y Hubbert 1994).

Aunque no ha existido una definición ni una forma de medir la satisfacción común, lo único que parece claro es que todas las perspectivas suponen una única dimensión de la variable referida a la evaluación de ciertas características en relación a algún estándar (Oliver 1992; Bitner y Hubert 1994; Hallowell 1996; Oliver 1999; Cassel y Eklof 200; Giese y Cote 2002; Bull, Coelho y Machás 2004; Yang y Peterson 2004).

Giese y Cote (2002) realizan una investigación que pretende encontrar puntos comunes en la literatura de satisfacción del consumidor. Los autores afirman que la falta de consenso ha limitado la capacidad para desarrollar las medidas adecuadas y comparar los resultados entre los estudios. Existen, por lo tanto, tres puntos de encuentro cuando analizamos la variable satisfacción: el tipo de respuesta, el objeto de la respuesta y el momento de la respuesta. La satisfacción se ha considerado como un tipo de respuesta emocional más que cognitiva, que puede variar en intensidad según el contexto en el que nos encontremos. El objeto de la misma implica alguna comparación con algún estándar (expectativas o deseos), y lo que se juzga puede ser un producto, una experiencia de compra, una decisión de compra, un establecimiento, un vendedor, etc. El momento en que se produce la respuesta suele ser tras la compra, con matices en cuanto a la duración de la misma.

En general, podemos afirmar que dos son las conceptualizaciones que más seguidores tienen a la hora de tratar la satisfacción del consumidor. Podemos distinguir claramente entre la corriente centrada en la satisfacción con una transacción específica, y la corriente basada en la satisfacción global del consumidor.

La primera corriente centrada en la transacción específica hace referencia a la satisfacción como un estado emocional que experimenta el individuo con la relación más 
reciente que ha tenido con la organización (Oliver 1993). El estado en cuestión se logra después de la experiencia o del proceso completo de consumo. El estado afectivo puede variar en intensidad según las variables situacionales presentes.

Por otro lado, la corriente basada en la satisfacción global, entiende la satisfacción del consumidor como la suma o acumulación de las evaluaciones realizadas de cada uno de los encuentros del consumidor con la empresa a lo largo del tiempo. Es decir, la satisfacción del consumidor se define como la evaluación global del total de compras de un consumidor y la experiencia de consumo con productos o servicios a través de un período de tiempo (Cronin y Taylor 1992; Anderson et al., 2004; Yang y Peterson 2004; Devesa et al. 2010; Yoon et al. 2010; Soon et al. 2013).

La investigación cualitativa realizada comparando estas dos corrientes revela que los consumidores consideran estas dos concepciones de la satisfacción de manera diferente (Bitner y Hubbert, 1994). Los consumidores son propensos a comentar sobre eventos particulares de una transacción de servicios (por ejemplo, acciones específicas de los empleados) cuando se le pregunta acerca de la satisfacción con transacciones específicas. Por el contrario, cuando se le pide información acerca de su satisfacción general, los consumidores tienden a comentar las impresiones globales y la experiencia general con la empresa.

Dado que la satisfacción global se basa en información de todas las experiencias anteriores con el proveedor de servicios, la satisfacción general puede ser vista como una agrupación de todas las satisfacciones de transacciones específicas anteriores (Parasuraman et al, 1994.; Teas, 1993). La satisfacción general puede basarse en muchas transacciones o sólo en algunas, dependiendo del número de veces que el consumidor ha realizado una compra en particular. En esencia, la satisfacción general es una agregación de todas las evaluaciones previas a las transacciones individuales y se actualiza después de cada transacción específica al igual que las expectativas de calidad general del servicio se actualizan después de cada transacción (Boulding et al., 1993). Cabe señalar, tal y como exponen los autores Jones y Suh (2000), que a pesar de que la satisfacción general 
en un momento t-1 tendrá un impacto en las expectativas que producen la satisfacción con una transacción específica en el momento $t$, esta satisfacción con la transacción específica sólo será influida indirectamente por la satisfacción general (a través de las expectativas). La satisfacción general en el momento $t$, dependerá de la satisfacción general en el momento t-1, así como la satisfacción de con la transacción específica (reflejando todas las satisfacciones con transacciones específicas anteriores), así como la satisfacción específica resultante de la transacción más reciente producida en el momento t (Boulding et al., 1993).

En general, la satisfacción de transacciones específicas puede no estar perfectamente correlacionada con la satisfacción general ya la calidad del servicio es probable que varíe de experiencia en experiencia, causando diferencias. La satisfacción general, por el contrario, puede ser vista una medida más estable y similar a una actitud general (Parasuraman et al., 1994). Por ejemplo, un consumidor puede tener una experiencia poco satisfactoria debido a la pérdida de equipaje en un vuelo de una aerolínea (es decir, baja satisfacción con la transacción específica) y aun así estar satisfecho con la línea aérea (es decir, la satisfacción general) debido a múltiples encuentros anteriores satisfactorios.

En este sentido, y en conclusión, Oliver (1996) define la satisfacción como un estado placentero que experimenta el consumidor. Este estado es consecuencia del juicio positivo de los aspectos obtenidos del consumo de un bien o servicio. En el presente trabajo utilizaremos esta conceptualización y nos referiremos a la satisfacción global o acumulada que se forma a lo largo del tiempo y que supone un proceso de aprendizaje y recuerdo de todas las transacciones previas (Garbarino y Johnson 1999; Sharma, Niedrich y Dobbins 1999; Devesa et al. 2010; Yoon et al. 2010; Soon et al. 2013). 


\subsubsection{Relación del valor percibido y la satisfacción}

En la tabla 4.3 se recogen algunos trabajos que han relacionado el valor percibido por el consumidor con la satisfacción. En general, existe cierta dificultad a la hora de diferenciar el valor percibido y la satisfacción, sin embargo tras un largo proceso de investigaciones se ha llegado a la conclusión de que se trata de constructos diferentes (Bolton y Drew 1994; Gale 1994; Rust y Oliver 1994; Slater 1997; Walters y Lancaster 1999; Yang y Peterson 2004; Caruana y Fenech 2005). La distinción entre ambos radica en que mientras la satisfacción está compuesta por actitudes, el valor percibido se refiere más a conductas (Butz y Goodstein 1996).

Tabla 4.3 - Trabajos sobre la relación del valor percibido con la satisfacción.

\begin{tabular}{|l|l|}
\hline \multicolumn{1}{|c|}{ AUTOR } & \multicolumn{1}{c|}{ APORTACIÓN } \\
\hline Gale (1994) & $\begin{array}{l}\text { Los consumidores satisfechos desertaran si encuentran otra oferta } \\
\text { con mayor valor para ellos. }\end{array}$ \\
\hline $\begin{array}{l}\text { Rust y Oliver } \\
(1994)\end{array}$ & El valor percibido influye en la satisfacción del consumidor. \\
\hline Anderson (1995) & $\begin{array}{l}\text { El valor del consumidor se incrementa cuando aumenta la } \\
\text { satisfacción y viceversa. }\end{array}$ \\
\hline $\begin{array}{l}\text { Butz y Goodstein } \\
(1996)\end{array}$ & $\begin{array}{l}\text { La satisfacción del consumidor está formada por actitudes, el valor } \\
\text { percibido se refiere a conductas. }\end{array}$ \\
\hline $\begin{array}{l}\text { Ravald y Grönroos } \\
(1996)\end{array}$ & $\begin{array}{l}\text { La satisfacción del consumidor depende de las percepciones de los } \\
\text { consumidores del valor recibido. }\end{array}$ \\
\hline $\begin{array}{l}\text { Fornell, et al. } \\
(1996) ; \text { Heskett, et } \\
\text { al. (1997); De } \\
\text { Ruyter, et al. } \\
(1997)\end{array}$ & $\begin{array}{l}\text { El valor percibido es un antecedente de la satisfacción del } \\
\text { consumidor. }\end{array}$ \\
\hline $\begin{array}{l}\text { Slater (1997); } \\
\text { Walters y } \\
\text { Lancaster (1999) }\end{array}$ & $\begin{array}{l}\text { La satisfacción del cliente se consigue cuando la empresa genera } \\
\text { valor para el consumidor. }\end{array}$ \\
\hline $\begin{array}{l}\text { Yang y Peterson } \\
(2004)\end{array}$ & $\begin{array}{l}\text { La satisfacción del consumidor está influida positivamente por el } \\
\text { valor percibido por el consumidor. }\end{array}$ \\
\hline
\end{tabular}




\begin{tabular}{|l|l|}
\hline \multicolumn{1}{|c|}{ AUTOR } & \multicolumn{1}{c|}{ APORTACIÓN } \\
\hline $\begin{array}{l}\text { Caruana y Fenech } \\
(2005)\end{array}$ & $\begin{array}{l}\text { El valor percibido por el consumidor determina la satisfacción } \\
\text { global del mismo. }\end{array}$ \\
\hline $\begin{array}{l}\text { Lin y Wang } \\
(2006)\end{array}$ & $\begin{array}{l}\text { La satisfacción de los consumidores es la respuesta total del } \\
\text { consumidor a las experiencias de compra en un entorno } \\
\text { determinado. }\end{array}$ \\
\hline $\begin{array}{l}\text { Sánchez e Iniesta } \\
(2009)\end{array}$ & $\begin{array}{l}\text { El valor percibido y la satisfacción del consumidor son variables } \\
\text { que guardan relación entre ellas, pero al mismo tiempo, representan } \\
\text { también constructos diferentes. Existen ciertas características en } \\
\text { común: ambos son juicios relativos; ambos son dependientes del } \\
\text { contexto y el consumo, ambos implican aspectos de costes y } \\
\text { beneficios, especialmente con respecto a la situación de uso }\end{array}$ \\
\hline Egan (2011) & $\begin{array}{l}\text { El valor percibido por el consumidor conduce hacia la } \\
\text { satisfacción del cliente, que a su vez es el principal antecedente } \\
\text { de las relaciones comerciales a largo plazo. }\end{array}$ \\
\hline Kim et al. (2013) & $\begin{array}{l}\text { El valor percibido la variable más importante para obtener ventaja } \\
\text { competitiva, pues de su resultado depende la satisfacción general. }\end{array}$ \\
\hline $\begin{array}{l}\text { Kesari y Atulkar } \\
(2016)\end{array}$ & $\begin{array}{l}\text { La satisfacción del consumidor es la respuesta a un proceso de } \\
\text { evaluación. Cuando el objetivo de compra del consumidor es } \\
\text { alcanzado satisfactoriamente, éste representa un logro. }\end{array}$ \\
\hline
\end{tabular}

Fuente: Elaboración propia.

En cuanto a la relación que mantienen ambos constructos, la mayor parte de autores argumentan que la satisfacción depende de la percepción de valor por el cliente (Rust y Oliver 1994; Fornell, et al. 1996; Ravald y Grönroos 1996; Heskett, et al. 1997; De Ruyter, et al. 1997; Slater 1997; Walters y Lancaster 1999; Yang y Peterson 2004; Caruana y Fenech 2005; Lin y Wang 2006; Sánchez e Iniesta 2009; Egan 2011; Kim et al. 2013 y Kesari y Atulkar 2016). Por ello nos vamos a fundamentar en estas investigaciones para proponer nuestra tercera hipótesis.

La satisfacción, se ha concebido tradicionalmente como la confirmación de las expectativas (Yi, 1990; Fornell, 1992; Oliver, 1993; Coelho y Machás, 2004). Este paradigma dominante afirma que los consumidores tienen estándares de comparación previos al consumo, y que observando el desempeño del mismo y comparándolo con 
dichos estándares se forman las percepciones de satisfacción. Estos estándares se refieren a información anterior referida a "lo que el consumidor espera que ocurra" en base a su experiencia previa.

De este modo, la satisfacción se puede asemejar a una creencia inferida, ya que se basa en una comparación de información nueva, que es el valor percibido, con otra información cumulativa ya procesada. De este modo planteamos nuestra tercera proposición (H3): El valor percibido por el consumidor tiene un efecto positivo y directo sobre satisfacción del mismo. En nuestro trabajo establecemos tres dimensiones de valor percibido. Así, planteamos una hipótesis para la valoración de cada una de las relaciones. Con ello, podremos evaluar el efecto de cada dimensión de del valor percibido sobre la satisfacción de manera separada:

H3a: El valor utilitarista percibido por el consumidor tiene un efecto positivo y directo sobre la satisfacción.

H3b: El valor ético percibido por el consumidor tiene un efecto positivo y directo sobre la satisfacción.

H3c: El valor emocional percibido por el consumidor tiene un efecto positivo y directo sobre la satisfacción. 


\subsection{LA LEALTAD}

Si retrocedemos a lo expuesto en capítulo segundo de la presente tesis, se define el marketing relacional como aquel enfoque centrado en la creación y el sostenimiento de la relación entre las dos partes que componen todo intercambio, es decir, el proveedor y el consumidor, a través del desarrollo del deseo de ser mutuamente empático, recíproco, y con el objetivo último de confiar y formar vínculos de lealtad a largo plazo (Callaghan et al. 1995, Morgan y Hunt 1994, Yau et al. 2000, Sin et al. 2005, Barroso et al. 2015).

Así, una vez expuestas las variables motivación, valor percibido (variable de evaluación por parte del consumidor) y satisfacción, presentamos a continuación la lealtad del consumidor como elemento clave en el planteamiento del marketing de relaciones. Ya que un consumidor leal, supondrá a largo plazo mejoras en la productividad así como incrementar los ingresos del negocio (Gwinnner, Gremler y Bitner, 1998) y reducir ciertos costes (Heskett, Sasser y Hart, 1990), que en definitiva incidirán en unos mayores y más estables beneficios para la empresa (Jacoby y Chestnut, 1978; Reichheld y Sasser, 1990; Weinstein y Johnson, 1999).

\subsubsection{Concepto de lealtad del consumidor}

La lealtad del consumidor es uno de los conceptos que se consideran fundamentales para explicar las elecciones de compra realizadas por los consumidores. Por ello no sorprende que este concepto haya ganado un gran interés tanto entre académicos como entre profesionales del campo del marketing y del comportamiento del consumidor (Moller y Hansen 2006). A pesar de los esfuerzos de los gerentes en programas de fidelización, la lealtad por parte del consumidor presenta cierta decadencia (Chancy 2001). Comparada con la lealtad más exclusiva del pasado, los consumidores presentan, de forma creciente, comportamientos de lealtad polígama (Uncles, Ehrenberg, y Hammond 1995; Uncles, Dowling y Hammond 2003; Rust, Lemon y Zeithaml 2004; 
Bennett y Rundle-Thiele 2005). Los consumidores mantienen cierta tendencia a dividir sus compras entre varias marcas dentro de una misma categoría de producto (Kau y Ehrenberg 1984; Knox y Denison 2000; Cooil, Keiningham, Aksoy y Hsu 2007). En este sentido, surge el concepto de "lealtad hacia el establecimiento principal", definido como el porcentaje de gasto realizado por un cliente en su establecimiento preferido (Kau y Ehrenberg 1984; Knox y Denison 2000; Terblanche y Boshoff 2006; Cooil, Keiningham, Aksoy y Hsu 2007). Por esto es especialmente importante entender el concepto de lealtad del consumidor ya que cada vez se hace más complicado para las empresas lograr dicha cuota de fidelidad (Moller y Hansen 2006).

Poder entender y medir la lealtad del cliente es importante para todas las empresas, pero especialmente para aquellas que han implementado, o tienen previsto implementar, programas de retención de clientes, como pueden ser las tarjetas de cliente (Stern y Hammond 2004). De hecho, son muchas las empresas que han creado programas relacionales para fomentar la lealtad entre sus clientes (Schiffman y Kanuk 2004). La idea está fundamentada en el concepto de marketing relacional de Berry (1983), y se basa en el hecho de que generando relaciones a largo plazo con nuestros clientes lleva a una reducción del número de clientes que abandona nuestra empresa, reduce ciertos costes e incrementa los beneficios (Harrison 2003a). En este sentido, la lealtad del consumidor es la variable clave de resultado de una estrategia de marketing relacional (Hennig-Thurau et al. 2002). Además existen trabajos que relacionan la lealtad del consumidor con la rentabilidad de la empresa (Anderson y Mital 1994; Hallowell 1996; Reichheld 1996; Anderson y Mital 2000; Kish 2000; Duncan y Elliot 2002), afirmando, por otro lado, que una empresa con una clientela leal posee una cierta ventaja competitiva. Sin embargo, es importante matizar que no todos los clientes leales son rentables para una empresa (Storbacka, 1994; 1997). Así, Anderson y Mittal (2000) concluyen que la rentabilidad de la relación con un cliente aumenta mediante la captación y retención de clientes de "alta calidad", con unos costes de fidelización y mantenimiento bajos y unos ingresos elevados. En este sentido, Dowling y Uncles (1997) afirman que para operativizar los programas 
de fidelización, es necesario conocer los patrones del comportamiento de lealtad de los consumidores.

En este apartado analizaremos las diferentes definiciones que se han realizado del concepto de lealtad del consumidor, y realizaremos una revisión de la investigación pasada sobre dicho concepto.

\subsubsection{Definición y evolución del concepto de lealtad}

La concepción de la lealtad ha evolucionado tanto en amplitud como en profundidad de significado a lo largo del tiempo. Su amplitud, se ve reflejada en los múltiples enfoques que incluyen marca, producto, vendedor, tienda y lealtad de servicio entre otros. Inicialmente estos enfoques, se desarrollaron a partir del paradigma de marketing transaccional, dando gran importancia a los bienes tangibles y a las transacciones realizadas. El desarrollo que ha experimentado la teoría de marketing a lo largo de los años ha influido en la evolución del concepto de lealtad, con una conceptualización y operacionalización del constructo más profunda y rica (Caruana 2004).

La investigación sobre la lealtad del consumidor se enfocó en sus inicios en la lealtad hacia la marca en los productos (Gremler y Brown 1996), centrándose en la dimensión comportamental de la lealtad, sin prestar mucha atención a lo que pensaba el cliente (Jacoby y Chestnut 1978; Gremler y Brown 1996; Caruana 2004; Howcroft, Heder y Durkin 2005). Como la mayoría de las investigaciones en el campo de los productos, en los servicios se ha realizado gran número de trabajos que miden comportamientos (Jacoby y Chesnut 1978; Hennig-Thurau y Klee 1997; Pritchard, Havitz y Howard 1999; Liang y Wang 2005). En este sentido, la lealtad frecuentemente se ha definido (Tabla 4.4) como un comportamiento observado (Jacoby 1971; Newman y Werbel 1973; Lijander y 
Strandvik 1995; Shoemaker 1998; Howcroft, Heder y Durkin 2005). Otros autores, han definido la lealtad del consumidor como el porcentaje de gasto que realiza éste en una marca específica o en un determinado establecimiento (East, Harris, Willson y Lomas 1995; Hennig-Thurau y Klee 1997; Pritchard, Havitz y Howard 1999; Liang y Wang 2005).

No obstante, las medidas comportamentales, como la repetición de compra o la secuencia de visitas, han sido criticadas por la falta de una base conceptual y por tener una pobre visión de lo que es realmente un proceso dinámico (Day 1969; Dick y Basu 1994; Bloemer y De Ruyter 1998; Oliver 1999; Szymigin y Cardigan 2001; Carroll y Ahuvia 2006; Johnson, Herrmann y Huber 2006; Moller y Hansen 2006). Por ejemplo, un bajo nivel de repeticiones de compra de un servicio concreto puede ser resultado de factores situacionales como la no disponibilidad, la búsqueda de variedad o la falta de preferencia por un proveedor (Reinartz y Kumar 2002; Liljander y Roos 2002; Aldlaigan y Buttle 2005). De este modo, la concepción comportamental de la lealtad no recoge los motivos subyacentes de la lealtad, en cambio es la disposición del cliente en términos de preferencias o intenciones lo que juega un importante papel a la hora de determinar la lealtad (Jain et al. 1987; Bloemer y Kasper 1995; Bloemer y De Ruyter 1998; Yang y Peterson 2004; Johnson, Herrmann y Huber 2006; Wang, Liang y Wu 2006). Además, el comportamiento de repetición de compra puede no estar basado en la preferencia del consumidor, ya que existen una serie de factores que actúan como barreras para el cliente (Guiltinan 1989; Lijander y Strandvik 1995; Jones et al. 2002; Burnham et al. 2003; Caruana 2004; Yang y Peterson 2004; Aydin y Özer 2005).

En esta línea Opperman (2000) afirma que prefiere las medidas comportamentales, argumentando que medir actitudes en un largo periodo de tiempo está fuera de nuestro alcance, y es en la mayoría de los casos impracticable. Así, debido a las dificultades de medición de la lealtad afectiva (afecto psicológico), las medidas comportamentales son utilizadas frecuentemente para operativizar la lealtad (Opperman, 2000). En la misma dirección se expresa O’Mally (1998), afirmando que en comparación 
a las medidas afectivas, las medidas comportamentales de la lealtad proporcionan una información más realista de lo bien que la marca está actuando frente a sus competidores, y los datos proporcionados facilitan el cálculo de valor de vida del cliente, se prestan a las predicciones por probabilidades y ayudan al desarrollo de promociones eficientes. Además, también añade que los avances en las tecnologías de bases de datos han incrementado la facilidad de recoger datos sobre la lealtad comportamental de los consumidores.

Sin embargo, mediante las aproximaciones de lealtad puramente comportamentales, es imposible detectar cualquier antecedente de la repetición de compra, y por consiguiente las empresas no incrementan su conocimiento de cómo deben de trabajar la lealtad del consumidor. Desde un punto de vista más determinista, la lealtad se conceptualiza como una actitud o una intención de recomprar y se cree que el investigador puede buscar los factores que generan dicho sentimiento de lealtad. Las investigaciones en este sentido ganaran en conocimiento sobre cómo crear y mantener clientes leales a una determinada marca (Odin et al. 2001; Moller y Hansen 2006). Además, la medición directa, comporta una serie de dificultades, ya que es difícil obtener información relativa a la secuencia de compras del consumidor. Si ello va unido al hecho de que la simple repetición de compra no es un buen indicador de lealtad, ya que no todos los que repiten la compra pueden considerarse clientes fieles, la medición indirecta comporta elementos más fiables para la medición de la lealtad (Cronin, Brady y Hult 2000). La perspectiva comportamental se caracteriza por su visión puramente mecánica, lo que impide proporcionar elementos valiosos para la explicación de un comportamiento dado y las razones que lo han provocado (Oliver 1999; Callarisa 2004; Caruana 2004; Host y Knie-Andersen 2004; Carroll y Ahuvia 2006; Efigie 2006; Leverin y Liljander 2006; Moller y Hansen 2006).

Dick y Basu (1994) sugieren un marco teórico basado en el concepto de lealtad como un constructo compuesto por una parte de actitudes, donde se dan sentimientos y afectos positivos, y un patrón de comportamiento. Se deduce, por tanto, la coexistencia 
de dos dimensiones de lealtad; una actitudinal y otra comportamental (Sheth y Parvatiyar 1995; Gremler y Brown 1996; Oliver 1999; Szymigin y Cardigan 2001; Carroll y Ahuvia 2006; Johnson, Herrmann y Huber 2006; Moller y Hansen 2006).

Tabla 4.4 - Definiciones de lealtad del consumidor.

\begin{tabular}{|l|l|}
\hline \multicolumn{1}{|c|}{ AUTORES } & \multicolumn{1}{c|}{ DEFINICIONES } \\
\hline $\begin{array}{l}\text { Cunningham } \\
\text { (1956) }\end{array}$ & $\begin{array}{l}\text { La lealtad de marca es la proporción de compras que realiza una familia de } \\
\text { una determinada marca, comprada con mayor frecuencia, respecto del total } \\
\text { gastado }\end{array}$ \\
\hline Jacoby (1971) & $\begin{array}{l}\text { La lealtad del consumidor es la repetición de compra del mismo proveedor, } \\
\text { resultado de procesos psicológicos }\end{array}$ \\
\hline $\begin{array}{l}\text { Newman } \\
\text { Werbel (1973) }\end{array}$ & $\begin{array}{l}\text { Aquellos consumidores que recompran la misma marca, considerando } \\
\text { únicamente esa marca, y no buscan información acerca de otras ofertas } \\
\text { alternativas }\end{array}$ \\
\hline $\begin{array}{l}\text { Jacoby y Chesnut } \\
(1978)\end{array}$ & $\begin{array}{l}\text { La lealtad de marca es intencionada (no aleatoria), con una respuesta } \\
\text { comportamental, expresada a lo largo del tiempo, a partir de un proceso de } \\
\text { decisión respecto de una o más marcas del conjunto de marcas posibles, y } \\
\text { que es resultado de un proceso psicológico }\end{array}$ \\
\hline $\begin{array}{l}\text { Dick y } \\
(1994)\end{array}$ & $\begin{array}{l}\text { Es un constructo compuesto por una parte de actitudes, donde se dan } \\
\text { sentimientos y afectos positivos, y un patrón de comportamiento }\end{array}$ \\
\hline East et al. (1995) & $\begin{array}{l}\text { La lealtad del consumidor está relacionada con la proporción de gasto } \\
\text { realizado por dicho consumidor en una marca específica o en un determinado } \\
\text { establecimiento }\end{array}$ \\
\hline $\begin{array}{l}\text { Gremler y Brown } \\
\text { (1996) }\end{array}$ & $\begin{array}{l}\text { La lealtad hacia un servicio es el grado en que un cliente manifiesta un } \\
\text { a dicho proveedor cuando surge la necesidad de dicho servicio }\end{array}$ \\
\hline
\end{tabular}




\begin{tabular}{|c|c|}
\hline AUTORES & DEFINICIONES \\
\hline $\begin{array}{l}\text { Bloemer y De } \\
\text { Ruyter (1998) }\end{array}$ & $\begin{array}{l}\text { La lealtad del consumidor hacia un establecimiento es una respuesta } \\
\text { comportamental intencionada (no aleatoria), expresada a lo largo del tiempo, } \\
\text { a partir de un proceso de decisión respecto de un establecimiento concreto } \\
\text { del conjunto de establecimientos posibles, y que es resultado de un proceso } \\
\text { psicológico (evaluación y decisión) resultando en un compromiso hacia el } \\
\text { establecimiento }\end{array}$ \\
\hline Oliver (1999) & $\begin{array}{l}\text { Un compromiso profundo de recompra de un producto o servicio preferido, } \\
\text { por consiguiente causará repetición de compra de la misma marca. Aunque } \\
\text { influencias del entorno y esfuerzos de marketing tienen el potencial de } \\
\text { provocar un comportamiento de cambio }\end{array}$ \\
\hline East et al. (2000) & $\begin{array}{l}\text { La lealtad del consumidor se puede describir como una predisposición } \\
\text { positiva hacia una marca o un establecimiento }\end{array}$ \\
\hline $\begin{array}{l}\text { Szymigin y } \\
\text { Cardigan (2001) }\end{array}$ & $\begin{array}{l}\text { Un sentimiento de compromiso por parte del individuo con un producto, } \\
\text { marca, un vendedor o unos servicios, situados por encima de la competencia, } \\
\text { y que tiene como consecuencia la repetición de la compra }\end{array}$ \\
\hline $\begin{array}{l}\text { Bloemer } \quad \text { y } \\
\text { Odekerken- } \\
\text { Schroder (2002) }\end{array}$ & $\begin{array}{l}\text { La lealtad hacia un proveedor es una preferencia actitudinal y } \\
\text { comportamental del consumidor hacia un determinado proveedor comparada } \\
\text { con las alternativas competidoras disponibles }\end{array}$ \\
\hline $\begin{array}{l}\text { Wallace, Giese y } \\
\text { Johnson (2004) }\end{array}$ & $\begin{array}{l}\text { La lealtad del consumidor hacia un establecimiento es una respuesta } \\
\text { comportamental intencionada (no aleatoria), expresada a lo largo del tiempo, } \\
\text { a partir de un proceso de decisión respecto de un establecimiento concreto } \\
\text { del conjunto de establecimientos posibles, y que es resultado de un proceso } \\
\text { psicológico (evaluación y decisión) resultando en un compromiso hacia el } \\
\text { establecimiento }\end{array}$ \\
\hline $\begin{array}{l}\text { Carroll y Ahuvia } \\
(2006)\end{array}$ & $\begin{array}{l}\text { La lealtad del consumidor es un aspecto intencional, representando el grado } \\
\text { de compromiso que mantiene un consumidor de recomprar la misma marca }\end{array}$ \\
\hline $\begin{array}{l}\text { Rauyruen } \\
\text { Millar (2006) }\end{array}$ & $\begin{array}{l}\text { La lealtad del consumidor es un concepto formado por dos dimensiones: una } \\
\text { actitudinal y otra comportamental. La lealtad actitudinal es el nivel de afecto } \\
\text { psicológico y de actitud favorable hacia un proveedor. Y la lealtad } \\
\text { comportamental es la disposición de los clientes de volver a comprar al } \\
\text { mismo proveedor y de mantener una relación con dicho proveedor }\end{array}$ \\
\hline
\end{tabular}




\begin{tabular}{|l|l|}
\hline \multicolumn{1}{|c|}{ AUTORES } & \multicolumn{1}{c|}{ DEFINICIONES } \\
\hline $\begin{array}{l}\text { Martínez y } \\
\text { Martínez (2009) }\end{array}$ & $\begin{array}{l}\text { Se puede considerar la lealtad como el grado de vinculación entre una marca } \\
\text { o empresa y el cliente. }\end{array}$ \\
\hline $\begin{array}{l}\text { Liu, Guo y Lee } \\
(2011)\end{array}$ & $\begin{array}{l}\text { La lealtad es una relación a largo plazo beneficiosa para los proveedores de } \\
\text { servicios, pues su base se centra en establecer una relación con los clientes } \\
\text { dinámica y duradera a lo largo del tiempo. }\end{array}$ \\
\hline $\begin{array}{l}\text { Swobodaa et al. } \\
(2013)\end{array}$ & $\begin{array}{l}\text { La lealtad hacia un comercio se define como la intención y la disposición } \\
\text { para la recompra en una tienda en particular, al mismo tiempo que se } \\
\text { identifican conductas de recomendación del comercio. }\end{array}$ \\
\hline $\begin{array}{l}\text { Castaldo et al. } \\
(2015)\end{array}$ & $\begin{array}{l}\text { El grado en que un cliente habitual muestra intención de compra con su } \\
\text { proveedor, posee una disposición de actitud positiva hacia el mismo, y al } \\
\text { mismo tiempo acude a este proveedor en cada ocasión que surge necesidad } \\
\text { de compra. }\end{array}$ \\
\hline $\begin{array}{l}\text { Athavale et al. } \\
(2015) .\end{array}$ & $\begin{array}{l}\text { La lealtad del consumidor es definida como la intención del cliente a llevar } \\
\text { a cabo un conjunto diverso de conductas que conducen a la necesidad de } \\
\text { mantener una relación comercial estable con un comercio específico. }\end{array}$ \\
\hline
\end{tabular}

Fuente: Elaboración propia.

En esta línea, autores como Rauyruen y Millar (2006) definen la lealtad del consumidor como un concepto formado por dos dimensiones: una actitudinal y otra comportamental. La lealtad actitudinal se basa en el nivel de afecto psicológico y de actitud favorable hacia un proveedor, en preferencias manifiestas, en un compromiso por parte del consumidor o en intenciones de recompra (Mellens et al. 1996; Rundle-Thiele y Mackay 2001). Por su parte, la lealtad comportamental se define en términos de recompras al mismo proveedor observadas durante un periodo determinado de tiempo (Mellens et al. 1996; Rundle-Thiele y Mackay 2001; Liu, Guo y Lee 2011). Además, de distinguir éstas dos dimensiones de lealtad, varios autores han afirmado que la dimensión actitudinal es anterior y determinante de la dimensión comportamental, ya que el comportamiento es la materialización de las intenciones que previamente había formado el individuo en su mente (Bloemer y De Ruyter 1998; Oliver 1999; Szymigin y Cardigan 2001; Yang y Peterson 2004; Carroll y Ahuvia 2006; Johnson, Herrmann y Huber 2006; 
Moller y Hansen 2006). La lealtad del consumidor también se ha definido como un compromiso de recompra por parte del consumidor de la misma marca (Oliver 1999; Szymigin y Cardigan 2001; Carroll y Ahuvia 2006), siendo dicho compromiso el antecedente de los comportamientos de recompra del consumidor (Oliver 1999; Szymigin y Cardigan 2001; Carroll y Ahuvia 2006; Johnson, Herrmann y Huber 2006; Moller y Hansen 2006; Cleeren et al. 2012).

De este modo, y según se ha ido argumentando a lo largo del punto, existen dos enfoques principales a la hora de definir y conceptualizar la fidelidad del consumidor: el enfoque comportamental y el enfoque actitudinal o afectivo (Jacoby y Chesnut 1978; Dekimpe, Steenkamp, Mellens y Vanden 1997; Dick y Basu 1994; Rundle-Thiele y Mackay 2001; McMullan y Gilmore 2003; Shankar, Smith y Rangaswamy 2003; Yi y La 2004; Terblanche y Boshoff 2006; Lei et al. 2011; Castaldo et al. 2015). En los inicios, desde la perspectiva comportamental, la medición de la lealtad se basaba en la observación directa de los comportamientos de repetición de compra realizados por los consumidores (Cunningham 1956; Tucker 1964; Day 1969; Jacoby 1971). A lo largo del tiempo han ido apareciendo otras medidas destinadas a captar la lealtad del cliente. Algunos investigadores utilizan en sus trabajos la secuencia de compras (Brown 1952; Brown 1953; Tucker 1964; McConnell 1968; Lawrence 1969), la probabilidad de recompra (Maffei 1960; Frank 1962), la probabilidad de mantener la misma marca en el futuro (Carpenter y Lehmann 1985; Colombo, Morrison y Green 1989; Dekimpe et al. 1997), la probabilidad de cambio de proveedor (Raju, Srinivasan y Lal 1990) o la proporción de compras que una familia realiza de la marca comprada habitualmente respecto a las marcas competidoras (Cunningham, 1956; Tucker 1964; Day 1969; Kostecki 1994). Knox y Dennison (2000) clasificaron las medidas de la lealtad del consumidor en cuatro categorías. La primera de ellas se refiere a medidas de comportamiento, que están enfocadas a averiguar el número de visitas realizadas a un establecimiento determinado en relación a otros. La segunda categoría la representan los ratios de abandono o deserción, que reflejan el grado de visitas realizadas por los clientes a un determinado establecimiento y su posterior patrón de cambio. En tercer lugar, 
presentan las medidas de gasto, referidas a la proporción del gasto realizado en el establecimiento preferido comparado con el gasto total realizado por dicho cliente (Kau y Ehrenberg 1984; Knox y Denison 2000; Liang y Wang 2005; Terblanche y Boshoff 2006; Cooil, Keiningham, Aksoy y Hsu 2007). La cuarta categoría recoge combinaciones de medidas de las tres categorías anteriores (Howcroft, Heder y Durkin 2003). Sin embargo esta clasificación únicamente trata medidas comportamentales, y por lo tanto mantienen las dificultades de medición y las deficiencias en la comprensión del proceso psicológico de la lealtad propias de dichas magnitudes (Jain et al. 1987; Bloemer y Kasper 1995; Bloemer y De Ruyter 1998; Odin et al. 2001; Yang y Peterson 2004; Johnson, Herrmann y Huber 2006; Moller y Hansen 2006; Wang, Liang y Wu 2006).

Por la otra parte, la lealtad actitudinal, entendida como una preferencia o compromiso emocional, se ha operativizado y se ha medido de varias maneras. A nivel general, hemos identificado trabajos que miden actitudes o sentimientos de lealtad (Butcher, Sparks y O'Callaghan 2001; Shankar, Smith y Rangaswamy 2003; Ball, Coelho y Machás 2004; Bennett, Härtel y McColl-Kennedy 2004; Bennett y Rundle-Thiele 2004; Host y Knie-Andersen 2004; Carroll y Ahuvia 2006; Efigie 2006; Leverin y Liljander 2006), otros trabajos que miden intenciones de comportamiento (Cronin y Taylor 1992; Anderson y Sullivan 1993; Zeithaml, Berry y Parasuraman 1996; Patterson y Spreng 1997; Bloemer, De Ruyter y Peeters 1998; Bloemer, De Ruyter y Wetzels 1999; De Ruyter y Bloemer 1999; Brady y Robertson 2000; Cronin, Brady y Hult 2000; Singh y Sirdeshmukh 2000; Martín 2001; Bloemer y Odekerken-Schröder 2002; Casado y Más 2002; Sirdeshmukh, Singh y Sabor 2002; Spreng y Chiou 2002; Callarisa 2004; Durvasula, Lysonski, Mehta y Tang 2004; Lee y Overby 2004; Patterson 2004; Veloutsou, Daskou y Daskou 2004; Yang y Peterson 2004; Yi y La 2004; Aydin y Özer 2005; Lin y Ding 2005; Johnson, Herrmann y Huber 2006). De igual forma hay artículos que recogen las actitudes de los consumidores junto a sus comportamientos de lealtad (Flavián, Martinez y Polo 2001; Rundle-Thiele y Mackay 2001; Caruana 2002; Kumar y Shah 2004; Noordhoff, Pauwels y Odekerken-Schröder 2004; Petrick 2004; Rodríguez, Camarero y Gutiérrez 2004; Wallace, Giese y Jonson 2004; Bloemer y Odekerken- 
Schröder 2006; Bove y Jonson 2006; Moller y Hansen 2006; Terblanche y Boshoff 2006). Aunque menos generalizado, también se ha encontrado algún trabajo que estudia las actitudes junto a intenciones de comportamiento (Hellier, Geursen, Carr y Richard 2003; Lim y Dubinsky 2004; Rayruen y Millar 2007). Finalmente, y en la línea de la propuesta de Oliver (1999), encontramos trabajos recogen los aspectos cognitivos de la lealtad junto a la actitud y comportamiento (Gremler y Brown 1999; McMullan y Gilmore 2003; Caruana 2004; Caruana y Fenech 2005; Liu, Guo y Lee 2011 ).

El dilema reside en el hecho de que la intención puede no generar comportamiento, y también que un comportamiento de repetición de compra no refleje las intenciones (Guiltinan 1989; Lijander y Strandvik 1995; Cronin, Brady y Hult 2000; Henning-Thurau y Hansen 2000; Jones et al. 2002; Burnham et al. 2003; Aydin y Özer 2005). Para solucionar estos inconvenientes, Oliver (1999) propuso un modelo de lealtad basado en el paradigma cognición-afecto-actuación. Según este modelo, el comportamiento de lealtad viene condicionado por la intención de lealtad del consumidor. Esta intención, a su vez, viene determinada por las actitudes hacia el producto o servicio. El modelo de formación de actitudes postula la existencia de elementos cognitivos y afectivos que son antecedentes, por tanto, de la intención de comportamiento. La medición del comportamiento de lealtad es complicado, ya que son conductas de comportamiento. Además la información comportamental de forma aislada, se caracteriza por tener un enfoque puramente mecánico, sin tener en cuenta otros elementos valiosos para la explicación de un comportamiento dado y las razones que lo han provocado (Oliver, 1999). Oliver (1999) también contempla ciertos obstáculos a la lealtad que pueden influir en el comportamiento final del consumidor.

Generalmente, la mayoría de los autores concluyen que no es aconsejable inferir la lealtad únicamente mediante indicadores de repetición de compra (Day 1969; Dick y Basu 1994; Bloemer y De Ruyter 1998; Oliver 1999; Szymigin y Cardigan 2001; Carroll y Ahuvia 2006; Johnson, Herrmann y Huber 2006; Moller y Hansen 2006). Son necesarios análisis adicionales para detectar realmente la lealtad del consumidor. Hay que 
tener en cuenta las creencias del consumidor, los afectos y las intenciones en un marco tradicional de estructura de la actitud del consumidor. En concreto estas tres fases del proceso de decisión deben de ir en la misma dirección si realmente existe lealtad hacia una marca. De este modo, las valoraciones de los atributos de la marca (creencias) deben ser preferibles a las de la competencia. Esta información debe coincidir con una preferencia afectiva (actitud) hacia la marca. Y el consumidor debe presentar un fuerte propósito (intención) de comprar dicha marca comparada con otras alternativas (Gremler y Brown 1999; Oliver 1999; McMullan y Gilmore 2003; Caruana 2004; Caruana y Fenech 2005).

La lealtad según Oliver (1999) se define como un compromiso profundo de recompra de un producto o servicio preferido, por consiguiente causará repetición de compra de la misma marca. Aunque influencias del entorno y esfuerzos de marketing tienen el potencial de provocar un comportamiento de cambio (Butcher, Sparks y O’Callaghan 2001; Caruana 2004; Yi y La 2004; Caruana y Fenech 2005).

Los consumidores forman su sentimiento de lealtad primero en una valoración cognitiva, que posteriormente genera un estado afectivo favorable hacia el proveedor de servicios. Este afecto genera, posteriormente una intención de recompra que finalmente se materializa en el comportamiento de recompra propiamente dicho (Oliver 1996; Macintosh y Loshin 1997; Gremler y Brown 1999; Oliver 1999; Gremler, Brown, Bitner y Parasuraman 2001; Caruana 2004; Yang y Peterson 2004; Caruana y Fenech 2005; Bove y Johnson 2006).

De este modo, para nuestro trabajo tomaremos la intención de comportamiento como elemento representativo de la variable lealtad, ya que es el mejor predictor que podemos utilizar a la hora de analizar los posibles comportamientos de recompra por parte del consumidor final (Guiltinan 1989; Lijander y Strandvik 1995; Cronin, Brady y Hult 2000; Henning-Thurau y Hansen 2000; Jones et al. 2002; Burnham et al. 2003; Aydin y 
Özer 2005; Lin y Ding 2005; Johnson, Herrmann y Huber 2006; Martínez y Martínez 2009; Liu, Guo y Lee 2011; Swobodaa et al. 2013; Castaldo et al. 2015).

\subsubsection{Relación entre la satisfacción y la lealtad}

La lealtad del consumidor hace referencia, por tanto, al compromiso de un consumidor a la hora de volver a comprar o seguir comprando los productos de un determinado comercio (Dick y Basu 1994, Oliver 1997, Jones et al. 2000, Kim et al. 2016). Los clientes leales son esenciales para las empresas, ya que cuesta menos mantener los clientes existentes que atraer a nuevos clientes (Anderson y Mittal, 2000). Además, los clientes leales tienden a hacer recomendaciones positivas con una elevada carga de credibilidad a las personas que les rodean (Babin et al. 2005 y Lee et al. 2007). La satisfacción del consumidor, como se desprende de lo expuesto, es uno de los principales antecedentes de la lealtad del consumidor (Bhattacherjee y Premkumar 2004, Jones et al. 2000 y Kim et al. 2004, Kim et al. 2016). Un cliente satisfecho con el comercio en el que realizó su compra tenderá a ser más leal hacia el mismo.

Por lo tanto, no es extraño que gran parte del esfuerzo de los gerentes de comercios minoristas se dirija a satisfacer a sus clientes con el fin de maximizar los beneficios que se obtienen de esta relación satisfactoria a largo plazo. Un cliente satisfecho es más probable que gaste más dinero en el negocio, así como también que permanezca más tiempo en el mismo (Chen, 2012).

La relación entre la satisfacción del cliente y la lealtad del cliente a largo ha sido estudiada por numerosos investigadores del sector del comercio minorista (Yang y Peterson 2004, Lam et al. 2004, Chen y Tsai 2008, Liu y Jang 2009 y Pan et al. 2012). Por lo tanto, se justifica una influencia positiva de la satisfacción del consumidor sobre la lealtad. La satisfacción hace referencia a creencias inferidas. Según los autores Fishbein y Ajzen (1975) las creencias inferidas son las que determinan la actitud o estado afectivo del individuo. En nuestro modelo, y según propone Oliver (1999), este estado afectivo se 
refiere a la lealtad. Por ello podemos pensar que la satisfacción es determinante de la lealtad del consumidor. En todo caso, lo que parece cierto es que a la satisfacción se le ha otorgado un papel predominante a la hora de buscar determinantes de la lealtad de los clientes (Martínez-Ribes, de Borja y Carvajal, 1999; Butcher, Sparks y O'Callaghan, 2001; Bloemer y Odekerken-Schröeder, 2002; Callarisa, 2004; Caruana y Fenech, 2005; Hess y Store, 2005; Chen y Tsai, 2008, Liu y Jang, 2009 Pan et al., 2012; El-Adly y Eid 2016 ). En esta misma dirección proponemos la siguiente hipótesis:

H4: La satisfacción del consumidor tiene un efecto directo y positivo en la lealtad. 


\subsection{MODELO GENERAL PROPUESTO DE LA MOTIVACIÓN DE COMPRA Y SU PAPEL EN LA OBTENCIÓN DE RESULTADOS COMERCIALES}

Llegados a este punto, vamos a presentar en la Figura 4.1 el modelo teórico que va a servir de base para el presente estudio y donde quedan recogidas las hipótesis de trabajo planteadas hasta el momento.

En primer lugar, tenemos motivación de compra del consumidor. Se trata de un constructo multidimensional con elementos cognitivos, afectivos y morales. Nos encontramos ante procesos o condiciones que provocan que los individuos se comporte de la manera que lo hacen, que además se producen cuando surge una necesidad que el consumidor desea satisfacer (Atkinson 1964; Kleinginna y Kleinginna 1981; Park y Mittal 1985; Robbins 2003, Solomon y Rabolt 2006; Franken 2006; Schunk et al. 2008; Schiffman y Kanuk 2009; Devesa et al. 2010; Reeve 2010; Solomon et al. 2013, Reeve 2014; Evans 2014; Hoffman 2015). En este sentido, y como hemos destacado en apartados anteriores si bien aquellos aspectos hedónicos y de disfrute son considerados como la forma más esencial de motivación no debemos olvidar los factores extrínsecos cuya integración en la estructura conductual del individuo representan una no menos importante fórmula motivacional. Si bien en nuestro trabajo se presentan aspectos utilitaristas, hedónicos y éticos, algunos de ellos están compuestos tanto por aspectos extrínsecos como intrínsecos por lo que su análisis se trabajará desde una perspectiva global.

A continuación, el valor percibido, entendido como la evaluación percibida de aquellos atributos del producto, atributos de sus resultados y consecuencias que resultan del uso que permiten que el cliente logre sus objetivos en las distintas situaciones de uso. Y que, en el presente estudio intentaremos estudiar en base a las mismas dimensiones que la motivación de compra, con el objetivo de evaluar cómo esas motivaciones (o condiciones internas) influyen o no influyen en la experiencia de compra. O si bien algún tipo concreto de esas motivaciones tienen mayor peso en el valor percibido que otras 
(Fodness 1994, Gnoth 1997 Williams 2004, Duman y Mattila 2005, Prebensen et al. 2012 y Kim et al. 2013).

Para la satisfacción, se utilizará la confirmación de las expectativas, siguiendo el paradigma disconfirmatorio en la formación de la misma (Yi 1990; Fornell 1992; Oliver 1993; McKinney et al. 2001). Este paradigma dominante afirma que los consumidores tienen estándares de comparación previos al consumo, y que, observando el desempeño del mismo y comparándolo con dichos estándares, se forman las percepciones de conformidad o disconformidad que producen una evaluación de satisfacción. El estándar de comparación más común son las expectativas predicativas (resultado o reflejo de las experiencias positivas y/o negativas), aunque también se han propuesto otros estándares (Fournier y Mick 1999). De este modo, un consumidor estará satisfecho cuando su evaluación hacia un producto o servicio (las percepciones) confirme o exceda sus expectativas. En este sentido, analizaremos individualmente también las dimensiones del valor percibido y su influencia en la satisfacción del mismo.

Finalmente, los consumidores forman su sentimiento de lealtad primero en una valoración cognitiva, que posteriormente genera un estado afectivo favorable hacia el proveedor. Este afecto genera, posteriormente una intención de recompra que finalmente se materializa en el comportamiento de recompra propiamente dicho (Oliver, 1996; Macintosh y Loshin, 1997; Gremler y Brown, 1999; Oliver, 1999; Gremler, Brown, Bitner y Parasuraman, 2001; Caruana, 2004; Yang y Peterson, 2004; Caruana y Fenech, 2005; Bove y Johnson, 2006). En este sentido, si bien los motivos de compra resultan una variable interesante de estudio, es necesario vincular la investigación a una variable de resultados comerciales que permita a los proveedores establecer relaciones duraderas con sus clientes 


\section{Figura 4.1. Modelo teórico de la motivación de compra del consumidor}

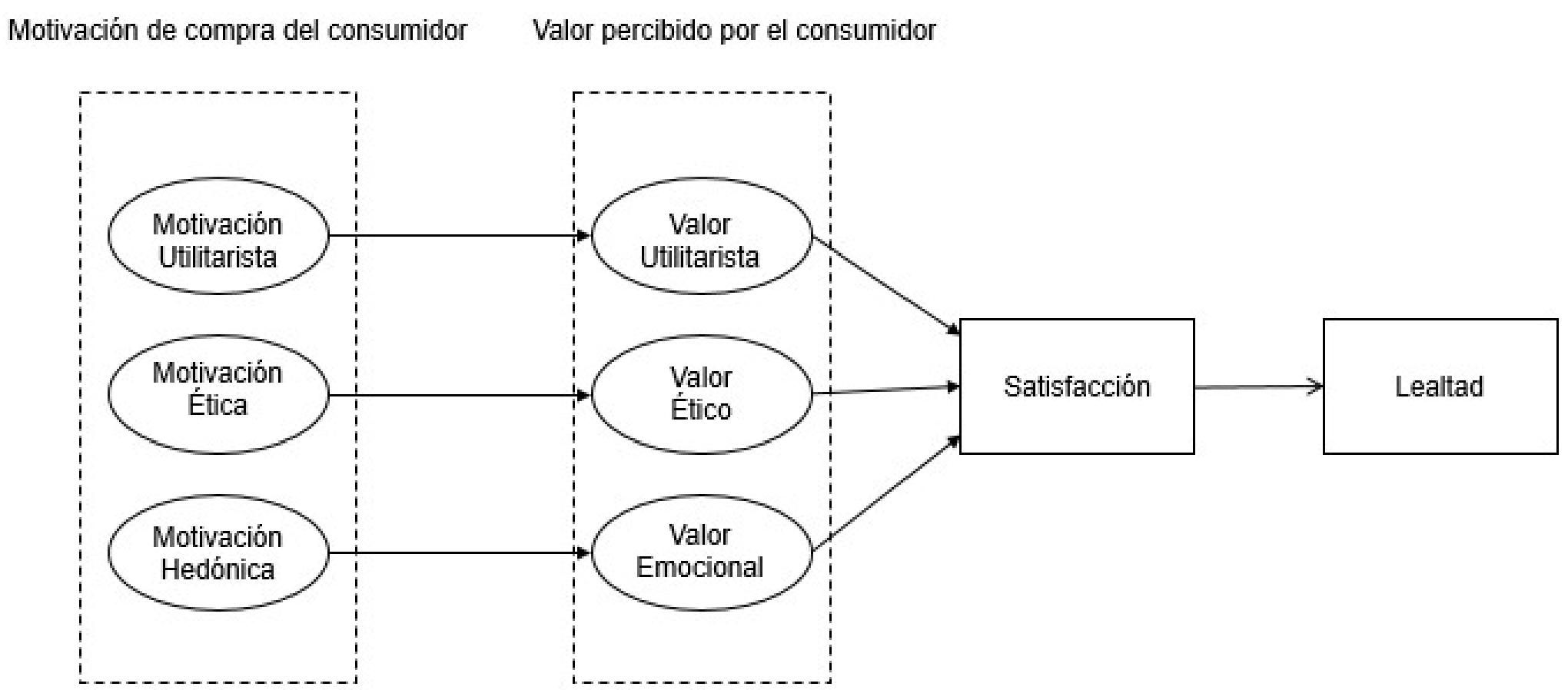




\subsection{EL TIPO DE COMERCIO COMO VARIABLE MODERADORA}

A efectos de la Ley 7/1996, de 15 de Enero, de ordenación del comercio minorista: "Se entiende por comercio minorista aquella actividad desarrollada profesionalmente con ánimo de lucro consistente en ofertar la venta de cualquier clase de artículos a los destinatarios finales de los mismos, utilizando o no un establecimiento".

Dentro del inmenso ámbito del comercio minorista, no existe consenso y homogeneidad en la denominación y descripción de las diversas formas comerciales (Fernández, 1999). Como apunta Parra, González y Villarejo (1998), en la práctica existen algunas formas comerciales que se denominan de distinta manera dependiendo del criterio que se siga, es decir, no existe un acuerdo sobre las definiciones de los diferentes tipos de establecimientos. Esta circunstancia va a influir directamente sobre la validez de las distintas fuentes estadísticas utilizadas a la hora de realizar cualquier estudio, ya que dependiendo del autor se puede incluir unos $\mathrm{u}$ otros establecimientos dentro de cada denominación.

En este sentido, en nuestro trabajo buscamos analizar las diferencias motivacionales entre los compradores de dos tipos de comercio muy específicos: el pequeño comercio urbano y los grandes centros comerciales.

A lo largo de los últimos años, los pequeños comercios urbanos tradicionales se han visto afectados por un gran número de fuerzas macro ambientales que han cambiado el panorama de la industria. Estos incluyen la propagación de las tiendas de descuento, la proliferación de centros comerciales suburbanos y el papel de internet como una plataforma alternativa / complementaria.

Además, la situación económica actual con la consiguiente caída del consumo, hace que las perspectivas de futuro no mejoren. Es evidente que en nuestras calles hay un gran número de negocios bajando sus persianas, mostrando el triste rótulo de "Se alquila" o "Se traspasa". Y en esta situación, los más afectados son los pequeños comerciantes, un 
grupo que ha sido a menudo ignorado en contextos generales de la investigación del comercio minorista (Cadeaux y Dubelaar, 2012). Un hecho sorprendente cuando los pequeños comerciantes urbanos son considerados como contribuyentes clave para la economía y el empleo, y catalizadores para la ciudad y la regeneración de la misma (Dixon, 2005).

Es en este punto que consideramos, ¿qué hace diferentes a los pequeños comercios urbanos del resto de comercios? ¿Qué lleva al consumidor a realizar sus compras en este tipo de comercios en lugar de otras áreas comerciales? ¿Hay algún valor asociado a este tipo de minorista que representa una fortaleza o una oportunidad?

La mayoría de estos problemas pueden ser respondidas si nos centramos en los factores que "mueven" un consumidor para realizar un determinado comportamiento de compra. A través de la comprensión de las motivaciones de los consumidores detrás de las compras, lo que los consumidores valoran desde los pequeños comerciantes se clarificará (Riberiro y Carvalho, 2010). En consecuencia, será posible identificar y trabajar sobre los valores más importantes que motivan a los consumidores realizar sus compras en los pequeños comercios.

Llegados a este punto, una vez establecida la cuestión principal que nos hace plantearnos el tipo de comercio como variable moderadora, pasamos ahora a realizar una caracterización de ambos.

Según exponen los autores Martínez et al. (1997), entendemos por pequeño comercio urbano, aquel comercio tradicional independiente, no asociado ni vinculado a ningún otro tipo de establecimiento; de tamaño pequeño, por el número de puntos de venta con que cuenta; la cifra de empleados y la dimensión del establecimiento; que dispone de una tecnología tradicional, por el régimen de venta utilizado, el equipamiento disponible y la formación de su personal; y cuya forma jurídica es una persona física. El ejercicio del comercio bajo el sistema tradicional se corresponde fundamentalmente con cuestiones de apariencia, es decir se trata de una forma de compra-venta en la que se da una intensa relación entre vendedor y cliente, de forma que éste tiene que demandar su 
necesidad y es asesorado directamente por el vendedor en el modo de satisfacerla. Esta relación suele producirse en locales de pequeña dimensión, ubicados en los entornos residenciales de las poblaciones, que están regentados muy directamente pos sus propietarios (Martínez, Sánchez, Sancho y Vega, 1997).

En contraposición, entendemos por gran centro comercial, aquel espacio ordenado, planificado, especializado en la venta al por menor y con una alta concentración de establecimientos bajo el mismo techo (García Escalona 2000, Escudero 2008). Siguiendo la clasificación de Jonathan Reynolds los grandes centros comerciales son superficies de entre 10.000 y 30.000 metros cuadrados ubicados en las áreas periféricas de las ciudades. Con una gran infraestructura de accesos y que aúnan espacios de compra y ocio.

Sin embargo, a efectos de nuestra investigación, la esencia del gran centro comercial se asemeja más que a sus características técnicas, a su naturaleza más esencial. En este sentido, presentamos la "Teoría del no lugar" (Augé, 1992), pues consideramos que es la aproximación más cercana al punto de partida del enfoque motivacional del consumidor de presente tesis. Dicha teoría planteada por el antropólogo francés Marc Augé, se basa en la diferenciación de dos tipos de espacios físicos: los no lugares y los lugares.

Los primeros se caracterizan por ser espacios de paso a alguna parte, de tránsito de ciudadanos acelerados. Son lugares situacionales, de movimiento y donde los encuentros suelen ser casuales, casi exclusivamente definido por el pasar de individuos. No aportan ni identidad ni personalidad, pues no es fácil interiorizar sus aspectos o componentes. Ejemplos claros de este tipo de "no lugares" son los aeropuertos, los andenes, las salas de espera o los centros comerciales donde más que nuestra identidad nos representa un billete de tren, una tarjeta médica o una tarjeta de crédito.

Por el contrario, los lugares son espacios de la ciudad con identidad e historia propia, que generan con el paso de años una identidad. Conjuntos históricos, parques, 
plazas y comercios que estimulan a la conversación, en definitiva, espacios donde conviven diferentes tipos de actividades que cuando se unen son capaces de crear un enfoque relacional completo.

Como Augé destaca en su publicación, el lugar no podrá nunca quedar completamente borrado, mientras que el no lugar no se define nunca completamente, son espacios donde se escribe y se borra una identidad y una relación de acuerdo a estrategias de conveniencia.

Y es que, si el punto de partida de la presente investigación es la motivación de compra como disposición interna fruto de las creencias, vivencias y cultura del individuo (entre muchas otras variables psicológicas de difícil medición), es ciertamente lógico asociar este punto de vista como elemento que defina la naturaleza de las dos tipologías de comercio.

Sin embargo, si retomamos la revisión de la literatura existente en lo relativo al tipo de comercio como variable moderadora no encontramos un gran número de trabajos que traten comparativamente ambos tipos de comercio. Aunque sí destacan la relevancia de los pequeños comercios en el contexto de las economías de las ciudades y hacen un llamamiento a investigar más en sus diferencias.

Burns y Warren (1995), analizan la decisión de comprar en un centro comercial regional que no sea el más cercano al lugar de residencia del consumidor, que por lo tanto, no parece ser una elección lógica en muchos casos. Tal comportamiento, sin embargo, parece ser relativamente común. Parecería, por tanto, que la elección de zona centro comercial no siempre se basa únicamente en la oferta y la ubicación de las alternativas comerciales disponibles. Aparece la hipótesis de que la elección de un centro comercial regional puede ser una vía para la expresión de la necesidad de un individuo para la unicidad. Sugiere que la actividad outshopping lo que se refiere a la elección de centro comercial regional, puede, al menos en parte, ser provocada por la singularidad personal, 
que puede ser experimentado por elegir a patrocinar centros comerciales regionales distintas de la que es la más cercana a su lugar de residencia.

En 1998, un interesante trabajo de los autores Bell, Ho y Tang desarrolla y valida un modelo de decisión del establecimiento de compra basado en la premisa básica de que cada consumidor tiene más posibilidades de realizar su compra en aquel tipo de establecimiento con el que asocie un menor nivel de costes asociados. Este coste al que hacen referencia los autores está compuesto por un apartado de tipo fijo y otro de tipo variable. Suponiendo con esta distinción que los compradores son influenciados principalmente por la ubicación de las tiendas y de los costes del desplazamiento asociados.

Posteriormente, ya en 2006, los autores Noble, Griffith y Adjei publican un interesante trabajo con el objetivo de obtener una mayor comprensión de la lealtad de consumidor con los pequeños comercios urbanos. La motivación de compra y el género de los encuestados fueron las principales variables utilizadas para la formulación de la hipótesis Los resultados indican que el género influye significativamente en la motivación de compra en el pequeño comercio urbano y en su lealtad.

En ese mismo año, Inagami et al. (2016), realizan un análisis descriptivo interesante en una línea similar en el sector de la alimentación en Estados Unidos. Aunque su aplicación es para el campo de la medicina, los resultados en torno a la decisión de compra son de utilidad para la presente investigación. Los autores intentan explicar la relación entre la ubicación de los barrios residenciales y la las tiendas de alimentación (tiendas de pequeño tamaño o grandes supermercados) en las que realizan las compras los vecinos que viven en los mismos. La mayoría de los hogares con los ingresos más bajos realizan la compra de alimentos en los supermercados, sin embargo aquellos con ingresos medio/altos realizaban en mayor medida sus compras en los pequeños comercio asociados con una mayor calidad. 
Como se ha podido apreciar, la mayoría de los trabajos que analizan el tipo de comercio en el que se realizan las compras lo hacen desde una perspectiva utilitarista. En este sentido, en el presente trabajo utilizaremos el tipo de establecimiento (pequeño comercio urbano o gran centro comercial) como variable moderadora, para así contribuir al conjunto de investigaciones que aportan información acerca de este tipo de decisiones en términos comerciales. 

CAPÍTULO 5. METODOLOGÍA DE LA INVESTIGACIÓN 



\section{CAPÍTULO 5. METODOLOGÍA DE LA INVESTIGACIÓN}

\subsection{OBJETIVO DE LA INVESTIGACIÓN}

El objetivo básico de la parte empírica es contrastar el modelo motivación de compra del consumidor. Por ello se intentarán contrastar las hipótesis planteadas en la revisión bibliográfica. Junto a este objetivo general se pretenden satisfacer una serie de objetivos más específicos.

En primer lugar, se pretenden contrastar las relaciones planteadas en el modelo teórico propuesto, y cuyas hipótesis presentamos en la Tabla 5.1. Además, se estudiarán las diferencias en la motivación de compra del consumidor entre consumidores del pequeño comercio y los grandes centros comerciales, así como sus implicaciones en el proceso de compra. Siendo analizados posteriormente sus relaciones con la experiencia de compra, la satisfacción y la formación de la lealtad como elemento representativo de resultados comerciales.

Tabla 5.1 - Resumen de las hipótesis planteadas.

\begin{tabular}{|c|c|}
\hline Hipótesis & Relación planteada \\
\hline H1 & Multidimensionalidad de la motivación de compra \\
\hline H2a & Motivación utilitarista $\rightarrow$ Valor percibido utilitarista \\
\hline H2b & Motivación ética $\rightarrow$ Valor percibido ético \\
\hline H2c & Motivación hedónica $\rightarrow$ Valor percibido emocional \\
\hline H3a & Valor percibido utilitarista $\rightarrow$ Satisfacción \\
\hline H3b & Valor percibido ético $\rightarrow$ Satisfacción \\
\hline H3c & Valor percibido emocional $\rightarrow$ Satisfacción \\
\hline H4 & Satisfacción $\rightarrow$ Lealtad \\
\hline
\end{tabular}

Fuente: Elaboración propia.

De este modo, comenzaremos realizando una descripción del sector de la distribución comercial, concretamente del sector del comercio minorista, y aportando ciertos datos sobre los productos de moda y complementos (tipo de compras que 
realizaron los encuestados). Se tratará la naturaleza del sector, la estructura y la composición del mismo.

A continuación trataremos el diseño del cuestionario, la selección de la muestra y el diseño del trabajo de campo y finalizaremos presentando las técnicas estadísticas utilizadas.

\subsection{DESCRIPCIÓN DEL SECTOR OBJETO DE ESTUDIO}

La distribución comercial está encuadrada, siguiendo la clasificación sectorial desagregada del INE, como actividad económica perteneciente al sector servicios. Según la Clasificación Nacional de Actividades Económicas (CNAE) de 2009 la distribución comercial se computa en la sección $\mathrm{G}$, que incluye: división 45 (venta y reparación de vehículos de motor y motocicletas), división 46 (comercio al por mayor e intermediarios del comercio, excepto de vehículos de motor y motocicletas) y la división 47 (comercio al por menor, excepto de vehículos de motor y motocicletas).

Si nos centramos, en la división 47, comercio minorista y según datos del Ministerio de Economía y Competitividad en su informe de evolución de comercio minorista enero-abril de 2016, los siguientes datos ilustrarán a grandes rasgos la naturaleza y características del sector:

- El comercio supone el 12,2\% del PIB total de la economía española (2014).

- El comercio minorista el 5,3\% del PIB total (2013).

- Las 469.938 empresas de comercio minorista suponen el $14,7 \%$ del total de empresas (a 1 de enero de 2015).

- Los 583.796 establecimientos de comercio minorista suponen el 16,2\% del total de establecimientos (a 1 de enero de 2015). 
- Los 1.845.600 ocupados en el comercio minorista, $1^{\circ}$ trimestre de 2016, suponen el 10,3\% del total de ocupados.

Como podemos apreciar en la Tabla 5.2, si analizamos ya comparativamente los índices de ventas en función de formatos comerciales con los últimos datos disponibles hasta abril de 2016 , en lo que va de año las grandes cadenas $(+5,6 \%)$ y las grandes superficies $(+4,6 \%)$ son aquellos formatos que más han visto aumentar sus ventas. En contraposición, las pequeñas cadenas $(+1 \%)$ y las empresas unilocalizadas $(+2,3 \%)$, aunque ven aumentar ligeramente sus índices de ventas son muy anteriores a sus competidores de mayor tamaño.

Tabla 5.2 - Índices de ventas corregidos por formatos comerciales

\begin{tabular}{|l|r|r|r|r|}
\hline & Deflactado & Mensual & Anual & $\begin{array}{l}\text { Media } \\
\text { anual }\end{array}$ \\
\hline ÍNDICE GENERAL & $\mathbf{9 0 , 9}$ & $\mathbf{0 , 6}$ & $\mathbf{4 , 1}$ & $\mathbf{4 , 0}$ \\
\hline MODOS DE DISTRIBUCIÓN & & & & \\
\hline 3. Empresas unilocalizadas & 84,1 & $-0,4$ & 2,3 & 3,0 \\
\hline 4. Pequeñas cadenas & 84,6 & $-0,8$ & 1,0 & 2,3 \\
\hline 5. Grandes cadenas & 105,7 & 2,4 & 5,6 & 4,9 \\
\hline 6. Grandes superficies & 88,2 & 1,2 & 4,3 & 3,7 \\
\hline
\end{tabular}

Fuente: INE 2016.

Tras este conjunto de datos expuestos acerca de la importancia del comercio para el global de la economía española y la reconocida aportación que realiza el comercio minorista a esta tarea. Se considera también necesario mostrar un de datos que hacen referencia a la situación actual del sector, que pese a su importancia, no se encuentre en una de sus mejores etapas.

Según los datos trimestrales de Instituto Nacional de Estadística, El gasto medio por hogar en términos corrientes aumentó un 1,4\% en 2015 y se situó en 27.420 euros, y así queda reflejado en la variación del gasto medio por hogar en los diferentes grupos 
(Tabla 5.3). Como podemos apreciar en la columna de tasa de variación anual, cuatro de los doce grupos de gasto ven disminuir su cuantía, destacar principalmente el grupo de transportes (-2,1\%), el grupo de Vivienda, agua, electricidad, gas y otros combustibles ($0,4 \%)$, otros bienes y servicios $(-0,4 \%)$ y comunicaciones $(-0,2 \%)$. En el polo opuesto se encuentran los grupos de hoteles cafés y restaurantes $(+9,1 \%)$, y mobiliario, equipamiento hogar $(+5,9 \%)$. En cuanto al grupo de artículos de vestir y calzado, objeto de nuestra investigación, podemos apreciar cómo la tasa de variación anual arroja datos positivos $(+1,4 \%)$, situándose el gasto medio del hogar en 1395 euros mensuales.

Tabla 5.3 - Gasto medio por hogar y por grupo en euros año 2015

\begin{tabular}{|c|c|c|c|}
\hline & $\begin{array}{l}\text { Gasto } \\
\text { medio } \\
\text { hogar }\end{array}$ & $\begin{array}{c}\text { Tasa } \\
\text { variación } \\
\text { anual } \\
\end{array}$ & $\begin{array}{c}\text { Diferencia } \\
\text { anual en euros }\end{array}$ \\
\hline TOTAL & 27.420 & 1.4 & 382 \\
\hline 1) Alimentos y bebidas no alcohólicas & 4.125 & 2,4 & 97 \\
\hline 2) Bebidas alcohólicas, tabaco & 523 & 2,5 & 13 \\
\hline 3) Artículos de vestir y calzado & 1.395 & 1,4 & 20 \\
\hline $\begin{array}{l}\text { 4) Vivienda, agua, electricidad, gas y otros } \\
\text { combustibles }\end{array}$ & 8.710 & $-0,4$ & -37 \\
\hline 5) Mobiliario, equipamiento hogar & 1.165 & 5,9 & 65 \\
\hline 6) Salud & 972 & 1,8 & 17 \\
\hline 7) Transportes & 3.185 & $-2,1$ & -69 \\
\hline 8) Comunicaciones & 792 & -0.2 & -1 \\
\hline 9) Ocio, espectáculos y cultura & 1.593 & 3,9 & 60 \\
\hline 10) Enseñanza & 380 & 3 & 11 \\
\hline 11) Hoteles, cafés y restaurantes & 2.548 & 9,1 & 213 \\
\hline 12) Otros bienes y servicios & 2.058 & $-0,4$ & -7 \\
\hline
\end{tabular}

Fuente: INE 2015.

Si analizamos en mayor profundidad el grupo de "Artículos de vestir y calzado", sobre los datos de los subgrupos "Calzado" y "Artículos de vestir" (Figura 5.1), podemos apreciar que ambos se produce un aumento del gasto medio en euros con los últimos datos disponibles a fecha de 2015. En el caso del calzado asciende 17 euros más de gasto medio, 
frente a los 3 euros de los artículos de vestir. Se puede apreciar cierto atisbo de recuperación económica con los datos que arrojan los estudios hasta este punto.

Figura 5.1 - Diferencia gasto medio en subgrupos

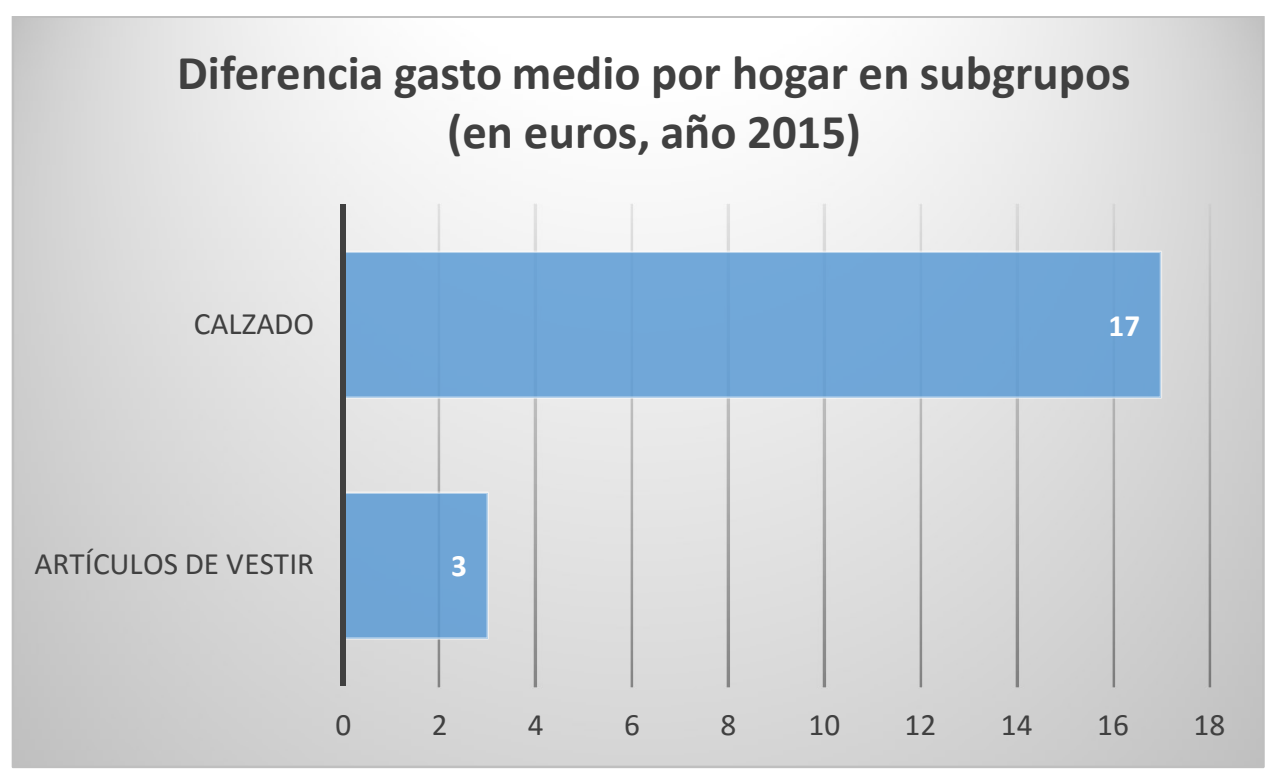

Fuente: INE 2015.

A continuación realizamos una revisión histórica de los datos de densidad comercial en España, es decir, del número de metros cuadrados destinados al comercio por cada 1000 habitantes (Figura 5.2). Si analizamos la tendencia podemos apreciar que es entre 1990 y 2010 cuando se produce el gran crecimiento o "boom" de las superficies comerciales. Quedando un ascenso claramente más tenue en los últimos diez. Actualmente la densidad comercial en España debe rondar los $330 \mathrm{~m} 2$ por cada mil habitantes, es decir, 0,33 metros por cada habitante. Según datos de la Asociación Española de Centros y Parques Comerciales, las provincias que destacan por una muy elevada densidad son Zaragoza, Las Palmas de Gran Canaria, Álava, Cádiz, Murcia, Valladolid y A Coruña. En el lado opuesto de la lista encontramos Melilla, Teruel, Lérida, Jaén y Gerona. 
Figura 5.2 - Evolución densidad comercial

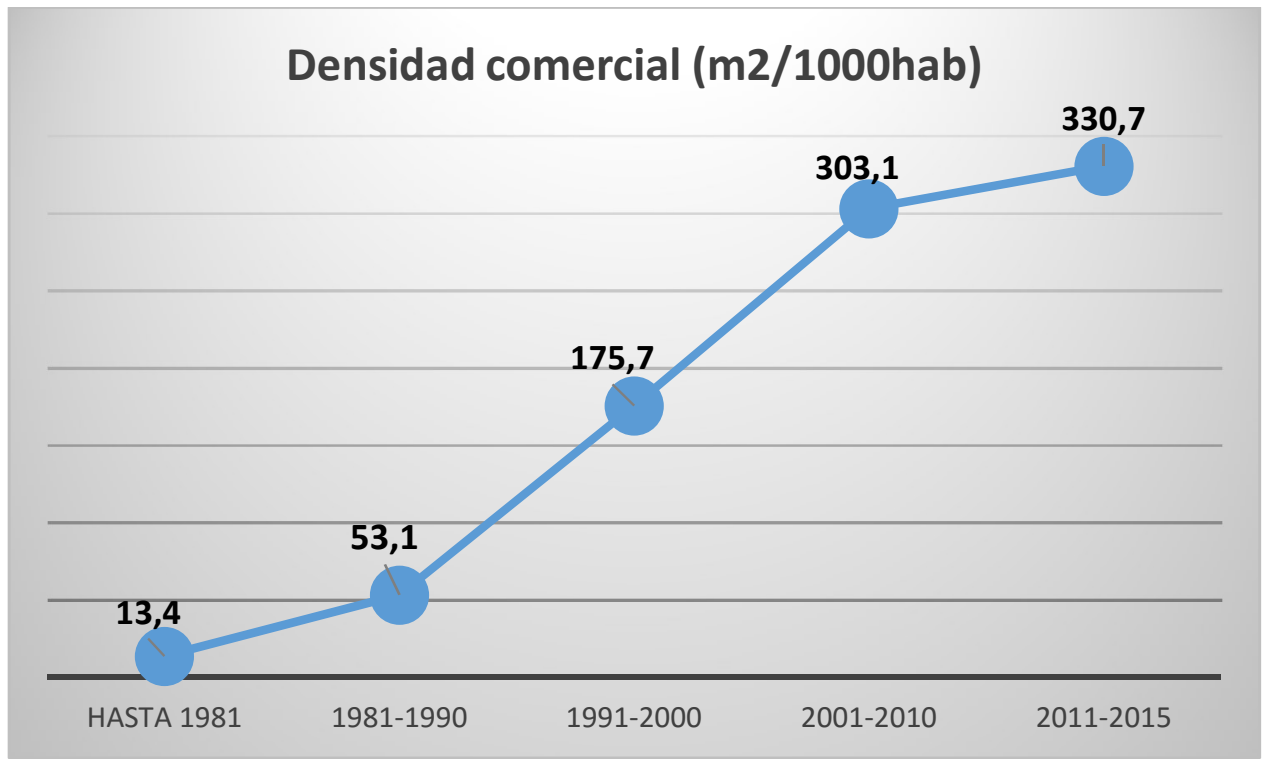

Fuente: AEDECC 2015.

Si ahora centramos nuestra atención en la Superficie Bruta Alquilable (SBA) que hay disponible en nuestro país, según datos de la Asociación Española de Centros y Parques Comerciales a finales de 2015 con 15.469.219 metros cuadrados repartidos entre los diferentes formatos comerciales (Tabla 5.4). En total existen en España 546 centros repartidos en las categorías de centro comercial muy grande $(3,6 \%)$, centro comercial grande $(14 \%)$, centro comercial mediano $(21,6 \%)$, centro comercial pequeño $(25,3 \%)$, hipermercado (18\%), parque comercial $(11,1 \%)$, centro de fabricantes $(2,4 \%)$ y centro de ocio (4\%). Si bien es cierto que entre los centros comerciales medianos y pequeños ya rondan el $50 \%$ de dicha superficie bruta alquilable. 
Tabla 5.4 - SBA por tipo de formato comercial

\begin{tabular}{|c|c|c|}
\hline $\begin{array}{c}\text { Tipo de formato } \\
\text { grande }\end{array}$ & $\begin{array}{c}\text { Número total de centros } \\
\text { Alquilable (SBA) }\end{array}$ \\
\hline $\begin{array}{c}\text { Centro comercial muy } \\
\text { Centro comercial grande }\end{array}$ & 2.350 .269 \\
\hline Centro comercial mediano & 76 & 3.933 .114 \\
\hline Centro comercial pequeño & 118 & 3.438 .677 \\
\hline Hipermercado & 138 & 1.595 .159 \\
\hline Parque comercial & 98 & 1.575 .305 \\
\hline Centro de fabricantes & 61 & 218.878 .673 \\
\hline Centro de ocio & 13 & 479.139 \\
\hline TOTAL & 22 & $\mathbf{1 5 . 4 6 9 . 2 1 9}$ \\
\hline
\end{tabular}

Fuente: AEDECC 2015.

En definitiva, tras esta breve caracterización de la situación actual del comercio minorista se pone de manifiesto por un lado la relevancia para el global de la economía del sector del comercio minorista desde el punto de vista del empleo, del desarrollo local o incluso del turismo. Por otro lado también los signos de leve mejoría en el maltrecho pequeño comercio tradicional, que pese a que no van a conseguir paliar el cierre de negocios sí otorgan ciertas señales de esperanza.

En este sentido, pasamos a continuación a caracterizar el sector textil de la moda y complementos, pues sus particularidades ejercerán una influencia relevante en la delimitación de las futuras implicaciones de la presente tesis doctoral. 


\subsubsection{Sector de la moda y complementos}

La industria de la moda y complementos es un sector que mueve un gran volumen de millones de euros a nivel mundial en lo que muchos autores denominan "moda de calle" o "moda de masas". Si analizamos en concreto las cifras de facturación en España (Figura 5.3) podremos apreciar cómo tras siete años de caídas acumuladas (intervalo 2007-2013), a partir del año 2014 se aprecia cierta mejora que podría ser asociada a cierta recuperación económica.

Figura 5.3 - Evolución de la facturación del comercio textil en España (millones de euros)

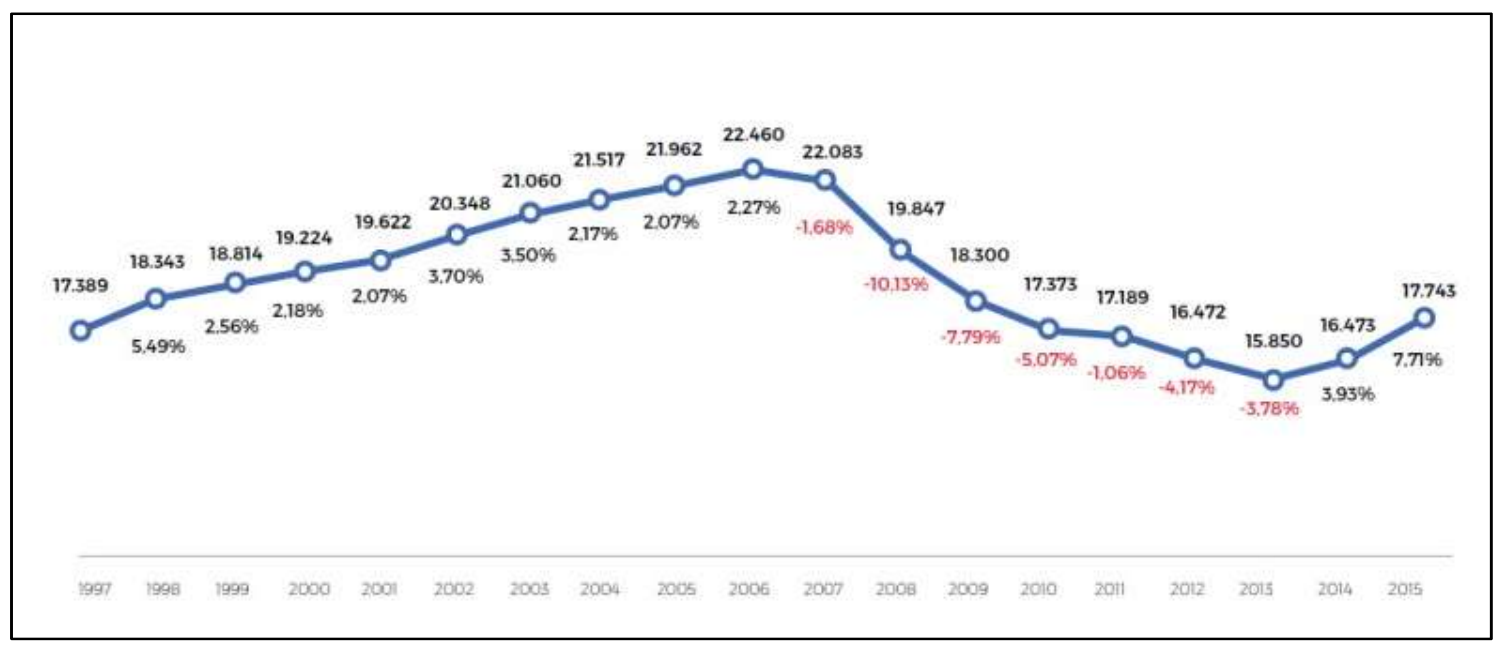

Fuente: ACOTEX (2015)

El mercado actual de la moda y complementos es un mercado altamente competitivo que requiere de una capacidad de actualización constante por parte de los comerciantes, para que los consumidores tenga disponible aquello que buscan en el momento que lo buscan (Bhardwaj y Fairhurst 2010). Es por tanto, más que evidente que los consumidores de este tipo de productos son exigentes, a la vez que también impulsivos en sus decisiones y con una carga emocional elevada asociada a la compra. Algunos 
autores acuñan el término "fast fashion" para referirse a este tipo relación comercial proveedor consumidor, en la que la clave se centra en la disponibilidad del producto en el momento adecuado (Bhardwaj y Fairhurst 2010).

En el año 2004, los autores Christopher, Lowson and Peck publican un artículo en el que exponen las cuatro características esenciales del mercado de la moda y complementos que han sido ampliamente utilizados en posteriores investigaciones del sector (Barnes and Lea-Greenwood 2006; Engle et al. 2010; Halvorsen et al. 2013; Dhurup 2014):

1. Los ciclos de vida de los productos son cortos: A menudo incluso efímeros, son diseñados para capturar la necesidad de un momento concreto, atendiendo a modas, y en consecuencia, el periodo en el que será vendible es probable que sea corto o de temporada (meses o incluso semanas).

2. Alto nivel de volatilidad: No es muy común en los productos textiles de moda y complementos que la demanda sea de tipo lineal o estable. Están sometidos a las modas, las tendencias e incluso los comportamientos más impulsivos.

3. Bajo nivel de previsibilidad: A consecuencia de la volatilidad, la demanda es extremadamente difícil de prever con exactitud, incluso dentro de un determinado período, por no hablar de la demanda de semana a semana o artículo por artículo.

4. Compra impulsiva o con una elevada carga emocional: La inmensa mayoría de las adquisiciones de los consumidores en moda y complementos se realizan en el punto de venta. En otras palabras, cuando el comprador se encuentra cara a cara con el producto y éste es de su agrado, el estímulo de compra es tan elevado que la necesidad de disponibilidad inmediata del mismo se vuelve un factor crítico para el resultado comercial. 
El mercado de la moda y complementos de hoy en día es altamente competitivo y con una constante necesidad de cambio y novedad (carga hedónica). Para los comercios minoristas es esencial saber hacer frente a este ritmo de trabajo, a la frecuencia en la que los productos disponibles en el comercio deben cambiar para así atraer la atención de los consumidores.

El papel de la moda y los complementos para los consumidores va más allá de la simple naturaleza del producto, destaca su valor social y emocional (O"Cass 2004). Sin embargo, con el creciente nivel de las expectativas y la variedad de productos demandados los comercios minoristas, principalmente aquellos de menor tamaño, se enfrentan al problema de predecir aquello que los consumidores buscaran, en qué momento lo harán y a qué nivel de precios. En consecuencia, no es tarea sencilla lograr alcanzar ese punto de equilibrio en el que vendedores y compradores puedan sostener esta relación comercial de manera sostenible y beneficiosa para ambas partes (Dhurup, 2014).

Sin embargo, el papel de la moda para cada consumidor varía en función de las características individuales de cada individuo, así como lo hace también su implicación con la compra (O"Cass 2004). Por lo tanto, el comportamiento de compra es algo complejo de predecir ya que depende de multitud factores inherentes y relativos a cada individuo en particular.

En definitiva, las elevadas exigencias del sector de la moda y complementos hace imprescindible contar con un flujo ininterrumpido de información del entorno para así conseguir mantenerse al día con las necesidades y demandas de los consumidores de este competitivo y demandante mercado con el objetivo de conseguir establecer relaciones duraderas y satisfactorias con los clientes (Rickman y Cosenza, 2007). 


\subsection{DISEÑO DEL CUESTIONARIO}

Para la recogida de la información se diseñó un cuestionario estructurado, formado por tres partes. En la primera, se plantearon unas preguntas introductorias para determinar si se había realizado alguna compra de moda y complementos recientemente y el tipo de establecimiento en el que se realizó la compra para así posteriormente conseguir diferenciar los consumidores del pequeño comercio y los consumidores de los centros comerciales. En la segunda parte, se preguntaba sobre la valoración propia de las variables de estudio (motivación de compra, valor percibido, satisfacción y lealtad) utilizando para ello una escala cerrada de tipo Likert con 5 posibilidades de respuesta. En la parte final se recogían una serie de preguntas generales de carácter personal.

Para la medición de las variables se recurrió a escalas que ya se habían validado en trabajos anteriores y que se ajustaban a las necesidades concretas de nuestra investigación. De este modo en la Tabla 5.5 se especifican las escalas de medición utilizadas para la elaboración del cuestionario, el número de ítems utilizados por variable y las referencias.

Para dar validez al cuestionario en noviembre de 2015 se realizó un pretest a 102 personas todas mayores de edad (50 hombres y 52 mujeres), siendo la mayoría trabajadores (70), aunque cabe destacar un número considerable de estudiantes (25) principalmente en las provincias de Castellón (39), Valencia (33) y Alicante (30). En este pretest se pretendía ver que todas las preguntas estuvieran correctamente formuladas para ser entendidas por cualquier ciudadano de a pie y que la información que obteníamos con las preguntas era la que nosotros esperábamos. 
Tabla 5.5 - Escalas de medición utilizadas.

\begin{tabular}{|c|c|c|l|}
\hline Variable & \multicolumn{1}{|c|}{ Indicadores } & $\mathbf{N}^{\mathbf{0}}$ ítems & \multicolumn{1}{|c|}{ Referencias } \\
\hline Motivación & Motivación utilitarista & 5 ítems & $\begin{array}{l}\text { Tauber 1972 } \\
\text { Westbrook y Black 1985 } \\
\text { Kim 2006 } \\
\text { Bezençon y Blili 2009 } \\
\text { Guiot y Roux 2010 } \\
\text { Chung 2015 } \\
\text { Barbopoulos y Johansson } \\
\text { 2016 }\end{array}$ \\
\hline Valor percibido & Motivación hedónica & 5 ítems \\
\hline Valor percibido ético & 6 ítems & $\begin{array}{l}\text { Gloval (Moliner et al. } \\
\text { 2005; Fandos et al. 2006; } \\
\text { Sánchez, et al. 2006) }\end{array}$ \\
\hline Lalor percibido emocional
\end{tabular}

Fuente: Elaboración propia.

Como se obtuvieron un número considerable de respuestas, procedimos a estudiar la validez de las escalas de medición mediante análisis factorial confirmatorio, siendo en la mayoría de los casos los resultados satisfactorios. Sin embargo sí que detectamos algunos problemas que intentamos solucionar de cara al trabajo de campo definitivo.

En concreto, se reestructuraron las preguntas relativas al valor percibido ético y emocional. En esta dimensión del valor percibido se detectaron problemas de comprensión e interpretación de las preguntas por parte de los encuestados lo que provocaba que la validez de la escala no fuera buena. Por ello se replantearon las 
preguntas en términos más llanos y se añadió un ítem a los cinco originales para evaluar en mayor detalle esta dimensión.

Finalmente, decidimos cambiar el orden de algunas preguntas para mejorar la comprensión del encuestado. Concretamente se desplazó el bloque de preguntas relativas a la lealtad a la parte final del cuestionario, justo antes de las preguntas generales. Y las referidas a la satisfacción se colocaron entre las del valor percibido y las de lealtad. Pensamos que el cuestionario planteado de esta forma quedaba en un orden más lógico y esto ayudaba al encuestado a entender la finalidad de la investigación viendo que las preguntas se planteaban en un orden más coherente y por ello se sentiría algo más implicado en la contestación del mismo. Queríamos evitar que los encuestados pudieran entrar en dinámicas de contestar sin pensar, con la única finalidad de terminar la encuesta y que les dejen en paz. Se trataba de presentar un cuestionario bien planteado, breve en la medida de lo posible y que el encuestado percibiera como útil en algún sentido.

Una vez realizados los cambios se mantuvo una reunión con el director de la empresa de investigación de mercados, presentándole el cuestionario y explicándole minuciosamente el objetivo del estudio y la finalidad concreta de cada pregunta. Finalmente le facilitamos la información sobre los requisitos que debía de cumplir la muestra y qué localidades pretendíamos estudiar. Se le pasó un listado cerrado de cuotas de encuestados por provincia, edad, sexo y tipo de establecimiento en el que se realizó la compra. Una vez aclarados nuestros objetivos, la empresa de investigación de mercados procedió a la realización del trabajo de campo propiamente dicho.

De este modo, y una vez recogidos los datos, en el siguiente punto vamos a mostrar los principales resultados obtenidos de los análisis de datos realizados. 


\subsection{SELECCIÓN DE LA MUESTRA Y TRABAJO DE CAMPO}

El universo lo forman individuos mayores de 18 años, que habían realizado alguna compra de moda y complementos en un plazo inferior a los dos últimos meses. Esto nos asegura que los encuestados mantienen reciente, al menos, la última experiencia de compra con un establecimiento comercial. Se realizaron 516 encuestas válidas, mediante cuestionario estructurado con preguntas cerradas y escala de respuesta tipo Likert de 5 puntos, a compradores de pequeño comercio y centros comerciales. Se consideraron seis grupos de edad: de 18 a 24 años, de 25 a 34 años, de 35 a 44 años, de 45 a 54 años, de 55 a 64 y de 65 o más años; El total de cuestionarios se completaron realizando 62 encuestas en Castellón, 263 en Valencia y 191 en Alicante. El resultado de esta distribución proporcional aparece recogido en la Tabla 5.6. Esta distribución por ciudades mantiene la proporción del censo de población de la Comunidad Valenciana para la fecha de realización del trabajo de campo. Esto da lugar a un error muestral del $\pm 4,40 \%$, para un nivel de confianza del $95,5 \%$ y un $p=q=0,5$.

Tabla 5.6- Distribución de la muestra por ciudad, edad y sexo.

\begin{tabular}{|c|c|c|c|c|c|c|c|c|c|}
\hline & Sexo & $\begin{array}{c}\text { De } 18 \\
\text { a } 24 \\
\text { años }\end{array}$ & $\begin{array}{c}\text { De } 25 \\
\text { a } 34 \\
\text { años }\end{array}$ & $\begin{array}{c}\text { De } 35 \\
\text { a } 44 \\
\text { años }\end{array}$ & $\begin{array}{c}\text { De } 45 \\
\text { a } 54 \\
\text { años }\end{array}$ & $\begin{array}{c}\text { De } 55 \\
\text { a } 64 \\
\text { años }\end{array}$ & $\begin{array}{c}65 \\
\text { años } 0 \\
\text { más }\end{array}$ & \multicolumn{2}{|c|}{ TOTAL } \\
\hline \multirow{2}{*}{ Castellón } & Hombres & 2 & 4 & 6 & 6 & 4 & 7 & 29 & \multirow{2}{*}{62} \\
\hline & Mujeres & 3 & 5 & 7 & 6 & 5 & 7 & 33 & \\
\hline \multirow{2}{*}{ Valencia } & Hombres & 11 & 19 & 27 & 24 & 19 & 29 & 129 & \multirow{2}{*}{263} \\
\hline & Mujeres & 11 & 20 & 28 & 25 & 20 & 30 & 134 & \\
\hline \multirow{2}{*}{ Alicante } & Hombres & 12 & 13 & 19 & 17 & 13 & 20 & 94 & \multirow{2}{*}{191} \\
\hline & Mujeres & 12 & 14 & 19 & 18 & 14 & 20 & 97 & \\
\hline \multicolumn{2}{|c|}{ TOTAL } & 51 & 75 & 106 & 96 & 75 & 113 & 516 & 516 \\
\hline
\end{tabular}


La selección de la Comunidad Valenciana como universo de estudio responde a una serie de factores relacionados con la naturaleza comercial e industrial de la comunidad autónoma, así como diversos factores diferenciales entre las provincias que hacían interesante su estudio de manera conjunta.

En primer lugar, según datos del INE, el 94\% de los negocios de la Comunidad Valencia son de pequeño tamaño, microempresas o están constituidas únicamente por autónomos. Por lo tanto, una parte muy importante del tejido empresarial valenciano es de propiedad familiar, lo que por una parte dota de independencia y flexibilidad, pero, al mismo tiempo, en la mayoría de casos, soportan las limitaciones de términos de competitividad de los pequeños formatos. Es evidente, por tanto, la relevancia de los pequeños comercios en el tejido económico de la comunidad.

Además, la producción del sector textil de moda y complementos de la Comunidad Valenciana, según datos del INE, representó en 2014 aproximadamente una cuarta parte de la producción total española. Concentrándose principalmente su producción en la provincia de Alicante.

Si analizamos la densidad comercial provincial de la Comunidad Valenciana (metros cuadrados destinados al comercio por cada mil habitantes), podemos apreciar en la Figura 5.4 que únicamente la provincia de Castellón se encuentra por debajo de la media nacional de $330 \mathrm{~m}^{2}$. Si analizamos cada provincia de manera separada, Castellón presenta una densidad comercial baja con $262 \mathrm{~m}^{2}$, seguida por Alicante con una densidad comercial media $\left(351 \mathrm{~m}^{2}\right)$ y finalmente Valencia que presenta una densidad comercial alta con $425 \mathrm{~m}^{2}$. Otro dato a destacar es la densidad media de la Comunidad Valenciana, que se sitúa en $346 \mathrm{~m}^{2}$, ligeramente por encima de la media nacional de $330 \mathrm{~m}^{2}$. Sin olvidar que en la provincia de Valencia se encuentra el 52,4\% de los centros comerciales de la Comunidad Valenciana y el 57,0\% de la SBA (Superficie Bruta Alquilable). 
Figura 5.4 - Densidad comercial provincial de la Comunidad Valenciana

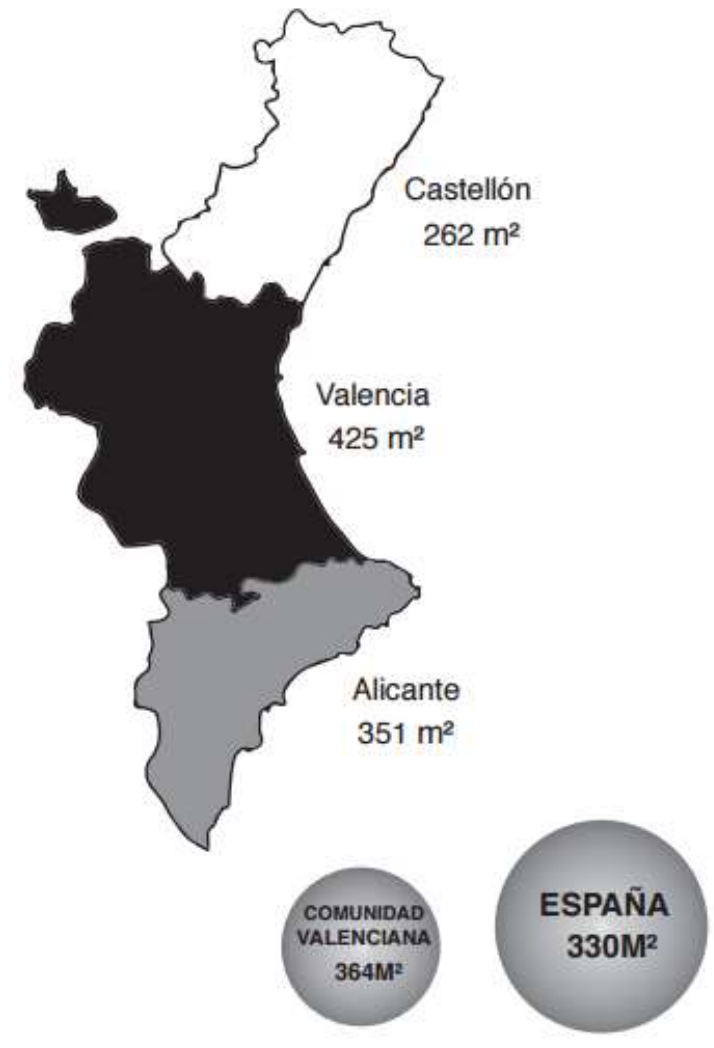

Fuente: AECC 2015, PATECO, INE.

En este sentido, una vez analizada a densidad comercial, Valencia y Alicante se posicionan en las primeras posiciones por ser las dos grandes zonas afluencia turística de la Comunidad Valenciana. Este hecho hace que estas dos provincias requieran de una infraestructura comercial más fuerte para así sostener la mayor incidencia turística. En gran medida se está otorgando cada vez más protagonismo al turismo como motor económico y al turismo de compras como oportunidad, mediante la generación de sinergias entre turismo y comercio. La provincia de Castellón, aunque también es receptora de un gran volumen de turistas, se trata de una ciudad con un carácter más industrial. 
Por lo tanto, una vez expuestas las motivaciones de la selección del universo de estudio, y retomando las hipótesis de trabajo planteadas, el enfoque de la investigación es causal, ya que se centra en el estudio de la motivación de compra del consumidor, la relación de la misma con el valor percibido de compra, la satisfacción y la consecución de la lealtad del consumidor. Estas relaciones serán determinadas a través de modelos de ecuaciones estructurales. Para tal fin, es necesaria la obtención de información cuantitativa y así poder confirmar las relaciones causales del modelo. Por ello se realizó una investigación de carácter transversal, cuya población objeto de estudio está compuesta por los compradores recientes de moda y complementos en el pequeño comercio o en un centro comercial (Tabla 5.7).

Tabla 5.7 - Ficha técnica de la investigación.

\begin{tabular}{|c|c|}
\hline & Ficha Técnica \\
\hline Universo: & $\begin{array}{l}\text { Compradores recientes de moda y complementos } \\
\text { residentes en la Comunidad Valenciana. }\end{array}$ \\
\hline $\begin{array}{l}\text { Método de recogida de } \\
\text { información: }\end{array}$ & Encuesta libre estructurada \\
\hline Ámbito del estudio: & $\begin{array}{l}\text { Sobre compradores de moda y complementos de la } \\
\text { Comunidad Valenciana. }\end{array}$ \\
\hline Tamaño de la muestra: & 516 encuestas válidas \\
\hline $\begin{array}{l}\text { Localización de la } \\
\text { muestra: }\end{array}$ & $\begin{array}{l}62 \text { encuestados de Castellón, } 263 \text { de Valencia y } 191 \text { de } \\
\text { Alicante. }\end{array}$ \\
\hline $\begin{array}{l}\text { Procedimiento de } \\
\text { muestreo: }\end{array}$ & $\begin{array}{l}\text { Procedimiento aleatorio y estratificado cumpliendo unas } \\
\text { cuotas preestablecidas por ciudad, por edad y sexo de los } \\
\text { encuestados y por tipo de establecimiento de compra. }\end{array}$ \\
\hline Error muestral: & $\pm 4,40 \%(\mathrm{p}=\mathrm{q}=0.5 ;$ nivel de confianza $=95.5 \%)$ \\
\hline Cuestionario: & $\begin{array}{l}\text { Cuestionario estructurado con preguntas cerradas (escala } \\
\text { Likert 1-5) }\end{array}$ \\
\hline $\begin{array}{l}\text { Fecha de trabajo de } \\
\text { campo: }\end{array}$ & Enero 2016 \\
\hline
\end{tabular}


Durante el mes de enero de 2016 se realizó la recogida de datos, que fue encargada a una empresa externa especializada, indicando que debían de realizar un número determinado de encuestas por provincia, teniendo en cuenta que la mitad debían responder al cuestionario sobre su compra en el pequeño comercio y la otra mitad sobre su compra en un centro comercial. En cada provincia, era necesario cubrir unas cuotas de encuestados por edades y por sexos, ya que hemos seguido la misma distribución que presentan los datos de empadronamiento de la Comunidad Valenciana a la hora de la selección de los encuestados.

El hecho de seleccionar la Comunidad Valenciana radica en que se trata de una comunidad autónoma con diversidad comercial. Si analizamos la densidad comercial de España, con los últimos datos disponibles, a finales de 2014 se situaba en $359 \mathrm{~m} 2$ por cada mil habitantes. En la Comunidad Valenciana, la provincia de Castellón cuenta con una densidad baja de 200 a $299 \mathrm{~m} 2$ cada mil habitantes. Valencia cuenta con una densidad alta entre 400 y $499 \mathrm{~m} 2$, mientras que Alicante se mantiene en un nivel medio entre 300 y $399 \mathrm{~m} 2$. 


\subsection{TÉCNICAS ESTADÍSTICAS UTILIZADAS}

En primer lugar se ha llevado a cabo un proceso de depuración de los cuestionarios con el fin de identificar y eliminar los casos atípicos (Uriel y Aldás, 2005). Los outliers o casos atípicos son aquellos casos para los que una, dos o múltiples variables toman valores extremos que los hacen diferir del comportamiento del resto de la muestra. Estos valores tan diferentes permiten al investigador sospechar que han sido generados de manera diferente al resto de los casos. Es importante detectarlos porque tienen unas consecuencias transcendentales en las conclusiones (Uriel y Aldás, 2005). En primer lugar, distorsionan los resultados al oscurecer el patrón de comportamiento del resto de casos y obtenerse conclusiones que, sin ellos, serían completamente distintas. Y, en segundo lugar, pueden afectar gravemente a una de las condiciones de aplicabilidad más habituales de la mayor parte de técnicas multivariantes: la normalidad. Dado que en este trabajo vamos a utilizar la técnica de Modelos de Ecuaciones Estructurales (SEM), es muy conveniente detectar y eliminar estos casos atípicos.

Uriel y Aldás (2005) sugieren que la mejor manera para identificar los casos atípicos desde un punto de vista multivariante, es estudiar si el vector de datos difiere del centroide. Esta opción es especialmente indicada en nuestro caso porque la técnica SEM exige la normalidad multivariante, por lo que el tratamiento de los casos atípicos a realizar debe ser multivariante. El método del centroide es un método jerárquico, que como resultado ofrece un conjunto de particiones secuenciales, que van desde un grupo por observación hasta la inclusión de todas las observaciones en un solo grupo (Miquel et al, 1996). Más concretamente, frente a otros métodos jerárquicos, el método del centroide basa su criterio de agrupación en la distancia existente entre las medias para todas las variables (centroides), es decir, calcula primero el centro de gravedad de cada cluster y a continuación se procede a agrupar teniendo en cuenta las distancias entre los distintos centros de gravedad. Los métodos jerárquicos permiten la representación gráfica en dendogramas. 
Con el fin de identificar los casos atípicos, en este estudio se ha llevado a cabo un análisis cluster, tomando como criterio de clasificación la distancia al centroide. El estudio de los casos atípicos a través de la técnica cluster llevó a confirmar un total de 388 observaciones válidas, divididas en dos grupos: 198 pertenecientes a clientes poco implicados con los temas financieros y 190 relativas a clientes muy implicados con los temas financieros. Esto da lugar a un error muestral del 5,1\%, para un nivel de confianza del $95,5 \%$ y un $p=q=0,5$.

La depuración de los cuestionarios supone una primera garantía de calidad de los datos. A partir de estos datos se pretenden realizar tres tipos de análisis. En primer lugar se llevará a cabo un estudio de la dimensionalidad, fiabilidad y validez de las escalas utilizadas. Con ello se pretende asegurar que se está midiendo el constructo que se pretende medir. Este análisis también permitirá depurar las escalas, eliminando aquellos ítems no significativos. La técnica que se utilizará será el Análisis Factorial Confirmatorio a través de la Técnica de Modelos de Ecuaciones Estructurales (SEM).

En segundo lugar se llevará a cabo un análisis descriptivo, con el fin de medir los niveles absolutos. Este análisis tiene una clara utilidad empresarial porque permite establecer el nivel de cada variable. En este análisis también se persigue establecer si existen diferencias significativas entre los clientes muy implicados con los temas financieros y los poco implicados con los mismos. Esto tiene implicaciones metodológicas, puesto que si existen suficientes diferencias significativas el contraste de los modelos se realizará de manera paralela en cada submuestra. Para esta parte se utilizará la técnica ANOVA que permite identificar diferencias significativas entre las medias de dos muestras independientes.

Finalmente, se procederá a contrastar las hipótesis planteadas. Dado que se trata de hipótesis causales se utilizará también el Análisis Factorial Confirmatorio a través de 
la Técnica de Modelos de Ecuaciones Estructurles (SEM) y más concretamente el Path Analysis.

Es obligado comentar que las técnicas multivariantes se basan en unas hipótesis de partida, que es necesario asegurar antes de su aplicación. La utilización de la técnica ANOVA y de Modelos de Ecuaciones Estructurales (SEM) supone la asunción de unos supuestos básicos. Más concretamente nos referimos a la normalidad multivariante de los datos, la homoscedasticidad, la linealidad y la independencia de las observaciones (Uriel y Aldás, 2005).

La normalidad se refiere a la distribución de cada variable. La violación de este supuesto supondría que se estaría incrementando el error tipo II, es decir, la probabilidad de no rechazar la hipótesis nula cuando ésta es, de hecho, falsa. Existen una serie de contrastes (Saphiro-Wilk, Kolmogorov-Smirnov, Anderson-Darling, Cramer-von Mises) y de procedimientos gráficos (asimetría y curtosis) para el análisis de la normalidad univariante. Para el análisis de la normalidad multivariante existen muy pocos contrastes (Mardia-curtosis, Mardia-apuntamiento, Henze-Zirkler). El método gráfico es muy similar a la normalidad univariante. Respecto a las consecuencias de la violación de este supuesto sobre las dos técnicas que vamos a utilizar en este estudio cabe decir que la no normalidad no tiene consecuencias sobre la técnica ANOVA, puesto que el hecho de que los residuos no se aproximen a una distribución normal no afecta de manera importante al estadístico F (Uriel y Aldás, 2005). Respecto a los Modelos de Ecuaciones Estructurales (SEM) la violación del supuesto de normalidad invalidaría las conclusiones del contraste por el incremento del error tipo II. En nuestro caso, para asegurar la normalidad de los datos, se toma como referencia la matriz de varianzas-covarianzas, calculada a partir de los datos normalizados tras aplicar el procedimiento normal scores ofrecido por PRELIS, que permite la normalización conjunta de las variables continuas objeto de análisis (Jöreskog y Sörbom, 1996a). Como resultado de este tratamiento previo, en todos los modelos parciales o totales contrastados los parámetros que determinan las relaciones entre las variables son siempre significativos, al ser los valores 
$\mathrm{t}$ asociados a los mismos superior a 1,96, y, además, se encuentran completamente estandarizados.

Respecto al segundo supuesto básico, la homoscedasticidad, conviene decir que se define de manera diferente según se hable de datos no agrupados (regresión lineal múltiple) o de datos agrupados (análisis de la varianza de un factor). En el primer caso la hipótesis de homoscedasticidad puede definirse como la asunción de que cada uno de los valores que puede tomar la distribución se mantiene constante para todos los valores de la otra variable continua. En el caso de datos agrupados la homoscedasticidad implica que la varianza de la variable continua es más o menos la misma en todos los grupos que conforma la variable no métrica que delimita los grupos. Para las técnicas que vamos a utilizar en este trabajo este supuesto no es trascendente. En el caso de la técnica ANOVA el estadístico F no se ve muy afectado por el hecho de que no exista homoscedasticidad, siempre que las muestras de los diferentes grupos sean del mismo o similar tamaño (como es el caso). En el caso de SEM la homoscedasticidad tampoco influye en la calidad de los resultados.

Respecto a la hipótesis de linealidad, hay que decir que es una asunción fundamental para todas aquellas técnicas que se centran en el análisis de las matrices de correlaciones o de varianzas-covarianzas, como el análisis factorial o los modelos de estructuras de covarianza. La razón es que el coeficiente de correlación de Pearson sólo podrá captar una relación si ésta es lineal. Desde este punto de vista las ecuaciones del modelo estructural son todas lineales como puede observarse:

Finalmente, con respecto a la hipótesis de independencia, cabe decir que dos observaciones se consideran que son independientes cuando los valores que toman las variables de ese caso no se ven influidos por las observaciones que hayan tomado en otro caso. Es decir, que las respuestas dadas por un individuo no influyen en las que dará otro. Según Uriel y Aldás (2005) la violación de este supuesto tiene influencias importantes sobre el nivel de significatividad y la potencia de las pruebas. En el procedimiento seguido 
las entrevistas han sido realizadas por entrevistadores profesionales, con el debido entrenamiento, y la selección de las unidades muestrales ha sido aleatoria. Todo ello garantiza el supuesto de la independencia.

Junto al estudio del cumplimiento de los supuestos básicos que permiten la utilización de las dos técnicas multivariantes seleccionadas, aún quedan algunas decisiones por tomar con respecto a la técnica de Modelos de Ecuaciones Estructurales (SEM). La primera decisión se refiere al procedimiento de estimación. Existen distintos procedimientos para realizar la estimación: máxima verosimilitud (ML), mínimos cuadrados generalizados (GLS), teoría de la distribución elíptica (EDT) y libre distribución asintótica (ADF). Un estudio de Hu, Bentler y Kano (1992), recogido por Uriel y Aldás (2005), comparó todos estos procedimientos mediante simulación de Monte Carlo. Se estudió como se comportaba cada procedimiento ante diferentes tamaños muestrales y ante la violación de las hipótesis de normalidad y de independencia. A la luz de los resultados de este estudio, Ullman (1996) realizó las siguientes recomendaciones en cuanto al procedimiento a utilizar en la técnica de Modelos de Ecuaciones Estructurales (SEM):

Los métodos ML y GLS son la mejor opción con pequeñas muestras siempre que sea plausible la asunción de normalidad e independencia.

En el caso en que ambos supuestos no parezcan razonables, se recomienda recurrir a la estimación ML denominada "escalada".

Dado que la muestra es pequeña y que es plausible la asunción de los supuestos de normalidad e independencia, el procedimiento que se utilizará en este estudio será el de máxima verosimilitud (ML) (Jöreskog y Sörbom, 1989, 1996b).

En cuanto a los estadísticos para el contraste del modelo, Uriel y Aldás (2005) consideran que el primer estadístico a analizar es la Chi-cuadrado, puesto que es un estadístico que realiza un contraste global del modelo. Este estadístico debe utilizarse con 
precaución con muestras grandes (más de 500), dado que pequeñas diferencias entre la matriz de covarianzas muestral y la estimada serán evaluadas como significativas por el contraste. Esta limitación en las muestras grandes ha llevado a desarrollar más de 30 indicadores ad hoc de bondad del ajuste. Son indicadores de ajuste parcial. En el presente trabajo utilizaremos tres de los más significativos: RMSEA (Root Mean Square Error of Approximation), GFI (Goodness of Fit Index) y AGFI (Adjusted Goodness of Fit Index). Para que un ajuste alcance buenos valores en estos indicadores el RMSEA debe ser próximo a 0 , pero sin alcanzarlo; el GFI y el AGFI deben ser muy próximos a 1 pero sin igualarlo. En cualquier caso, el estadístico que debe guiar la mejora del ajuste de un modelo es la chi-cuadrado, intentando alcanzar un valor de t superior a 1,96.

Un último aspecto metodológico sobre el que Uriel y Aldás (2005) llaman la atención es en la importancia de tener en cuenta una serie de recomendaciones con el fin de tomar las decisiones adecuadas en la técnica de Modelos de Ecuaciones Estructurales (SEM). En este sentido, en el presente trabajo se seguirán todas sus sugerencias metodológicas:

1. Utilizar muestras grandes. Los modelos basados en menos de 100 o 150 casos llevan a modelos finales poco estables si las modificaciones se basan en los datos y en la teoría. En nuestro caso la muestra válida es de 516, lo cual es un tamaño que garantiza un error muestral bajo y un modelo final estable.

2. Hacer pocas modificaciones. Es posible que las primeras modificaciones puedan estar derivadas de un modelo que refleje las relaciones poblacionales; las siguientes, probablemente, reflejarán relaciones específicas de la muestra.

3. Realizar sólo aquellos cambios que puedan ser interpretados desde una perspectiva teórica o tengan soporte en trabajos precedentes. En todo caso, se deben detallar todos los cambios realizados sobre el modelo inicial.

4. Seguir un procedimiento paralelo de especificación. Siempre que sea posible, el investigador debería trabajar con dos muestras independientes. Si las dos 
muestras desembocan en las mismas especificaciones del modelo, se podrá tener una mayor confianza en la estabilidad del mismo. En este sentido, en el presente trabajo se pretende trabajar de manera paralela en dos muestras: la de compradores del pequeño comercio y la de compradores del gran centro comercial. La primera cuenta con 254 casos mientras la segunda cuenta con 262. El tamaño de ambas submuestras supera los 150 casos recomendados en el punto 1 .

5. Finalmente, describir detalladamente las limitaciones del estudio. 

CAPÍTULO 6. ANÁLISIS DE RESULTADOS 



\section{CAPÍTULO 6. ANÁLISIS DE RESULTADOS}

En el presente capítulo se muestran los resultados del estudio cuantitativo realizado. En primer lugar se analizarán las propiedades psicométricas de las escalas. A continuación se llevará a cabo un análisis descriptivo de la muestra. Finalmente se contrastará el modelo causal propuesto.

Cuando nos planteamos la escala de medición de un constructo es necesario analizar antes de proseguir si, desde el punto de vista conceptual, nos encontramos ante un modelo formativo o reflectivo (Diamantopoulos y Winklohofer 2001; Jarvis, Mackenzie y Podaskoff 2003) ya que el proceso de validación de la escala no es exactamente el mismo. En nuestro modelo las diferentes variables objeto de estudio son de carácter reflectivo si tenemos en cuenta los criterios de Jarvis et al (2003). En base a ello, para validar las escalas se estudiarán la dimensionalidad, validez y fiabilidad de las mismas. De este modo, se realizará el estudio de la dimensionalidad, fiabilidad y validez de cada uno de los constructos que conforman el modelo. El análisis se realiza sobre la totalidad de la muestra.

En cuanto al método utilizado para el contraste las hipótesis del modelo teórico planteado en la parte empírica, en el presente trabajo se aplicará el enfoque de dos etapas (two-step) propuesto por Anderson y Gerbing (1988). Ello implica que, en primer lugar, es necesario determinar la calidad de las escalas de medida utilizadas, es decir, fundamentar los componentes del modelo conceptual. Con dicha finalidad, se realiza un análisis factorial confirmatorio con todas las escalas conjuntamente, de este modo se puede determinar la validez divergente de las mismas, junto con la dimensionalidad, fiabilidad y validez convergente. Posteriormente, se presentan los resultados del análisis descriptivo, y finalmente se contrastan las relaciones causales del modelo conceptual. Este enfoque en dos etapas permite maximizar la interpretación tanto de los resultados de la determinación de la calidad de las escala de medida, como de los resultados obtenidos de las relaciones planteadas en el modelo conceptual. 


\subsection{DIMENSIONALIDAD, FIABILIDAD Y VALIDEZ DE LAS ESCALAS DE MEDICIÓN}

En este primer apartado del capítulo nos centramos en la primera fase de la técnica twostep propuesta por Anderson y Gerbing (1988). Se lleva a cabo un análisis factorial confirmatorio, que aporta una valoración del ajuste global de los datos, es decir, nos permite determina la validez convergente, la validez discriminante y la fiabilidad de las escalas.

Tras la realización del primer análisis factorial confirmatorio se comprueba que es necesario eliminar algunos de los ítems inicialmente considerados (Tablas 6.1 y 6.2).Se trata de dos ítems cuyas cargas factoriales son inferiores a 0,6 (Bagozzi 1980; Bagozzi y Yi 1988; Hair, et al. 2006) y por ello consideramos que la escala mejorará si son eliminados, pues en caso contrario dificultarían la validez convergente de las escalas de medida que las incluyen.

En concreto los ítems son los siguientes:

- "Una buena compra es aquella que se realiza con rapidez" $(0,46)$. Incluido dentro de la motivación utilitarista de la escala motivacional.

- "En este tipo de establecimientos espero encontrar productos originales y auténticos" $(0,42)$. Incluido dentro de la motivación ética de la escala motivacional.

Por tanto, la motivación utilitarista y la motivación ética pasan de tener cinco indicadores a tener cuatro. 
Tabla 6.1 - Análisis de las escalas de medida (I)

\begin{tabular}{|c|c|c|c|}
\hline & FACTORES e ítems & $\begin{array}{c}\text { Cargas } \\
\text { factoriales }\end{array}$ & $\mathbf{T}$ \\
\hline & MOTIVACIÓN UTILITARISTA (MU) & & \\
\hline 1 & $\begin{array}{l}\text { Me gusta sentir que he conseguido aquello que he planificado } \\
\text { para esa compra. }\end{array}$ & 0,86 & 25,81 \\
\hline 2 & $\begin{array}{l}\text { Me siento satisfecho tras conseguir comprar todo aquello que } \\
\text { buscaba. }\end{array}$ & 0,89 & 24,99 \\
\hline $3 *$ & Una buena compra es aquella realizada con rapidez. & 0,46 & 10,76 \\
\hline 4 & Es importante poder realizar las compras con comodidad. & 0,62 & 14,47 \\
\hline \multirow[t]{2}{*}{5} & $\begin{array}{l}\text { Valoro poder conseguir buenas oportunidades relación } \\
\text { calidad precio. }\end{array}$ & 0,83 & 19,63 \\
\hline & MOTIVACIÓN ÉTICA (ME) & & \\
\hline 1 & $\begin{array}{l}\text { Por lo que yo sé, en este tipo de establecimiento actúan de } \\
\text { forma honesta y justa. }\end{array}$ & 0,62 & 15,82 \\
\hline $2 *$ & $\begin{array}{l}\text { En este tipo de establecimiento espero encontrar productos } \\
\text { originales y auténticos. }\end{array}$ & 0,42 & 10,32 \\
\hline 3 & $\begin{array}{l}\text { Con la realización de la compra sentí que estaba } \\
\text { contribuyendo a la economía local. }\end{array}$ & 0,86 & 32,17 \\
\hline 4 & $\begin{array}{l}\text { Valoro el comportamiento moral de este tipo de } \\
\text { establecimientos. }\end{array}$ & 0,85 & 27,24 \\
\hline \multirow[t]{2}{*}{5} & $\begin{array}{l}\text { Comprando en este tipo de establecimientos siento que estoy } \\
\text { haciendo lo correcto. }\end{array}$ & 0,85 & 28,6 \\
\hline & MOTIVACIÓN HEDÓNICA (MH) & & \\
\hline 1 & Ir de compras es una actividad que me gusta. & 0,88 & 28,65 \\
\hline 2 & $\begin{array}{l}\text { Para mi ir de compras es una manera de disfrutar y evadirme } \\
\text { del estrés diario. }\end{array}$ & 0,88 & 30,25 \\
\hline 3 & En periodos de rebajas es cuando más disfruto comprando. & 0,66 & 16,79 \\
\hline 4 & Me encanta ir de compras con mi familia y amigos. & 0,63 & 16,19 \\
\hline \multirow[t]{2}{*}{5} & $\begin{array}{l}\text { Me gusta mucho mantenerme al día con la moda y las nuevas } \\
\text { tendencias. }\end{array}$ & 0,78 & 23,72 \\
\hline & VALOR PERCIBIDO UTILITARISTA (VU) & & \\
\hline 1 & $\begin{array}{l}\text { Es sencillo estacionar y/o acceder al establecimiento que } \\
\text { busco. }\end{array}$ & 0,72 & 19,57 \\
\hline 2 & $\begin{array}{l}\text { El esfuerzo total que llevo a cabo para realizar la compra es } \\
\text { razonable. }\end{array}$ & 0,75 & 23,15 \\
\hline 3 & $\begin{array}{l}\text { El coste que me genera acudir a este tipo de comercio en } \\
\text { comparación con otros es razonable. }\end{array}$ & 0,80 & 24,26 \\
\hline 4 & $\begin{array}{l}\text { Los precios son razonables de acuerdo con el producto o } \\
\text { servicio recibido. }\end{array}$ & 0,79 & 21,52 \\
\hline
\end{tabular}




\begin{tabular}{|c|c|c|c|}
\hline & FACTORES e ítems & $\begin{array}{c}\text { Cargas } \\
\text { factoriales }\end{array}$ & $\mathbf{T}$ \\
\hline 5 & $\begin{array}{l}\text { Los precios en este centro son cercanos a la media del } \\
\text { mercado. }\end{array}$ & 0,73 & 20,91 \\
\hline 6 & $\begin{array}{l}\text { En general no tengo que hacer grandes desplazamientos ni } \\
\text { perder mucho tiempo para comprar en este tipo de } \\
\text { establecimiento. }\end{array}$ & 0,73 & 18,64 \\
\hline & VALOR PERCIBIDO ÉTICO (VE) & & \\
\hline 1 & Las personas que compran aquí están bien consideradas. & 0,76 & 23,14 \\
\hline 2 & $\begin{array}{l}\text { Se obtiene cierto reconocimiento por comprar en este tipo de } \\
\text { comercio. }\end{array}$ & 0,83 & 30,19 \\
\hline 3 & $\begin{array}{l}\text { Considero positivo que la gente compre en este tipo de } \\
\text { comercio. }\end{array}$ & 0,84 & 26,97 \\
\hline 4 & $\begin{array}{l}\text { Pienso que el que compra en este tipo de comercio tiene } \\
\text { cierto nivel. }\end{array}$ & 0,80 & 23,95 \\
\hline 5 & Me gusta que la gente me vea comprando aquí. & 0,90 & 32,00 \\
\hline \multirow[t]{2}{*}{6} & $\begin{array}{l}\text { Disfruto viendo a la gente comprando en este tipo de } \\
\text { establecimiento. }\end{array}$ & 0,92 & 34,79 \\
\hline & VALOR PERCIBIDO EMOCIONAL (VH) & & \\
\hline 1 & Estoy contento/a con este tipo de establecimiento. & 0,84 & 26,32 \\
\hline 2 & En él me siento relajado/a. & 0,71 & 19,30 \\
\hline 3 & El personal me proporciona sensaciones positivas. & 0,76 & 19,58 \\
\hline 4 & El personal no me agobia. & 0,68 & 15,36 \\
\hline \multirow[t]{2}{*}{5} & $\begin{array}{l}\text { En general me siento a gusto comprando en este tipo de } \\
\text { establecimiento. }\end{array}$ & 0,73 & 20,32 \\
\hline & SATISFACCIÓN (SAT) & & \\
\hline 1 & Estoy realmente satisfecho con este tipo de establecimiento. & 0,77 & 20,41 \\
\hline 2 & Estoy satisfecho con el servicio proporcionado. & 0,75 & 20,16 \\
\hline 3 & $\begin{array}{l}\text { La respuesta a las cuestiones planteadas sobre el } \\
\text { producto/servicio es eficiente. }\end{array}$ & 0,78 & 20,73 \\
\hline 4 & Suelen resolver todas mis dudas y cuestiones. & 0,82 & 22,03 \\
\hline 5 & $\begin{array}{l}\text { Suelo encontrar una solución adecuada a mis necesidades en } \\
\text { este tipo de comercio }\end{array}$ & 0,79 & 21,69 \\
\hline 6 & $\begin{array}{l}\text { Se cumplieron las expectativas que tenía puestas en el } \\
\text { establecimiento. }\end{array}$ & 0,79 & 21,75 \\
\hline \multirow[t]{2}{*}{7} & En general, el proceso de compra fue satisfactorio. & 0,82 & 21,76 \\
\hline & LEALTAD (LEA) & & \\
\hline 1 & $\begin{array}{l}\text { Intento acudir a este tipo de establecimiento cada vez que } \\
\text { necesito o deseo ir de compras. }\end{array}$ & 0,64 & 15,37 \\
\hline 2 & $\begin{array}{l}\text { Considero este tipo de establecimiento como mi opción } \\
\text { principal de compras. }\end{array}$ & 0,70 & 16,96 \\
\hline
\end{tabular}




\begin{tabular}{|l|l|c|c|}
\hline & FACTORES e ítems & $\begin{array}{c}\text { Cargas } \\
\text { factoriales }\end{array}$ & T \\
\hline 3 & $\begin{array}{l}\text { Acudo a este tipo de establecimiento cuando busco obtener } \\
\text { información sobre algún producto que me interesa. }\end{array}$ & 0,91 & 29,15 \\
\hline 4 & $\begin{array}{l}\text { Cuando necesito un producto determinado acudo a este tipo } \\
\text { de centro. }\end{array}$ & 0,88 & 29,82 \\
\hline
\end{tabular}

Ajuste del modelo:

Chi-cuadrado $=313,8391 ; \mathrm{gl}=308 ; \mathrm{P}=0,23453 ; \mathrm{RMSEA}=0,013 ; \mathrm{CFI}=0,979$; $\mathrm{NNFI}=0,978$

(*) Este ítem se elimina de la escala.

Tabla 6.2 - Análisis de las escalas de medida (II)

\begin{tabular}{|l|c||c|}
\hline & $\begin{array}{c}\text { Fiabilidad } \\
\text { compuesta (IFC) }\end{array}$ & $\begin{array}{l}\text { Varianza extraída } \\
\text { promedio (AVE) }\end{array}$ \\
\hline $\begin{array}{l}\text { MOTIVACIÓN } \\
\text { UTILITARISTA }\end{array}$ & 0,86 & 0,61 \\
\hline $\begin{array}{l}\text { MOTIVACIÓN } \\
\text { ÉTICA }\end{array}$ & 0,85 & 0,59 \\
\hline $\begin{array}{l}\text { MOTIVACIÓN } \\
\text { HEDÓNICA }\end{array}$ & 0,88 & 0,64 \\
\hline $\begin{array}{l}\text { VALOR PERCIBIDO } \\
\text { UTILITARISTA }\end{array}$ & 0,89 & 0,61 \\
\hline $\begin{array}{l}\text { VALOR PERCIBIDO } \\
\text { ÉTICO }\end{array}$ & 0,94 & 0,74 \\
\hline $\begin{array}{l}\text { VALOR PERCIBIDO } \\
\text { EMOCIONAL }\end{array}$ & 0,86 & 0,61 \\
\hline SATISFACCIÓN & 0,92 & 0,67 \\
\hline LEALTAD & 0,87 & 0,67 \\
\hline
\end{tabular}

Una vez llevada a cabo la depuración de la escala a través de la eliminación de dos ítems, se obtiene un modelo que ajusta y que cumple todos los requisitos de dimensionalidad, fiabilidad y validez, tal y como se muestran en las tablas 6.3 y 6.4 , y que se pasan a ser comentados en las próximas líneas. 
El ajuste del modelo viene determinado por la existencia de una probabilidad asociada a la chi-cuadrado superior a 0,05. En nuestro trabajo esta probabilidad es de 0,113810 y por tanto, existe un ajuste global del modelo (Jöreskog y Sörbom 1996).

En cuanto a la validez convergente, esta queda demostrada por dos motivos: en primer lugar, las cargas factoriales son significativas y superiores a 0,6 en todos los casos (Bagozzi 1980; Bagozzi y Yi 1988; Hair et al. 2006), y en segundo lugar, porque la varianza extraída promedio (AVE) para cada uno de los factores es siempre superior a 0,5 (Fornell y Larcker 1981).

Finalmente, la fiabilidad de las escalas es demostrada porque los índices de fiabilidad compuesta de cada una de las dimensiones obtenidas son superiores a 0,6 en todos los casos (Bagozzi y Yi 1988).

En cuanto a la dimensionalidad, son obtenidas ocho dimensiones:

1. Motivación utilitarista de compra.

2. Motivación ética de compra.

3. Motivación hedónica de compra.

4. Valor utilitarista percibido.

5. Valor ético percibido.

6. Valor emocional percibido.

7. Satisfacción.

8. Lealtad.

La motivación de compra utilitarista, la motivación ética y la motivación hedónica forman el apartado más relativo disposición o a la condición interna del individuo. Mientras que el valor percibido utilitarista, ético y hedónico son el resultado de la experiencia de compra. Posteriormente la satisfacción es definida como un estado afectivo, y finalmente la lealtad como elemento conductual o comportamental.

A continuación se muestran los ítems que forman cada una de las dimensiones ordenados en función de sus cargas factoriales: 
La motivación utilitarista está formada por cuatro ítems (tras ser eliminado uno de ellos en la depuración inicial):

1. Me siento satisfecho tras conseguir comprar todo aquello que buscaba $(0,90)$.

2. Me gusta sentir que he conseguido aquello que he planificado para esa compra $(0,87)$

3. Valoro poder conseguir buenas oportunidades en relación calidad precio $(0,82)$.

4. Es importante poder realizar las compras con comodidad $(0,62)$.

La motivación ética, al igual que la dimensión interior, después de la depuración inicial pasa de cinco a cuatro ítems:

1. Con la realización de la compra sentí que estaba contribuyendo a la economía local $(0,87)$.

2. Valoro el comportamiento moral de este tipo de establecimientos $(0,85)$.

3. Comprando en este tipo de establecimientos siento que estoy haciendo lo correcto $(0,85)$.

4. Por lo que yo sé, en este tipo de establecimientos actúan de forma honesta y justa $(0,64)$.

La motivación hedónica de compra está compuesta por cinco ítems:

1. Ir de compras es una actividad que me gusta $(0,88)$.

2. Para mi ir de compras es una manera de disfrutar y evadirme del estrés diario $(0,88)$.

3. Me gusta mucho mantenerme al día con la moda y las nuevas tendencias $(0,78)$.

4. En periodos de rebajas es cuando más disfruto comprando $(0,66)$.

5. Me encanta ir de compras con mi familia y amigos $(0,63)$.

El valor utilitarista percibido por el consumidor está compuesto por seis ítems:

1. El coste que me genera acudir a este tipo de comercio en comparación con otros es razonable $(0,80)$. 
2. Los precios son razonables de acuerdo con el producto o servicio recibido $(0,79)$.

3. El esfuerzo total que llevo a cabo para realizar la compra es razonable $(0,75)$.

4. Los precios en este centro son cercanos a la media del mercado $(0,73)$.

5. En general no tengo que hacer grandes desplazamientos ni perder mucho tiempo para comprar en este tipo de establecimiento $(0,73)$.

6. Es sencillo estacionar y/o acceder al establecimiento que busco $(0,72)$.

El valor ético percibido por el consumido está compuesto por los siguientes dos ítems:

1. Disfruto viendo a la gente comprando en este tipo de establecimiento $(0,92)$.

2. Me gusta que la gente me vea comprando aquí $(0,90)$.

3. Considero positivo que la gente compre en este tipo de establecimiento $(0,84)$.

4. Se obtiene cierto reconocimiento por comprar en este tipo de comercio $(0,83)$.

5. Pienso que el que compra en este tipo de comercio tiene cierto nivel $(0,80)$.

6. Las personas que compran aquí están bien consideradas $(0,76)$.

El valor hedónico percibido por el consumidor está formado por cinco items:

1. Estoy contento/a con este tipo de establecimiento $(0,84)$.

2. El personal me proporciona sensaciones positivas $(0,76)$.

3. En general me siento a gusto comprando en este tipo de comercio $(0,73)$.

4. En él me siento relajado/a $(0,71)$.

5. El personal no me agobia $(0,68)$

La satisfacción de compra del consumidor la componen siete ítems:

1. En general, el proceso de compra fue satisfactorio $(0,82)$.

2. Suelen resolver todas mis dudas y cuestiones $(0,82)$.

3. Se cumplieron las expectativas que tenía puestas en el comercio $(0,79)$.

4. Suelo encontrar una solución adecuada a mis necesidades en este tipo de comercio $(0,79)$. 
5. Las respuestas a las cuestiones planteadas sobre el producto fueron eficientes $(0,78)$.

6. Estoy realmente satisfecho con este tipo de comercio $(0,77)$.

7. Estoy satisfecho con el servicio y la atención recibida $(0,75)$.

Por último, la lealtad la forman cuatro ítems:

1. Acudo a este tipo de establecimiento cuando busco obtener información sobre algún producto que me interesa $(0,90)$.

2. Cuando necesito un producto determinado acudo a este tipo de comercio $(0,87)$.

3. Considero este tipo de establecimiento como mi opción principal de compras $(0,70)$.

4. Intento acudir a este tipo de establecimiento cada vez que necesito o deseo ir de compras $(0,65)$.

Tabla 6.3 - Análisis de las escalas de medida (III)

\begin{tabular}{|l|l|l|c|}
\hline & FACTORES e ítems & $\begin{array}{c}\text { Cargas } \\
\text { factoriales }\end{array}$ & T \\
\hline & MOTIVACIÓN UTILITARISTA (MU) & 0,87 & 25,82 \\
\hline 1 & $\begin{array}{l}\text { Me gusta sentir que he conseguido aquello que he planificado } \\
\text { para esa compra. }\end{array}$ & $\begin{array}{l}\text { Me siento satisfecho tras conseguir comprar todo aquello que } \\
\text { buscaba. }\end{array}$ & 0,90 \\
\hline 3 & Es importante poder realizar las compras con comodidad. & 0,62 & 13,71 \\
\hline 4 & $\begin{array}{l}\text { Valoro poder conseguir buenas oportunidades relación calidad } \\
\text { precio. }\end{array}$ & 0,82 & 19,42 \\
\hline MOTIVACIÓN ÉTICA (ME) & $\begin{array}{l}\text { Por lo que yo sé, en este tipo de establecimiento actúan de } \\
\text { forma honesta y justa. }\end{array}$ & 0,64 & 15,12 \\
\hline 2 & $\begin{array}{l}\text { Con la realización de la compra sentí que estaba contribuyendo } \\
\text { a la economía local. }\end{array}$ & 0,87 & 33,20 \\
\hline 3 & $\begin{array}{l}\text { Valoro el comportamiento moral de este tipo de } \\
\text { establecimientos. }\end{array}$ & 0,85 & 27,32 \\
\hline 4 & $\begin{array}{l}\text { Comprando en este tipo de establecimientos siento que estoy } \\
\text { haciendo lo correcto. }\end{array}$ & 0,85 & 28,05 \\
\hline
\end{tabular}




\begin{tabular}{|c|c|c|c|}
\hline & FACTORES e ítems & $\begin{array}{c}\text { Cargas } \\
\text { factoriales }\end{array}$ & $\mathbf{T}$ \\
\hline & MOTIVACIÓN HEDÓNICA (MH) & & \\
\hline 1 & Ir de compras es una actividad que me gusta. & 0,88 & 28,70 \\
\hline 2 & $\begin{array}{l}\text { Para mi ir de compras es una manera de disfrutar y evadirme } \\
\text { del estrés diario. }\end{array}$ & 0,88 & 30,24 \\
\hline 3 & En periodos de rebajas es cuando más disfruto comprando. & 0,66 & 16,82 \\
\hline 4 & Me encanta ir de compras con mi familia y amigos. & 0,63 & 16,18 \\
\hline 5 & $\begin{array}{l}\text { Me gusta mucho mantenerme al día con la moda y las nuevas } \\
\text { tendencias. }\end{array}$ & 0,78 & 23,69 \\
\hline & VALOR PERCIBIDO UTILITARISTA (VU) & & \\
\hline 1 & $\begin{array}{l}\text { Es sencillo estacionar y/o acceder al establecimiento que } \\
\text { busco. }\end{array}$ & 0,72 & 19,57 \\
\hline 2 & $\begin{array}{l}\text { El esfuerzo total que llevo a cabo para realizar la compra es } \\
\text { razonable. }\end{array}$ & 0,75 & 23,15 \\
\hline 3 & $\begin{array}{l}\text { El coste que me genera acudir a este tipo de comercio en } \\
\text { comparación con otros es razonable. }\end{array}$ & 0,80 & 24,25 \\
\hline 4 & $\begin{array}{l}\text { Los precios son razonables de acuerdo con el producto o } \\
\text { servicio recibido. }\end{array}$ & 0,79 & 21,53 \\
\hline 5 & $\begin{array}{l}\text { Los precios en este centro son cercanos a la media del } \\
\text { mercado. }\end{array}$ & 0,73 & 20,92 \\
\hline 6 & $\begin{array}{l}\text { En general no tengo que hacer grandes desplazamientos ni } \\
\text { perder mucho tiempo para comprar en este tipo de } \\
\text { establecimiento. }\end{array}$ & 0,73 & 18,65 \\
\hline & VALOR PERCIBIDO ÉTICO (VE) & & \\
\hline 1 & Las personas que compran aquí están bien consideradas. & 0,76 & 23,13 \\
\hline 2 & $\begin{array}{l}\text { Se obtiene cierto reconocimiento por comprar en este tipo de } \\
\text { comercio. }\end{array}$ & 0,83 & 30,19 \\
\hline 3 & $\begin{array}{l}\text { Considero positivo que la gente compre en este tipo de } \\
\text { comercio. }\end{array}$ & 0,84 & 26,98 \\
\hline 4 & $\begin{array}{l}\text { Pienso que el que compra en este tipo de comercio tiene cierto } \\
\text { nivel. }\end{array}$ & 0,80 & 23,97 \\
\hline 5 & Me gusta que la gente me vea comprando aquí. & 0,90 & 32,00 \\
\hline 6 & $\begin{array}{l}\text { Disfruto viendo a la gente comprando en este tipo de } \\
\text { establecimiento. }\end{array}$ & 0,92 & 34,80 \\
\hline & VALOR PERCIBIDO EMOCIONAL (VH) & & \\
\hline 1 & Estoy contento/a con este tipo de establecimiento. & 0,84 & 26,31 \\
\hline 2 & En él me siento relajado/a. & 0,71 & 19,30 \\
\hline 3 & El personal me proporciona sensaciones positivas. & 0,76 & 18,65 \\
\hline 4 & El personal no me agobia. & 0,68 & 15,35 \\
\hline 5 & $\begin{array}{l}\text { En general me siento a gusto comprando en este tipo de } \\
\text { establecimiento. }\end{array}$ & 0,73 & 20,33 \\
\hline
\end{tabular}




\begin{tabular}{|l|l|l|c|}
\hline & FACTORES e ítems & $\begin{array}{c}\text { Cargas } \\
\text { factoriales }\end{array}$ & T \\
\hline & SATISFACCIÓN (SAT) & & \\
\hline 1 & Estoy realmente satisfecho con este tipo de establecimiento. & 0,77 & 20,41 \\
\hline 2 & Estoy satisfecho con el servicio proporcionado. & 0,75 & 20,16 \\
\hline 3 & $\begin{array}{l}\text { La respuesta a las cuestiones planteadas sobre el } \\
\text { producto/servicio es eficiente. }\end{array}$ & 0,78 & 20,72 \\
\hline 4 & Suelen resolver todas mis dudas y cuestiones. & 0,82 & 22,16 \\
\hline 5 & $\begin{array}{l}\text { Suelo encontrar una solución adecuada a mis necesidades en } \\
\text { este tipo de comercio }\end{array}$ & 0,79 & 21,69 \\
\hline 6 & $\begin{array}{l}\text { Se cumplieron las expectativas que tenía puestas en el } \\
\text { establecimiento. }\end{array}$ & 0,79 & 21,75 \\
\hline 7 & En general, el proceso de compra fue satisfactorio. & 0,82 & 21,75 \\
\hline & $\begin{array}{l}\text { LEALTAD (LEA) } \\
\text { Intento acudir a este tipo de establecimiento cada vez que } \\
\text { necesito o deseo ir de compras. }\end{array}$ & 0,65 & 15,67 \\
\hline 2 & $\begin{array}{l}\text { Considero este tipo de establecimiento como mi opción } \\
\text { principal de compras. }\end{array}$ & 0,70 & 17,22 \\
\hline 3 & $\begin{array}{l}\text { Acudo a este tipo de establecimiento cuando busco obtener } \\
\text { información sobre algún producto que me interesa. }\end{array}$ & 0,90 & 29,03 \\
\hline 4 & $\begin{array}{l}\text { Cuando necesito un producto determinado acudo a este tipo de } \\
\text { centro. }\end{array}$ & 0,87 & 29,61 \\
\hline
\end{tabular}

Ajuste del modelo:

Chi-cuadrado=756,7809; $\mathrm{gl}=711 ; \mathrm{P}=0,113810 ; \mathrm{RMSEA}=0,024 ; \mathrm{CFI}=0,987$; $\mathrm{NNFI}=0,985$ 
Tabla 6.4 - Análisis de las escalas de medida (IV)

\begin{tabular}{|l||c||c|}
\hline & $\begin{array}{c}\text { Fiabilidad } \\
\text { compuesta } \\
\text { (IFC) }\end{array}$ & $\begin{array}{c}\text { Varianza extraída } \\
\text { promedio (AVE) }\end{array}$ \\
\hline $\begin{array}{l}\text { MOTIVACIÓN } \\
\text { UTILITARISTA }\end{array}$ & 0,88 & 0,70 \\
\hline $\begin{array}{l}\text { MOTIVACIÓN } \\
\text { EITICA }\end{array}$ & 0,87 & 0,69 \\
\hline $\begin{array}{l}\text { MOTIVACIÓN } \\
\text { HEDÓNICA }\end{array}$ & 0,88 & 0,64 \\
\hline $\begin{array}{l}\text { VALOR PERCIBIDO } \\
\text { UTILITARISTA }\end{array}$ & 0,89 & 0,61 \\
\hline $\begin{array}{l}\text { VALOR PERCIBIDO } \\
\text { EITICO }\end{array}$ & 0,94 & 0,74 \\
\hline $\begin{array}{l}\text { VALOR PERCIBIDO } \\
\text { EMOCIONAL }\end{array}$ & 0,86 & 0,61 \\
\hline SATISFACCIÓN & 0,92 & 0,67 \\
\hline LEALTAD & 0,86 & 0,67 \\
\hline
\end{tabular}

A continuación, en la tabla 6.5 se muestran la validez discriminante de los constructos considerados en el modelo, que se evalúa a través de la varianza extraída promedio-AVE (Fornell y Larcker 1981). Para ello un constructo debe compartir más varianza con sus indicadores que con otros constructos del modelo. Esto sucede cuando la raíz cuadrada del AVE entre cada par de factores es superior a la correlación estimada entre dichos factores, tal y como sucede en el presente caso lo que ratifica su validez discriminante.

Del análisis de las escalas de medida se desprende la multidimensionalidad contrastada de la variable motivación, con la inclusión de dimensión ética en su estudio (Tauber 1972, Westbrook y Black 1985, Kim 2006, Bezençon y Blili 2009, Guiot y Roux 2010, Ribeiro y Carvalho 2010, Chung 2015, Barbopoulos y Johansson 2016). Así pues queda contrastada y aceptada la primera hipótesis del presente trabajo. La motivación de compra del consumidor es por tanto, un constructo multidimensional formado por tres dimensiones: motivación utilitarista, motivación ética y motivación hedónica (H1). 
Tabla 6.5 - Análisis de las escalas de medida (V)*

\begin{tabular}{|l|c|c|c|c|c|c|c|c|}
\cline { 2 - 9 } & MOTIV. UT. & MOTIV. ET. & MOTIV. HED. & VALOR. UT. & VALOR. ET. & VALOR. EM. & SATISF. & LEALTAD \\
\hline MOTIV. UT. & $\mathbf{0 , 8 3}$ & & & & & & \\
\hline MOTIV. ET. & $-0,10$ & $\mathbf{0 , 8 3}$ & & & & & & \\
\hline MOTIV. HED. & 0,47 & 0,36 & $\mathbf{0 , 8 0}$ & & & & & \\
\hline VALOR. UT. & 0,42 & 0,53 & 0,41 & $\mathbf{0 , 7 8}$ & & & & \\
\hline VALOR. ET. & $-0,31$ & 0,69 & 0,28 & 0,30 & $\mathbf{0 , 8 6}$ & & & \\
\hline VALOR EM. & 0,33 & 0,66 & 0,65 & 0,57 & 0,38 & $\mathbf{0 , 8 0}$ & & \\
\hline SATISF. & 0,26 & 0,69 & 0,55 & 0,62 & 0,48 & 0,41 & $\mathbf{0 , 8 1}$ & \\
\hline LEALTAD & $-0,09$ & 0,69 & 0,42 & 0,51 & 0,67 & 0,60 & 0,40 & $\mathbf{0 , 8 2}$ \\
\hline
\end{tabular}

* Debajo de la diagonal: correlación estimada entre los factores.

Diagonal: raíz cuadrada de la varianza extraída. 


\subsection{ANÁLISIS DESCRIPTIVO}

Una vez realizados los análisis de fiabilidad, dimensionalidad y validez de las escalas de medición, pasamos a continuación a realizar el análisis descriptivo de las mismas. En el presente apartado se presentarán las características de la muestra y las valoraciones medias de las respuestas que han realizado los encuestados en los diferentes apartados. Diferenciando entre aquellos consumidores que realizaron sus compras en pequeños comercios urbanos y aquellos que lo hicieron en grandes centros comerciales, ya que esta variable va a ser utilizada como moderadora en el posterior apartado relativo a las relaciones causales.

\subsubsection{Descripción del perfil de la muestra}

El universo ha estado formado por individuos mayores de 18 años, que han realizado compras en comercios de moda y complementos de su localidad en los últimos dos meses. El hecho de introducir esta primera condición o limitación se basa en la composición del cuestionario, pues a lo largo del mismo se presentan un conjunto de preguntas relacionadas con la experiencia de compra y por ello era relevante que dicha experiencia fuese reciente.

En cuanto al reparto de encuestados por tipo de comercio en el que realizaron las compras (Tabla 6.6), podemos apreciar que se encuentran equitativamente distribuidos entre aquellos que realizaron sus compras en pequeños comercios urbanos y aquellos que lo realizaron en un gran centro comercial. 
Tabla 6.6 - Reparto de la muestra según el tipo de comercio en el que realizaron las compras.

\begin{tabular}{|c|c|c|}
\hline Grupo & Frecuencia & $\mathbf{\%}$ \\
\hline $\begin{array}{c}\text { Pequeño comercio } \\
\text { urbano }\end{array}$ & 254 & 49,2 \\
\hline $\begin{array}{c}\text { Gran centro } \\
\text { comercial }\end{array}$ & 262 & 50,8 \\
\hline TOTAL & 516 & 100 \\
\hline
\end{tabular}

En cuanto al reparto de encuestados por provincias (Tabla 6.7), podemos apreciar que siguiendo la estructura poblacional de las provincias objeto de estudio, se encuentran distribuidos los encuestados de manera equitativa entre pequeño comercio urbano y gran centro comercial.

Tabla 6.7 - Tipo de establecimiento donde se realizó la compra y provincia.

\begin{tabular}{|c|c|c|c|}
\hline Grupo & Provincia & Frecuencia & \% \\
\hline \multirow{4}{*}{$\begin{array}{c}\text { Pequeño comercio } \\
\text { urbano }\end{array}$} & Castellón & 30 & 11.8 \\
\cline { 2 - 4 } & Valencia & 130 & 51.2 \\
\cline { 2 - 4 } & Alicante & 94 & 37 \\
\cline { 2 - 4 } & Total & 254 & 100 \\
\hline \multirow{3}{*}{$\begin{array}{c}\text { Gran centro } \\
\text { comercial }\end{array}$} & Castellón & 32 & 12.2 \\
\cline { 2 - 4 } & Valencia & 133 & 50.8 \\
\cline { 2 - 4 } & Alicante & 97 & 37 \\
\cline { 2 - 4 } & Total & 262 & 100 \\
\hline
\end{tabular}


En cuanto a la distribución por tramos de edad de los compradores encuestados (Tabla 6.8), se puede ver que no existen grandes diferencias entre los grupos. Siguiendo la estructura poblacional de la Comunidad Valenciana, aparecen representados los diferentes grupos de edad en cada uno de los tipos de comercio objeto de estudio en el presente trabajo.

Tabla 6.8 - Distribución de encuestados por tramos de edades y tipo de comercio en el que se realizó la compra.

\begin{tabular}{|c|c|c|c|}
\hline Grupo & Tramos de edad & Frecuencia & $\%$ \\
\hline \multirow{7}{*}{$\begin{array}{c}\text { Pequeño comercio } \\
\text { urbano }\end{array}$} & De 18 a 24 años & 25 & 10 \\
\hline & De 25 a 34 años & 36 & 14.3 \\
\hline & De 35 a 44 años & 53 & 20.2 \\
\hline & De 45 a 54 años & 47 & 18.6 \\
\hline & De 55 a 64 años & 37 & 14.7 \\
\hline & 65 años o más & 56 & 22.2 \\
\hline & Total & 254 & 100 \\
\hline \multirow{7}{*}{$\begin{array}{c}\text { Gran centro } \\
\text { comercial }\end{array}$} & De 18 a 24 años & 27 & 10.3 \\
\hline & De 25 a 34 años & 38 & 14.5 \\
\hline & De 35 a 44 años & 54 & 20.6 \\
\hline & De 45 a 54 años & 48 & 18.3 \\
\hline & De 55 a 64 años & 38 & 14.5 \\
\hline & 65 años o más & 57 & 21.8 \\
\hline & Total & 262 & 100 \\
\hline
\end{tabular}


En cuanto a la distribución por género de los compradores encuestados (Tabla 6.9), se puede apreciar ambos se encuentran representados de manera proporcional a la estructura general de población, siendo ligeramente superior el porcentaje de mujeres que de hombres.

Tabla 6.9 - Distribución de encuestados por género y tipo de comercio en el que se realizó la compra.

\begin{tabular}{|c|c|c|c|}
\hline Grupo & Género & Frecuencia & \% \\
\hline \multirow{2}{*}{$\begin{array}{c}\text { Pequeño comercio } \\
\text { urbano }\end{array}$} & Mujer & 128 & 50 \\
\cline { 2 - 4 } & Hombre & 126 & 50 \\
\cline { 2 - 4 } & Total & 254 & 100 \\
\hline \multirow{3}{*}{$\begin{array}{c}|c| \\
\text { Gran centro } \\
\text { comercial }\end{array}$} & Mujer & 136 & 51.9 \\
\cline { 2 - 4 } & Hombre & 126 & 48.1 \\
\cline { 2 - 4 } & Total & 262 & 100 \\
\hline
\end{tabular}

Si nos fijamos en la ocupación principal de los encuestados (Tabla 6.10), observamos que en general en ambos tipos de establecimiento, el 50\% de los compradores se encuentran en activo. En cuanto al resto de ocupaciones, se encuentran distribuidas de manera bastante similar entre ambos tipos de establecimiento. 
Tabla 6.10 - Distribución de encuestados por ocupación principal y tipo de establecimiento en el que se realizó la compra.

\begin{tabular}{|c|c|c|c|}
\hline Grupo & Ocupación & Frecuencia & $\%$ \\
\hline \multirow{6}{*}{$\begin{array}{c}\text { Pequeño comercio } \\
\text { urbano }\end{array}$} & Estudiante & 42 & 16.5 \\
\hline & Trabaja & 128 & 50.3 \\
\hline & Trabaja en el hogar & 18 & 7.1 \\
\hline & Jubilado/a & 56 & 22 \\
\hline & Parado/a & 10 & 4.1 \\
\hline & Total & 254 & 100 \\
\hline \multirow{6}{*}{$\begin{array}{c}\text { Gran centro } \\
\text { comercial }\end{array}$} & Estudiante & 32 & 12.1 \\
\hline & Trabaja & 130 & 50 \\
\hline & Trabaja en el hogar & 30 & 11.4 \\
\hline & Jubilado/a & 56 & 21.3 \\
\hline & Parado/a & 14 & 5.2 \\
\hline & Total & 262 & 100 \\
\hline
\end{tabular}

En la Tabla 6.11, mostramos la distribución de los encuestados según nivel de estudios superado. Se puede apreciar que, comparativamente, el mayor porcentaje de compradores en ambos casos posee el Bachiller o FP2, rondando el 30\%. Sin embargo, podemos apreciar una ligera diferencia en la proporción de aquellos compradores con estudios universitarios medios y superiores, siendo de un $45.7 \%$ en el pequeño comercio urbano, frente al $35.9 \%$ en los centros comerciales. 
Tabla 6.11 - Distribución de encuestados según su nivel de estudios superado y tipo de establecimiento en el que se realizó la compra.

\begin{tabular}{|c|c|c|c|c|}
\hline Grupo & Nivel de estudios & Frecuencia & $\%$ & $\begin{array}{c}\% \\
\text { acumulado }\end{array}$ \\
\hline \multirow{7}{*}{$\begin{array}{c}\text { Pequeño } \\
\text { comercio urbano }\end{array}$} & Sin estudios & 2 & 0.8 & 0.8 \\
\hline & $\begin{array}{c}\text { Primarios (hasta } \\
10 \text { años) }\end{array}$ & 12 & 4.7 & 5.5 \\
\hline & $\begin{array}{c}\text { Primarios (EGB, } \\
\text { FP1) }\end{array}$ & 40 & 15.7 & 21.2 \\
\hline & Bachiller o FP2 & 84 & 33.1 & 54.3 \\
\hline & $\begin{array}{c}\text { Universitarios } \\
\text { medios }\end{array}$ & 66 & 26 & 80.3 \\
\hline & $\begin{array}{c}\text { Universitarios } \\
\text { superiores }\end{array}$ & 50 & 19.7 & 100 \\
\hline & Total & 254 & 100 & \\
\hline \multirow{7}{*}{$\begin{array}{l}\text { Gran centro } \\
\text { comercial }\end{array}$} & Sin estudios & 10 & 3.8 & 3.8 \\
\hline & $\begin{array}{c}\text { Primarios (hasta } \\
10 \text { años) }\end{array}$ & 20 & 7.6 & 11.4 \\
\hline & $\begin{array}{c}\text { Primarios (EGB, } \\
\text { FP1) }\end{array}$ & 44 & 16.8 & 28.2 \\
\hline & Bachiller o FP2 & 94 & 35.9 & 64.1 \\
\hline & $\begin{array}{c}\text { Universitarios } \\
\text { medios }\end{array}$ & 82 & 31.3 & 95.4 \\
\hline & $\begin{array}{c}\text { Universitarios } \\
\text { superiores }\end{array}$ & 12 & 4.6 & 100 \\
\hline & Total & 262 & 100 & \\
\hline
\end{tabular}

Si nos fijamos en esta ocasión en el nivel de ingresos totales mensuales del hogar de los encuestados (Tabla 6.12). Observamos que el 68,5\% de los compradores del pequeño comercio urbano afirman tener unos ingresos mensuales totales superiores a 1500 euros, siendo ese mismo porcentaje en el centro comercial del 35,9\%. 
Tabla 6.12 - Distribución de encuestados por nivel de ingresos totales mensuales y tipo de establecimiento en el que se realizó la compra.

\begin{tabular}{|c|c|c|c|c|}
\hline Grupo & $\begin{array}{l}\text { Ingresos } \\
\text { mensuales }\end{array}$ & Frecuencia & $\%$ & $\begin{array}{c}\% \\
\text { acumulado }\end{array}$ \\
\hline \multirow{6}{*}{$\begin{array}{c}\text { Pequeño } \\
\text { comercio urbano }\end{array}$} & 0-1000 euros & 20 & 7.9 & 7.9 \\
\hline & $1001-1500$ euros & 60 & 23.6 & 31.5 \\
\hline & $1501-2000$ euros & 74 & 29.1 & 60.6 \\
\hline & 2001-2500 euros & 72 & 28.3 & 88.9 \\
\hline & $\begin{array}{l}\text { Más de } 2500 \\
\text { euros }\end{array}$ & 28 & 11.1 & 100 \\
\hline & Total & 254 & 100 & \\
\hline \multirow{6}{*}{$\begin{array}{l}\text { Gran centro } \\
\text { comercial }\end{array}$} & $0-1000$ euros & 58 & 22.1 & 22.1 \\
\hline & $1001-1500$ euros & 110 & 42 & 64.1 \\
\hline & $1501-2000$ euros & 60 & 23 & 87.1 \\
\hline & $2001-2500$ euros & 18 & 6.9 & 94 \\
\hline & $\begin{array}{l}\text { Más de } 2500 \\
\text { euros }\end{array}$ & 16 & 6 & 100 \\
\hline & Total & 262 & 100 & \\
\hline
\end{tabular}


Si analizamos el número de miembros en el hogar de los encuestados según el tipo de establecimiento en el que se realizó la compra (Tabla 6.13), observamos que en general las distribuciones son muy similares. Sin embargo, los hogares con tres miembros o menos representan aproximadamente el $80 \%$ de los encuestados del centro comercial, frente al $60 \%$ del pequeño comercio hurbano.

Tabla 6.13 - Distribución de encuestados por número de miembros en el hogar y tipo de establecimiento en el que se realizó la compra.

\begin{tabular}{|c|c|c|c|c|}
\hline Grupo & Miembros hogar & Frecuencia & $\%$ & $\begin{array}{c}\% \% \\
\text { Acumulado }\end{array}$ \\
\hline \multirow{6}{*}{$\begin{array}{c}\text { Pequeño } \\
\text { comercio urbano }\end{array}$} & 1 & 26 & 10.2 & 10.2 \\
\hline & 2 & 70 & 27.5 & 37.7 \\
\hline & 3 & 56 & 22 & 59.7 \\
\hline & 4 & 76 & 30 & 89.7 \\
\hline & 5 o más & 26 & 10.3 & 100 \\
\hline & Total & 254 & 100 & \\
\hline \multirow{6}{*}{$\begin{array}{c}\text { Gran centro } \\
\text { comercial }\end{array}$} & 1 & 42 & 16 & 16 \\
\hline & 2 & 114 & 43.5 & 59.5 \\
\hline & 3 & 48 & 18.3 & 77.8 \\
\hline & 4 & 40 & 15.3 & 93.1 \\
\hline & 5 o más & 18 & 6.9 & 100 \\
\hline & Total & 262 & 100 & \\
\hline
\end{tabular}


A continuación analizamos la proporción hogares con niños entre los encuestados diferenciando entre los dos tipos de establecimiento en los que se realizaron las compras (Tabla 6.14). Apreciamos que $84 \%$ de los encuestados que realizaron su compra en grandes centros comerciales sí tienen niños, frente al 58.3\% que representan ese mismo grupo entre los encuestados del pequeño comercio urbano.

Tabla 6.14 - Distribución de encuestados con niños en el hogar y tipo de establecimiento en el que se realizó la compra.

\begin{tabular}{|c|c|c|c|}
\hline Grupo & Niños en el hogar & Frecuencia & \% \\
\hline \multirow{2}{*}{$\begin{array}{c}\text { Pequeño comercio } \\
\text { urbano }\end{array}$} & Sí & 148 & 58.3 \\
\cline { 2 - 4 } & No & 106 & 41.7 \\
\cline { 2 - 4 } & Total & 254 & 100 \\
\hline \multirow{2}{*}{$\begin{array}{c}\text { Gran centro } \\
\text { comercial }\end{array}$} & Sí & 220 & 84 \\
\cline { 2 - 4 } & No & 42 & 16 \\
\cline { 2 - 4 } & Total & 262 & 100 \\
\hline
\end{tabular}


Si analizamos la distribución de los compradores encuestados por tamaño de la población de residencia y el tipo de establecimiento en el que se realizó la compra (Tabla 6.15), observamos que aproximadamente el $70 \%$ de los encuestados que realizaron su compra en un centro comercial residen en una población menor a 50.000 habitantes. En contraposición, ese mismo porcentaje entre los encuestados del pequeño comercio urbano residen en poblaciones de más 500.000 habitantes.

Tabla 6.15 - Distribución de encuestados por tamaño de la población de residencia y tipo de establecimiento en el que se realizó la compra.

\begin{tabular}{|c|c|c|c|c|}
\hline Grupo & $\begin{array}{c}\text { Tamaño } \\
\text { población } \\
\text { (habitantes) }\end{array}$ & Frecuencia & $\%$ & $\begin{array}{c}\% \\
\text { acumulado }\end{array}$ \\
\hline \multirow{5}{*}{$\begin{array}{c}\text { Pequeño } \\
\text { comercio urbano }\end{array}$} & Hasta 50.000 & 20 & 7.9 & 7.9 \\
\hline & $50.000-200.000$ & 48 & 18.9 & 26.8 \\
\hline & $200.000-500.000$ & 16 & 6.2 & 33 \\
\hline & Más de 500.000 & 170 & 67 & 100 \\
\hline & Total & 254 & 100 & \\
\hline \multirow{5}{*}{$\begin{array}{c}\text { Gran centro } \\
\text { comercial }\end{array}$} & Hasta 50.000 & 174 & 66.4 & 66.4 \\
\hline & $50.000-200.000$ & 62 & 23.7 & 90.1 \\
\hline & $200.000-500.000$ & 14 & 5.3 & 95.4 \\
\hline & Más de 500.000 & 12 & 4.6 & 100 \\
\hline & Total & 262 & 100 & \\
\hline
\end{tabular}


Si nos fijamos en el gasto mensual medio en moda y complementos en función del tipo de establecimiento (Tabla 6.16), observamos que el $85 \%$ de los encuestados que realizaron su compra en centro comercial gastan 100 euros o menos al mes en moda y complementos, frente $47.3 \%$ que representa ese mismo grupo entre los compradores del pequeño comercio urbano.

Tabla 6.16 - Distribución de encuestados por gasto mensual medio en moda y complementos y tipo de establecimiento en el que se realizó la compra.

\begin{tabular}{|c|c|c|c|c|}
\hline Grupo & $\begin{array}{c}\text { Gasto mensual } \\
\text { moda y } \\
\text { complementos } \\
\text { (euros) }\end{array}$ & Frecuencia & $\%$ & $\begin{array}{c}\% \\
\text { acumulado }\end{array}$ \\
\hline \multirow{6}{*}{$\begin{array}{c}\text { Pequeño } \\
\text { comercio urbano }\end{array}$} & $0-50$ & 36 & 14.2 & 14.2 \\
\hline & $50-100$ & 84 & 33.1 & 47.3 \\
\hline & $100-150$ & 82 & 32.3 & 79.6 \\
\hline & $150-200$ & 44 & 17.3 & 96.9 \\
\hline & Más de 200 & 8 & 3.1 & 100 \\
\hline & Total & 254 & 100 & \\
\hline \multirow{6}{*}{$\begin{array}{l}\text { Gran centro } \\
\text { comercial }\end{array}$} & $0-50$ & 136 & 52 & 52 \\
\hline & $50-100$ & 86 & 33 & 85 \\
\hline & $100-150$ & 26 & 10 & 95 \\
\hline & $150-200$ & 8 & 3 & 98 \\
\hline & Más de 200 & 6 & 2 & 100 \\
\hline & Total & 262 & 100 & \\
\hline
\end{tabular}




\subsubsection{Análisis descriptivo de los datos obtenidos}

En el presente apartado del trabajo se presentan los principales resultados obtenidos de las valoraciones medias realizadas por los encuestados sobre las preguntas del cuestionario cuyas escalas se validaron en el primer punto de este capítulo. Las valoraciones ofrecidas son las medias aritméticas de las respuestas obtenidas sobre una escala de tipo Likert con valores comprendidos entre 1 y 5 puntos, siendo 1 la peor puntuación y 5 la mejor. En concreto se pregunta sobre la motivación, el valor percibido, la satisfacción y la lealtad con dos tipos de establecimientos minoristas: el pequeño comercio urbano y los grandes centros comerciales. En consecuencia, y tal y como sucede en el punto anterior, los resultados se presentan divididos en dos grupos: "compradores del pequeño comercio urbano" y "compradores de gran centro comercial”. Además, en las tablas se incluye el indicador de significatividad del análisis ANOVA. Este análisis se ha realizado para estudiar si las diferencias en las valoraciones de cada grupo se pueden considerar o no significativas. Se distinguirán con un asterisco (*) los indicadores que sí indiquen diferencias significativas en las valoraciones de los grupos.

En lo relativo a los resultados de la motivación utilitarista de compra (Tabla 6.17) se puede apreciar que existen diferencias significativas en los cuatro ítems que componen la misma. En todos ellos, los compradores de los grandes centros comerciales realizan valoraciones significativamente superiores. Destaca el 4,65 en valoración de oportunidades en relación calidad precio entre los compradores del centro comercial frente al 3,84 de media en el pequeño comercio urbano. Podríamos decir que el comprador del centro comercial es un comprador más utilitaristamente motivado que el comprador del pequeño comercio urbano. 
Tabla 6.17 - Motivación utilitarista de compra por tipo de establecimiento.

\begin{tabular}{|c|c|c|c|c|c|}
\hline $\mathbf{N}^{\mathbf{0}}$ & Motivación utilitarista de compra & Grupo & $\mathbf{N}$ & Media & Sig. \\
\hline \multirow{3}{*}{1} & \multirow{3}{*}{$\begin{array}{l}\text { Me gusta sentir que he conseguido } \\
\text { aquello que he planificado para esa } \\
\text { compra. }\end{array}$} & $\begin{array}{l}\text { Pequeño } \\
\text { comercio }\end{array}$ & 254 & 3.61 & \multirow{3}{*}{$0.000 *$} \\
\hline & & $\begin{array}{l}\text { Gran centro } \\
\text { comercial }\end{array}$ & 262 & 4.55 & \\
\hline & & Total & 516 & 4.08 & \\
\hline \multirow{3}{*}{2} & \multirow{3}{*}{$\begin{array}{l}\text { Me siento satisfecho tras conseguir } \\
\text { comprar todo aquello que buscaba. }\end{array}$} & $\begin{array}{l}\text { Pequeño } \\
\text { comercio }\end{array}$ & 254 & 3.59 & \multirow{3}{*}{$0.000 *$} \\
\hline & & $\begin{array}{l}\text { Gran centro } \\
\text { comercial }\end{array}$ & 262 & 4.55 & \\
\hline & & Total & 516 & 4.08 & \\
\hline \multirow{3}{*}{3} & \multirow{3}{*}{$\begin{array}{l}\text { Es importante poder realizar las } \\
\text { compras con comodidad. }\end{array}$} & $\begin{array}{l}\text { Pequeño } \\
\text { comercio }\end{array}$ & 254 & 3.48 & \multirow{3}{*}{$0.000 *$} \\
\hline & & $\begin{array}{c}\text { Gran centro } \\
\text { comercial }\end{array}$ & 262 & 4.20 & \\
\hline & & Total & 516 & 4.02 & \\
\hline \multirow{3}{*}{4} & \multirow{3}{*}{$\begin{array}{l}\text { Valoro poder conseguir buenas } \\
\text { oportunidades calidad precio. }\end{array}$} & $\begin{array}{l}\text { Pequeño } \\
\text { comercio }\end{array}$ & 254 & 3.84 & \multirow{3}{*}{$0.000 *$} \\
\hline & & $\begin{array}{l}\text { Gran centro } \\
\text { comercial }\end{array}$ & 262 & 4.65 & \\
\hline & & Total & 516 & 4.26 & \\
\hline
\end{tabular}

$\left(^{*}\right)$ Existen diferencias significativas entre las valoraciones de los grupos.

En cuanto a los resultados de la motivación ética de compra (Tabla 6.18) se puede apreciar que también existen diferencias significativas en los cuatro ítems que compone. Aunque, sin embargo, las valoraciones son generalmente inferiores. En todos los casos, los compradores del pequeño comercio urbano realizan valoraciones significativamente superiores. Destaca el 3.38 en la valoración de la contribución a la economía local con la compra, frente al 1.99 de media en el centro comercial. Podríamos 
decir que el comprador del pequeño comercio es un comprador más éticamente motivado que el comprador del centro comercial.

Tabla 6.18 - Motivación ética de compra por tipo de establecimiento.

\begin{tabular}{|c|c|c|c|c|c|}
\hline $\mathbf{N}^{\mathbf{0}}$ & Motivación ética de compra & Grupo & $\mathbf{N}$ & Media & Sig. \\
\hline \multirow{3}{*}{1} & \multirow{3}{*}{$\begin{array}{l}\text { Por lo que yo sé, en este tipo de } \\
\text { establecimiento actúa de forma } \\
\text { honesta y justa. }\end{array}$} & $\begin{array}{l}\text { Pequeño } \\
\text { comercio }\end{array}$ & 254 & 3.59 & \multirow{3}{*}{$0.001 *$} \\
\hline & & $\begin{array}{l}\text { Gran centro } \\
\text { comercial }\end{array}$ & 262 & 3.32 & \\
\hline & & Total & 516 & 3.45 & \\
\hline \multirow{3}{*}{2} & \multirow{3}{*}{$\begin{array}{l}\text { Con la realización de mi compra sentí } \\
\text { que estaba contribuyendo a la } \\
\text { economía local. }\end{array}$} & $\begin{array}{l}\text { Pequeño } \\
\text { comercio }\end{array}$ & 254 & 3.38 & \multirow{3}{*}{$0.000 *$} \\
\hline & & $\begin{array}{l}\text { Gran centro } \\
\text { comercial }\end{array}$ & 262 & 1.99 & \\
\hline & & Total & 516 & 2.67 & \\
\hline \multirow{3}{*}{3} & \multirow{3}{*}{$\begin{array}{l}\text { Valoro el comportamiento moral de } \\
\text { este tipo de establecimientos. }\end{array}$} & $\begin{array}{l}\text { Pequeño } \\
\text { comercio }\end{array}$ & 254 & 3.63 & \multirow{3}{*}{$0.000 *$} \\
\hline & & $\begin{array}{l}\text { Gran centro } \\
\text { comercial }\end{array}$ & 262 & 2.54 & \\
\hline & & Total & 516 & 3.07 & \\
\hline \multirow{3}{*}{4} & \multirow{3}{*}{$\begin{array}{l}\text { Comprando en este tipo de } \\
\text { establecimientos siento que estoy } \\
\text { haciendo lo correcto. }\end{array}$} & $\begin{array}{l}\text { Pequeño } \\
\text { comercio }\end{array}$ & 254 & 3.49 & \multirow{3}{*}{$0.000 *$} \\
\hline & & $\begin{array}{l}\text { Gran centro } \\
\text { comercial }\end{array}$ & 262 & 2.49 & \\
\hline & & Total & 516 & 2.98 & \\
\hline
\end{tabular}

$\left(^{*}\right)$ Existen diferencias significativas entre las valoraciones de los grupos. 
En lo relativo a los resultados de la motivación hedónica de compra (Tabla 6.19) se puede apreciar que a diferencia de los casos anteriores, no existen diferencias significativas en todos los ítems. Las valoraciones no son muy elevadas, sin alcanzar el cuatro de media en ninguno de los casos. Destaca el 3.71 en la valoración del disfrute de las compras entre los compradores del centro comercial, frente al 3.35 de media en el pequeño comercio urbano. Podríamos decir que en este caso, no existe un patrón dominante dependiendo del tipo del establecimiento en el que realicen las compras a la hora de disfrutar en mayor o menor medida de las compras.

Tabla 6.19 - Motivación hedónica de compra por tipo de establecimiento.

\begin{tabular}{|c|c|c|c|c|c|}
\hline $\mathbf{N}^{\mathbf{0}}$ & Motivación hedónica de compra & Grupo & $\mathbf{N}$ & Media & Sig. \\
\hline \multirow{3}{*}{1} & \multirow{3}{*}{$\begin{array}{l}\text { Ir de compras es una actividad que me } \\
\text { gusta. }\end{array}$} & $\begin{array}{l}\text { Pequeño } \\
\text { comercio }\end{array}$ & 254 & 3.35 & \multirow{3}{*}{$0.000 *$} \\
\hline & & $\begin{array}{l}\text { Gran centro } \\
\text { comercial }\end{array}$ & 262 & 3.71 & \\
\hline & & Total & 516 & 3.53 & \\
\hline \multirow{3}{*}{2} & \multirow{3}{*}{$\begin{array}{c}\text { Para mi ir de compras es una manera } \\
\text { de disfrutar y evadirme del estrés } \\
\text { diario. }\end{array}$} & $\begin{array}{l}\text { Pequeño } \\
\text { comercio }\end{array}$ & 254 & 3.22 & \multirow{3}{*}{0.605} \\
\hline & & $\begin{array}{c}\text { Gran centro } \\
\text { comercial }\end{array}$ & 262 & 3.16 & \\
\hline & & Total & 516 & 3.19 & \\
\hline \multirow{3}{*}{3} & \multirow{3}{*}{$\begin{array}{l}\text { En periodos de rebajas es cuando más } \\
\text { disfruto comprando. }\end{array}$} & $\begin{array}{l}\text { Pequeño } \\
\text { comercio }\end{array}$ & 254 & 3.39 & \multirow{3}{*}{0.406} \\
\hline & & $\begin{array}{c}\text { Gran centro } \\
\text { comercial }\end{array}$ & 262 & 3.48 & \\
\hline & & Total & 516 & 3.43 & \\
\hline \multirow{3}{*}{4} & \multirow{3}{*}{$\begin{array}{l}\text { Me encanta ir de compras con mi } \\
\text { familia o amigos. }\end{array}$} & $\begin{array}{l}\text { Pequeño } \\
\text { comercio }\end{array}$ & 254 & 3.35 & \multirow{3}{*}{$0.000 *$} \\
\hline & & $\begin{array}{l}\text { Gran centro } \\
\text { comercial }\end{array}$ & 262 & 2.82 & \\
\hline & & Total & 516 & 3.08 & \\
\hline
\end{tabular}




\begin{tabular}{|c|c|c|r|r|c|}
\hline $\mathbf{N}^{\mathbf{0}}$ & Motivación hedónica de compra & Grupo & N & Media & Sig. \\
\hline \multirow{2}{*}{5} & \multirow{2}{*}{$\begin{array}{c}\text { Me gusta mucho mantenerme al día } \\
\text { con la moda y las nuevas tendencias. }\end{array}$} & $\begin{array}{c}\text { Pequeño } \\
\text { comercio }\end{array}$ & 254 & 3.19 & \\
\cline { 3 - 6 } & $\begin{array}{c}\text { Gran centro } \\
\text { comercial }\end{array}$ & 262 & 2.92 & \multirow{2}{*}{$0.000^{*}$} \\
\cline { 3 - 6 } & Total & 516 & 3.05 & \\
\hline
\end{tabular}

$\left(^{*}\right)$ Existen diferencias significativas entre las valoraciones de los grupos.

Siguiendo con un nivel medio de respuesta no excesivamente elevado, analizamos a continuación el valor utilitarista percibido por el consumidor en función del tipo de establecimiento (Tabla 6.20). En esta ocasión, al igual que sucedía en la motivación de compra utilitarista, son más altas las valoraciones realizadas por los consumidores del centro comercial. Esta vez la puntuación más alta corresponde al hecho de la cercanía de los precios a la media del mercado en el centro comercial (3.62) y la más baja al coste que conlleva realizar las compras en el pequeño comercio urbano (3.29). Aunque el resto de diferencias no son significativas.

Tabla 6.20 - Valor utilitarista percibido por tipo de establecimiento.

\begin{tabular}{|c|c|c|c|c|c|}
\hline $\mathbf{N}^{\mathbf{0}}$ & Valor utilitarista percibido & Grupo & $\mathbf{N}$ & Media & Sig. \\
\hline \multirow{3}{*}{1} & \multirow{3}{*}{$\begin{array}{c}\text { Es sencillo estacionar y/o acceder al } \\
\text { establecimiento que busco. }\end{array}$} & $\begin{array}{l}\text { Pequeño } \\
\text { comercio }\end{array}$ & 254 & 3.38 & \multirow{3}{*}{0.232} \\
\hline & & $\begin{array}{l}\text { Gran centro } \\
\text { comercial }\end{array}$ & 262 & 3.50 & \\
\hline & & Total & 516 & 3.44 & \\
\hline \multirow{3}{*}{2} & \multirow{3}{*}{$\begin{array}{l}\text { El esfuerzo total que llevo a cabo para } \\
\text { realizar la compra es razonable. }\end{array}$} & $\begin{array}{l}\text { Pequeño } \\
\text { comercio }\end{array}$ & 254 & 3.46 & \multirow{3}{*}{0.901} \\
\hline & & $\begin{array}{l}\text { Gran centro } \\
\text { comercial }\end{array}$ & 262 & 3.45 & \\
\hline & & Total & 516 & 3.45 & \\
\hline
\end{tabular}




\begin{tabular}{|c|c|c|c|c|c|}
\hline $\mathbf{N}^{\mathbf{0}}$ & Valor utilitarista percibido & Grupo & $\mathbf{N}$ & Media & Sig. \\
\hline \multirow{3}{*}{3} & \multirow{3}{*}{$\begin{array}{l}\text { El coste que me genera acudir a este } \\
\text { tipo de comercio en comparación con } \\
\text { otros es razonable. }\end{array}$} & $\begin{array}{l}\text { Pequeño } \\
\text { comercio }\end{array}$ & 254 & 3.29 & \multirow{3}{*}{$0.001 *$} \\
\hline & & $\begin{array}{l}\text { Gran centro } \\
\text { comercial }\end{array}$ & 262 & 3.61 & \\
\hline & & Total & 516 & 3.45 & \\
\hline \multirow{3}{*}{4} & \multirow{3}{*}{$\begin{array}{l}\text { Los precios son razonables de acuerdo } \\
\text { con el producto o servicio recibido. }\end{array}$} & $\begin{array}{l}\text { Pequeño } \\
\text { comercio }\end{array}$ & 254 & 3.29 & \multirow{3}{*}{$0.049 *$} \\
\hline & & $\begin{array}{l}\text { Gran centro } \\
\text { comercial }\end{array}$ & 262 & 3.45 & \\
\hline & & Total & 516 & 3.38 & \\
\hline \multirow{3}{*}{5} & \multirow{3}{*}{$\begin{array}{l}\text { Los precios en este centro son } \\
\text { cercanos a la media del mercado. }\end{array}$} & $\begin{array}{l}\text { Pequeño } \\
\text { comercio }\end{array}$ & 254 & 3.38 & \multirow{3}{*}{$0.002 *$} \\
\hline & & $\begin{array}{l}\text { Gran centro } \\
\text { comercial }\end{array}$ & 262 & 3.62 & \\
\hline & & Total & 516 & 3.50 & \\
\hline \multirow{3}{*}{6} & \multirow{3}{*}{$\begin{array}{l}\text { En general no tengo que hacer grandes } \\
\text { desplazamientos ni perder mucho } \\
\text { tiempo para comprar en este tipo de } \\
\text { establecimiento. }\end{array}$} & $\begin{array}{l}\text { Pequeño } \\
\text { comercio }\end{array}$ & 254 & 3.53 & \multirow{3}{*}{$0.002 *$} \\
\hline & & $\begin{array}{l}\text { Gran centro } \\
\text { comercial }\end{array}$ & 262 & 3.24 & \\
\hline & & Total & 516 & 3.38 & \\
\hline
\end{tabular}

(*) Existen diferencias significativas entre las valoraciones de los grupos.

En cuanto a los resultados de valor ético por tipo de establecimiento (Tabla 6.21) se puede apreciar que existen grandes diferencias significativas en los cuatro ítems que la componen. En todos los casos, los compradores del pequeño comercio urbano realizan valoraciones significativamente superiores. Destaca el 3.18 en la valoración de la consideración social de compra en este tipo de establecimiento, en contraposición, los compradores de los grandes centros comerciales dan una valoración media de 1,48 al ítem "me gusta que me vean comprado aquí". 
Tabla 6.21- Valor ético percibido por tipo de establecimiento.

\begin{tabular}{|c|c|c|c|c|c|}
\hline $\mathbf{N}^{\mathbf{o}}$ & Valor ético percibido & Grupo & $\mathbf{N}$ & Media & Sig. \\
\hline \multirow{3}{*}{1} & \multirow{3}{*}{$\begin{array}{l}\text { Las personas que compran aquí están } \\
\text { bien consideradas. }\end{array}$} & $\begin{array}{l}\text { Pequeño } \\
\text { comercio }\end{array}$ & 254 & 3.18 & \multirow{3}{*}{$0.000 *$} \\
\hline & & $\begin{array}{l}\text { Gran centro } \\
\text { comercial }\end{array}$ & 262 & 2.21 & \\
\hline & & Total & 516 & 2.69 & \\
\hline \multirow{3}{*}{2} & \multirow{3}{*}{$\begin{array}{l}\text { Se obtiene cierto reconocimiento por } \\
\text { comprar en este tipo de comercio. }\end{array}$} & $\begin{array}{l}\text { Pequeño } \\
\text { comercio }\end{array}$ & 254 & 3.05 & \multirow{3}{*}{$0.000 *$} \\
\hline & & $\begin{array}{l}\text { Gran centro } \\
\text { comercial }\end{array}$ & 262 & 1.63 & \\
\hline & & Total & 516 & 2.33 & \\
\hline \multirow{3}{*}{3} & \multirow{3}{*}{$\begin{array}{l}\text { Considero positivo que la gente } \\
\text { compre en este tipo de comercio. }\end{array}$} & $\begin{array}{l}\text { Pequeño } \\
\text { comercio }\end{array}$ & 254 & 3.13 & \multirow{3}{*}{$0.000 *$} \\
\hline & & $\begin{array}{l}\text { Gran centro } \\
\text { comercial }\end{array}$ & 262 & 2.00 & \\
\hline & & Total & 516 & 2.56 & \\
\hline \multirow{3}{*}{4} & \multirow{3}{*}{$\begin{array}{l}\text { Pienso que el que compra en este tipo } \\
\text { de comercio tiene cierto nivel. }\end{array}$} & $\begin{array}{l}\text { Pequeño } \\
\text { comercio }\end{array}$ & 254 & 3.00 & \multirow{3}{*}{$0.000^{*}$} \\
\hline & & $\begin{array}{l}\text { Gran centro } \\
\text { comercial }\end{array}$ & 262 & 2.02 & \\
\hline & & Total & 516 & 2.50 & \\
\hline \multirow{3}{*}{5} & \multirow{3}{*}{$\begin{array}{l}\text { Me gusta que la gente me vea } \\
\text { comprando aquí. }\end{array}$} & $\begin{array}{l}\text { Pequeño } \\
\text { comercio }\end{array}$ & 254 & 2.84 & \multirow{3}{*}{$0.000 *$} \\
\hline & & $\begin{array}{l}\text { Gran centro } \\
\text { comercial }\end{array}$ & 262 & 1.48 & \\
\hline & & Total & 516 & 2.15 & \\
\hline \multirow{3}{*}{6} & \multirow{3}{*}{$\begin{array}{l}\text { Disfruto viendo a la gente comprando } \\
\text { en este tipo de establecimiento. }\end{array}$} & $\begin{array}{l}\text { Pequeño } \\
\text { comercio }\end{array}$ & 254 & 2.93 & \multirow{3}{*}{$0.000^{*}$} \\
\hline & & $\begin{array}{l}\text { Gran centro } \\
\text { comercial }\end{array}$ & 262 & 1.37 & \\
\hline & & Total & 516 & 2.14 & \\
\hline
\end{tabular}


En lo relativo a los resultados del valor hedónico percibido en función del tipo de establecimiento (Tabla 6.22) se puede apreciar que de nuevo, y como ya ocurría con la motivación hedónica de compra, no existen diferencias significativas en todos los ítems que la componen. Aunque, sin embargo, en esta ocasión las valoraciones significativamente superiores se producen en todos los casos entre los compradores del pequeño comercio urbano. Destaca el 3.52 en la valoración de "me siento a gusto comprando en este tipo de centro", frente al 2.99 de media en el gran centro comercial en el apartado de "me siento relajado en este tipo de establecimiento". Podríamos decir que si el comprador hedónicamente motivado tenía un carácter más universal, en la valoración de la experiencia de compra obtiene mejores valoraciones el pequeño comercio.

Tabla 6.22 - Valor emocional percibido por tipo de establecimiento.

\begin{tabular}{|c|c|c|c|c|c|}
\hline $\mathbf{N}^{\mathbf{0}}$ & Valor emocional percibido & Grupo & $\mathbf{N}$ & Media & Sig. \\
\hline \multirow{3}{*}{1} & \multirow{3}{*}{$\begin{array}{l}\text { Estoy contento/a con este tipo de } \\
\text { establecimiento. }\end{array}$} & $\begin{array}{l}\text { Pequeño } \\
\text { comercio }\end{array}$ & 254 & 3.57 & \multirow{3}{*}{0.579} \\
\hline & & $\begin{array}{c}\text { Gran centro } \\
\text { comercial }\end{array}$ & 262 & 3.61 & \\
\hline & & Total & 516 & 3.59 & \\
\hline \multirow{3}{*}{2} & \multirow{3}{*}{ En él me siento relajado/a. } & $\begin{array}{l}\text { Pequeño } \\
\text { comercio }\end{array}$ & 254 & 3.38 & \multirow{3}{*}{$0.000^{*}$} \\
\hline & & $\begin{array}{c}\text { Gran centro } \\
\text { comercial }\end{array}$ & 262 & 2.96 & \\
\hline & & Total & 516 & 3.17 & \\
\hline \multirow{3}{*}{3} & \multirow{3}{*}{$\begin{array}{l}\text { El personal me proporciona } \\
\text { sensaciones positivas. }\end{array}$} & $\begin{array}{l}\text { Pequeño } \\
\text { comercio }\end{array}$ & 254 & 3.48 & \multirow{3}{*}{$0.000^{*}$} \\
\hline & & $\begin{array}{c}\text { Gran centro } \\
\text { comercial }\end{array}$ & 262 & 3.13 & \\
\hline & & Total & 516 & 3.30 & \\
\hline
\end{tabular}




\begin{tabular}{|c|c|c|c|c|c|}
\hline $\mathbf{N}^{\mathbf{0}}$ & Valor emocional percibido & Grupo & $\mathbf{N}$ & Media & Sig. \\
\hline \multirow{3}{*}{4} & \multirow{3}{*}{ El personal no me agobia. } & $\begin{array}{l}\text { Pequeño } \\
\text { comercio }\end{array}$ & 254 & 3.50 & \multirow{3}{*}{0.857} \\
\hline & & $\begin{array}{c}\text { Gran centro } \\
\text { comercial }\end{array}$ & 262 & 3.52 & \\
\hline & & Total & 516 & 3.51 & \\
\hline \multirow{3}{*}{5} & \multirow{3}{*}{$\begin{array}{l}\text { En general me siento a gusto } \\
\text { comprando en este tipo de } \\
\text { establecimiento. }\end{array}$} & $\begin{array}{l}\text { Pequeño } \\
\text { comercio }\end{array}$ & 254 & 3.52 & \multirow{3}{*}{$0.031 *$} \\
\hline & & $\begin{array}{c}\text { Gran centro } \\
\text { comercial }\end{array}$ & 262 & 3.23 & \\
\hline & & Total & 516 & 3.42 & \\
\hline
\end{tabular}

(*) Existen diferencias significativas entre las valoraciones de los grupos.

A continuación presentamos los resultados de la satisfacción en función del tipo de establecimiento (Tabla 6.23). Se puede apreciar que no existen diferencias significativas en todos los apartados y que además, de nuevo, las valoraciones medias no son muy elevadas. Aunque, sin embargo, en nivel de satisfacción medio es superior en el pequeño comercio en todas aquellas cuestiones que sí son significativas. Destaca el 3.72 en la valoración de la información y atención percibida por los empleados en el pequeño comercio urbano, frente al 3.19 de media en el gran centro comercial. Por otro lado, si analizamos las cuestiones que no obtienen diferencias significativas, podemos ver que nos encontramos antes las cuestiones más generales de la satisfacción de compra. 
Tabla 6.23 - Satisfacción por tipo de establecimiento.

\begin{tabular}{|c|c|c|c|c|c|}
\hline $\mathbf{N}^{0}$ & Satisfacción & Grupo & $\mathbf{N}$ & Media & Sig. \\
\hline \multirow{3}{*}{1} & \multirow{3}{*}{$\begin{array}{l}\text { Estoy realmente satisfecho con este } \\
\text { tipo de establecimiento. }\end{array}$} & $\begin{array}{l}\text { Pequeño } \\
\text { comercio }\end{array}$ & 254 & 3.45 & \multirow{3}{*}{0.460} \\
\hline & & $\begin{array}{l}\text { Gran centro } \\
\text { comercial }\end{array}$ & 262 & 3.39 & \\
\hline & & Total & 516 & 3.42 & \\
\hline \multirow{3}{*}{2} & \multirow{3}{*}{$\begin{array}{c}\text { Estoy satisfecho con el servicio } \\
\text { proporcionado. }\end{array}$} & $\begin{array}{l}\text { Pequeño } \\
\text { comercio }\end{array}$ & 254 & 3.53 & \multirow{3}{*}{$0.000 *$} \\
\hline & & $\begin{array}{l}\text { Gran centro } \\
\text { comercial }\end{array}$ & 262 & 3.19 & \\
\hline & & Total & 516 & 3.36 & \\
\hline \multirow{3}{*}{3} & \multirow{3}{*}{$\begin{array}{c}\text { La respuesta a las cuestiones } \\
\text { planteadas sobre el producto/servicio } \\
\text { es eficiente. }\end{array}$} & $\begin{array}{l}\text { Pequeño } \\
\text { comercio }\end{array}$ & 254 & 3.72 & \multirow{3}{*}{$0.000 *$} \\
\hline & & $\begin{array}{l}\text { Gran centro } \\
\text { comercial }\end{array}$ & 262 & 3.17 & \\
\hline & & Total & 516 & 3.44 & \\
\hline \multirow{3}{*}{4} & \multirow{3}{*}{$\begin{array}{l}\text { En mi última compra resolvieron } \\
\text { todas mis dudas y cuestiones. }\end{array}$} & $\begin{array}{l}\text { Pequeño } \\
\text { comercio }\end{array}$ & 254 & 3.65 & \multirow{3}{*}{$0.006^{*}$} \\
\hline & & $\begin{array}{l}\text { Gran centro } \\
\text { comercial }\end{array}$ & 262 & 3.42 & \\
\hline & & Total & 516 & 3.53 & \\
\hline \multirow{3}{*}{5} & \multirow{3}{*}{$\begin{array}{l}\text { En mi última compra encontré una } \\
\text { solución adecuada a mis necesidades. }\end{array}$} & $\begin{array}{l}\text { Pequeño } \\
\text { comercio }\end{array}$ & 254 & 3.59 & \multirow{3}{*}{0.694} \\
\hline & & $\begin{array}{l}\text { Gran centro } \\
\text { comercial }\end{array}$ & 262 & 3.55 & \\
\hline & & Total & 516 & 3.57 & \\
\hline 6 & $\begin{array}{l}\text { Se cumplieron las expectativas que } \\
\text { tenía puestas en el establecimiento. }\end{array}$ & $\begin{array}{l}\text { Pequeño } \\
\text { comercio }\end{array}$ & 254 & 3.52 & $0.001 *$ \\
\hline
\end{tabular}




\begin{tabular}{|c|c|c|c|c|c|}
\hline $\mathbf{N}^{\mathbf{o}}$ & Satisfacción & Grupo & $\mathbf{N}$ & Media & Sig. \\
\hline & & $\begin{array}{c}\text { Gran centro } \\
\text { comercial }\end{array}$ & 262 & 3.22 & \\
\hline & & Total & 516 & 3.37 & \\
\hline \multirow{3}{*}{7} & \multirow{3}{*}{$\begin{array}{l}\text { En general, el proceso de compra fue } \\
\text { satisfactorio. }\end{array}$} & $\begin{array}{l}\text { Pequeño } \\
\text { comercio }\end{array}$ & 254 & 3.69 & \multirow{3}{*}{0.106} \\
\hline & & $\begin{array}{l}\text { Gran centro } \\
\text { comercial }\end{array}$ & 262 & 3.56 & \\
\hline & & Total & 516 & 3.62 & \\
\hline
\end{tabular}

(*) Existen diferencias significativas entre las valoraciones de los grupos.

En cuanto a los resultados de lealtad del consumidor en función del establecimiento de compra (Tabla 6.24) se puede apreciar que tampoco existen diferencias significativas en todos los apartados. Por un lado las valoraciones son poco elevadas, sin superar el 3,5 de valoración media. Aunque, sin embargo, en aquellos apartados significativamente diferentes, destaca el pequeño comercio urbano. Destaca el 3,45 de valoración media entre los compradores del pequeño comercio en apartado "cuando necesito un producto determinado acudo a este tipo de centro", frente al 2,32 del mismo ítem entre los grandes centros comerciales. Por otro, en la búsqueda de orientación e información obtiene mejores resultados el pequeño comercio $(3,33)$ frente al gran centro comercial $(2,37)$.

Tabla 6.24 - Lealtad por tipo de establecimiento.

\begin{tabular}{|c|c|c|c|r|c|}
\hline $\mathbf{N}^{\mathbf{0}}$ & Lealtad & Grupo & N & Media & Sig. \\
\hline \multirow{3}{*}{1} & \begin{tabular}{c} 
Intento acudir a este tipo de \\
\cline { 3 - 5 }
\end{tabular} & $\begin{array}{c}\text { Pequeño } \\
\text { comercio }\end{array}$ & 254 & 3.52 & \\
\cline { 3 - 5 } & $\begin{array}{c}\text { establecimiento cada vez que necesito } \\
\text { o deseo ir de compras. }\end{array}$ & $\begin{array}{c}\text { Gran centro } \\
\text { comercial }\end{array}$ & 262 & 3.45 & \multirow{2}{*}{0.416} \\
\cline { 2 - 5 } & Total & 516 & 3.49 & \\
\cline { 2 - 5 } & & &
\end{tabular}




\begin{tabular}{|c|c|c|c|c|c|}
\hline $\mathbf{N}^{\mathbf{O}}$ & Lealtad & Grupo & $\mathbf{N}$ & Media & Sig. \\
\hline \multirow{3}{*}{2} & \multirow{3}{*}{$\begin{array}{l}\text { Considero este tipo de establecimiento } \\
\text { como mi opción principal de compras. }\end{array}$} & $\begin{array}{l}\text { Pequeño } \\
\text { comercio }\end{array}$ & 254 & 3.25 & \multirow{3}{*}{0.057} \\
\hline & & $\begin{array}{l}\text { Gran centro } \\
\text { comercial }\end{array}$ & 262 & 3.08 & \\
\hline & & Total & 516 & 3.16 & \\
\hline \multirow{3}{*}{3} & \multirow{3}{*}{$\begin{array}{l}\text { Acudo a este tipo de establecimiento } \\
\text { cuando busco obtener información } \\
\text { sobre algún producto que me interesa. }\end{array}$} & $\begin{array}{l}\text { Pequeño } \\
\text { comercio }\end{array}$ & 254 & 3.33 & \multirow{3}{*}{$0.000 *$} \\
\hline & & $\begin{array}{l}\text { Gran centro } \\
\text { comercial }\end{array}$ & 262 & 2.37 & \\
\hline & & Total & 516 & 2.84 & \\
\hline \multirow{3}{*}{4} & \multirow{3}{*}{$\begin{array}{l}\text { Cuando necesito un producto } \\
\text { determinado acudo a este tipo de } \\
\text { centro. }\end{array}$} & $\begin{array}{l}\text { Pequeño } \\
\text { comercio }\end{array}$ & 254 & 3.45 & \multirow{3}{*}{$0.000 *$} \\
\hline & & $\begin{array}{l}\text { Gran centro } \\
\text { comercial }\end{array}$ & 262 & 2.32 & \\
\hline & & Total & 516 & 2.88 & \\
\hline
\end{tabular}

$\left.{ }^{*}\right)$ Existen diferencias significativas entre las valoraciones de los grupos

Una vez realizado el estudio del perfil de la muestra y el análisis descriptivo de los datos obtenidos, podemos concluir que es la segmentación de la muestra atendiendo al tipo de establecimiento en el que realizó la compra (pequeño comercio urbano o gran centro comercial) ha sido adecuada ya que se obtienen diferencias significativas en sus diferentes valores, y al mismo tiempo aparecen datos relevantes en su caracterización sociodemográfica.

Los clientes que realizaron sus compras en el pequeño comercio urbano parecen tener un nivel formativo más elevado, así como también un nivel de ingresos mensuales algo superiores. Se trata de un grupo de hogares más reducidos en general, con un porcentaje inferior de niños en el mismo si lo comparamos con los hogares del gran centro comercial. En general, estos compradores habitan en poblaciones grandes, de lo que se 
desprende que evitan el desplazamiento a las afueras de las ciudades donde suelen localizarse los grandes centros comerciales. El gasto mensual medio en moda y complementos es también superior en este grupo de encuestados. En cuanto a la motivación de compra en este tipo de establecimiento podemos afirmar que obtenemos valoraciones absolutas superiores en la dimensión ética y en ciertos aspectos del factor hedónico y de disfrute. En lo relativo al valor percibido de la compra, los resultados siguen la misma línea obteniendo valoraciones superiores en los aspectos éticos y mejorando también dichas valores en los aspectos hedónicos. Se trata además del grupo con valoraciones significativamente más altas en satisfacción y lealtad.

Por su parte, los compradores que realizaron sus compras en el gran centro comercial responden a un perfil de familia más amplía y con niños. Aunque parece apreciarse un nivel de ingresos mensuales algo inferior, así como también el nivel de estudios superado. El gasto mensual en moda y complementos es en la gran mayoría de los casos (95\%) inferior a 150 euros mensuales. En general, su motivación de copra obtiene valoraciones absolutas superiores en todos los apartados de la dimensión utilitarista, así como posteriormente en el mismo valor percibido. En cuanto a la motivación hedónica, obtienen valoraciones significativamente inferiores a las de los compradores del pequeño comercio urbano, así como también sucede en los apartados de satisfacción y lealtad.

De este modo, en el próximo apartado se presentará el análisis de las relaciones causales y el contraste de las hipótesis planteadas para el modelo general, el modelo propuesto para el pequeño comercio urbano y el modelo del gran centro comercial. 


\subsection{ANÁlisis DE LAS RELACIONES CAUSALES DEL MODELO ESTRUCTURAL Y CONTRASTE DE LAS HIPÓTESIS}

Siguiendo la metodología del enfoque de dos etapas (two-step) de Anderson y Gerbing (1988), una vez realizada la estimación del modelo de medición, procedemos a estimar el modelo estructural, a través de la aplicación del análisis path con variables latentes (Jöreskog y Sörbom 1996), con el objetivo de contrastar las hipótesis teóricas planteadas. En la Figura 6.1 y en la tabla 6.25 se muestra el resultado del modelo estructural general, el ajuste del modelo es adecuado ya que la probabilidad asociada al estadístico chicuadrado es superior a $0,05(0,113810)$. A continuación se analizan los efectos de las variables incluidas en el modelo.

Una vez presentados los resultados del modelo general, serán expuestos los modelos específicos para el pequeño comercio urbano y para el gran centro comercial. Del mismo modo que en apartado general, serán expuestas sus estimaciones y se contrastaran las hipótesis planteadas para estos dos casos específicos.

\section{La motivación de compra y el valor percibido}

La primera de las relaciones planteadas en las hipótesis del trabajo basa en la influencia que ejerce la motivación de compra sobre el valor percibido. Ambas variables están formadas por tres dimensiones. Por consiguiente, tal y como se desprendía de la revisión de la literatura realizada, un comportamiento motivado ejerce cierta influencia en la valoración de la experiencia de compra en la dimensión a la que la misma hace referencia.

En primer lugar destaca la motivación de compra hedónica, como la dimensión que mayor influencia ejerce sobre la variable experiencial de compra hedónica $(0,75)$. A continuación es la motivación ética la que presenta efecto más destacable sobre el valor ético percibido en la compra $(0,70)$. Finalmente, con un peso algo inferior encontramos el efecto de la motivación utilitarista de compra sobre el valor utilitarista percibido $(0,45)$. 
En consecuencia, este análisis permite ratificar el cumplimiento de la segunda de las hipótesis de trabajo donde según la línea de los trabajos de Fodness 1994, Gnoth 1997 Williams 2004, Duman y Mattila 2005, Prebensen et al. 2012 y Kim et al. 2013, la motivación de compra del consumidor tiene un efecto directo y positivo sobre el valor percibido en la compra.

\section{EI valor percibido por el consumidor y la satisfacción.}

En la tercera hipótesis planteada se consideraba la influencia del valor percibido sobre la satisfacción de consumidor. En la Figura 6.1 se aprecia como el valor percibido sí tiene efectos positivos y directos sobre la variable afectiva. Sin embargo, es la dimensión hedónica del valor percibido $(0,64)$ aquella que tiene un mayor efecto sobre la satisfacción del consumidor, así como ya sucedía en la relación motivación-valor percibido. A continuación, es el valor utilitarista aquel que ejerce el segundo mayor efecto sobre la satisfacción $(0,39)$. En tercer lugar, el valor ético con un efecto de 0,39 sobre la satisfacción de compra.

\section{La satisfacción y la lealtad}

La cuarta hipótesis del trabajo se planteaba la relación entre la satisfacción y la lealtad o intención de recompra. De los resultados obtenidos se determina que existe una fuerte relación entre la satisfacción de compra y la lealtad en el modelo general $(0,73)$, algo que en la literatura aparece con cierto consenso preestablecido (Martínez-Ribes, de Borja y Carvajal, 1999; Butcher, Sparks y O'Callaghan, 2001; Bloemer y Odekerken-Schröeder, 2002; Callarisa, 2004; Caruana y Fenech, 2005; Hess y Store, 2005). 
Figura 6.1 - Contrastación modelo general

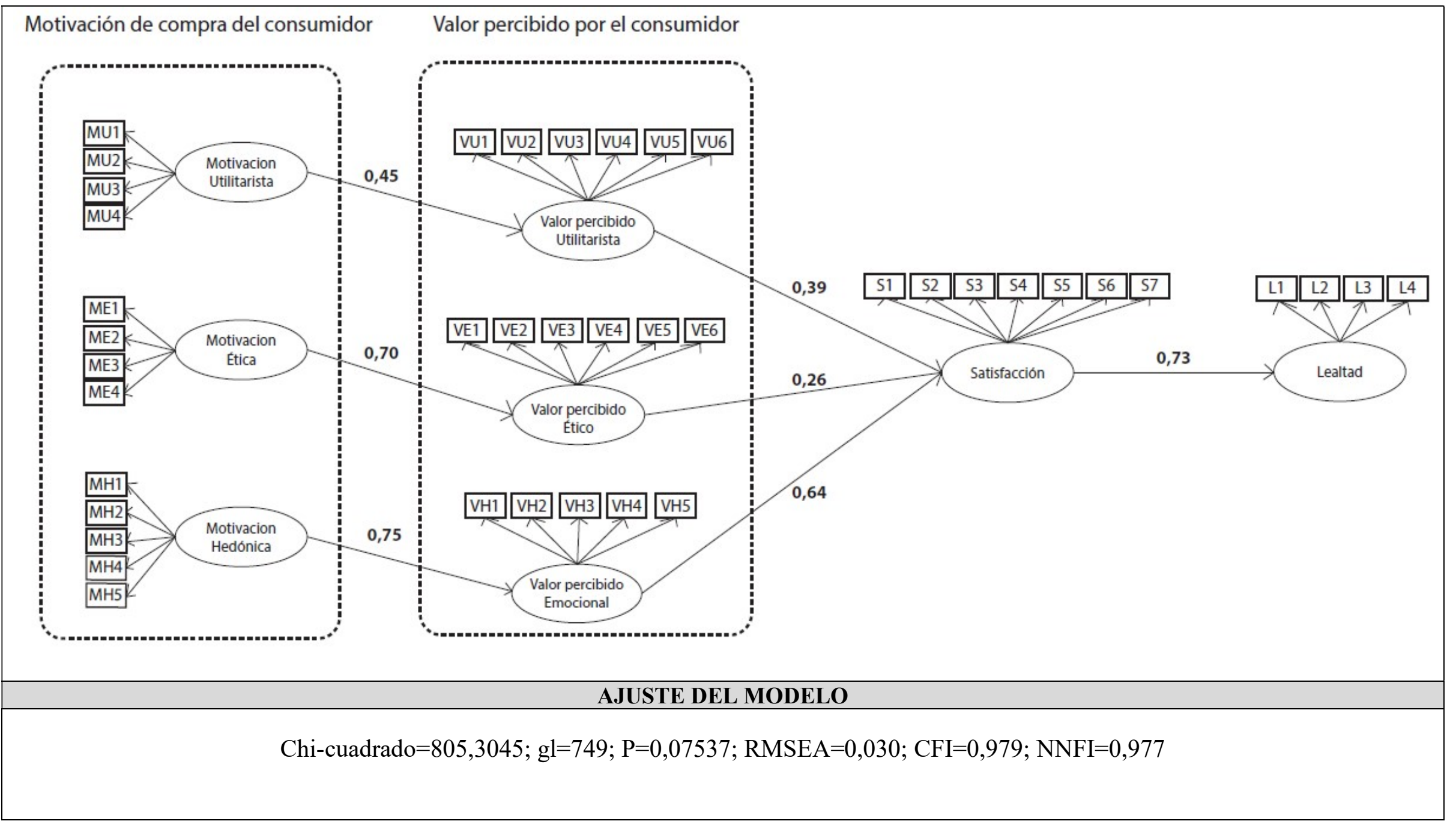

* Relaciones causales no significativas $(\mathrm{T}<1,96)$. 
Tabla 6.25 - Relaciones causales y contrastes de hipótesis I

\begin{tabular}{|l|c|c|c|}
\hline RELACIONES CAUSALES & $\begin{array}{c}\text { VALOR } \\
\text { RELACIÓN }\end{array}$ & T & Hipótesis \\
\hline $\begin{array}{l}\text { Motivación utilitarista } \rightarrow \text { Valor } \\
\text { utilitarista percibido }\end{array}$ & 0,45 & 9,96 & H2a $\square$ \\
\hline $\begin{array}{l}\text { Motivación ética } \rightarrow \text { Valor ético } \\
\text { percibido }\end{array}$ & 0,70 & 25,37 & H2b $\square$ \\
\hline $\begin{array}{l}\text { Motivación hedónica } \rightarrow \text { Valor } \\
\text { emocional percibido }\end{array}$ & 0,75 & 18,34 & H2c $\square$ \\
\hline $\begin{array}{l}\text { Valor utilitarista percibido } \rightarrow \\
\text { Satisfacción }\end{array}$ & 0,39 & 11,08 & H3a $\square$ \\
\hline $\begin{array}{l}\text { Valor ético percibido } \rightarrow \\
\text { Satisfacción }\end{array}$ & 0,26 & 10,40 & H3b $\square$ \\
\hline $\begin{array}{l}\text { Valor hedónico percibido } \rightarrow \\
\text { Satisfacción }\end{array}$ & 0,73 & 21,02 & H4 $\square$ \\
\hline Satisfacción $\rightarrow$ Lealtad
\end{tabular}

(*) Relaciones causales no significativas $(\mathrm{T}<1,96)$. 


\subsubsection{Modelo estructural: pequeño comercio urbano}

Una vez presentados los resultados del modelo general, serán expuestos los modelos específicos para el pequeño comercio urbano y para el gran centro comercial. Del mismo modo que en apartado general, serán expuestas sus estimaciones y se contrastaran las hipótesis planteadas para estos dos casos específicos.

A continuación presentamos el modelo estructural para la motivación de compra y sus efectos en el pequeño comercio urbano. En la Figura 6.2 y en la tabla 6.26 se muestra el resultado del modelo estructural general, el ajuste del modelo es adecuado ya que la probabilidad asociada al estadístico chi-cuadrado es superior a 0,05 $(0,07)$. En las próximas líneas se analizan los efectos de las variables incluidas en el modelo.

\section{La motivación de compra y el valor percibido}

La primera de las relaciones planteadas en las hipótesis del trabajo se basa en la influencia que ejerce la motivación de compra sobre el valor percibido. Ambas variables están formadas por tres dimensiones. Por consiguiente, tal y como se desprendía de la revisión de la literatura realizada, un comportamiento motivado ejerce cierta influencia en la valoración de la experiencia de compra en la dimensión a la que la misma hace referencia.

En primer lugar, para el caso del pequeño comercio urbano, destaca la motivación ética de compra como la dimensión que mayor influencia ejerce sobre la variable experiencial de compra ética $(0,79)$. A continuación es la motivación hedónica aquella que presenta el efecto más destacable sobre el valor hedónico percibido en la compra $(0,68)$. Finalmente, con un peso algo inferior encontramos el efecto de la motivación utilitarista de compra sobre el valor utilitarista percibido $(0,21)$. En esta segunda hipótesis de trabajo, si la comparamos con el resultado del modelo general, destaca el peso de la 
motivación ética compra sobre el valor ético, que pasa de ser la segunda relación más fuerte a ser la primera.

\section{El valor percibido por el consumidor y la satisfacción.}

En la tercera hipótesis planteada se consideraba la influencia del valor percibido sobre la satisfacción de consumidor. En la Figura 6.2 se aprecia como el valor percibido sí tiene efectos positivos y directos sobre la variable afectiva. En este sentido, es curioso que la relación el efecto más fuerte se genere desde el valor hedónico hacia la satisfacción $(0,68)$. A continuación, es el valor utilitarista $(0,43)$ el que ocupa el segundo puesto en cuanto al peso de la relación. Finalmente, la relación del valor ético con la satisfacción $(0,13)$.

En esta ocasión, el orden de las relaciones en cuanto a su peso no difiere de las establecidas en el modelo general.

\section{La satisfacción y la lealtad}

La cuarta hipótesis del trabajo se planteaba la relación entre la satisfacción y la lealtad o intención de recompra. De los resultados obtenidos se determina que existe una fuerte relación entre la satisfacción de compra y la lealtad en el modelo general $(0,70)$, algo que en la literatura aparece con cierto consenso preestablecido (Martínez-Ribes, de Borja y Carvajal, 1999; Butcher, Sparks y O'Callaghan, 2001; Bloemer y Odekerken-Schröeder, 2002; Callarisa, 2004; Caruana y Fenech, 2005; Hess y Store, 2005). 
Figura 6.2 - Contrastación modelo pequeño comercio urbano

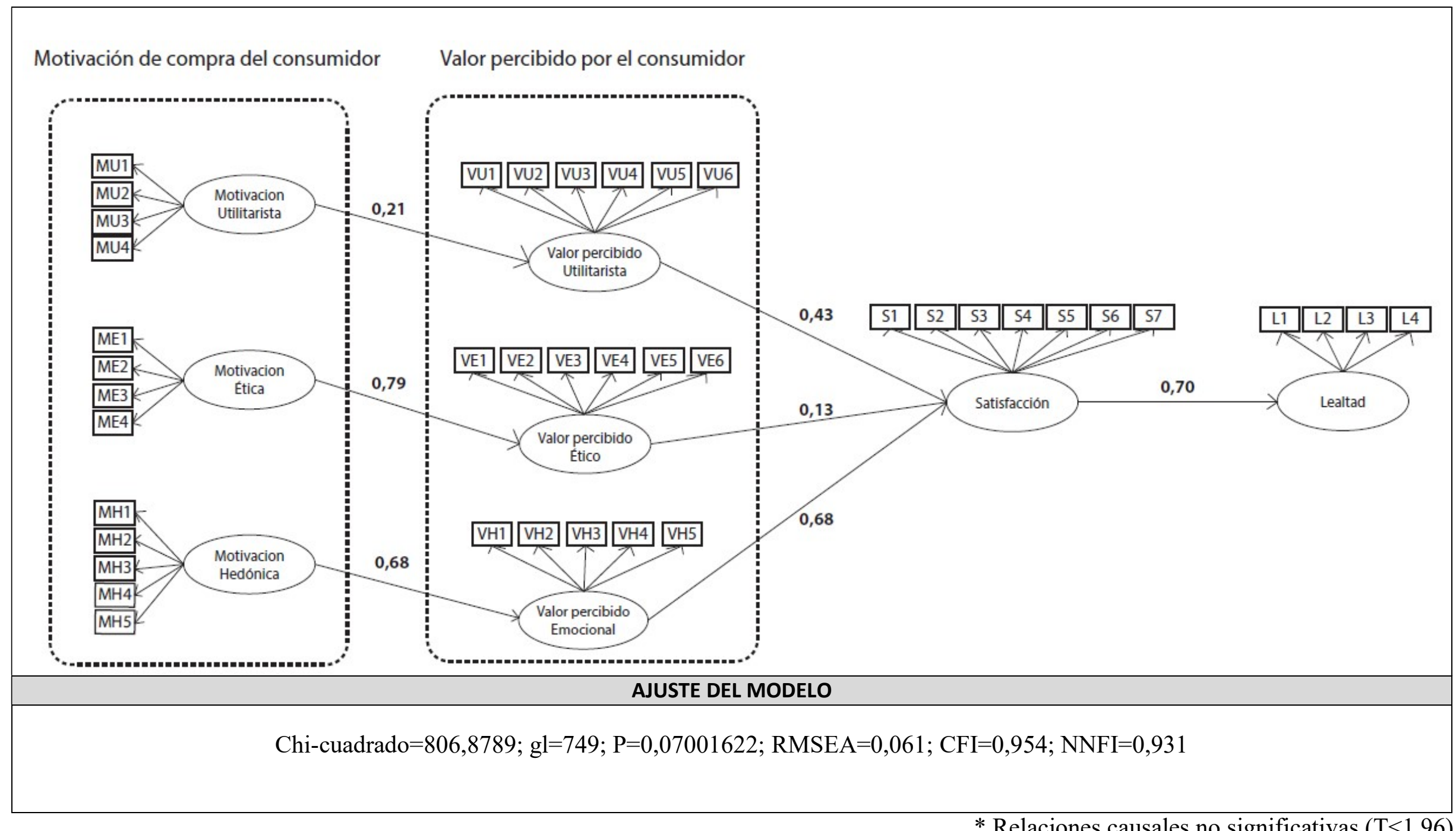

* Relaciones causales no significativas $(\mathrm{T}<1,96)$ 
Tabla 6.26 - Relaciones causales y contrastes de hipótesis II

\begin{tabular}{|l|c|c|c|}
\hline RELACIONES CAUSALES & $\begin{array}{c}\text { VALOR } \\
\text { RELACIÓN }\end{array}$ & T & Hipótesis \\
\hline $\begin{array}{l}\text { Motivación utilitarista } \rightarrow \text { Valor } \\
\text { utilitarista percibido }\end{array}$ & 0,21 & 3,51 & H2a $\square$ \\
\hline $\begin{array}{l}\text { Motivación ética } \rightarrow \text { Valor ético } \\
\text { percibido }\end{array}$ & 0,79 & 9,80 & H2b $\square$ \\
\hline $\begin{array}{l}\text { Motivación hedónica } \rightarrow \text { Valor } \\
\text { hedónico percibido }\end{array}$ & 0,68 & 12,91 & H2c $\square$ \\
\hline $\begin{array}{l}\text { Valor utilitarista percibido } \rightarrow \\
\text { Satisfacción }\end{array}$ & 0,43 & 8,39 & H3a $\square$ \\
\hline $\begin{array}{l}\text { Valor ético percibido } \rightarrow \\
\text { Satisfacción }\end{array}$ & 0,13 & 3,48 & H3b $\square$ \\
\hline $\begin{array}{l}\text { Valor emocional percibido } \rightarrow \\
\text { Satisfacción }\end{array}$ & 0,70 & 9,93 & H3c $\square$ \\
\hline Satisfacción $\rightarrow$ Lealtad & 10,39 & H4 \\
\hline
\end{tabular}

(*) Relaciones causales no significativas $(\mathrm{T}<1,96)$ 


\subsubsection{Modelo estructural: gran centro comercial}

Una vez presentados los resultados del modelo general y los resultados del modelo del pequeño comercio, será expuesto a continuación el modelos específico para el para el gran centro comercial. Del mismo modo que en apartado general, serán expuestas sus estimaciones y se contrastaran las hipótesis planteadas para estos dos casos específicos.

En la Figura 6.3 y en la tabla 6.27 se muestra el resultado del modelo estructural general, el ajuste del modelo es adecuado ya que la probabilidad asociada al estadístico chi-cuadrado es superior a 0,05 (0,085). En las próximas líneas se analizan los efectos de las variables incluidas en el modelo.

\section{La motivación de compra y el valor percibido}

La primera de las relaciones planteadas en las hipótesis del trabajo se basa en la influencia que ejerce la motivación de compra sobre el valor percibido. Ambas variables están formadas por tres dimensiones. Por consiguiente, tal y como se desprendía de la revisión de la literatura realizada, un comportamiento motivado ejerce cierta influencia en la valoración de la experiencia de compra en la dimensión a la que la misma hace referencia.

En primer lugar, para el caso del gran centro comercial, destaca la motivación utilitarista de compra como la dimensión que mayor influencia ejerce sobre la variable experiencial de compra utilitarista $(0,94)$. A continuación, sorprendentemente, es la motivación ética aquella que presenta el efecto más destacable sobre el valor ético percibido en la compra $(0,68)$. Finalmente, encontramos el efecto de la motivación hedónica de compra sobre el valor hedónico percibido $(0,65)$. En esta segunda hipótesis de trabajo, si la comparamos con el resultado del modelo general, destaca el peso de la motivación utilitarista compra sobre el valor utilitarista, que pasa de ser la tercera relación más fuerte a ser la primera. 


\section{El valor percibido por el consumidor y la satisfacción.}

En la tercera hipótesis planteada se consideraba la influencia del valor percibido sobre la satisfacción de consumidor. En la Figura 6.3 se aprecia como el valor percibido sí tiene efectos positivos y directos sobre la variable afectiva. En este sentido, la relación con el efecto más fuerte se genera entre el valor hedónico de la compra hacia la satisfacción $(0,55)$. A continuación, es el valor utilitarista $(0,49)$ el que ocupa el segundo puesto en cuanto al peso de la relación. Finalmente, destacar la no significatividad del efecto del valor ético sobre la satisfacción.

En esta ocasión, aparece una relación no significativa, y además, no es aquella dimensión que mayor efecto ejerce sobre el valor percibido aquella que mayor efecto ejerce al mismo tiempo sobre la satisfacción.

\section{La satisfacción y la lealtad}

La cuarta hipótesis del trabajo se planteaba la relación entre la satisfacción y la lealtad o intención de recompra. De los resultados obtenidos se determina que existe una fuerte relación entre la satisfacción de compra y la lealtad en el modelo general $(0,68)$, algo que en la literatura aparece con cierto consenso preestablecido (Martínez-Ribes, de Borja y Carvajal, 1999; Butcher, Sparks y O'Callaghan, 2001; Bloemer y Odekerken-Schröeder, 2002; Callarisa, 2004; Caruana y Fenech, 2005; Hess y Store, 2005). 
Figura 6.3 Contrastación modelo gran centro comercial

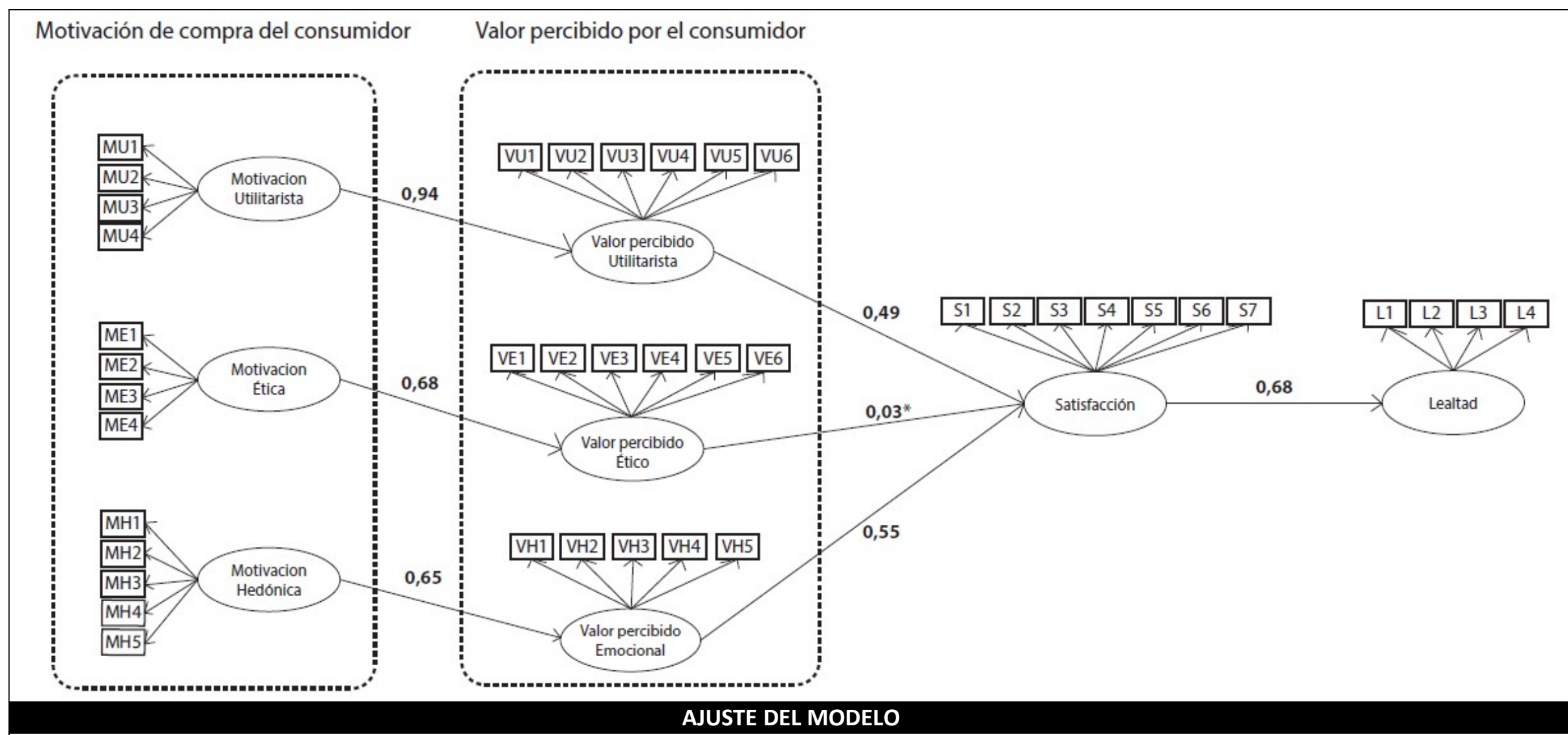

Chi-cuadrado=802,6204; $\mathrm{gl}=749 ; \mathrm{P}=0,085222153 ; \mathrm{RMSEA}=0,052 ; \mathrm{CFI}=0,961 ; \mathrm{NNFI}=0,953$

* Relaciones causales no significativas $(\mathrm{T}<1,96)$ 
Tabla 6.27 - Relaciones causales y contrastes de hipótesis III

\begin{tabular}{|l|c|c|c|}
\hline RELACIONES CAUSALES & $\begin{array}{c}\text { VALOR } \\
\text { RELACIÓN }\end{array}$ & T & Hipótesis \\
\hline $\begin{array}{l}\text { Motivación utilitarista } \rightarrow \text { Valor } \\
\text { utilitarista percibido }\end{array}$ & 0,94 & 18,62 & H2a $\square$ \\
\hline $\begin{array}{l}\text { Motivación ética } \rightarrow \text { Valor ético } \\
\text { percibido }\end{array}$ & 0,68 & 16,51 & H2b $\square$ \\
\hline $\begin{array}{l}\text { Motivación hedónica } \rightarrow \text { Valor } \\
\text { hedónico percibido }\end{array}$ & 0,65 & 12,66 & H2c $\square$ \\
\hline $\begin{array}{l}\text { Valor utilitarista percibido } \rightarrow \\
\text { Satisfacción }\end{array}$ & 0,49 & 8,61 & H3a $\square$ \\
\hline $\begin{array}{l}\text { Valor ético percibido } \rightarrow \\
\text { Satisfacción }\end{array}$ & 0,03 & $0,64 *$ & H3b $\mathbf{~}$ \\
\hline $\begin{array}{l}\text { Valor emocional percibido } \rightarrow \\
\text { Satisfacción }\end{array}$ & 0,68 & 21,02 & H3c $\square$ \\
\hline Satisfacción $\rightarrow$ Lealtad
\end{tabular}

(*) Relaciones causales no significativas $(\mathrm{T}<1,96)$. 

CAPÍTULO 7. CONCLUSIONES 



\section{CAPÍTULO 7. CONCLUSIONES}

En el presente capítulo se presentan las principales aportaciones del trabajo, tanto a nivel teórico como empírico. En este sentido, se presentan, en primer lugar, las conclusiones generales del estudio realizado, y en dos puntos siguientes se trata de ofrecer una aplicación a la realidad de la gestión diaria del pequeño comercio urbano. Para finalizar presentamos las limitaciones encontradas al trabajo y mostramos las principales líneas de investigación que pretendemos acometer en el futuro.

\subsection{CONCLUSIONES}

Los pequeños comercios urbanos tradicionales sufren en su actividad diaria el peso de la elevada competencia que caracteriza el sector, la fuerza de los grandes formatos minoristas a nivel regional, nacional o internacional se expande continuamente (Noble, Griffith y Adjei 2006; Cadeaux y Dubelaar 2012). En este sentido, si tenemos en cuenta el papel de este tipo de comercios como catalizadores de la economía local y el empleo, se pone de manifiesto la necesidad de proporcionar ayuda o soporte a este tipo de formatos para en cierto modo contribuir al cierre masivo de establecimientos e intentar mejorar los resultados comerciales. Y este ha sido, a grandes rasgos, el punto de partida de la presente tesis doctoral, contribuir al sustento del pequeño comercio urbano.

En esta línea, el marketing transaccional tradicional, con su perspectiva cortoplacista y su enfoque centrado en las características del producto y las transacciones individuales, es cada vez más discordante con el entorno altamente competitivo en el que hoy en día se mueven las empresas (De Wulf. et al. 2001, Christopher, Payne y Ballantyne 2002, Zineldin y Philipson 2007, Palmatier et al. 2009, Alrubaiee y Al-Nazer 2010, Hau y Ngo 2012, Huang 2015, Yoganathan, Jebarajakirthy y Traichon 2015). 
Añadiendo el hecho que estos pequeños negocios, más tradicionales, están evolucionando gradualmente y a lento paso hacia un marketing relacional, centrado en la atracción de clientes y en el aporte de un valor añadido (Badi, Wang y Prike 2016). Este enfoque de marketing relacional, por lo tanto, se centra en mantener relaciones a largo plazo mutuamente beneficiosas entre compradores y vendedores (Spekman y Carraway 2006). Es decir, en alcanzar la lealtad de los consumidores hacia el establecimiento, lo cual representa un objetivo a alcanzar.

En la tarea de analizar esa relación encaminada a la obtención de la lealtad de los consumidores, centramos nuestra atención en el punto de partida más inicial del proceso de compra: la motivación de compra.

La motivación de compra es definida por tanto como un proceso interno o condición que activa o desencadena el comportamiento, le da dirección hacia un objetivo Atkinson 1964; Kleinginna y Kleinginna 1981; Park y Mittal 1985; Robbins 2003, Solomon y Rabolt 2006; Franken 2006; Schunk et al. 2008; Schiffman y Kanuk 2009; Devesa et al. 2010; Reeve 2010; Solomon et al. 2013, Reeve 2014; Evans 2014; Hoffman 2015). A nivel empírico hemos contrastado que la motivación de compra del consumidor es un constructo multidimensional formado por tres dimensiones: motivación utilitarista, motivación hedónica y motivación ética.

En lo que respecta a la dimensionalidad de la variable, la motivación utilitarista de compra hace referencia a la parte más racional de la variable motivación, recogiendo los aspectos cognitivos y funcionales del comportamiento del consumidor. Por lo tanto, el comportamiento del consumidor utilitarista puede ser descrito como un enfoque racional que implica o se relaciona con una compra que se realiza de manera eficiente, incluso si la realización de la misma no proporciona ninguna diversión (Babin et al., 2004). Es valorada la consecución de los objetivos comerciales preestablecidos, así como la comodidad de la compra. 
La motivación hedónica, en cambio, evalúa los aspectos como la emoción, la excitación, la alegría o la aventura que rodean a la compra. Mide la relevancia del disfrute y de la interacción social, aspectos puramente afectivos. Los motivos de compra hedónicos son similares a los utilitaristas, la diferencia se presenta en la naturaleza de la "tarea" a realizar. En esta ocasión, el objetivo es experimentar diversión, fantasía y estimulación sensorial, en lugar de una consecución eficiente y rápida de la meta en cuestión (Babin et al., 1994).

La motivación ética responde al apartado moral que se asocia a la compra. Esta dimensión hace referencia además las personas que han intervenido o intervendrán en que ese producto o servicio llegue a manos del consumidor (Strong 1996). Los consumidores éticamente motivados tienen en cuenta si el negocio promueve la inclusión de empleados que pertenecen a minorías étnicas o grupos desfavorecidos, como las personas mayores o las personas con discapacidad.

Sin embargo, la motivación de compra se define, como bien hemos remarcado anteriormente, como una disposición interna o condición que es previa a la experiencia de compra. Y no es hasta que el consumidor vive la experiencia de compra cuando se presenta el primer "juicio" entre aquello que se había generado en su mente y que la había movido a seleccionar un tipo de establecimiento es realmente consecuente con aquello que ha percibido.

En este sentido, el valor percibido por el consumidor que representa la evaluación global que realiza el individuo de su experiencia de compra. Estas evaluaciones, que se realizan tanto a nivel cognitivo como afectivo al igual que sucede con la motivación, son valoraciones primarias derivadas de la observación y experiencia directa del individuo. A nivel empírico hemos contrastado que el valor percibido por el consumidor está formado por un constructo multidimensional, que se compone por tres dimensiones; una de base cognitiva y dos de naturaleza más afectiva. 
La dimensión del valor utilitarista percibido hace referencia a aspectos cognitivos, como son la valoración de las instalaciones de la entidad, la facilidad de localización y acceso, el coste asociado a acudir a un tipo de establecimiento determinado, así como trato del personal de atención. Como vemos, se trata de un conjunto de aspectos que intentan medir en general la facilidad y efectividad de compra, pues se trata de valores puramente utilitaristas orientados a la consecución de un objetivo práctico.

En cuanto a la parte afectiva del valor percibido, ésta se divide en dos dimensiones. Una primera emocional que recoge los sentimientos que el cliente experimenta en su experiencia compra. En este apartado cobra especial importancia las cualidades interpersonales del personal de atención, ya que el consumidor valora que no lo agobien, que le traten bien, que le faciliten la vida y en general que le proporcionen sensaciones positivas. Todo esto propiciará que el individuo se sienta a gusto en el establecimiento y esté, a nivel general, contento.

Por su parte el valor ético es la segunda de las dimensiones afectivas (con cierto componente moral) del valor percibido. Esta dimensión recoge la influencia que puede tener el entorno más inmediato del consumidor en su percepción de valor. En este apartado el individuo valora tanto la aprobación social que posee ese tipo de establecimiento, como la que cree que tendrá él por ser realizar sus compras en el mismo. Es un aspecto que el comprador valora y tiene en cuenta a la hora de elegir su establecimiento de compra.

En definitiva, podemos decir que de las evaluaciones de estas tres dimensiones de la experiencia de compra del consumidor en el tipo de establecimiento minorista el nivel de satisfacción que se forme el individuo y lealtad hacia el comercio.

En este sentido, y ya encaminando este primer apartado experiencial hacia la consecución de la lealtad, Oliver (1996) define la satisfacción como un estado placentero 
que experimenta el consumidor. Este estado es consecuencia del juicio positivo de los aspectos obtenidos del consumo de un bien o servicio. En el presente trabajo hemos esta conceptualización y nos referiremos a la satisfacción global o acumulada que se forma a lo largo del tiempo y que supone un proceso de aprendizaje y recuerdo de todas las transacciones previas (Garbarino y Johnson 1999; Sharma, Niedrich y Dobbins 1999; Devesa et al. 2010; Yoon et al. 2010; Soon et al. 2013).

Es decir, la satisfacción de compra del consumidor, se ha concebido tradicionalmente como la confirmación de las expectativas (Yi, 1990; Fornell, 1992; Oliver, 1993; Coelho y Machás, 2004). Este paradigma dominante afirma que los consumidores tienen estándares de comparación previos al consumo, y que observando el desempeño del mismo y comparándolo con dichos estándares se forman las percepciones de satisfacción. Estos estándares se refieren a información anterior referida a "lo que el consumidor espera que ocurra" en el comercio en base a su experiencia previa.

En el apartado final del modelo, encontramos la lealtad como herramienta de medición de la obtención de resultados comerciales. La lealtad según Oliver (1999) se define como un compromiso profundo de recompra de un producto o servicio preferido, por consiguiente causará repetición de compra de la misma marca. Aunque influencias del entorno y esfuerzos de marketing tienen el potencial de provocar un comportamiento de cambio (Butcher, Sparks y O'Callaghan 2001; Caruana 2004; Yi y La 2004; Caruana y Fenech 2005).

Los consumidores forman su sentimiento de lealtad primero en una valoración cognitiva, que posteriormente genera un estado afectivo favorable hacia el proveedor de servicios. Este afecto genera, posteriormente una intención de recompra que finalmente se materializa en el comportamiento de recompra propiamente dicho (Oliver 1996; Macintosh y Loshin 1997; Gremler y Brown 1999; Oliver 1999; Gremler, Brown, Bitner 
y Parasuraman 2001; Caruana 2004; Yang y Peterson 2004; Caruana y Fenech 2005; Bove y Johnson 2006).

De este modo, para nuestro trabajo hemos utilizado la intención de comportamiento como elemento representativo de la variable lealtad, ya que es el mejor predictor que podemos utilizar a la hora de analizar los posibles comportamientos de recompra por parte del consumidor final (Guiltinan 1989; Lijander y Strandvik 1995; Cronin, Brady y Hult 2000; Henning-Thurau y Hansen 2000; Jones et al. 2002; Burnham et al. 2003; Aydin y Özer 2005; Lin y Ding 2005; Johnson, Herrmann y Huber 2006; Martínez y Martínez 2009; Liu, Guo y Lee 2011; Swobodaa et al. 2013; Castaldo et al. 2015).

Sin embargo, si retomamos la revisión de la literatura existente en lo relativo al tipo de comercio como variable moderadora no encontramos un gran número de trabajos que traten comparativamente ambos tipos de comercio. Aunque sí destacan la relevancia de los pequeños comercios en el contexto de las economías de las ciudades y hacen un llamamiento a investigar más en sus diferencias.

A efectos de las particularidades de nuestra investigación, la esencia de la variable moderadora no es principalmente en las características más técnicas, sino en su naturaleza más esencial. En este sentido, se presentó la “Teoría del no lugar” (Augé, 1992), pues consideramos que es la aproximación más cercana al punto de partida del enfoque motivacional del consumidor de la presente tesis. Dicha teoría planteada por el antropólogo francés Marc Augé, se basa en la diferenciación de dos tipos de espacios físicos: los no lugares y los lugares.

Los primeros se caracterizan por ser espacios de paso a alguna parte, de tránsito de ciudadanos acelerados. Son lugares situacionales, de movimiento y donde los encuentros suelen ser casuales, casi exclusivamente definido por el pasar de individuos. No aportan ni identidad ni personalidad, pues no es fácil interiorizar sus aspectos o 
componentes. Ejemplos claros de este tipo de "no lugares" son los aeropuertos, los andenes, las salas de espera o los centros comerciales donde más que nuestra identidad nos representa un billete de tren, una tarjeta médica o una tarjeta de crédito.

Por el contrario, los lugares son espacios de la ciudad con identidad e historia propia, que generan con el paso de años una identidad. Conjuntos históricos, parques, plazas y comercios que estimulan a la conversación, en definitiva, espacios donde conviven diferentes tipos de actividades que cuando se unen son capaces de crear un enfoque relacional completo.

Como Augé destaca en su publicación, el lugar no podrá nunca quedar completamente borrado, mientras que el no lugar no se define nunca completamente, son espacios donde se escribe y se borra una identidad y una relación de acuerdo a estrategias de conveniencia.

Y es que, si el punto de partida de la presente investigación es la motivación de compra como disposición interna fruto de las creencias, vivencias y cultura del individuo (entre muchas otras variables psicológicas de difícil medición), es ciertamente lógico asociar este punto de vista como elemento que defina la naturaleza de las dos tipologías de comercio. 
Una vez expuestas las principales conclusiones del apartado teórico, pasamos ahora a pormenorizar los resultados del análisis comparativo de la motivación de compra en el pequeño comercio urbano y los grandes centros comerciales.

En el caso de los compradores que realizaron sus compras en el pequeño comercio urbano podemos observar que comparativamente son unos consumidores significativamente más éticamente motivados si los comparamos con los del gran centro comercial.

Además, confirmamos la relación existente entre la motivación y su posterior repercusión en las valoraciones tras la experiencia compra, es decir, la motivación de compra se postula como antecedente del valor percibido por el consumidor. Como ya hemos comentando, al tratarse de unos compradores con una motivación ética más elevada, también lo es así la relación entre esta variable y el valor percibido ético fruto de la experiencia de compra. Seguido por la relación de la motivación hedónica y el valor percibido emocional, y finalmente la motivación utilitarista y el valor percibido utilitarista.

En este sentido, además, debemos destacar que la motivación de compra representa una disposición interna, fruto de creencias, experiencias u otros valores que ejercen influencia en la posterior valoración por parte de consumidor. Sin embargo, no es esta la única variable que puede influir en esta percepción por parte del consumidor, por lo que debe ser tenida en cuenta como una variable sobre que la que además de conocer su relevancia en esta relación, podemos trabajar. Una de las principales aportaciones de esta primera relación es la posibilidad de acciones comerciales que intensifiquen esa identificación de valores éticos, hedónicos y utilitaristas de tal forma que su intensidad consiga desencadenar ese comportamiento deseado.

Hemos comentando en apartados anteriores de la presente tesis que según la Teoría de la Autodeterminación (TAD), que la motivación varía en su dirección, pero también lo hace en su intensidad. Y en ese sentido, en la distinción entre una motivación 
de compra más intrínseca o pura y otra motivación guiada por incentivos o extrínseca radica el segundo pilar que avala la posibilidad de trabajar con herramientas comerciales esos aspectos motivacionales que finalmente desencadenen el comportamiento.

Los compradores del pequeño comercio, además, son unos compradores exigentes y ciertamente complejos. Los motivos éticos son aquellos que significativamente comparando desencadenan el comportamiento de selección de este tipo de establecimiento para realizar sus compras, que posteriormente guarda una relación positiva y elevada con los valores éticos percibidos en la experiencia de compra. Lo cual es un hecho relevante, pues existen congruencia entre aquello que despierta o energiza la conducta y aquello que se vive en el comercio. Sin embargo, pese a que pueda parecer no muy lógico, no son las mismas naturalezas de factores los que generan la satisfacción del consumidor. $\mathrm{Y}$ esta cuestión es ciertamente interesante, pues supone que no son los mismos valores los que llevan a elegir el pequeño comercio y los que hacen que el cliente se sienta satisfecho, lo que tiene repercusiones en los resultados comerciales, siendo estos el objetivo máximo de todo gerente.

Por lo tanto, a la hora de determinar la satisfacción del consumidor, son los valores emocionales o hedónicos aquellos que ejercen una mayor influencia. Es decir, pese a que el motivo principal que lleva a comprar en este tipo de pequeños formatos es de carácter ético o moral (sentimiento de estar haciendo el bien), son aspectos afectivos como el disfrute, la interacción social o las sensaciones aquellas que determinarán que los clientes se sientan satisfechos y la posibilidad generar un cliente leal se multiplique.

A continuación son los aspectos más cognitivos o funcionales aquellos que ejercen la segunda mayor relación sobre la satisfacción del consumidor. La facilidad de acceso al tipo de comercio, la localización o la disponibilidad de parking gratuito representan también un conjunto de aspectos relevantes en la generación de la satisfacción. 
Y finalmente, pese a que pueda parecer contradictorio, encontramos los aspectos éticos con una relación ligeramente inferior la satisfacción. Lo que se desprende de esta relación es que esos valores éticos o morales que desencadenan en esa primera fase el comportamiento, que posteriormente es congruente con lo experimentado en comercio, representan un aspecto inherente a la naturaleza del tipo de establecimiento que de cierto modo se da por supuesto por el cliente. Con la realización de sus compras, en la mente del consumidor se activa esa sensación de "estoy haciendo el bien", sin embargo, este exigente consumidor para volver a comprar en ese mismo comercio, exige algo más. Exige disfrute, originalidad, olores, música sorpresa, etc.

La relación posterior entre la satisfacción y la lealtad es positiva y elevada. En ese sentido, de este modelo se desprende la necesidad de los gerentes de los pequeños comercio en trabajar en un doble plano. Por un lado, no olvidar que son principalmente los motivos éticos lo que llevan al consumidor a desencadenar sus compras en el pequeño comercio, y este aspecto pese a su naturaleza inherente, debe ser fomentado y explícitamente trabajado a través de campañas que fomenten el reconocimiento social de los clientes.

Sin embargo, para satisfacer a este exigente consumidor, se deben trabajar los aspectos emocionales y hedónicos en el punto de venta. El mercado de la moda y complementos es un mercado exigente y rápido. Altamente competitivo y con una constante necesidad de cambio y novedad (carga hedónica). Para los comercios minoristas es esencial saber hacer frente a este ritmo de trabajo, a la frecuencia en la que los productos disponibles en el comercio deben cambiar para así atraer la atención de los consumidores. $\mathrm{Y}$ es que para los consumidores, la moda va más allá de la simple naturaleza del producto, destaca su valor social y emocional (O"Cass 2004).

Sin embargo, el papel de la moda para cada consumidor varía en función de las características individuales de cada individuo, así como lo hace también su implicación con la compra (O"Cass 2004). Por lo tanto, el comportamiento de compra es 
algo complejo de predecir ya que depende de multitud factores inherentes y relativos a cada individuo en particular.

En contraposición, encontramos al comprador del gran centro comercial, un consumidor significativamente más utilitarista y funcional, orientación a la consecución ágil de los objetivos de la compra. Un consumidor preocupado por conseguir acceder fácilmente a las instalaciones, encontrar todo aquello que busca en un mismo comercio y así realizar su compra con rapidez y agilidad.

Al igual que sucedía en el caso anterior, existen relaciones positivas y directamente entre las tres dimensiones motivacionales y sus homónimas derivadas de la experiencia de compra. Siendo la motivación utilitarista la relación más fuerte con el valor percibido utilitarista, seguida por la motivación ética y su influencia en el valor percibido éticos y la motivación hedónica y su relación con el valor percibido emocional o hedónico. A grandes rasgos, en el comprador del centro comercial es llamativo que la motivación ética de compra represente la segunda relación más fuerte con el valor percibido tras la compra. Sin embargo, es posible que la reputación social y la consideración de los centros comerciales de la Comunidad Valenciana sean positivas entre los consumidores.

Sin embargo, en el segundo plano, ocurre algo similar a lo sucedido entre los compradores del pequeño comercio urbano. Aquellos aspectos que inicialmente desencadenaban el comportamiento de compra, no son los mismo que posteriormente determinan la satisfacción del consumidor, que finalmente son las variables que en cierto modo van a determinar la obtención de resultados comerciales.

En esta ocasión, vuelven a ser los aspectos emocionales, hedónicos y de disfrute aquellos que tienen una mayor influencia en la satisfacción. El sentirse relajado, sensaciones positivas, que el personal no genere presión en la compra y el sentirse en general contento en este tipo de establecimiento son el principal factor que determina la 
satisfacción de estos consumidores. En segundo lugar encontramos, como es obvio, el valor percibido utilitarista, si por algo destacan los centros comerciales es por su amplitud de horarios, extrema accesibilidad y la disposición de un amplio abanico de comercios en los que realizar sus compras sin tener que realizar grandes desplazamientos. Y finalmente, debemos destacar que los valores éticos no tienen una influencia significativa sobre la satisfacción del consumidor. Es decir, en la formación de la satisfacción del consumidor del gran centro comercial, dos son los grandes valores sobre los que hay que hacer hincapié: aspectos emocionales o hedónicos y muy de cerca también, los aspectos utilitaristas. Estos segundos valores, igual que sucede con los valores éticos, en cierta medida son inherentes a la naturaleza de la oferta comercial, pues desde su diseño y construcción van parejos a la misma.

Es confirmada también, la relación entre la satisfacción del consumidor y la lealtad del mismo. En este sentido, destacar que aquellos motivos que mueven al consumidor a realizar sus compras en el gran centro comercial son de manera evidente los motivos utilitaristas, aunque en ese segundo plano en el cambio hacia la fidelidad del consumidor, es el disfrute aquello que hace volver al comprador.

Una vez expuestas las principales conclusiones de los modelos específicos en función del tipo de establecimiento, pasamos a continuación a realizar unas consideraciones extraídas del modelo general propuesto en la presente tesis.

A grandes rasgos, parece ser que la motivación de compra sí es diferente en función del tipo de establecimiento en el que se realizan las compras, sí existen un conjunto de valores que caracterizan o definen cada tipo de formato comercial que son apreciados por los consumidores y así resultan sus valoraciones. Además, los resultados de ese primer plano de análisis que asocia disposiciones internas del consumidor con el desarrollo del comportamiento de compra no son los mismos que aquellos que definen la satisfacción del consumidor, o aquello que denominamos segundo plano orientado a la consecución de resultados comerciales. 
Sin embargo, en el caso del modelo general, podemos apreciar que sí coincide el valor principal de ese primer plano con el valor principal del segundo plano. Los valores hedónicos y de disfrute representan en ambos casos, un desencadenante de comportamiento de compra, y un desencadenante de resultados comerciales.

Un modelo simplificado, que ciertamente no contempla la naturaleza propia de cada uno de modelos propuestos en función del tipo de comercio en el que se realizó la compra.

En nuestro caso concreto, podemos confirmar que el tipo de establecimiento y su naturaleza sí determina ese primer motivo que desencadena el comportamiento de compra, En el caso del pequeño comercio nos referimos a factores de tipo ético, mientras que el centro comercial se trata de factores utilitaristas. Además, en la orientación a la consecución de resultados comerciales a través de la satisfacción hacia la lealtad, es en ambos casos el apartado hedónico o emocional el que determina principalmente el camino hacia el objetivo.

En definitiva, tal y como ya hemos comentado a lo largo de las conclusiones, los gerentes de los pequeños comercios urbanos deben ser conscientes de la naturaleza de su oferta y las consecuencias que ello conlleva. Sabiendo trabajar ese enfoque ético a un primer nivel, ese reconocimiento que refuerza toda motivación de compra con un carácter altamente intrínseco. Así como también ser conscientes de que aquello que lleva al consumidor a su comercio, no es aquello que lo mantendrá como cliente. El desarrollo de acciones encaminadas a mantener al día y disponibles en todo momento aquellos productos de moda y complementos que desea adquirir el consumidor en un momento determinado es esencial en esta industria tan volátil y con una elevada carga afectiva. 


\subsection{IMPLICACIONES PARA LA GESTIÓN}

Como primera implicación para la gestión, ofrecer un modelo que se inicia en el punto de partida del proceso de toma de decisiones de compra, en su plano más abstracto del que tenemos acceso a cierta información, es decir, en la motivación de compra (Caber y Albayrak 2016). Que, además, posteriormente se verá reforzado o no por la experiencia de compra, la satisfacción y las consecuencias en la intención de recompra. En este sentido aportamos toda una serie de escalas que van a servir al directivo de marketing para planificar y controlar toda una serie de aspectos que el consumidor aprecia y valora y que permanecerán en el tiempo. Además, como elemento clave de este trabajo, la diferenciación entre el pequeño comercio urbano y grandes centros comerciales, aporta información desde ambos puntos de vista que es interesante para el desarrollo de la actividad comercial de estos negocios en el entorno altamente competitivo en el que se desenvuelven.

La tesis ofrece una explicación global de porqué en su fase más inicial un consumidor selecciona un pequeño comercio o un gran centro comercial para la realización de sus compra, poniendo de manifiesto factores relativos a la naturaleza inherente de los formatos comerciales que en muchas ocasiones pasan desapercibidos para el comerciante.

Además, también hay que decir que no todos los consumidores ponderan del mismo modo los atributos valorados y a veces ni siquiera valoran las mismas cuestiones. Es por ello fundamental contar con una buena segmentación de los. En este sentido también hemos aportado nuestro granito de arena. Aunque siempre es complicado generalizar sobre colectivos de personas sí que podemos dar, a partir de nuestro análisis descriptivo, unas pequeñas pinceladas de algunas características diferenciadoras de estos dos colectivos. 
A nivel general, los clientes que realizaron sus compras en el pequeño comercio urbano parecen tener un nivel formativo más elevado, así como también un nivel de ingresos mensuales algo superiores. Se trata de un grupo de hogares más reducidos en general, con un porcentaje inferior de niños en el mismo si lo comparamos con los hogares del gran centro comercial. En general, estos compradores habitan en poblaciones grandes, de lo que se desprende que evitan el desplazamiento a las afueras de las ciudades donde suelen localizarse los grandes centros comerciales. El gasto mensual medio en moda y complementos es también superior en este grupo de encuestados. En cuanto a la motivación de compra en este tipo de establecimiento podemos afirmar que obtenemos valoraciones absolutas superiores en la dimensión ética y en ciertos aspectos del factor hedónico y de disfrute. En lo relativo al valor percibido de la compra, los resultados siguen la misma línea obteniendo valoraciones superiores en los aspectos éticos y mejorando también dichas valores en los aspectos hedónicos. Se trata además del grupo con valoraciones significativamente más altas en satisfacción y lealtad.

Por su parte, los compradores que realizaron sus compras en el gran centro comercial responden a un perfil de familia más amplía y con niños. Aunque parece apreciarse un nivel de ingresos mensuales algo inferior, así como también el nivel de estudios superado. El gasto mensual en moda y complementos es en la gran mayoría de los casos (95\%) inferior a 150 euros mensuales. En general, su motivación de copra obtiene valoraciones absolutas superiores en todos los apartados de la dimensión utilitarista, así como posteriormente en el mismo valor percibido. En cuanto a la motivación hedónica, obtienen valoraciones significativamente inferiores a las de los compradores del pequeño comercio urbano, así como también sucede en los apartados de satisfacción y lealtad.

Es relevante también destacar que aunque existe una relación directa y positiva entre la motivación de compra y valor percibido por consumidor tras la experiencia de compra en todas sus dimensiones, no debemos limitar la comprensión del presente modelo a esta primera parte. En una segunda aproximación debemos ser capaces de 
distinguir entre aquellos factores que llevan desencadenar una determinado comportamiento de compra a través de la selección del tipo de comercio en el que realizar la transacción, y aquellos factores que realmente influyen sobre la satisfacción del consumidor y posteriormente en la lealtad. Pues es en esta segunda aproximación donde realmente el gerente del pequeño comercio será capaz de identificar de manera diferenciada aquellos factores que llevan iniciar el comportamiento y aquellos que llevan a mantenerlo ya la obtención de resultados comerciales, que al fin y al cabo es el objetivo final de todo negocio. La implicación para la gestión se centra saber trabajar en ese doble plano, pues sobre la motivación se puede trabajar a través de incentivos, y aunque no es la motivación de compra el único factor que lleve a desencadenar el comportamiento de compra, sí es uno sobre el que se puede trabajar. 


\subsection{LIMITACIONES Y FUTURAS LÍNEAS DE INVESTIGACIÓN}

Una de las principales limitaciones del estudio es su aplicación al sector concreto de la moda y complementos. Para la realización de la presente tesis se tomaron dos decisiones importantes, la elección de la Comunidad Valenciana como universo de estudio y el sector de la moda y complementos como el tipo de compra realizada a analizar. Ambas decisiones fueron tomadas en base a la naturaleza económica de la comunidad autónoma, así como de las características de la tipología de productos en la determinación de la motivación de compra. Sin embargo, como es obvio, el estudio podría haberse realizado a nivel nacional y haberse seleccionado otras tipologías de producto. En ese sentido, como futuras líneas investigación se plantean la aplicación del modelo de origen motivacional de compra en otras áreas geográficas nacionales e internacionales para contrastar su validez. Así como también su aplicación en otros tipos de productos o incluso en servicios, en tipologías más concretas dentro del sector textil como puede ser la compra de moda de segunda mano o la moda sostenible. Siendo también interesante realizar distinciones en función de la implicación del consumidor con la compra en cuestión, ya que ciertamente no debe ser tratada de igual modo la adquisición de un pantalón vaquero y la adquisición de un vestido de novia. Al variar la implicación se podría esperar una modificación de las motivaciones de compra en su dirección e intensidad.

En el presente trabajo se ha analizado de manera comparativa el pequeño comercio urbano y los grandes centros comerciales. El motivo de esta distinción radica en el hecho de la peculiaridad y de la tradición asociada a estos comercios céntricos ubicados en el casco histórico de las ciudades. Sin embargo, no debemos olvidar las formas organizativas a las que estos pequeños comercios están recurriendo para hacer frente a la presión de los grandes centros comerciales ubicados en las periferias de las ciudades. Nos estamos refiriendo a los centros comerciales abiertos, entendidos como una forma de organización comercial con una imagen y estrategia propia y con una concepción global de oferta comercial, servicios, cultura y ocio en una zona delimitada de la ciudad (Casares 
y Rebollo, 2004). Si bien para el presente trabajo que fijaba en el punto de partida la motivación de compra del consumidor debíamos recurrir a la forma más elemental del $\mathrm{CCA}^{1}$, que son los pequeños comercios que lo componen, es evidente que en futuros trabajos podría ser tratado desde una perspectiva comparativa. Los centros comerciales cerrados (CCC) y los centros comerciales abiertos (CCA), pese a su interesante crecimiento en los últimos años no cuentan con representación en la literatura existente y es por ello que sería interesante considerarla una futura línea de investigación.

Por otro lado, el hecho de incluir una dimensión ética o moral en la medición de la motivación de compra es un factor que en diversos trabajos que tratan la motivación de compra ha sido identificado como una consecuencia de la recesión económica. En este sentido, la prudencia llevaría repetir el estudio en los próximos años para así poder ratificar que su inclusión como una tercera dimensión motivacional no es solo fruto de la significativa coyuntura por la que se ha atravesado a lo largo de los últimos años.

Por otro lado, la motivación de compra ha sido analizada desde una perspectiva multidimensional, basándonos en la naturaleza del motivo que conduce a desencadenar el comportamiento. Sin embargo, existen algunos autores que están comenzando a introducir nuevas perspectivas en la medición de la variable que no atienden estrictamente a su naturaleza, sino más bien al origen y trasfondo psicológico que la rodea. En esta línea, en el campo del marketing Arnold y Reynolds (2009) establecen que los consumidores motivados actúan en base a un tipo de conductas direccionadas, o bien a la obtención de una meta o un objetivo, o bien a la prevención y a la seguridad que ofrecen conductas ya repetidas con anterioridad.

En esta línea también se ha expuesto en apartados anteriores la distinción entre motivación extrínseca y motivación intrínseca como dimensiones de la variable motivacional. La motivación intrínseca es una motivación natural que surge de manera

\footnotetext{
${ }^{1}$ También conocidos como Centros Comerciales de Área Urbana, que según Molinillo y Parra (2001) recogen mejor la realidad descrita pero su uso no se encuentra extendido en el tejido empresarial.
} 
espontánea, mientras que la motivación extrínseca que proviene de incentivos y consecuencias externas (dinero, alabanza, atención, aprobación, premios...) En el campo del marketing no ha sido utilizada en un gran número de trabajos, si bien en el campo del turismo sí ha sido ampliamente utilizada. Si bien es cierto que se trata de una perspectiva más simple, a la hora de operativizar en el ámbito de la gestión empresarial puede resultar interesante. En definitiva, el estudio de la variable motivación de compra con su elevado contenido psicológico abre multitud de posibilidades en su medición en futuros trabajos de investigación en este campo. 

BIBLIOGRAFÍA 



\section{BIBLIOGRAFÍA}

Achrol, R.S. (1991), "Evolution of the Marketing Organization: New Forms for Dynamic Environments", Journal of Marketing, vol. 55, pp. 77-93.

Achrol, R.S. (1997), "Changes in the Theory of Interorganizational Relations in Marketing: Toward a Network Paradigm, Journal of the Academy of Marketing Science", 25, no 1, pp. 56-71.

Achrol, R.S. y Gundlach, G.T. (1999), "Legal and social safeguards against opportunism in exchange", Journal of Retailing, 71, 1, pp.107-24.

Achrol, R.S., Reve, T. y Stern, L. W. (1983), “The Environment of Marketing Channel Dyads: A Framework for Comparative Analysis", The Journal of Marketing, 47, 4, pp. 55-67.

ACOTEX (2015), El comercio textil en cifras (Informe 2015).

Ahmed, Z., Ghingold, M. and Dahari, Z. (2007), "Malaysian shopping mall behavior: an explanatory study”, Asia Pacific Journal of Marketing and Logistics, 19, pp. 331-348.

Aijo, T. (1996), "The theoretical and philosophical underpinnings of relationship marketing: environmental factors behind the changing marketing paradigm", European Journal of Marketing, vol. 30, $\mathrm{n}^{\mathrm{o}} 2$, pp.8-18.

Ailawadi, K.L. and Keller, K.L. (2004), "Understanding retail branding: conceptual insights and research priorities”, Journal of Retailing, 80, pp. 331-342.

Albrecht, K. (1994), “Customer Value”, Executive Excellence, 11, pp. 14-21.

Alet I. y Vilaginés, J. (1994), Marketing relacional. Cómo obtener clientes leales y rentables, Gestión 2000, Barcelona.

Alet, J. (1994) Marketing relacional, Ed. Gestión 2000.com, Barcelona

Alrubaiee, L. and Al-Nazer, N. (2010), "Investigate the impact of relationship marketing orientation on customer loyalty: the customer's perspective", International Journal of Marketing Studies, 2, pp. 155-173.

Altman, I. y Taylor, D. A. (1973), Social Penetration, New York: Holst, Rinehart, Winston

AMA (2004), accessible desde: www.marketingpower.com. 
Ambler, T. y Styles, C. (2000), "The future of relational research in international marketing: constructs and conduits”, International Marketing Review, vol. 17, $\mathrm{n}^{\mathrm{o}}$ 6, pp. $492-5508$.

Amit, R. y Zott, C. (2001), "Value creation in e-business", Strategic Management Journal, Vol. 22, No. 6/7, pp. 493-520,

Andaleeb, S. S. (1996), "Explaining the Commitment of Family Planning Fieldworkers in Bangladesh", International Family Planning Perspectives, vol. 22, n 1, pp.10-15

Anderson, E. y Weitz, B. (1992), "Determinants of continuity in. conventional industrial channel dyads", Journal of Marketing Research, vol. 29, n 1, pp. 18-34.

Anderson, E.W. (1995), An economic approach to understanding how customer satisfaction affects buyer perceptions of value. Proceedings of the VI AMA Winter Educators Conference, pp. 102-107.

Anderson, E.W. y Sullivan, M.V. (1993), "The Antecedents and Consequences of Customer Satisfaction for Firms", Marketing Science, 12, pp.125-143.

Anderson, E.W., Fornell, C. and Mazvancheryl, S.K. (2004), “Consumer satisfaction and shareholder value", Journal of Marketing. 68, pp. 172-185.

Anderson, J. C., Håkansson, H., \& Johanson, J. (1994). "Dyadic Business Relationships within a Business Network Context", Journal of Marketing, Vol. 58 (October 1994), $1-15$.

Anderson, J.C. and Gerbing, D.W. (1984): "The effect of sampling error on convergence, improper solutions, and goodness-of-fit indices for maximum likelihood confirmatory factor analysis", Psychometrika, 49, pp. 155-173.

Anderson, J.C. and Narus, J.A. (1984), “A model of the distributor's perspective of the distributor-manufacturer working relationships", Journal of Marketing, vol. 48, pp. $62-74$.

Anderson, J.C. and Narus, J. A. (1990), “A model of Distributor Firm and Manufacturer Firm Working Partnerships", Journal of Marketing, Vol. 54, pp. 42-58.

Anderson, R.E. and Srinivasan, S.S. (2003), "E-satisfaction and e-loyalty: a contingency framework", Psychology and Marketing, 20, pp. 123-138. 
Anderson, W. E. and Mittal, V. (2000), "Strengthening the satisfaction-profit chain", Journal of Service Research, vol. 3, nº 2, pp. 107-120.

Andrews, J. C., Durvasula, S. and Akhter, S. H. (1990), "A Framework for Conceptualizing and Measuring the Involvement Construct in Advertising Research", Journal of Advertising, vol. 19, $\mathrm{n}^{\mathrm{o}}$ 4, pp. 27-40.

Antil, J. H. (1984), "Conceptualization and operationalization of involvement", Advances in Consumer Research, $\mathrm{n}^{\circ} 11$, pp. 203-209.

Antón, C. y Rodríguez A.I. (2000), Influencia del grado de elaboración del proceso de elección entre marcas y de las características del consumidor en la lealtad hacia la marca, Revista europea de dirección y economía de la empresa, vol. 9, nº 3, pp. 125 146.

Aparicio de Castro, G., De Elizagarte, V. y Zorrilla, P. (2006), Estrategias horizontales para mejorar la competitividad del comercio urbano, Instituto de Economía Aplicada a la Empresa, Universidad del País Vasco.

Araujo, L. y Easton, G. (1996), “Strategy: Where is the Pattern?”, Organization, vol. 3, $\mathrm{n}^{\mathrm{o}} 3$, pp. 361-383.

Arndt, J. (1983), “The Political Economy Paradigm: Foundation for Theory Building in Marketing”, Journal of Marketing, vol. 47, n 4, pp. 44-54

Arnold, M.J. and Reynolds, K.E. (2003), "Hedonic Shopping Motivations", Journal of Retailing, 79, pp.77-95.

Arnold, M.J. and Reynolds, K.E. (2009), "Affect and Retail Shopping Behavior: Understanding the Role of Mood Regulation and Regulatory Focus", Journal of Retailing, 85, pp. 308-320.

Arnold, M.J. and Reynolds, K.E. (2012), "Approach and Avoidance Motivation: Investigating Hedonic Consumption in a Retail Setting”, Journal of Retailing, 88, pp. 409-411.

Athavale, A.S., Banahan, B.F., Bentley, J.P. and West-Strum, D. (2015), “Antecedents and consequences of pharmacy loyalty behavior", Int J Pharm and Healthcare Market, 9, pp. 36-55. 
Atkinson, J. (1964). “An introduction to motivation”, University series in psychology. Van Nostrand: University of Michigan.

Auge, M. (1992). Los no lugares: espacios de anonimato. Colection La Librairie du XXé siecle.

Babin, B.J., Chebat, J.C. and Michon, R. (2004), "Perceived appropriateness and its effect on quality, affect and behavior", Journal of Retailing and Consumer Services, 11, pp. 287-298.

Babin, B.J., Darden W.R. and Griffin, M. (1994), "Work and/or fun: measuring hedonic and utilitarian shopping value”, Journal of Consumer Research, 20, pp. 644-656.

Badi, S., Wang, L. and Pryke, S. (2016), "Relationship marketing in Guanxi networks: A social network analysis study of Chinese construction small and medium-sized enterprises", Industrial Marketing Management.

Bagozzi R. and Yi, Y. (1988): “On the evaluation of structural equation models”, Journal of the Academy of Marketing Science, 16 (1), pp. 74-94.

Bagozzi, R. (1980): Causal Modeling in Marketing. Wiley \& Sons, New York.

Bagozzi, R. and Heatherton, T. (1994), “A general approach to represent multifaceted personality constructs: application to state self-esteem", Structural Equation Modeling, 1, pp. 35-67.

Bagozzi, R.P. (1975), "Marketing as exchange”, Journal of Marketing, 39 (October), pp. 32-39.

Bagozzi, R.P. (1978), "Construct-validity of affective, behavioral, and cognitive components of attitude by analysis of covariance structures". Multivariate Behavioral Research, vol. 13, $\mathrm{n}^{\mathrm{o}} 1$, pp. 9-31.

Baker, M.J. (1995a), Marketing - philosophy or function?, in Baker, M.J. (Eds),Companion Encyclopedia of Marketing, Routledge, London, pp.3-22.

Baker, M.J. (1995b), The future of marketing, in Baker, M.J. (Eds), Companion Encyclopedia of Marketing, Routledge, London, pp.1003-18.

Baker, M.J., Buttery, E.A., Richter-Buttery, E.M. (1998), "Relationship Marketing in Three Dimensions", Journal of Interactive Marketing, 12, pp. 47-62. 
Ball, D., Coelho, P.S. and Machas, A. (2004), "The role of communication and trust in explaining customer loyalty: an extension to the ECSI Model”, European Journal of Marketing, 38, pp. 1272-1293.

Ballantyne, D. (1994). "Marketing at the crossroads: an editorial commentary on relationship marketing", Asia-Australia Marketing Journal, vol. 2 nº1, pp. 37-43.

Bamberg, S., Ajzen, I. and Schmidt, P. (2003), "Choice of travel mode in the theory of planned behavior: The roles of past behavior, habit, and reasoned action", Basic and Applied Social Psychology, vol. 25, $\mathrm{n}^{\mathrm{o}}$ 3, pp. 175-187.

Band, W.A. (1991), Creating Value for Customers, John Wiley \& Sons, New York.

Bandura, A. (1977). Social Learning Theory. New York: General Learning Press.

Baran, R. and Galka R. (2013). CRM: The Foundation of Contemporary Marketing Strategy. Routledge Publisher.

Barbopoulos, I. and Johansson, L.O (2016),"A multi-dimensional approach to consumer motivation: exploring economic, hedonic, and normative consumption goals", Journal of Consumer Marketing, 33, pp. $75-84$.

Bardhi, F. and Arnould, E. (2005), "Thrift shopping: combining utilitarian thrift and hedonic treat benefits", Journal of Consumer Behavior, 4, pp. 223-233.

Bhardwaj, V. and Fairhust, A. (2010), "Fast fashion: response to changes in the fashion Industry”. The International Review of Retail, Distribution and Consumer Research, 20, pp.165-173.

Barroso, M.J., Galera, C. and Valero, V. (2015), "Proposal of a social alliance success model from a relationship marketing perspective: A meta-analytical study of the theoretical foundations”, BRQ Business Research Quarterly, 3, pp. 188-203.

Barquero, J.D. y Barquero, M. (2010). Marketing relacional y comunicación para situaciones de crisis: Qué hacer antes, durante y después, para proteger y salvar su empresa. Profit Editorial.

Barroso, C. y Martín, E. (1999), Marketing Relacional. Madrid, ESIC.

Barroso, C. y Martín, E. (2000), Desarrollo del Marketing Relacional en España, Revista Europea de Dirección y Economía de la Empresa, vol. 9, nº 3, pp. 25 - 46. 
Batra, R. and Ahtola, O. (1991), "Measuring the hedonic and utilitarian sources of consumer attitudes", Marketing Letters, 2, pp. 159-170.

Beach, F.A. (1955). “The descent of instinct”. Psychological Review, 62, pp. 401-410.

Beatty, S.E., Mayer, M.L, Coleman, J.E., Reynolds, K.E. and Lee, J. (1996), CustomerSales Associate Retail Relationships, Journal of Retailing, vol. 72, otoño, pp. 223247.

Beck, L. y Ajzen, I. (1991) Predicting dishonest actions using the Theory of Planned Behavior. Journal of Research in Personality, $\mathrm{n}^{\mathrm{o}} 25$, pp. 285-301.

Becker, M. H. (1974), The Health Belief Model and Personal Health Behavior, Health Education Monographs, vol. 2, pp. 324-473.

Bell, R., Ho, T. and Tang, C. (1998), "Determining Where to Shop: Fixed and Variable Costs of Shopping”, Journal of Marketing Research, Vol. 35, No. 3, pp. 352-369

Bello, L. y Gómez, J. (1997), Interacciones entre marketing industrial y marketing de relaciones, Revista Asturiana de Economía, n. ${ }^{\circ}$ 9, pp. 7-21.

Bendapudi, N. y Berry, L.L. (1997), Customer Receptivity to Relationship Marketing, Journal of Retailing, vol. 73, $\mathrm{n}^{\mathrm{o}}$ 1, pp. 15-37.

Bennett, R. y Rundle-Thiele, S.R. (2004), Customer satisfaction should not be the only goal, Journal of Services Marketing, Vol 18, No. 7, p. 514-523.

Bennett, R. y Rundle-Thiele, S.R. (2005), The Brand Loyalty Cycle: Implications for Marketers, Journal of Brand Management, Vol 12, No 4, pp 250-263.

Bennett, R., Hartel, C. \& McColl-Kennedy, J. R. 2004, 'A taxonomy of expressed emotion in complaints', in Proceedings of the 33rd EMAC Conference: Worldwide Marketing, eds J. L. Manuera-Aleman, Universidad de Murcia, Murcia, Spain.

Berger, P.D. y Nasr, N.I. 1998. 'Customer lifetime value: Marketing models and applications', Journal of Interactive Marketing, vol. 12, $\mathrm{n}^{\mathrm{o}} .1$, pp. 17-30.

Bergeron, J., Roy, J., \& Fallu, J. (2008). Pleasantly surprising clients: a tactic in relationship marketing for building competitive advantage in the financial services sector. (cover story). Canadian Journal of Administrative Sciences, vol. 25, nº 3, pp. 171-184. 
Berry, L.L. (1983), Relationship Marketing., en Emerging Perspectives on Services Marketing, Eds. Berry, L.L., Shostack, G.L. y Upah, G.D., American Marketing Association, Chicago.

Berry, L.L. (1995), "Relationship marketing of services-growing interest, emerging perspectives", Journal of the Academy of Marketing Science, 23, pp. 236-245.

Berry, L.L. (2002), Un buen servicio ya no basta, Norma: Bogotá.

Berry, L.L. and Parasuraman, A. (1993), "Building a new academic field- the case of services marketing", Journal of Retailing, 69, pp. 13-60.

Bezençon, V. and Blili, S. (2009), "Fair trade managerial practices: Strategy, organisation and engagement", Journal of Business Ethics, 90, pp. 90-115.

Bezjian-Avery, A., Calder, B. y Iacobucci, D. (1998), New Media Interactive Advertising vs. Traditional Advertising, Journal of Advertising Research, Vol. 38, Issue 4, pp. 23-32.

Bhattacherjee, A. and Premkumar, G. (2004), "Understanding changes in belief and attitude toward information technology usage: a theoretical model and longitudinal test", Management Information Systems Quarterly, 28, pp. 229-254.

Bienstock, C.C., Stafford, M.R. y Stafford, T.F. (2006), The Role of Technology in Industrial Customers' Perceptions of Logistics Service Quality and Purchase Intentions, Developments in Marketing Science, Vol. 29, pp. 122-132.

Bigné, J.E. y Sánchez, J. (2001), Investigaciones europeas de dirección y economía de la empresa. Antecedentes y efectos de la actitud hacia el anuncio. Propuesta de un modelo de variables latentes, Investigaciones Europeas de Dirección y Economía de la Empresa, vol. 2, nº 7, pp. 41-62.

Bigné, J.E., Andreu, L., Chumpitaz, R. And Swaen, V. (2005), “Efectos de las variables ambientales y atribución en las emociones en centros comerciales. Una aplicación en la compra de pefumería y cosmética”, Revista Española de Investigación en Marketing ESIC, 3, pp. 45-68.

Bigné, J.E., Moliner, M.A. y Callarisa LL.J. (2000), “El valor y la fidelización de clientes: una propuesta de modelo dinámico de comportamiento", Revista Europea de Dirección y Economía de la empresa, 9, pp. 65-78. 
Bitner, M. J. (1990), Evaluating service encounters: The effects of physical surroundings and employee responses, Journal of Marketing, vol. 54,pp. 69-82.

Bitner, M. J. (1995), Building Service Relationships: It's All About Promises, Journal of the Academy of Marketing Science, vol. 23, nº 4, pp. 246-51.

Bitner, M.J. and Hubbert, A.R. (1994), Encounter Satisfaction Versus Overall Satisfaction Versus Quality, in Rust, R.T., y R.L. Oliver (eds.), Service Quality: New Directions in Theory and Practice, Thousand Oaks, CA, Sage Publications, pp. 72-94. Bitner, M.J., Booms, B.H., \& Tetreault, M.S. (1990), The service encounter: Diagnosing favorable and unfavorable incidents, Journal of Marketing, vol. 54, pp. 71-84.

Blesa, A. (2000), Influencia de la Orientación al Mercado del Fabricante en las Relaciones en el Canal de Distribución, Tesis Doctoral, Universidad de Valencia.

Bloch, P. and Richins, M. (1983), "Shopping Without Purchase: An Investigation of Consumer Browsing Behavior", Advances in Consumer Research, 10, pp. 389-393.

Bloch, P. H. (1981), An exploration into the scaling of consumers' involvement with a product class, en Monroe, K.B., Advances in Consumer Research, Vol. 8, pp. 6165.

Bloch, P.H., Sherrell, D.L. and Ridgeway, N.M. (1986) Consumer search: an extended framework, Journal of Consumer Research, nº 13, pp. 119-126.

Bloemer, J. y K. de Ruyter (1998), AOn the Relationship Between Store Image, Store Satisfaction and Store Loyalty, European Journal of Marketing, vol. 32, no 5/6, pp. 499-513.

Bloemer, J., De Ruyter, K., y Wetzels, M., (1999), Linking Perceived Service Quality and Service Loyalty: A Multi-dimensional Perspective. European Journal of Marketing, vol 33, no 11/12, pp. 1082-1106.

Bloemer, J.M.M. y H.D.P. Kasper (1995). The complex relati $\neg$ onship between consumer satisfaction and brand loyalty. Journal of Economic Psychology 16, 311-329.

Bloemer, J.M.M. y Odekerken-Schroder, G. (2002) Store satisfaction and store loyalty explained by customer- and store related factors, Journal of Consumer Satisfaction, Dissatisfaction and Complaining Behavior, vol. 15, p. 68-80. 
Bloemer, J.M.M. y Odekerken-Schroder, G. (2006). The psychological antecedentes of enduring customer relationships: an empirical study in a bank setting. Journal of Relationship Management, vol. 4, nº 3, pp. 252, 265.

Bloemer, J.M.M., de Ruyter, K. y Peeters, P. (1998), On the relationship between financial institutions image, quality, satisfaction and loyalty. International Journal of Bank Marketing, vol. 16, $\mathrm{n}^{\mathrm{o}}$ 7, pp. 276-286.

Blois, K.J. 1996. Vertical quasi-integration. In Firms, organizations and contracts: A reader in industrial organization, edited by P.J. Buckley and J. Michie. Oxford: Oxford University Press, 320-358.

Bloom, B., Asher, S. y White, S. (1978). Marital disruption as a stressor: A review and analysis. Psychological Bulletin, vol. 85, pp. 867-894.

Bolles, R. C. (1975). Theory of motivation. New York: Harper and Row.

Bolton, R. N. and Drew, J. H. (1991), “A longitudinal analysis of the impact of service changes on customer attitudes", Journal of Marketing, 55, pp. 1-9.

Bolton, R. N. and Drew, J. H. (1994), Linking customer satisfaction to service operation and outcomes, in Oliver and Rust (Eds),Service Quality: New Directions in Theory and Practice, Sage, Thousand Oaks, CA, pp.173-200.

Bonoma, T.V. y Wesley J.J. (1978), The Social Psychology of Industrial Buying and Selling, Industrial Marketing Management, vol. 7, n 4, pp. 213-24.

Boulding, W.; Kalra, A.; Staelin, R. y Zeithaml, V.A. (1993), “A Dynamic Process Model of Service Quality: From Expectations to Behavioral Intentions”, Journal of Marketing Research, 30, pp. 7-27.

Bove, L. L. y Johnson, L. W. (2006) Customer loyalty to one service worker: should it be discouraged?, International Journal of Research in Marketing, 23 (1), 79-91.

Brodie, R. J., Coviello, N. E., Brookes, R. W. y Little, V. (1997), Towards a paradigm shift in marketing: an examination of current marketing practices, Journal of Marketing Management, Vol. 13, No. 5, pp. 383-406.

Brown, G.H. (1952), Brand loyalty: fact or fiction?, Advertising Age, vol. 23, no junio, pp. 53-55.

Burgos, E. (2007), Marketing relacional: cree un plan de incentivos eficaz, Netbiblo. 
Burton, D. (2005), Marketing Theory Matters. British Journal of Management, vol. 16, $\mathrm{n}^{\mathrm{o}} 1$, pp. 5-18.

Buttle, F. (2008), Customer relationship management: concepts and technologies, Elsevier Ltd, Oxford.

Buttle, F. (1996), Relationship marketing: theory and practice, ed. Paul Chapman, Londres.

Buttle, F. (1999). Relationship marketing. In F. Buttle (Ed.), Relationship marketing: Theory and practice. New York: Paul Chapman.

Butz, H.E. and Goldstein, L.D. (1996), "Measuring customer value: Gaining the strategic advantage", Organizational Dynamics, 24, pp.63 - 77.

Caber, M. and Albayrak, T. (2016). 'Push or pull? Identifying rock climbing tourists' motivations", Tourism Management, 55, pp. 74-84.

Callaghan, M., McPhail, J. and Yau, O.H.M. (1995), Dimensions of a relationship marketing orientation: an empirical exposition. In: Proceedings of the 7th Biannual World Marketing Congress; Melbourne, Australia, 7(2), 10-65.

Callarisa, L.J., Moliner, M.A. y Rodríguez, R.M. (2002). «El componente emocional del valor percibido: un estudio cualitativo». XIV Encuentros de Profesores Universitarios de Marketing, Granada, pp. 169-180.

Callarisa, LL.J. (2004), La multidimensionalidad del valor percibido en el marketing de relaciones en un entorno industrial: Una aplicación en las relaciones proveedorfabricante del sector cerámico español, Tesis Doctoral, Universidad de Valencia.

Camarero, M.C. (1998), Las Relaciones Comerciales a Largo Plazo entre Empresas. Propuesta de un Modelo Integrador de Enfoques, Tesis Doctoral, Universidad de Valladolid.

Camarero, M.C. y Gutiérrez, J (2000), Propuesta de un modelo explicativo de de las relaciones a largo plazo entre empresas, Revista Europea de Dirección y Economía de la Empresa, Vol.9, no 3, pp.89-111.

Camarero, M.C., Gutiérrez, J. y San Martín, S. (2005) The impact of customer relationship marketing on the firm performance: a Spanish case. Journal of Services Marketing, vol. 19, nº 4, pp. 234-244 
Carbó, S., López, R. y Rodríguez, F. (2001), Medición de la competencia en mercados bancarios regionales, Revista de Economía Aplicada, vol. 32, nº 11, pp. 5-33

Carroll, B. A. y Ahuvia, A. C. (2006), Some antecedents and outcomes of brand love, Marketing. Letters, vol .17, $\mathrm{n}^{\mathrm{o}}$ 2, pp. 79-89.

Caruana A. \& Fenech N. (2005), The effect of perceived value and overall satisfaction on loyalty: A study among Maltese dental patients, Journal of Medical Marketing, vol. $5, \mathrm{n}^{\circ} 3$, pp. 245-255

Caruana, A. (2002). Service Loyalty: The effect of service quality and the mediating role of satisfaction. European Journal of Marketing, vol. 36, nº 7/8, pp. 811-826.

Casado, A.B. and Más, F.J, (2002), "The consumer's reaction to delays in service", International Journal of Service Industry Management, vol. 13, n ${ }^{\circ}$ 2, pp. 118-140.

Casares, J. y Rebollo, A. (2004), Distribución comercial, Madrid: Civitas.

Cassel, C. and Eklöf, J. (2001), Modelling customer satisfaction and loyalty on aggregate levels - experience from the ECSI pilot study, Proceedings of the 6th TQM World Congress, Saint Petersbourg, pp.307-14.

Castaldo, S., Grosso, M., Mallarini, E. and Rindone, M. (2015), "The Missing Path to Gain Customers loyalty in Pharmacy Retail: the Role of the Store in Developing Satisfaction and Trust", Research in Social and Administrative Pharmacy, available online.

Celsi, R.L. and Olson. J.C. (1988), "The Role of Involvement in Attention and Comprehension Process”, Journal of Consumer Research, no 15 (Septiembre), pp. 210-233.

Chang, C.C. and Chen, C.W. (2015), "Examining Hedonic and Utilitarian Bidding Motivations in Online Auctions: Impacts of Time Pressure and Competition", International Journal of Electronic Commerce, 19, pp. 39-65.

Chen, C.F. and Tsai, M.H. (2008), "Perceived value, satisfaction, and loyalty of TV travel product shopping: involvement as a moderator", Tourism Management., 29 (6), pp. $1166-1171$ 
Chiles, T.H. and McMakin, J.F. (1996), Integrating variable risk preferences, trust, and transaction cost economics, Academy of Management Review, vol. 21, n ${ }^{\circ} .4, p p$. 1055-80.

Chiu, Y.H., Lee, W. and Chen, T. (2014), "Environmentally responsible behavior in ecotourism: antecedents and implications", Tourism Management, 40, pp. 321-329.

Chorianopoulos, A. (2016). Effective CRM using Predictive Analytics. Wiley Publish.

Christopher, M., Lowson, R. and Peck, H. (2004), "Creating agile supply chains in the fashion industry", International Journal of Retail and Distribution Management, Vol. 32, pp.367-376.

Christopher M., Payne A. \& Ballantyne D. (1998). Relationship marketing: Bringing quality, customer service and marketing together. The Chartered Institute Marketing.

Christopher, M, Payne, AFT y Ballantyne, D, (1991), Relationship Marketing: Bringing Quality, Customer Service, and Marketing Together, Butterworth-Heinemann.

Christopher, M., Payne, A. and Ballantyne, D. (2002). Relationship marketing: Creating stakeholder value. Elsevier, Oxford.

Christopher, M., Payne, A. y Ballantyne, D. (1994); Marketing relacional. Integrando la calidad, el servicio al cliente y el marketing, ed. Diaz de Santos, Madrid.

Christy, R., Oliver G. y Penn, J. (1996), El marketing de relaciones en los mercados de consumo, Journal of Marketing Management, vol. 12 pp.175 - 187

Chung, Y.S. (2015), "Hedonic and utilitarian shopping values in airport shopping behavior", Journal of Air Transport Management, 49, pp. 28-34.

Churchill, G.A. y Surprenant, C. (1982), “An Investigation into the Determinants of Customer Satisfaction”, Journal of Marketing Research, 19, pp. 491-504.

Coase, R.H. (1937), The Nature of the Firm, Economica, New Series, vol. 4, no 16, pp. 386-405.

Coelho, P.S. y Machás, A. (2004), The role of communication and trust in explaining customer loyalty: an extension to the ECSI model, European Journal of Marketing, vol. 38, no 9/10, pp. 1272-1293. 
Cooil, Keiningham, Aksoy y Hsu, 2007 Cooil, C., Keiningham, T.L., Aksoy, L. y Hsu, M. (2007) A Longitudinal Analysis of Customer Satisfaction and Share of Wallet: Investigating the Moderating Effect of Customer Characteristics. Journal of Marketing, vol. 71, $\mathrm{n}^{\mathrm{o}}$ 1, pp. 67-83.

Cook, K.S., Emerson, R.M. (1984), Exchange networks and the analysis of complex organizations, Annual Review of Sociology, Vol. 15 pp.97-118. Coviello et al., 1998

Coviello, N.E. y Brodie, R.J. (1998), From transaction to relationship marketing: an investigation of managerial perceptions and practices, Journal of Strategic Marketing, vol. 6, nº 3, pp. 171-186.

Coviello, N.E., Brodie, R.J. y Grönroos, C. (1998), Transactional or relational marketing? A cross-national investigation of contemporary practice, in Andersson, $\mathrm{P}$. (Eds),Proceedings of the 27th Annual Conference of the European Marketing Academy, Elanders Gotab, Stockholm, vol. 1, pp.445-51.

Cravens, D.W., Grant, K., Ingram, T.N., Laforge, R.W., Young, C. (1992), In search of excellent sales organizations, European Journal of Marketing, vol. 26 No.1, pp.623.

Cronin, J. J., y Taylor, S.A. (1992), “Measuring Service Quality: A Reexamination and Extension", Journal of Marketing, 56, pp. 55-68.

Cronin, J.J., Brady, M.K. y Hult, G.T.M. (2000), Assessing the effects of quality, value, and customer satisfaction on consumer behavioral intentions in service environments, Journal of Retailing, vol. 76, $\mathrm{n}^{\mathrm{o}}$ 2, pp.193-218.

Cronin, J.J.; Brady, M.K.; Brand, R.R.; Hightower, R. y Shemwell, D.J. (1997), A CrossSectional Test of the Effect and Conceptualization of Service Value, Journal of Services Marketing, vol. 11, $\mathrm{n}^{\circ}$ 6, pp. 375-391.

Crosby, L.A., Evans, K.R., Cowles, D. (1990), Relationship quality in services selling: an interpersonal influence perspective, Journal of Marketing, vol. 54, julio, pp.6881.

Cunningham, Ross M. (1956), Brand Loyalty-What Where How Much?, Harvard Business Review, nº 34, pp. 116-128. 
Dahlstrom,M.C.R. y Nygaard, A. (1995), A Preliminary Investigation of Ownership Conversions in Franchised Distribution Systems, Journal of Applied Business Research, vol. 11, n 2, pp. 1-8.

Davies, J., Foxall, G., y Pallister, J. (2002), Beyond the intention-behavior mythology: an integrated model of recycling, Marketing Theory, vol. 2, n 1, pp.29-113.

Davis, L.E. y Ajzen, I. (2002). The Decision of African American Students to Complete High School: An Application of the Theory of Planned Behavior. Journal of Educational Psychology, vol. 94, nº4, pp. 810-819.

Day, G.S. (1969), A Two Dimensional Concept of Brand Lo-yalty, Journal of Advertising Research, vol. 9, septiembre, pp. 29-35.

Day, G.S. (1970), Buyyer attitudes and brand choice behavior, Chicago, Free Press.

Day, G.S. (1973), Consumer Behavior: Theoretical Sources, Engleword Cliffs, Prentice Hall.

De Charms, R. (1968), Personal Causation. New York: Academic Press.

De Juan, M.D. (2004), Comercialización y Retailing: Distribución comercial aplicada. Pearson Prentice Hall.

De Ruyter, K., Birgelen, M., y Wetzels, M. (1998), Consumer ethnocentrism in international services marketing, International Business Review, vol. 7, pp. 185202.

De Ruyter, V.S.R., Lewen, G.D., Strong, S.P. and Koberle, R. (1997), "Reproducibility and variability in neural spike trains", Science, 275, pp. 1805-1807.

De Wulf, K., Odekerken-Schröder, G. and Iacobucci, D. (2001), "Investments in consumer relationships: A cross-country and cross-industry exploration", Journal of Marketing, 65, pp. 33-50.

Dekimpe, M. G., Steenkamp, J.E.M., Mellens, M. y Abeele, P.V. (1997), Decline and Variability in Brand Loyalty, International Journal of Research in Marketing, vol. $14, n^{\circ} 5$, pp. 405-20.

Delgado , M. y Munuera, J. L. (1998), La confianza hacia la marca en el ámbito de la lealtad del consumidor, actas de X Encuentro de Profesores Universitarios de Marketing, ESIC, Madrid, pp. 449-455. 
Derbaix, C. y Vanden Abeele, P. (1985), Consumer Inferences and Consumer Preferences. The Status of Cognition and Consciousness in Consumer Behavior Theory, International Journal of Research in Marketing, $\mathrm{n}^{\mathrm{o}}$ 2, pp. 157-174.

Devesa, M., Laguna, M. and Palacios, A. (2010), "The role of motivation in visitor satisfaction: Empirical evidence in rural tourism”, Tourism Management, 31, pp. 547552.

Dholakia, R.R. (1999), "Going shopping: key determinants of shopping behaviors and motivations", International Journal of Retail \& Distribution Management, 27, pp. 15465.

Dholakia, Utpal M. (2001), A motivational process model of product involvement and consumer risk perception, European Journal of Marketing, vol. 35, $\mathrm{n}^{\mathrm{o}}$ 11/12, pp. $1340-1362$.

Diamantopoulos, A. and Winklhofer, H. (2001), "Index Construction with Formative Indicators: An Alternative to Scale Development", Journal of Marketing Research, 38, 2, pp. 269-277.

Dick, A.S. y Basu, K., 1994. A customer loyalty: Toward an integrated conceptual framework. Journal of Academy of Marketing Science, vol. 22, nº 2, pp. 99-113.

Dodds, W.B, Monroe, K.B. y Grewal, D. (1991), Effects of Price, Brand and Store Information on Buyers' Product Evaluations, Journal of Marketing Research, vol. 28, agosto, pp. 307-319.

Donaldson, Lex (1996), The Normal Science of Structural Contingency Theory, in Handbook of Organization Studies, Stewart Clegg, Cynthia Hardy, and Walter R. Nord, eds. London: Sage Publications, 57-76.Doyle y Roth, 1992

Doney, P.M. y Cannon, J.P. (1997), An Examination of the Nature of Trust in BuyerSeller Relationships, Journal of Marketing, vol. 61, abril, pp. 35-51.

Doney, P.M., Cannon, J.P. \& Mullen, M.R. (1998), Understanding the influence of national culture on the development of trust, Academy of Management Review, vol. 23, no 3, pp. 601-620.

Donthu, N., Cherian, J. y Bhargava, M. (1993), Factors Influencing Recall of Outdoor Advertising, Journal of Advertising Research, vol. 33, n 3, pp. 64-72. 
Dowd, K. and Burke, K.J. (2013), "The influence of ethical values and food choice motivations on intentions to purchase sustainably sourced foods" Appetite, 69, pp.137-144.

Dowling, G.R. y Uncles, M. (1997), Do Customer Loyalty Programs Really Work?, Sloan Management Review, Vol. 38, nº 4, pp. 71-82

Drichoutis, A.C., Lazaridis, P. y Nayga, R.M. (2007), An assessment of product class involvement in food purchasing behavior, European Journal of Marketing, vol. 41, $\mathrm{n}^{\mathrm{o}} 7 / 8$, pp. 888-914.

Duman, T. and Mattila, A.S. (2005), "The role of affective factors on perceived cruise vacation value", Tourism Management, 26, pp. 311-323.

Duncan E. y Elliot G. (2002), Customer Service Quality and Financial Performance among Australian Retail Financial Institutions, Journal of Financial Services Marketing, Vol. 7 no. 1. pp. 25-41.

Dhurup, M. (2014). Impulsive Fashion Apparel Consumption: The Role of Hedonism, Fashion Involvement and Emotional Gratification in Fashion Apparel Impulsive Buying Behaviour in a Developing Country. Mediterranean Journal of Social Sciences, 5(8), 168-177. doi:10.5901/mjss.2014.v5n8p168

Durvasula, Lysonski, Mehta y Tang, 2004; Durvasula, S.;Lysonski, S.;Mehta, S. y Tang, B.P. (2004), Forging relationships with services: The antecedents that have an impact on behavioural outcomes in the life insurance industry, Journal of Financial Services Marketing, vol. 8, $\mathrm{n}^{\mathrm{o}}$ 4, pp. 314-326.

Dwyer, R.F., Schurr, P.H.y Oh, S. (1987), Developing buyer-seller relationships, Journal of Marketing, vol. 51, $\mathrm{n}^{\mathrm{o}}$ 2, pp.11-27.

Eagly, A.H, y Chaiken, S. (1993). The Psychology of Attitudes, Fort Worth, TX: Harcourt Brace Jovanovich.

Eagly, A.H, y Chaiken, S. (2007), The advantages of an inclusive definition of attitude, Social Cognition, vol. 25, pp. 582-602.

East, R., Harris, P., Willson, G. y Lomax, W. (1995), Loyalty to Supermarkets, The International Review of Retail, Distribution and Consumer Research, vol. 5, $\mathrm{n}^{\mathrm{o}} 1$, pp. 99-109. 
East, R.; Hammond, K.; Harris, P. y Lomax, W. (2000). First-store loyalty and retention, Journal of Marketing Management, vol. 16, nº 4, pp. 307-325.

Egan, J. (2011). Relationship marketing: exploring relational strategies in marketing (4th ed.). Financial Times/ Prentice Hall.

Eiriz V. and Wilson, D. (2006), "Research in relationship marketing: antecedents, traditions and integration”, European Journal of Marketing, 40, pp.275-291.

El-Adly, M. (2007), "Shopping malls attractiveness: A segmentation approach", International Journal of Retail and Distribution Management, 35, pp. 936-950.

El-Adly, M. and Eid, R. (2015), "Measuring the perceived value of malls in a non-western context: the case of the UAE", International Journal of Retail and Distribution Management, 43, pp. 849-869.

El-Adly, M. and Eid, R. (2016), “An empirical study of the relationship between shopping environment, customer perceived value, satisfaction, and loyalty in the UAE malls context", Journal of Retailing and Consumer Services, 31, 217-227.

Elliott, R. y Hamilton, E. (1991), Consumer Choice Tactics and Leisure Activities, International Journal of Advertising, vol. 10, pp. 325-332.

Emerson, R.M. (1962), Power-dependence relations, American Sociological Review, Vol. 27 pp.31-41.

Engel, J.R. y Blackwell, R.D. (1982), Consumer Behavior Hinsdale, Illinois, The Dryden Press.

Evans, P. (2014). Motivation and Emotion (PLE: Emotion). Psychology Press; Reissue edition.

Farmaki, A. (2012), “An exploration of tourist motivation in rural settings: The case of Troodos, Cyprus", Tourism Management Perspectives, 2-3, pp. 72-78.

Fischer, E. and Arnold, S. (1990), "More Than a Labor of Love: Gender Roles and Christmas Gift Shopping," Journal of Consumer Research, 17, pp. 333-345.

Fishbein, M., and Ajzen, I. (1975). Belief, attitude, intention, and behavior: An introduction to theory and research. Reading, MA: Addison-Wesley.

Fodness, D. (1994), “Measuring Tourist Motivation”, Annals of Tourism Research, 21, pp. 555-81. 
Fornell C. (1992), “A National Customer Satisfaction Barometer: The Swedish Experience", Journal of Marketing, 6, pp. 06-21.

Fornell, C. and Larcker, D.F. (1981): "Evaluating structural equations models with unobservable variables and measurement error", Journal of Marketing Research, 18, pp. 39-50.

Fornell, C., Johnson, M.D., Anderson, E.W., Cha, J. and Bryant, B.A. (1996), "The American Customer Satisfaction Index: Nature, Purpose and Findings”, Journal of Marketing, 60, pp. 7-18.

Foscht, T., Schloffer, J., Maloles, C y Chia, S.L. (2009), Assessing the outcomes of Generation-Y customers' loyalty, The International Journal of Bank Marketing, vol. $27, \mathrm{n}^{\mathrm{o}} 3, \mathrm{pp} .218-241$.

Fournier, S. y Mick, D.G. (1999), “Rediscovering Satisfaction”, Journal of Marketing, 63, pp. 5-28.

Foxall, G.R., 1997. Explaining consumer behaviour: From social cognition to environmental control. In: Cooper, C.L. y Robertson, I., Editors, 1997. International Review of Industrial and Organisational Psychology, nº12, pp. 231-297.

Frank, R.E. (1962), Brand Choice as Probability Process, Journal of Business, vol. 35, pp. 43-56.

Franken, R. (2006). Human motivation. Florence, KY: Wadsworth.

Frasquet, M. (2000), Centros comerciales: gestión y competitividad, Valencia: Conselleria d'Indústria i Comerç.

Frasquet, M. y Vallet, T. (2001), Los factores clave en la gestión estratégica de centros comerciales: Una investigación empírica, Boletín económico ICE, octubre, pp. 2338.

Frazier, G. L. (1983), Interorganizational Exchange Behavior in Marketing Channels: A Broadened Perspective, Journal of Marketing, vol. 47 (octubre), pp. 68-78.

Frazier, G. L., Speckman, R. E. y O’Neal, C. R., (1988). Interorganizational Exchange Behavior in Marketing Channels: A Broader Perspective. Journal of Marketing, vol. 52, octubre, pp. 52-67. 
Frazier, G.L. y Antia, K.D. (1995), Exchange relationships and interfirm power in channels of distribution, Journal of the Academy of Marketing Science, vol. 23, $\mathrm{n}^{\mathrm{o}}$ 4, pp. 305-320.

Freestone, O. and McGoldrick, P. (2008), "Motivations of the ethical consumer", Journal of Business Ethics, 79, pp. 445-467.

Freud, S. (1915). Instincts and their vicissitudes. SE, 14: 117-140. London: Hogart.

Friederichs, S., Bolman, C., Oenema, A., Verboon, P. and Lechner, L. (2016), “Exploring the working mechanisms of a web-based physical activity intervention, based on selfdetermination theory and motivational interviewing”, Internet Interventions, 3, pp. 817.

Fullerton, Gordon (2005), The Service Quality-Loyalty Relationship in Retail Services: Does Commitment Matter?, Journal of Retailing and Consumer Services, vol.12, $\mathrm{n}^{\mathrm{o}}$ 2, pp. 99-111.

Gabbott, M. y Hogg, G (1999), Consumer Involvement in Services, Journal of Business Research, vol. 46, nº 2, pp. 159-166.

Gale, B.T. (1994), Managing Customer Value, The Free Press, New York.

Galera, C., Galán, M., Velero, V. y López, J.A. (1999), Marketing de relaciones en el ámbito de los mercados industriales", AEDEM, XIV Congreso Nacional-VIII Congreso Hispano Francés: Inteligencia Empresarial. La gestión del conocimiento en la empresa, pp. 97-105.

Ganesan, S. (1994), Determinants of Long-Term Orientation in Buyer-Seller Relationships, Journal of Marketing, vol. 58, abril, pp. 1-19.

Ganesan, S. y Hess, R. (1997), Dimensions and Levels of Trust: Implications for Commitment to a Relationship, Marketing Letters, vol. 8, nº 4, pp. 439-448.

Garbarino, E. and Johnson M.S (1999), “The Different Roles of Satisfaction, Trust, and Commitment in customer Relationship", Journal of Marketing, 63, pp. 70.

Gaski, J.F. (1984), The theory of power and conflict in channels of distribution, Journal of Marketing, Vol. 48, $\mathrm{n}^{\circ}$ verano, pp. 9-29

Gassenheimer, J.B., Houston, F.S. y Davis, J. (1998), The Role of Economic Value, Social Value and Perceptions of Fairness in Interorganizational Relationship 
Retention Decisions, Journal of Academy of Marketing Science, vol. 26, no 4, pp. 322-337.

Geyskens, I., Steenkamp, J., y Kumar, N. (1998), The effects of trust and interdependence on relationship commitment: A trans-Atlantic study, International Journal of Research in Marketing, vol. 13, pp. 303-317.

Geyskens, I., Steenkamp, J.B. and Nirmalya, K. (1999), “A Meta-Analysis of Satisfaction in Marketing Channel Relationships”, Journal of Marketing Research, 36, pp. 223238.

Giese, J.L. and Cote, J.A. (2002), "Defining Consumer Satisfaction”, Academy of Marketing Science Review, 1, pp. 1-34.

Giese, J.L. y Cote, J.A. (1999), Defining Consumer Satisfaction, Academy of Marketing Science Review, vol. 2000, $\mathrm{n}^{\mathrm{o}}$. 1, pp. 1-34. Disponible en: www.amsreview.org/articles.htm

Gnoth, J. (1997), “Tourism Motivation and Expectation Formation”, Annals of Tourism Research, 24, pp. 283-304.

Gómez, A. (2006), Marketing relacional, directo e interactivo, RA-MA editorial.

Gómez, J.T., Bello, A.L. y Cervantes, M. (2000), Del marketing de relaciones al marketing postmoderno, Revista Europea de Dirección y Economía de la Empresa, vol. $9, \mathrm{n}^{\mathrm{o}} 3$, pp. 113-124.

Goshal, S. y Bartlet, C.A. (1993), Un nuevo manifiesto a favor del management, Harvard Deusto Business Review, n 93, pp. 12-26.

Grace, D. and O’Cass, A. (2005), “An examination of the antecedents of repatronage intentions across different retail store formats", Journal of Retailing and Consumer Services, 12, pp. 227-243.

Graham, J.L. (1988) 'Deference Given the Buyer: Variafions Across Twelve Cultures', en Co-operative Strategies in International Business (Eds). Contractor, F.J. y Lorange, P. (Lexington, Mass) Lexington Books, pp. 473-485.

Grayson, K. y Ambler, T. (1999), The Dark Side of Long-Term Relationships in. Marketing Services, Journal of Marketing Research, vol. 36, febrero, pp. 132-141. 
Gremler D. D., Brown S.W., Bitner M.J. y Parasuraman, A. (2001), Customer Loyalty and Satisfaction : What resonates in Service Context?, working paper, disponible en www.gremler.net.

Gronroos, C. (1984). Strategic management and marketing in the service sector. New York: Chart Bratwell.

Grönroos, C. (1989), "Defining marketing: A market- oriented approach”, European Journal of Marketing, 1, pp. 52-60.

Grönroos, C. (1990), Service Management and Marketing: Managing the Moments of Truth in Service Competition, Lexington Books, and Lexington, MA.

Grönroos, C. (1994), "From marketing mix to relationship marketing: towards a paradigm shift in marketing”, Management Decision, 32, pp.4-20.

Grönroos, C. (1995), "Relationship marketing: The strategy continuum", Journal of the Academy of Marketing Science, 23, pp. 252-254.

Grönroos, C. (1997), "Value-driven relational marketing: From products to resources and competencies”. Journal of Marketing Management, 13, pp. 407-419.

Grönroos, C. (2000), "Relationship marketing: interaction, dialoge and value", Revista Europea de Dirección y Economía de la Empresa, 9, pp. 13-24.

Grönroos, C. (2001), Service Management and Marketing: A Customer Relationship Management Approach, 2nd ed., Wiley, New York, NY.

Groth, J.C. (1995a), "Exclusive Value and the Pricing of Services", Management Decision, 33, pp. 22-29.

Groth, J.C. (1995b), "Important Factors in the Sale and Pricing of Services", Management Decision, 33, pp. 29-34.

Gruen, T. (1995), The outcome set of relationship marketing in consumer markets, International Business Review, vol. 4, pp.447-469.

Guiot, D. and Roux, D. (2010), “A Second-hand Shoppers' Motivation Scale: Antecedents, Consequences and Implications for Retailers”, Journal of Retailing, 86, pp. 355-371.

Gummesson, E. (1987), The new marketing- developing long-term interactive relathionships, Long Range Planning, vol. 20, nº 4, pp. 10-20. 
Gummesson, E. (1991), Marketing revisited: The crucial role of the part-time marketers, European Journal of Marketing, vol. 25, nº 2, pp. 60-67.

Gummesson, E. (1997a), Relationship marketing as a paradigm shift: Some conclusions from the 30R approach, Management Decision, vol. 35, nº 4, pp. 267-272.

Gummesson, E. (1997b), In Search of Marketing Equilibrium: Relationship Marketing versus Hypercompetition, Journal of Marketing Management, Vol. 13, No. 5, pp.421-30.

Gummesson, E. (1999), “Total relationship marketing: Experimenting with a synthesis of research frontiers", Australasian Marketing Journal, 7, pp. 72-85.

Gummesson, E. (2000), Qualitative Methods in Management, 2nd rev. ed., Sage, Thousand Oaks, CA,

Gummesson, E. (2002), Practical value of adequate marketing management theory, European Journal of Marketing, Vol. 36 No.3, pp.325-49.

Gummesson, E. (2008), Total relationship marketing, Elsevier Ltd, Oxford

Gundlach, G.T; Achrol, R.S y Mentzer, J.T (1995):The Structure of Commitment in Exchange, Journal of Marketing, vol.59, $\mathrm{n}^{\mathrm{o}}$ 1, pp. 78.

Gundlach, T.G. y Murphy, P.E. (1993), Ethical and Legal Foundations of. Relational Marketing Exchanges, Journal of Marketing, vol. 57, pp.35-46.

Gwinner, K.P., Gremler, D., Bitner, M.J. (1998), Relational benefits in services industries: the consumer's perspective, Journal of the Academy of Marketing Science, Vol. 26 No.2, pp.101-14.

Haanpää, L. (2005), "Shopping for fun or for needs? A study of shopping values, styles and motives of Finnish consumers in 2001-2003", Proceedings of the 7th Conference of European Sociological Association, Torun, Poland, September, pp. 9-12.

Hair, J.H., Black, W.C., Babin, B.J., Anderson, R.E. and Tatham, R.L. (2006): Multivariate Data Analysis. 6 Ed. Upper Saddle River, NJ: Prentice Hall.

Hâkansson, H. (1982), International Marketing and Purchasing of Industrial Goods, John Wiley \& Sons, Nueva York.

Håkansson, H. (Ed.) (1987), Industrial Technology Development - a Network Approach. London: Croom Helm. 
Hales, C. (1991), Cautious incremental consumption: A neglected consumer risk reduction strategy, European Journal of Marketing, vol. 25, nº 7, pp. 7-21.

Hallén, L., Johanson, J. y Hâkansson, H. (1991), Interfirm adaptation in business relationships, Journal of Marketing, vol. 55, abril, pp. 29-37.

Hallowell, R. (1996), “The Relationships of Customer Satisfaction, Customer Loyalty, and Profitability: an Empirical Study", International Journal of Service Industry Management, 7, pp. 27-42.

Hardeep, K.S. (2010). Psychology: Part I. PHI Learning.

Harker, M.J. (1999), Relationship marketing defined? An examination of current relationship marketing definitions, Marketing Intelligence \& Planning, vol. 17, $\mathrm{n}^{\mathrm{o}}$ 1, pp. $13-20$

Harper, G. and Makatouni, A. (2002), "Consumer perception of organic food production and farm animal welfare", British Food Journal, 104, pp. 287-299.

Harris, L.C. y Goode, M.M.H. (2004), The four levels of loyalty and the pivotal role of trust: a study of online service dynamics, Journal of Retailing, vol. 80, Issue 2, pp. 139-158.

Hart, C., Doherty, N. y Ellis-Chadwick, F. (2000), Retailer Adoption of the Internet Implications for retail marketing. European Journal of Marketing, vol. 34, no. 8, pp. 954-974.

Hart, C.W.L., Heskett, J.L. y Sasser JR., W.E. (1990), The profitable art of service recovery, Harvard Business Review, vol. 68, (julio-agosto), pp. 148-156.

Hart, S., Smith, A., Sparks, L. and Tzokas, N. (1999), “Are Loyalty Schemes a Manifestation of relationship marketing?", Journal of Marketing Management, 15, pp. $541-562$.

Hau, L.N. and Ngo, L.V. (2012), "Relationship marketing in Vietnam: an empirical study", Asia Pacific Journal of Marketing Logistics, 24, pp. 222-235.

Havlena, W. and Hoolbrook, M. (1986), "The varieties of consumption experience: comparing two typologies of emotion in consumer behavior", Journal of Consumer Research, 13, pp. 394-404. 
Healy, M, Hastings, K, Brown, L. Y Gardiner, M. (2001), The old, the new and the complicated. A trilogy of marketing relationships, European Journal of Marketing, vol. $35, n^{\circ} 1-2$, pp 182-193.

Heide, J.B. (1994), Interorganizational governance in marketing channels, Journal of Marketing, vol. 35, $\mathrm{n}^{\mathrm{o}}$ enero, pp. 182-193.

Heide, J.B. y John, G. (1988), The role of dependence balancing in safeguarding transaction-specific assets in conventional channels. Journal of Marketing, Vol. 52 (January); pp. 20 - 35

Hellier, P.K., Geursen, G.M. Carr, R.A. and Rickard, J.A. (2003) "Customer repurchase intention: A general structural equation model", European Journal of Marketing, 37, pp. $1762-1800$.

Hennig-Thurau, T. and Hansen, U. (2000), Relationship marketing: Gaining competitive advantages through customer satisfaction and customer retention, Springer-Verlag, Berlin.

Hennig-Thurau, T. and Klee, A. (1997), “The Impact of Customer Satisfaction and Relationship Quality on Customer Retention: A Critical Reassessment and Model Development”, Psychology \& Marketing, 14, pp. 737-765.

Hennig-Thurau, T., Gwinner, K.P. and Gremler, D.D. (2002), "Understanding relationship marketing outcomes”, Journal of Service Research, 4, pp. 230-247.

Hermosilla, J., Rodrigo, C. y Fernández, M. (1997), Las Grandes Superficies Comerciales en la Comunidad Valenciana, Valencia: Departament de Geografía, Universitat de València.

Hess, J. y Story, J. (2005), Trust-based commitment: multidimensional consumer-brand relationships, Journal of Consumer Marketing, vol. 22, $\mathrm{n}^{\circ}$ 6, pp. 313-322.

Hewett, K. y O'Bearden, W. (2001), Dependence, trust and relational behaviour on the part of foreign subsidiary marketing operations: implications for managing global marketing operations, Journal of Marketing, vol. 65, $n^{\circ}$ 4, pp. 51-66.

Higie, R.A. y Feick, L.F. (1989), Enduring involvement: conceptual and measurement issues In Srull, T.K. (Eds.), Advances in Consumer Research, nº 16, pp. 690-695. 
Hirschmann, E. C. and Hoolbrook, M.B. (1982), "Hedonic consumption: emerging concepts”, Journal of Marketing, 46, pp. 92-101.

Hoffman, B (2015). Motivation for learning and performance. Oxford: Academic PressEl Sevier.

Hoffman, D. and Novak, T. (1996). "Marketing in hypermedia computer-mediated environments: conceptual foundations", Journal of Marketing, 60, pp. 50-68.

Holbrook, M.B., (Ed), (1999). Consumer value: A framework for analysis and research, Routledge, Nueva York.

Holmlund, M. (1996), A Theoretical Framework of Perceived Quality in Business Relationships. Helsingfors, Swedish School of Economics Finland.

Horovitz, J. (2000), Los siete secretos del servicio al cliente, Pearson Educación, S.A., Madrid.

Huang, M. (2015), “The influence of relationship marketing investments on customer gratitude in retailing”, Journal of Business Research, 68, pp. 1318-1323.

Huber, F., Herrmann, A. y Morgan, R. E. (2001), Gaining competitive advantage through customer value oriented management. Journal of Consumer Marketing, vol. 18, $\mathrm{n}^{\mathrm{o}}$ 1, pp. 41-53.

Huitt, W. (2011), "Motivation to learn: An overview". Educational Psychology Interactive, Valdosta, GA: Valdosta State University.

Hull, C.L. (1943). Principles of Behavior: an introduction to behavior theory. Oxford: England.

Hunt, S. D.; Ray, N. M. y Wood, V. R. (1985), Behavioral Dimensions of Channels of Distribution: Review and Synthesis., Journal of the Academy of Marketing Science, Vol. 13, no 3, pp. 1-24.

Hunt, S.D. (1997), Competing through relationship: Grouding relationship marketing in resource-advantage theory, Journal of Marketing Management, vol 13, pp. 431-445. Huppertz, J. (2000), Satisfaction, intention and complaining behaviour as predictors of customer retention or defection, paper presented to Ninth Annual American Marketing Asociation's Frontiers in Services Conference, Owen Graduate School of Management, Vanderbilt University, Nashville, Tennessee. 
Iacobucci, D. and Hibbard, J. (1999), “Toward an Encompassing Theory of Business Marketing Relationships (BMRs) and Interpersonal Commercial Relationships (ICRs): An Empirical Generalization”, Journal of Interactive Marketing, vol. 13, $\mathrm{n}^{\circ}$ 3, pp. 13-33.

Inagami, S., Cohen, D., Finch, B. and Asch, S. (2006), "You Are Where You Shop: Grocery Store Locations, Weight, and Neighborhoods" American Journal of Preventive Medicine, 31, pp.10-17.

Iniesta, M. A. (2000), El compromiso en la relación de intercambio entre consumidor y minorista, Tesis Doctoral, Universidad de Almería.

Jackson, B.B. (1985), Build customer relationships that last, Harvard Business Review, pp. $120-128$.

Jacoby, J. (1969), Towards a Multi-brand Model of Brand Loyalty, Department of Psychology, Purdue University, West Lafayette.

Jacoby, J. (1971), Brand Loyalty: A Conceptual Defi nition, Proceedings, 79th American Phycological Association Convention, pp. 655-656.

Jacoby, J. y Chestnut, R.W. (1978), Brand loyalty measurement and management, John Wiley \&Sons, Nueva York.

Jacoby, J. y Kynner,D.B. (1973), Brand Loyalty versus Repeat Purchasing Behavior, Journal of Marketing Research, vol. 10, pp. 1-9.

Jain, A.K., Pinson, C. y Malhotra, N.K. (1987), Customer Loyalty as a construct in the marketing of bank services, International Journal of Bank Marketing, vol. 5, pp.4972 ;

Jamal, A. y Anastasiadou, K. (2009), Investigating the Effects of Service Quality Dimensions and Expertise on Loyalty, European Journal of Marketing, vol. 43, pp. 91-102.

James, W. (1890). The Principles of Psychology, Vol. 1. Dover Books on Biology, Psychology, and Medicine.

Jarvis, C.B., Mackenzie, S.B. and Podsakoff, P.M. (2003), “A Critical Review of Construct Indicators and Measurement Model Misspecification in Marketing and Consumer Research”, Journal of Consumer Research, 30, pp. 199-218. 
Johnson, D. y Grayson, K. (2005), Cognitive and Affective Trust in Service. Relationships, Journal of Business Research, Vol. 58, no 4, abril, pp. 500-507.

Johnson, M. D., Herrmann, A. y Huber, F. (2006), The Evolution of Loyalty. Intentions, Journal of Marketing, vol. 70, abril, pp. 122-132.

Jones, M.A. and Suh, J. (2000) "Transaction-specific satisfaction and overall satisfaction: an empirical analysis", Journal of Services Marketing, 14, pp.147 - 159.

Jones, M.A., Reynolds, K. E. y Arnold, M. J. (2006). Hedonic and Utilitarian Shopping Value: Investigating Differential Effects on Retail Outcomes. Journal of Business Research, vol. 59, nº 9,pp. 974- 981.

Jones, T.O., y Sasser, W.E. (1995), Why satisfied customers defect?, Harvard Business Review, no 73, pp. 91-99.

Jöreskog, K.G. and Sörbom, D. (1996): LISREL 8: Structural Equation Modeling with the SIMPLIS Command Language. Chicago: Scientific Software International.

Jöreskog, K.G. y Sörbom, D. (1989), LISREL 7: A guide to the program and applications, Chicago: SPSS Inc.

Jöreskog, K.G. y Sörbom, D. (1996b), Lisrel 8 User's Reference Guide. Chicago: Scientific Software International.

Josiam, B.M., Kinley, T.R. \& Kim, Y.K. (2005), Involvement and the Tourist Shopper: Using the Involvement Construct to Segment the American Tourist-Shopper at the Mall. Journal of Vacation Marketing, vol. 11, $\mathrm{n}^{\mathrm{o}}$ 2, pp. 135-154,

Jüttner, U. y Wehrli, H.P. (1994), Relationship Marketing from a Value System Perspective, International Journal of Service Industry Management, vol. 5, nº 5, pp. 54-73.

Kalyanaram, G. y Little, J. (1994), An Empirical Analysis of Latitude of Price Acceptance in Consumer Package Goods. Journal of Consumer Research, vol. 21, pp. 408-418. Kang, J. and Park-Poaps, H. (2010), "Hedonic and utilitarian shopping motivations of fashion leadership", Journal of Fashion Marketing and Management, 14, pp. 312-328. Kau, A.K. y Ehrenberg, A.S.C. (1984), Patterns of Store Choice, Journal of Marketing Research, vol. 21, pp. 399-409. 
Kassim, N. and Abdullah, N.A. (2010), "The effect of perceived service quality dimensions on customer satisfaction, trust, and loyalty in e-commerce settings: A cross cultural analysis”, Asia Pacific Journal of Marketing, Vol. 22 (3), pp.351-371.

Kaufmann, P.J. y Stern, L.W. (1988), Relational Exchange Norms, Perceptions of Unfairness, and Retained Hostility in Commercial Litigation, The Journal of Conflict Resolution, vol. 32, nº 3, pp. 534-552

Kerin, R.A., Jain, A.J. y Howard, D.J. (1992), Store shopping experience and consumer price-qyality-value perceptions, Journal of Retailing, vol. 68, $\mathrm{n}^{\mathrm{o}} 1$, invierno, pp. 376-397.

Kesari, B. and Atulkar, S. (2016), "Satisfaction of mall shoppers: A study on perceived utilitarian and hedonic shopping values", Journal of Retailing and Consumer Services, 31 , pp. 22-31.

Kim, H. (2006), "Using hedonic and utilitarian shopping motivations to profile inner city consumers", Journal of Shopping Center Research, 13, pp. 57-79.

Kim, J., Morris, J. D. \& Swait, J. (2008) Antecedents of true brand loyalty. Journal of Advertising, vol. 37, pp. 99-117.

Kim, M. y Hunter, J. (1993), Relationships among attitudes, intentions \& behavior, Communication Research, $n^{\circ}$ 20, pp. 331-64.

Kim, M.K., Park, M.C. and Jeong, D.H. (2004), “The effects of customer satisfaction and switching barrier on customer loyalty in Korean mobile telecommunication services", Telecommunications Policy, 28, pp. 145-159.

Kim, M.K., Wong, S.F., Chang, Y. and Park, J.H. (2016), “Determinants of customer loyalty in the Korean smartphone market: Moderating effects of usage characteristics", Telematics and Informatics, 33, pp. 936-949.

Kim, Y.H., Kim, D.J. and Wachter, K. (2013), “A study of mobile user engagement (MoEN): Engagement motivations, perceived value, satisfaction, and continued engagement intention", Decision Support Systems, 56, pp. 361-370.

Kinard, B.R. y Capella, M.L. (2006), Relationship marketing: The influence of consumer involvement on perceived service benefits, Journal of Services Marketing, vol. 20, $n^{\circ} 6$, pp. 359-368. 
Kish, J. (2000), Before your customers leave, Journal of Bank Marketing, Vol. 32 No.2, pp.30-41.

Kleinginna, P. and Kleinginna, A. (1981), "A categorized list of motivation definitions, with a suggestion for a consensual definition”, Motivation and Emotion, Vol. 5.

Knox, S. y Denison, T. (2000), Store Loyalty: Its. Impact on Retail Revenue. An Empirical Study of Purchasing. Behaviour in the UK, Journal of Retailing and Consumer Services, vol. 7, pp. 33-45.

Ko de Ruyter, Josee Bloemer (1999), Customer loyalty in extended service settings: The interaction between satisfaction, value attainment and positive mood, International Journal of Service Industry Management, vol 10, nº 3, pp. 320-336.

Kopetz, C. (2007), "The quest for multifinality in goal pursuit", Dissertation Abstracts International, 69, p. 1378.

Kostecki, M.M. (1994), Marketing strategies for services: Globalisation, client orientation, deregulation, Pergamon Press, Oxford.

Kostojohn, S., Paulen, B. and Johnson, M. (2011), “CRM Fundamentals”. Apress.

Kotler, P. (1972), A Generic Concept of Marketing, Journal of Marketing, vol. 36, $\mathrm{n}^{\mathrm{o}} 2$, pp. $46-54$

Kotler, P. (1991), Marketing Management: Analysis, planning and control, Englewood Cliffs, Prentice Hall.

Kotler, P. (1995), Marketing for Hospitality and Tourism. Prentice Hall,

Kotler, P. (2000), Dirección de Marketing, Prentice Hall.

Kraus, S.J. (1995), Attitudes and the prediction of behavior: a meta-analysis of the empirical literature, Personality and Social Psychology Bulletin, vol. 21, $\mathrm{n}^{\mathrm{o}}$ 1, pp. $58-75$.

Krugman, H.E. (1965), The Impact of Television Advertising: Learning Without Involvement, Public Opinion Quarterly, vol. 29, otoño, pp. 349-56.

Kuhl, J. y Beckmann, J., (1985), Action control: From cognition to behavior, SpringerVerlag, W. Berlin.

Kumar, V. y Shah, D. (2004), Building and sustaining profitable customer loyalty for the 21 st century, Journal of Retailing, vol. 80, nº 4, pp. 317-330. 
Kurland, N., (1995), Ethical intentions and the theories of reasoned action and planned behavior. Journal of Applied Social Psychology, vol. 25, pp. 297-313.

Kuster, I. (2000), El marketing de relaciones, Quaderns de treball, $\mathrm{n}^{\circ}$ 106, Universitat de Valéncia.

Küster, I., Aldás, J., Torán, F. y Vila, N. (2000), El marketing de relaciones en el contexto de la venta personal, AEDEM, XIV Congreso Nacional. La gestión del conocimiento en la empresa, Libro de actas, pp. 125-136.

Kwon, K.N., Lee, M.H. y Kwon, Y.J. (2008); The effect of perceived product characteristics on private brand purchases, Journal of Consumer Marketing, vol 25, $\mathrm{n}^{\mathrm{o}} 2$, pp. 105-114.

Laaksonen, P. (1994), Consumer Involvement Concepts and Research, Routledge, Londres.

Lam, S.Y., Shankar, V. y Murthy, M.K. (2004), Customer Value, Satisfaction, Loyalty, and Switching Costs: An Illustration from a Business-to-Business Service Context, Journal of the Academy of Marketing Science, vol. 32, n³, pp. 293-311.

Lambe, C.J., Spekman, R.E. y Hunt, S.D. (2000), Interimistic relational exchange: conceptualizacion and propositional development, Journal of the Academy of Marketing Science, vol. 28, $\mathrm{n}^{\mathrm{o}}$ 2, pp. 212-225.

Lambin, J.J. (1995), Marketing estratégico. McGraw-Hill, Madrid. $3^{\text {a }}$ edición.

Lapierre, J. (2000), "Customer-perceived value in industrial contexts", Journal of Business \& Industrial Marketing, 15, pp. 122-140.

Larzelere, R.E. y Huston, T.L. (1980), The dyadic trust scale: toward understanding interpersonal trust in close relationships, Journal of Marriage and the Family, agosto, pp. 595-604.

Lastovicka, John L. y David M. Gardner (1979), Components of Involvement, en Attitude Research Plays for High Stakes, Eds. J. C. Maloney and B. Silverman, Chicago: AMA, pp. 53-73.

Latour, S.A. and Peat, N.C. (1979), Conceptual and methodological issues in satisfaction research, in William L. and A. Arbor (eds.), Advances in Consumer Research, $n^{\circ}$ 6, Michigan. 
Laurent, G. y Kapferer, J.N. (1985), Measuring Consumer Involvement Profiles, Journal of Marketing Research, vol. 22, $\mathrm{n}^{\mathrm{o}} 1$, pp.41-53.

Lawrence, R.J. (1969), Patterns of buyer behavior: Time for a new approach?, Journal of Marketing Research, vol. 6, $\mathrm{n}^{\circ}$ 2, pp. 137-144.

Leblanc, G. y Nguyen, N. (1999), Listening to the customer's voice: examining perceived service value among business college students, The International Journal of Educational Management, vol.13, nº 4, pp. 187-198.

Lee, E.J. y Overby, J.W. (2004). Creating Value for Online Shoppers: Implications for Satisfaction and Loyalty. Journal of Consumer Satisfaction, Dissatisfaction and Complaining Behavior, vol. 17, pp. 54-67.

Lee, R., Murphy, J. y Neale, L. (2009), The Interaction of Consumption Characteristics on Social Norms, Journal of Consumer Marketing, vol. 26, nº4, pp. 277-285.

Lee, Y., Lee, J. and Hwang, Y. (2015), "Relating motivation to information and communication technology acceptance: Self-determination theory perspective”, Computers in Human Behavior, 51, pp. 418-428.

Leigh, J.H. y Menon, A. (1987), Audience involvement effects on the information processing of umbrella print advertising, Journal of Advertisisng, vol. 16, $\mathrm{n}^{\mathrm{o}} 3$, pp. 3-12.

Leverin, A. y Lijander, V. (2006), Does relationship marketing improve customer relationship satisfaction and loyalty?, International Jorunal of Bank Marketing, vol. 24, no 4, pp. 232-251.;

Lewicki, R. J., McAllister, D. J. \& Bies, R. J. (1998), Trust and distrust: New relationships and realities, Academy of Management Review, vol. 23, nº 3, pp. 438-458

Lewin, J.E. y Johnston, W.J. (1997), Relationship marketing theory in practice, Journal of Business Research, vol. 39, $\mathrm{n}^{\circ}$ 1, pp.23-31.

Li, F. y Miniard, P.W. (2006), On the Potential for Advertising to Facilitate Trust in the Advertised Brand, Journal of Advertising, vol. 35, no 4, pp. 101-112.

Li, F. y Nicholls, J.A.F. (2000), Transactional or Relationship Marketing: Determinants of Strategic Choices, Journal of Marketing Management;, vol. 16, nº 5, pp. 449-464. 
Liang, C. \& Wang, W. (2005), Integrative research into the financial services industry in Taiwan: relationship bonding tactics, relationship quality and behavioural loyalty. Journal of Financial Services Marketing, vol. 10, $\mathrm{n}^{\mathrm{o}} 1$, pp. 65-83.

Lieberman, M., Montgomery, D. (1988), First mover advantages, Strategic Management Journal, vol. 9, $\mathrm{n}^{\mathrm{o}} .1, \mathrm{pp} .41-58$.

Lijander, V. y Strandvik, T. (1992), Different types of customer service expectations in relation to perceived value. Proceedings of the XXI Annual Conference European Marketing Academy, no 2, pp. 1351-1354.

Liljander,V. y Roos, I. (2002), Customer-relationship levels: From spurious to true relationships, Journal of Services Marketing, vol. 16, $\mathrm{n}^{\circ} 7$, pp. 1-34.

Lim, H. y Dubinsky, J.A. (2004), Consumers' perceptions of e-shopping characteristics: an expectancy-value approach, Journal of Services Marketing, vol. 18, nº7, pp.50013.

Lin, C. y Ding, C.G. (2005), Opening the black box: Assessing the mediating mechanism of relationship quality and the moderating effects of prior experience in ISP service, International Journal of Service Industry Management, vol. 16, $\mathrm{n}^{\circ}$ 1,pp. 55-80.

Lin, L.Y. y Chen, C.S. (2006), “The influence of the country-of-origin image, product knowledge and product involvement on consumer purchase decisions: an empirical study of insurance and catering services in Taiwan", Journal of Consumer Marketing, vol. 23, $\mathrm{n}^{\mathrm{o}}$ 5, pp. 248-265.

Lindenberg, S. and Steg, L. (2007), "Normative, gain and hedonic goal frames guiding environmental behavior", Journal of Social Issues, 63, pp. 117-137.

Lindgren, A. (2004), "Relationship use and market dynamism: a model of relationship evolution", Journal of Marketing Management, vol. 20, pp.825-38.

Liu, C., Guob, Y. and Lee, C. (2011), “The effects of relationship quality and switching barriers on customer loyalty", International Journal of Information Management, 31, pp.71-79.

Lombart, C. and Louis, D. (2012), “Consumer satisfaction and loyalty: Two main consequences of retailer personality", Journal of Retailing and Consumer Services, $6,644-652$. 
López de Castro, E. (2010), El marketing y la reconfiguración de las estructuras comerciales: los centros comerciales, Colección Mediterráneo Económico, Fundación Cajamar, Volumen 11.

Lord, K.R., Lee, M.S. and Saucr, P.L. (1995), "The Combined Influence Hypothesis: Central and Peripheral Antecedents of Attitude toward the Ad", Journal of Advertising, vol. 24, primavera, pp. 73-85.

Lovelock, C. (1991), Services marketing, text, cases and readings, $2^{\mathrm{a}}$ ed., Prentice Hall. Luhmann, N. (1988), Familiarity, Confidence, Trust: Problems and Alternatives, en Diego Gambetta (ed.) Trust: Making and Breaking of Cooperative Relations. pp. 94-107. Oxford: Blackwell.

Lusch, R. and Brown, J.R. (1996), Interdependence, contracting, and relational behavior in marketing channels, Journal of Marketing, vol. 60, octubre, pp.19-38.

Lutz, R., Karoly, P. and Okun, M. (2008), "The why and the how of goal pursuit: Selfdetermination, goal process cognition, and participation in physical exercise", Psychology of Sport and Exercise, 9, pp.559-575.

Lutz, RJ. y Winn, P.R. (1974), Developing a bayesian measure of brand loyalty: A preliminary report, en Curhan, R.C. (Ed.), Proceedings of the American Marketing Association, vol. 36, Chicago.

Macneil, I.R. (1980), The New Social Contract: An Inquiry into Modern Contractual Relations, Yale University Press, London.

Maffei, R. B. 1960. Brand preferences and simple Markov processes. Operation Reserarch, vol. 8, nº 2 pp. 210-218.

Magrath, A.J. (1995), Buscando nuevas fórmulas de obtener valor añadido, Marketing y Ventas, Ed. Deusto.

Martin, C.A. and Turley, L.W. (2004),"Malls and consumption motivation: an exploratory examination of older Generation Y consumers", International Journal of Retail \& Distribution Management, 32, pp. $464-475$.

Martín, D. (2001), El valor percibido como determinante de la fidelidad del cliente, Tesis Doctoral, Universidad de Sevilla. 
Martin, J. D. y Beerli, A. (1996), Antecedentes y Consecuencias de la Implicación de los Individuos hacia los Productos, Ponencia presentada en el X Congreso Nacional y VI Congreso Hispano-Francés, Granada.

Martin, V., Ponder, N. y Lueg, J.E. (2009), Price fairness perceptions and customer loyalty in a retail context, Journal of Business Research. Vol. 62, nº 6, pp. 588-593.

Martínez, J.A. y Martínez, L. (2009). Percepción del empleado y del cliente en servicios públicos deportivos. Revista Internacional de Medicina y Ciencias de la Actividad Física y el Deporte, vol. 9, nº 34, pp. 158-178

Martínez-Ribes, J.M., De Borja, L. y Carvajal, P. (1999), Fidelizando clientes. Detectar y mantener al cliente leal, ED. Gestión 2000.

Martín-Ruiz, D., Gremler, D.D., Washburn, J.H. and Cepeda-Carión, G. (2008), “Service value revisited: specifying a higher-order, formative measure", Journal of Business Research, 61, pp. 1278-1291.

Mattson, J. (1991), Better Business by the ABC of Values. Studentliteratur, Lund.

Maudos, J. y Pastor, J.M. (2000), La eficiencia del sistema bancario español en el contexto de la unión europea, Papeles de Economía Española, nº. 84/85, pp. 155168.

Mayer, R.C., Davis, J.H. y Schoorman, F.D. (1995), An Integrative Model of Organizational Trust, The Academy of Management Review, vol. 20, no . 3, pp. 709734.

McAllister, D.J. (1995), Affect and cognition based trust as foundations for interpersonal cooperation in organizations, Academy of Management Journal, vol. 38, $\mathrm{n}^{\mathrm{o}} 1$, pp.24-59.

McConnell, J.D. (1968), The Development of Brand Loyalty: An Experimental Study», Journal of Marketing Research, vol. 5, n. ${ }^{\circ}$ 1, pp. 13-19.

McDougall, G. H. G., y Levesque, T., (2000), Customer Satisfaction with Services: Putting Perceived Value into the Equation, Journal of Services Marketing, vol. 14, no 5, pp. 392-410.

McGoldrick, P. (2002). Retail Marketing, 2nd ed. McGraw-Hill, Maidenhead. 
McGuire, W.J., (1974), Psychological Motives and Communication Gratification, en: Blumler, J.G. y Katz, E. Edit., The Uses of Mass Communications, Sage Publications, Beverly Hills, CA

McIntyre, F. S., Thomas, J. L., Tullis, K. J. y Joyce, A. Y. (2004), Assessing effective exchange relationships: an exploratory examination, Journal of Marketing Theory and Practice, vol. 12, $\mathrm{n}^{\mathrm{o}}$ 1, pp. 36-48.

Mckenna, R. (1991), Relationship Marketing: Successful Strategies for the Age of the Customer, Perseus Books

Mckenna, R. (1994), Marketing de relaciones: cómo crear y mantener un vínculo permanente entre la empresa y sus clientes, Paidós, Barcelona

McKinney, V., Yoon, K. and Zahedi, F. (2001), "The Measurement of Web-Customer

Satisfaction: An Expectation and Disconfirmation Approach", Information Systems Research, pp. 296-315.

McMullan, R. y Gilmore, A. (2003), The conceptual development of customer loyalty measurement: A proposed scale, Journal of Targeting, Measurement \& Analysis for Marketing, vol. 11, nº 3, pp. 392-410.

Mellens, M, M. Dekimpe, G. y J. B.E.M Steenkamp. (1996), A Review of Brand-Loyalty Measures in Marketing. Tijdschrift voor Economie en Management, 41, 507-533.

Melnyk, Valentina, Stijn M. J. van Osselaer, y Tammo Bijmolt (2009), Are Women More Loyal Customers than Men? Gender Differences in Consumer Loyalty to Firms and Individual Service Providers, Journal of Marketing, vol.73, $\mathrm{n}^{\circ} 4$, pp. 82-96.

Miles, R. y Snow, C. (1986), Organizations: new concepts for new forms, California Management Review, vol. 28, $\mathrm{n}^{\circ} 2$, pp. 68-73.

Miles, R. y Snow, C. (1992), Causes of Failure in Network Organizations, California Management Review, vol. 34, no 4,pp. 53-72.

Miquel, S., Bigné, E., Lévy, J. P., Cuenca, A. C. y Miquel, M. J. (1996). Investigación de Mercados, McGraw-Hill. Madrid.

Mitchell, R. (1999), The research base of community based rehabilitation, Disability and Rehabilitation, $n^{\circ} 21$, pp 459-468. 
Mittal, B. (1982), Understanding the Bases and Effects of Involvement in the Consumer Choice Process, Ph.D. Dissertation, University of Pittsburgh.

Mohr, J.J., Fisher, R.J. y Nevin, J.R. (1996), “Collaborative Communication in Interfirm Relationships: Moderating Effects of Integration and Control", Journal of Marketing, Vol. 60, No. 3, pp. 103-115.

Moliner, B., Gil, I. and Ruiz, M.E. (2011), "Conceptualizing and measuring loyalty: towards a conceptual model of tourist loyalty antecedents", Journal of Vacation Marketing, 17, pp. 65-81.

Moliner, M.A. y Callarisa, L.J. (1997),’El marketing relacional o la superación del paradigma transaccional", Revista Europea de Dirección y Economía de la Empresa, vol. 6, n. ${ }^{\circ}$ 2, pp. 67-80.

Molinillo, S. y Parra F. (2001), Marketing relacional y actividad comercial en los centros urbanos, ESIC MARKET, ISSN 0212-1867.

Molinillo, S. (2002), Centros comerciales de área urbana, Madrid: ESIC Editorial.

Molinillo, S. (2014), Distribución comercial aplicada, Madrid: ESIC Editorial.

Mollá, A., Berenguer, G., Gómez, M.A. y Quintanilla, I. (2006), Comportamiento del Consumidor, Barcelona: Editorial UOC.

Moller, J. and Hansen, T. (2006), “An empirical examination of brand loyalty”, Journal of Product \& Brand Management, 15, pp. 442-449.

Moller, J. and Hansen, T. (2006), “An empirical examination of brand loyalty”, Journal of Product \& Brand Management, vol.15, nº 7, pp. 442-449.

Möller, K. and Halinen, A. (2000), "Relationship Marketing Theory: Its roots and directions", Journal of Marketing Management, vol. 16, nº 1/3, pp.29-54.

Möller, K.E. (1994), Interorganizational Marketing Exchange: Metatheoretical Analysis of Current Research Approaches. In: Laurent, G., Lilien, G. and Pras, B. Boston, Kluwer (Eds.), Research Traditions in Marketing, pp.348-382

Monroe, K. (1990), Pricing: Making profitable decisions, McGraw Hill, New York.

Moorman, C., Deshpandé, R and Zaltman, G. (1993), "Factor affecting trust in market research relationships". Journal of Marketing, vol. 57, 1, pp. 81-101. 
Moorman, C., Zaltman, G. and Deshpande, R. (1992), "Relationships between Providers and Users of market research: The dynamics of trust within and between organisations", Journal of Marketing Research, vol. 29, pp. 314-28.

Morgan, R. M. (2000) Relationship Marketing and Marketing Strategy: The Evolution of Relationship Marketing Strategy within the Organization. In J. N. Sheth and A. Parvatiyar (Eds.), Handbook of Relationship Marketing, pp. 481-504 Thousand Oaks, CA: Sage Publications.

Morgan, R. M. y Hunt S.D. (1994), The commitment-trust theory of relationship marketing, Journal of Marketing, vol.58, pp. 20-38.

Morris, D.J. (1995), A unitary approach to international mediation, Madison, CT: Market Power Institute.

Morris, M.H., Brunyee, J. y Page, M. (1998), Relationship Marketing in Practice: Myths and Realities, Industrial Marketing Management,vol. 27, nº 4, pp. 359-371.

Mudambi, R. y Mudambi, S.M. (1995), From Transaction Costs to Relationship Marketing: A Model of Buyer-Supplier Relations, International Business Review, vol. 4, no 4, pp. 419-33.

Muehling, D.D, Laczniak, R.N. y Andrews, J.C. (1993), Defining, operationalizing, and using involvement in advertising research: A review, Journal of Current Issues and Research in Advertising, vol. 15, $\mathrm{n}^{\mathrm{o}}$ 1, pp. 21-57.

Muehling, D.D, Laczniak, R.N. y Stoltman, J.J. (1991), The Moderating Effects of Ad Message Involvement: A Reassessment, Journal of Advertising, vol. 20, $\mathrm{n}^{\mathrm{o}} 2$, pp. 29-38.

Naudé, P. y Buttle, F. (2000), Assessing relationship quality, Industrial Marketing Management, vol. 29, nº.4, pp.351-361.

Ndubisi, N.O. and Matanda, M.J. (2011), "Industrial marketing strategy and B2B management by SMEs", Industrial Marketing Management, 40, pp. 334-335.

Nevin, J.R. (1995), Relationship marketing and distribution channels: exploring fundamental issues, Journal of the Marketing of Science, vol. 23, $n^{\circ} 4$, pp. 327-334

Newell, F. (1997), New Rules of Marketing, McGraw Hill 
Nicholls, A.J. (2002), "Strategic options in fair trade retailing", International Journal of Retail \& Distribution Management, 30, pp.6 - 17.

Nicholson, C.Y., Compeau, L.D. y Sethi, R., (2001), The Role of Interpersonal Trust in Building. Long-Term Channel Relationships, Journal of the Academy of Marketing Science, vol. 29, no 1, pp. 3-15.

Nickels, WG. y Wood, MB. (1997), Marketing: Relationships, Quality, Value, Worth Publishers, New York.

Nikhashemi, S., Tarofder, A., Gaur, S. and Haque, A. (2016), “The Effect of Customers' Perceived Value of Retail Store on Relationship between Store Attribute and Customer Brand Loyalty: Some Insights from Malaysia”, Procedia Economics and Finance, 37, pp. 432-438.

Noble, S.M., Griffith, D.A. and Adjei, M.T. (2006), "Drivers of local merchant loyalty: Understanding the influence of gender and shopping motives”, Journal of Retailing, 82, pp. 177-188.

Nooteboom, B., Berger, H. y Noorderhaven, N.G. (1997), Effects of trust and governance on relational risk, Academy of Management Journal, vol. 40, nº 2, pp. 308-338.

Noria, N. y Garcia-Pont, C. (1991), Global strategic lincages and industrial structure, Strategic Management Journal, vol. 12, pp. 105-124.

Novo, M. (2005). Educación ambiental y educación no formal: dos realidades que se realimentan, en Revista de Educación, $n^{\circ} 338$, monográfico sobre Educación no formal. Madrid. Ministerio de Educación y Ciencia.

Nueno, J.L. et al. (2000), Claves para el éxito del pequeño comercio, Madrid: Instituto de Estudios del Libre Comercio (IDELCO).

Nwokocha, I., Bao, Y., Johnson, W.C. y Brotspies, H.V. (2005), Product fit and consumer attitude toward brand extensions: the moderating role of product involvement, Journal of Marketing Theory and Practice, vol. 13, no 3, pp.13-49.

O'Cass, A. (2004), "Fashion clothing consumption: antecedents and consequences of fashion clothing involvement”, European Journal of Marketing, 38, pp. 869-882. 
Odin, Y., Odin, N. y Valette-Florence, P. (2001). "Conceptual and Operational Aspects of Brand Loyalty. An Empirical Investigation”, Journal of Retailing, vol. 53, $\mathrm{n}^{\mathrm{o}} 2$, pp. $75-84$.

Ogden, J. (2003). Some problems with social cognition models: A pragmatic and conceptual analysis. Health Psychology, 22, 424-428.

Okazaki, S., Li, H. y Hirose, M. (2009), Consumer Privacy Concerns and Preference for Degree of Regulatory Control: A Study of Mobile Advertising in Japan, Journal of Advertising, vol. 38, $\mathrm{n}^{\mathrm{o}}$ 4, pp. 63-79.

Oliva, T.A.; Oliver, R.L. y MacMillan, I.C. (1992), A Catastrophe Model for Developing Service Satisfaction Strategies. Journal of Marketing, Vol. 56, nº 3, pp. 83-95.

Oliver, R.L. (1980), “A Cognitive Model of the Antecedents and Consequences of Satisfaction Decisions", Journal of Marketing Research, 17, pp. 460-469.

Oliver, R.L. (1992), “Changing the Social Relations of Research Production”, Disability, Handicap \& Society, 7, 2, pp. 101-115.

Oliver, R.L. (1993), A conceptual model of service quality and service satisfaction: compatible goals, different concepts. In Swartz, T. A., Bowen, D. E., y Brown, S. W., (eds.), Advances in Services Marketing and Management 2. Greenwich, Conn.: JAI Press, pp. 65-85.

Oliver, R.L. (1996), Satisfaction: A Behavioral Perspective on the Customer, McGrawHill, New York.

Oliver, R.L. (1997), Satisfaction: A Behavioral perspective on the consumer, McGrawHill International Editions, New York.

Oliver, R.L. (1999), “Whence consumer loyalty?”, Journal of Marketing, 63, pp. 33-45.

Oliver, R.L. y Bearden, W.O. (1983), The Role of Involvement in Satisfaction Processes, in Advances in Consumer Research, Ann Arbor, MI: Association for Consumer Research.

Olson, J. M., \& Zanna, M. P. (1993). Attitudes and attitude change. Annual Review of Psychology, vol. 44, pp. 117-154.

O'Mally, L. (1998). Can loyalty schemes really build loyalty?. Marketing Intelligence and. Planning, vol. 16, $\mathrm{n}^{\mathrm{o}} 1$, pp. 47-55. 
Opperman, M., (2000), Where Psychology and Geography Interface in Tourism Research and Theory. En: Woodside, A., Crouch, G., Mazanec, J., Opperman, M. y Sakai, M., Editors, 2000, Consumer Psychology of Tourism, Hospitality and Leisure, Cabi Publishing, New York, pp. 19-37.

Ostrom, A. y Iacobucci, D. (1995), Consumer trade-offs and the evaluation of services, Journal of Marketing, vol. 59, (enero), pp. 17-28.

Palmatier, R. W., Dant, R. P., Grewal, D. y Evans, K. (2006), Factors influencing the effectiveness of relationship marketing: A meta-analysis, Journal of Marketing, vol. $70, \mathrm{n}^{\mathrm{o}} 4$, pp.136-153.

Palmatier, R.W., Jarvis, C.B., Bechkoff, J.R. and Kardes, F.R. (2009), "The role of customer gratitude in relationship marketing”, Journal of Marketing, 73, pp. 1-18.

Palmer, A. (1994), Principles of Services Marketing, McGraw-Hill

Pan, Y., Sheng, S. and Xie, F. (2012), “Antecedents of customer loyalty: an empirical synthesis and re-examination”, J. Retail. Consum. Serv., 19 (1), pp. 150-158.

Pappu, R. and Quester, P. (2006), "Does customer satisfaction lead to improved brand equity? An empirical examination of two categories of retail brands", Journal of Product and Brand Management, 15 (1), pp. 4-14.

Parasuraman, A. (1997), Reflections on gaining competitive advantage through customer value. Journal of the Academy of Marketing Science, vol. 25, nº 2, pp. 154-161.

Parasuraman, A. y Grewal, D. (2000a), Serving customers and consumers effectively in the twenty-first century: A conceptual framework and overview. Journal of the Academy of Marketing Science, vol. 28, nº 1, pp. 9-16.

Parasuraman, A. y Grewal, D. (2000b), The impact of technology on the quality-valueloyalty chain: a research agenda. Journal of the Academy of Marketing Science, vol. 28, $\mathrm{n}^{\mathrm{o}} 1$, pp. 168-174.

Parasuraman, A., Berry, L.L. y Zeithaml, V.A. (1991), Refinement and reassessment of the SERVQUAL scale', Journal of Retailing, vol. $67 \mathrm{n}^{\circ}$ 4, pp. 420-50.

Parasuraman, A., Zeithaml, V.A. and Berry, L.L. (1994), "Reassessment of expectations as a comparison standard in measuring service quality: implications for further research", 58, pp. 111-124. 
Parasuraman, A., Zeithaml, V.A. y Berry, L.L. (1985), A conceptual model of service quality and its implication for future research, Journal of Marketing, vol. 49, abril, pp. $41-50$.

Parasuraman, A., Zeithaml, V.A. y Berry, L.L. (1988), "SERVQUAL: a multiple-item scale for measuring consumer perceptions of service quality", Journal of Retailing, 64, pp. 12-40.

Park, C. W. and Mittal, B. (1985), “A Theory of Involvement in Consumer Behavior: Problems and Issues," Research in Consumer Behavior, 23, pp. 201-232.

Park, C.W. and Young, S.M. (1986), "Consumer Response to Television Commercials: The Impact of Involvement and Background Music on Brand Attitude Formation”, Journal of Marketing Research, vol. 23, n. 1, pp. 11-24.

PATECO (2015), Informe Anual de la Distribución Comercial Minorista en la Comunitat Valenciana.

Patterson, P.G. and Spreng, R. (1998), "Modelling the relationship between perceived value, satisfaction and repurchase intentions in a business-to-business context: an empirical examination", International Journal of Service Industry Management, Vol. $8 \mathrm{n}^{\circ} .5, \mathrm{pp} .414-434$.

Patterson, P.G. and Spreng, R.A. (1997), "Modeling the relationship between perceived value, satisfaction and repurchase intentions in a business-to-business, services context: An empirical examination", International Journal of Service Industry Management, vol. 8, $\mathrm{n}^{\mathrm{o}}$ 5, pp. 414-434.

Payne, A. (1995), Advances in Relationship Marketing, Kogan Page, London.

Payne, A., Christopher, M., Clark, M. y Peck, H. (1997), Relationship marketing for competitive advantage: winning and keeping customers, Butterworth Heinemann

Peck, H, Payne, A, Christopher, M, y Clark, M (1999), Relationship Marketing: Strategy and Implementation, Butterworth-Heinemann, Oxford.

Peppers, D. y Rogers, M. (1993), A new marketing paradigm: Share of customer, not market share, Managing Service Quality, vol. 5, $\mathrm{n}^{\circ} 3$, pp. 14-18.

Peppers, D. y Rogers, M. (1997), Enterprise one to one: Tools for competing in the interactive age, Doubleday Dell Publishing Group. 
Peter, J.P. y Olson, J.C. (1987), Consumer Behavior: Marketing Strategy Perspectives, Homewood: Irwin.

Peter, J.P. Y Olson, J.C. (1999), Consumer behavior and marketing strategy, $5^{\mathrm{a}}$ ed., Irwin McGraw-Hill, Nueva York.

Peterson, R.A. (1995), Relationship marketing and the consumer, Journal of the Academy of Marketing Science, vol. 23, nº 4, pp.278-281.

Petri, H., y Govern, J.M. (2006), Motivación: teoría, investigación y aplicaciones, Madrid: Thomson Paraninfo.

Petrick, J.F. (2002), "Experience use history as a segmentation tool to examine golf travellers' satisfaction, perceived value and repurchase intentions", Journal of Vacation Marketing, 8, pp. 332-342.

Petrick, J.F. (2004) “Are loyal visitors desired visitors?”, Tourism Management, 25, pp. 463-470.

Piercy, N.F. y Cravens, D.W. (1995), The network paradigm and the marketing organization, European Journal of Marketing, vol. 29, nº 9, pp. 7-34.

Ping, R.A (1993), The effects of satisfaction and structural constraints on retailer exiting, voice, loyalty, opportunism and neglect, Journal of Retailing, vol. 69, n 3, pp.32052.

Ping, R.A. (1994), Does Satisfaction Moderate the Association between Alternative Attractiveness and Exit Intention in a Marketing Channel?, Journal of the Academy of Marketing Science, vol. 22, $\mathrm{n}^{\mathrm{o}}$ 4,pp. 364-371.

Pittman, T.S., Emery, J. and Boggiano, A.K. (1982), “Intrinsic and extrinsic motivational orientations: Reward-induced changes in preference for complexity", Journal of Personality and Social Psychology, 42(5), pp. 789-797.

Porter, M. (1980), Competitive Strategy, Free Press, New York.

Porter, M. (1985), Competitive advantage: Creating and sustaining superior performance, Free Press, Nueva York.

Prebensen, N.K., Woo, E., Chen, J.C. and Uysal, M. (2012), "Motivation and Involvement as Antecedents of the Perceived Value of the Destination Experience”, Journal of Travel Research, 52, pp. 253-264. 
Prenshaw, P.J., Kovar, S.E. y Burke, K.G. (2006), The impact of involvement on satisfaction for new, nontraditional, credence-based service offerings, Journal of Services Marketing, vol. 20, $\mathrm{n}^{\circ}$ 7, pp. 439-452.

Price, L.L. y Arnould, E.J. (1999), Commercial friendships: service provider-client relationships in context, Journal of Marketing, vol.63, $n^{\circ} 4$, pp. 38-56.

Pritchard, M. P., Havitz, M. E., y Howard, D. R. (1999), Analyzing the commitmentloyalty link in service contexts. Journal of the Academy of Marketing Science, vol. 27, no 3, pp. 333-348.

Prochaska, J.O. y DiClemente, C.C. (1992), Stages of Change in the Modification of Problem Behaviors, Newbury Park, CA, Sage.

Provan, K.G. y Milward, H.B. (1995), Do networks really work? A framework for evaluating public-sector organizational networks, Public Administration Review, Vol. 61, No. 4, pp. 414-423

Puig, J. (2013). Estrategias de Email Marketing y Marketing Relacional Online

Rapp, S. y Collins, T. (1991), El nuevo rumbo del marketing, McGraw-Hill, Madrid.

Rapp, S. y Collins, T. (1996), El nuevo maxi-marketing, McGraw-Hill, Madrid.

Rasoolimanesh, S.M., Dahalan, N. and Jaafar, N. (2016) “Tourists' perceived value and satisfaction in a community-based homestay in the Lenggong Valley World Heritage Site", Journal of Hospitality and Tourism Management, 26, pp.72-81.

Ratchford, B.T. y Vaughn, R. (1989), On the Relationships Between Motives and Purchase Decisions: Some Empirical Approaches, en Advances in Consumer Research, vol. 16, T.K. Srull, ed. Provo.

Rauyruen, P. y Miller K.E. (2007), Relationship quality as a predictor of B2B customer loyalty. Journal of Business Research, vol. 60, n 1, pp. 21-31.

Ravald, A. and Grönroos, C. (1996), "The value concept and relationship marketing", European Journal of Marketing, 30, pp. 19-30.

Reeve, J. (2010). Motivación y Emoción. Madrid: McGraw-Hill.

Reeve, J. (2014). Understanding Motivation and Emotion. Hoboken: John Wiley \& Sons Inc. 
Reichheld, F.F. (1993), Loyalty-based management, Harvard Business Review, marzoabril, pp. 64-73.

Reichheld, F.F. (1996), The Loyalty Effect, Mass, Harvard Business School Press, Boston.

Reichheld, F.F. (2001), The loyalty effect: The hidden force behind growth, profits, and lasting value, Harvard Business School Press

Reichheld, F.F. y Sasser JR., W.E. (1990), Zero defections: quality comes to services. Harvard Business Review, vol. 68, (septiembre/ octubre), pp. 105-111.

Reinares y Ponzoa (2004), Marketing relacional: Un nuevo enfoque para la seducción y la fidelización del cliente, Prentice Hall Dinancial Times, Madrid.

Reinares, P. y Calvo, S. (1999), Gestión de la Comunicación Comercial. McGraw-Hill, Madrid.

Reinares, P. y Ponzoa, J.M. (2002). Marketing relacional. Prentice Hall, Madrid.

Reinares, P. y Ponzoa, J.M. (2004), Marketing relacional: Un nuevo enfoque para la seducción y la fidelización del cliente, Prentice Hall Dinancial Times, Madrid.

Reinartz, W.J. y Kumar, V. (2000), On the profitability of long-life customers in a noncontractual setting: An empirical investigation and implications for Marketing, Journal of Marketing, vol. 64, $n^{\circ} .4$, pp. 17-35

Reinartz, W.J. y Kumar, V. (2002), The Mismanagement of Customer Loyalty,. Harvard Business Review, vol. 80, Julio, pp. 86-94.

Reinartz, W.J. y Kumar, V. (2003), The impact of customer relationship characteristics on profitable lifetime duration, Journal of Marketing, vol. 67, $\mathrm{n}^{\circ} 1$, pp. 77-99.

Rempel, J.K., Holmes, J.G. \& Zanna, M.P. (1985), Trust in close relationships, Journal of Personality and Social Psychology, no 49, pp. 95-112.

Renninger, K.A. and Hidi, S. (2015). The power of interest for motivation and engagement. New York: Routledge.

Reynolds, K. y Beatty, S. (1999), Customer benefits and company consequences of customer-salesperson relationship in retailing, Journal of Retailing, vol. 75, $\mathrm{n}^{\mathrm{o}} 1$. 
Ribeiro, P. and Carvalho, S. (2010). "Hedonic and utilitarian shopping motivations among Portuguese young adult consumers", International Journal of Retail \& Distribution Management, 38, pp. 538-558.

Richins, M.L. y Bloch, P.H. (1991), Post-Purchase Product Satisfaction: Incorporating the Effects of Involvement and Time, Journal of Business Research, vol. 23, septiembre, pp.145-158

Richins, M.L., Bloch, P.H. y McQuarrie, E.F. (1992), How Enduring and Situational Involvement Combine to Create Involvement Responses, Journal of Consumer Psychology, vol. 1, no 2, pp. 143-153.

Rickman, T. A., and Cosenza, R. M. (2007), "The changing digital dynamics of multichannel marketing: The feasibility of the weblog: text mining approach for fast fashion trending", Journal of Fashion Marketing and Management, 11, pp. 604-621.

Rindfleisch, A. y Heide, J.B. (1997), Transaction Cost Analysis: Past, Present, and Future Applications, Journal of Marketing, vol. 61, octubre, pp. 30-54.

Robbins, S.P. (2003). Organizational Behavior. USA: Prentice Hall.

Robicheaux, R.A. y Coleman, J.E. (1995), The estructure of marketing cannel relationships, Journal of the Academy of Marketing Science, vol. 22, $n^{\circ} 1$, pp. 3851.

Robinette, S., Brand, C. \& Lenz, V. (2001), Emotion Marketing: the hallmark way of winning customer for life, New York: McGraw-Hill.

Rodríguez, S., Camarero, C. y Gutierrez, J (2002),Lealtad y valor en la relación del consumidor. Una aplicación al caso de los servicios financieros, Actas del XIV Encuentro de profesores Universitarios de Marketing (Granada), pp.429-446

Rogers, R.W. (1975), A protection motivation theory of fear appeals and attitude change, Journal of Psychology, vol. 91, pp. 93-114.

Rokkan, A.I. y Haugland, S.A. (2002), Developing relational exchange, European Journal of Marketing, vol.36, $\mathrm{n}^{\mathrm{o}}$ 1/2, pp. 211-230.

Rosendo, V. y Laguna P. (2014). Marketing Relacional. Editorial Dykinson, S.L.

Rothschild, M.L. (1984), Perspectives on Involvement: Current Problems and Future Directions, Advances in Consumer Research, nº 11, pp. 216-217. 
Rousseau, D., Sitkin, S.B., Burt, R.S. y Camerer, C. (1998), Not so different after all: a cross-discipline view of trust, Academy of Management Review-, vol. 23, $\mathrm{n}^{\mathrm{o}}$. 3, pp. 393-404.

Rundle-Thiele, S., Mackay, M.M., (2001) Assesing the performance of brand loyalty measures, Journal of Services Marketing, vol. 15, nº 7, pp. 529-546.

Rust, R.T. and Oliver, R.L. (1994), Service Quality Insights and Managerial Implications from the Frontier, in Rust, R.T y Oliver, R.L. (eds.), Service Quality New Directions in Theory and Practice. Beverly Hills: Sage.

Rust, R.T., Lemon, K.N. y Zeithaml, V.A. (2004), Return on Marketing: Using Customer Equity to Focus Marketing Strategy, Journal of Marketing, vol. 68, n 1, pp. 109127

Rust, T., Zeithaml, V. y Lemmon, K. (2000), Driving Customer Equity, The Free Press, Nueva York.

Ryan, R. M. (1982). "Control and information in the intrapersonal sphere: An extension of cognitive evaluation theory", Journal of Personality and Social Psychology, 43, pp. $450-461$.

Ryan, R.M. and Deci, E.L. (2000), "Intrinsic and Extrinsic Motivations: Classic Definitions and New Directions", Contemporary Educational Psychology, 25, pp. 5467.

Sainz de Vicuña, J.M. (2000), Marketing estratégico para el pequeño y mediano comercio, Bilbao: Ediciones PMP.

Sainz de Vicuña, J.M. (2001), La distribución comercial: opciones estratégicas, Madrid: ESIC Editorial.

Sako, M. and Helper, S. (1998), "Determinants of trust in supplier relations: evidence from the automotive industry in Japan and the United States", Journal of Economic Behavior and Organization, $\mathrm{n}^{\circ} 34$, pp. 387-417.

Sánchez, J., Callarisa, LL.J., Rodríguez, R.M. and Moliner, M.A. (2006), "Perceived value of the purchase of a tourism product", Tourism Management, 27, pp. 394-409. 
Sánchez, R. and Iniesta, M.A. (2009), "Efficiency and quality as economic dimensions of perceived value: Conceptualization, measurement, and effect on satisfaction", Journal of Retailing and Consumer Services, 6, pp. 425-433.

Santesmases, M. (1999), Marketing. Conceptos y estrategias, Pirámide.

Sarlak, M.A. and Fard, R.S. (2009)."The impact of CRM on the customer satisfaction in agricultural", Am. J. Econ. Bus. Admin., 1, pp. 167-172.

DOI: 10.3844/ajebasp. 167.172, 2009.

Scarpi, D. (2006), "Fashion stores between fun and usefulness", Journal of Fashion Marketing and Management, 10, pp. 7-24.

Schiffman, L.G. y Kanuk, L.L. (2004), Consumer Behaviour, New Jersey: Prentice- Hall Inc.

Schiffman, F. and Kanuk L. (2009). Consumer Behavior. New York: Prentice Hall.

Schlenker, B., Helm, B., y Tedeschi, J. (1973), “The effects of personality and situational variables on behavioral trust", Journal of Personality and Social Psychology, vol. 25, pp.419-27.

Schofield, P. and Thompson, K. (2007), "Visitor Motivation, Satisfaction and Behavioral Intention: The 2005 Naadam festival, Ulaanbaatar." International Journal of Tourism Research, 9, pp. 329-344.

Schunk, D. H., Pintrich, P. R., and Meece, J., L. (2008). Motivation in education. Upper Saddle. River, NJ: Pearson Merrill Prentice Hall.

Schwartz, S. and Waterman A. (2006), "Changing interests: A longitudinal study of intrinsic motivation for personally salient activities", Journal of Research in Personality, 40, pp. 1119-1136.

Shaffer, T.R. y Sherrell, D.L. (1997), Consumer Satisfaction with Health Care. Services: The Influence of Involvement, Psychology \& Marketing, vol. 14, nº 3, pp. 261-285.

Shankar, V., Smith, A.K. y Rangaswamy, A. (2003), Customer satisfaction and loyalty in online and offline environments, International Journal of Research in Marketing, vol. $20, \mathrm{n}^{\mathrm{o}} 2$, pp. 153-175. 
Shapiro, F. (1989), Eye movement desensitization: A new treatment for post-traumatic stress disorder, Journal of Behavior Therapy and Experimental Psychiatry, vol. 20, $\mathrm{n}^{\mathrm{o}} 3$, pp. 211-217.

Shapiro, F. y Varian, H. R., (1999), Information Rules: A Strategic Guide to the Network Economy, Boston: Harvard Business School Press.

Sharma, S., Niedrich, R.W. y Dobbins, G. (1999), A Framework for Monitoring Customer Satisfaction: An Empirical Illustration, Industrial Marketing Management, $n^{\circ} 28$, pp. 231-243.

Shaw, D. and Shiu, E. (2002), “An assessment of ethical obligation and self-identity in ethical consumer decision-making: a structural equation modeling approach", International Journal of Consumer Studies, 26, pp. 286-293.

Sheeran, P. y Taylor, S. (1999), Predicting intentions to use condoms: A meta-analysis and comparison of the theories of reasoned action and planned behavior, Journal of Applied Social Psychology, vol. 29, pp. 1624-1675.

Shepard, L. (1995), Using assessment to improve learning, Educational Leadership, vol. 52, pp.38-43.

Sheppard, B. H., Hartwick, J., y Warshaw, P.R (1988), The theory of reasoned action: A meta-analysis of past research with recommendations for modifications and future research, Journal of Consumer Research, vol. 15, pp. 325-343.

Sherif, M. y Cantril, H. (1947), The psychology of ego-involvements, New York: Wiley.

Sherrnan, S.J. y Fazio, R.H. (1983), Parallels between attitudes and traits as predictors of behavior, Journal of Personality, vol. 51, pp. 308-345.

Sherry, J.F. (1990), “A Sociocultural analysis of a midwestern American flea market”, Journal of Consumer Research, 17, pp. 13-30.

Sheth, J. N. and Parvatiyar, A. (2002), "Evolving relationship marketing into a discipline", Journal of Relationship Marketing, 1, pp.3-31.

Sheth, J. N., and Parvatiyar, A. (1995a), "Relationship marketing in consumer markets: Antecedents and consequences", Journal of the Academy of Marketing Science, 23, pp. $255-271$. 
Sheth, J. N., and Parvatiyar, A. (1995b), "The Evolution of Relationship Marketing", International Business Review, 4, pp. 397-418.

Sheth, J.N. (1976), Buyer-Seller Interaction: A Conceptual Framework, in Beverlee B. Anderson, ed., Advances in Consumer Research, Cincinnati: Association for Consumer Research, pp. 382-386.

Sheth, J.N. and Parvatiyar, A. (2000), Handbook of relationship marketing, Sage Publications, Thousands Oaks, California.

Sheth, J.N., Gardner, D.M. and Garrett, D.E. (1988). Marketing Theory. Evolution and Evaluation. John Wiley \& Sons, Canada.

Sheth, J.N., Newman, B.I. and Gross, B.L. (1991a), "Why we buy what we buy: A theory of consumption values", Journal of Business Research, 22, pp. 159-170.

Sheth, J.N., Newman, B.I. and Gross, B.L. (1991b), Consumption values and market choices: theory and applications, Southwestern Publications, Cincinnati.

Shoemaker, S. (1998), Strategic Approach to Segmenting the University Dining Population: It is More than Class Rank, Journal of Restaurant \& Foodservice Marketing, vol. 3, $\mathrm{n}^{\mathrm{o}} .1$, pp. 1-33.

Sin, L.Y.M. et al. (2005), "Relationship marketing orientation: scale development and cross-cultural validation", Journal of Business Research, 58, pp. 94-185.

Singh, J. (1990), Voice, exit and negative word of mouth behaviours: an investigation across three service categories, Journal of the Academy of Marketing Science, vol. $18, \mathrm{n}^{\mathrm{o}} 1$.

Singh, J. y Sirdeshmukh, D (2000), Agency and Trust Mechanisms in Relational Exchanges, Journal of the Academy of Marketing Science, vol. 28, nº 1, pp.150167.

Sirdeshmukh, D., Singh, J. y Sabol, B. (2002). Consumer Trust, Value, and loyalty in Relational Exchanges. Journal of Marketing, vol. 66, n ${ }^{\mathrm{o}}$ 1, pp. 15-37.

Sitkin, S. B. y Pablo, A. L. (1992), Reconceptualizing the determinants of risk behavior, Academy of Management Review, vol. 17, nº 9-39.

Sitkin, S., Roth, N. (1993), Explaining the limited effectiveness of legalistic 'Remedies' for trust/distrust, Organizational Science, vol. 4, pp.367-92. 
Sivakumar, K. y Raj, S. P. (1997), Quality Tier Competition: How Price Change Influences Brand Choice and Category Choice, Journal of Marketing, vol. 61, julio, pp.71-84.

Slater, S.F. (1997), "Developing a customer value-based theory of the firm", Journal of the Academy of Marketing Science, 25, pp. 162-167.

Slater, S.F. y Narver, J.C. (1994), Market orientation, customer value, and superior performance, Business Horizons, vol. 37, (marzo/abril), pp. 22-28.

Slater, S.F., (1997), Developing a customer value-based theory of the firm. Journal of the Academy of maketing Science, vol. 25, $\mathrm{n}^{\mathrm{o}} 2$, pp. 162-167.

Smith, S.M. y Beatty, S.E. (1984), Development of a generalized involvement scale, en Paul F. Anderson y Michael J. Ryan (Eds), 1984 AMA Winter Educators Conference: Scientific Method in Marketing, Chicago: American Marketing Association, pp. 229-232.

Söderlund, N.L. (1998), Customer satisfaction and its consequences on customer behaviour revisited: The impact of different levels of satisfaction on word-ofmouth, feedback to the supplier and loyalty, International Journal of Service Industry Management, vol. 9, $\mathrm{n}^{\mathrm{o}} 2$, pp. 169-188.

Soh, H., Reid, L.N. y King, K.W. (2009), Measuring Trust in Advertising:Development and Validation of the ADTRUST Scale, Journal of Advertising, vol. 38, n 2, pp. 83-103.

Solomon, M. and Rabolt, N. (2006). Consumer behavior in fashion". Harlow: Prentice Hall.

Solomon, M., Bamossy, G., Askegaard, S., and Hogg, M. K. (2013). Consumer behavior: A European perspective. Harlow: Pearson Education.

Spekman, R., y Mohr, J. (1994), Characteristics of Partnership Success: Partnership. Attribute, Communications Behaviour, and Conflict Resolution, Strategic Management Journal, vol. 15, no 2, pp. 135-152.

Spekman, R.E. and Carraway, R. (2006), "Making the transition to collaborative buyerseller relationships: an emerging framework", Industrial Marketing Journal., 35, pp. $10-19$. 
Spreng, R y Chiou, J. (2002), A cross-cultural assessment of the satisfaction formation process, European Journal of Marketing, vol. 36, no 7/8, pp. 829-839.

Spreng, R.A., Dixon, A.L. y Olshavsky, R.W. (1993), The impact of perceived value on consumer satisfaction, Journal of Consumer Satisfaction, Dissatisfaction and Complaining Behaviour, vol. 6, pp. 50-55.

Srinivasan, S.S., Anderson, R. and Ponnavolu, K. (2002), "Customer Loyalty in Ecommerce: An Exploration of its Antecedents and Consequences", Journal of Retailing, vol. 78, $\mathrm{n}^{\mathrm{o}} 1$, pp. 41-50.

Srivastava, R.K., Sherwani, T. A., and Fahey, L. (2000), "Market-based assets and shareholder value: A framework for analysis”, Journal of Marketing, vol. 62, pp. 218.

Stabell, C. and Fjelstand, O. (1998), "Configuring value for competitive advantage: on Caín, shops and networks”, Strategic Management Journal, vol. 19, pp. 413-437.

Stern, B., Thompson, C. and Arnold, E. (1998), "Narrative Analysis of a Marketing Relationship: The Consumers perspective”, Psychology \& Marketing, vol. 15, $\mathrm{n}^{\circ}$ 3, pp.195-214.

Stern, L.W. and Reve, T. (1980), 'Distribution Channels as Political Economies: a Framework for Comparative Analysis', Journal of Marketing, vol. 44, pp. 52-64.

Stern, L.W. and Brown, J.E. (1969), Distribution Channels: A Social System Perspective, en Distribution Channels: Behavioral Dimensions, L.W. Stem, ed. Boston: Mifflin Company,

Stern, L.W. y El-Ansary, A., (1992), Marketing Channels, Prentice Hall

Stern, P. and Hammond, K. (2004), “The Relationship Between Customer Loyalty and Purchase Incidence", Marketing Letters, vol. 15, pp. 1-19.

Stone, R.N. (1984), The Marketing Characteristics of Involvement. In Advances in Consumer Research, vol. 11, Thomas C. Kinnear, ed., Provo: Association for Consumer Research, pp. 210-215.

Strong, C. (1996), "Features contributing to the growth of ethical consumerism - a preliminary investigation", Marketing intelligence and Planning, 14, pp. 5-13. 
Suh, J., Janda, S. and Seo, S. (2006) "Exploring the role of culture in trust development with service providers", Journal of Services Marketing, vol. 20, nº4, pp. 265-273.

Sun, X., Chi, C.G. and Xu, H. (2013), "Developing destination loyalty: the case of Hainan Island", Annals of Tourism Research, 43, pp. 547-577.

Swan, J.E. and Trawick, I.F. (1981), "Disconfirmation of expectations and satisfaction with a retail service", Journal of Retailing, vol. 57, pp. 40-67.

Sweeney, J.C. y Soutar, G. (2001), “Consumer perceived value: The development of multiple item scale", Journal of Retailing, vol. 77, n 2, pp. 203-220.

Sweeney, J.C., Soutar, G N., and Johnson, L.W. (1999), "The role of perceived risk in the quality-value relationship: A study in a retail environment”, Journal of Retailing, 75, pp. 77-105.

Swobodaa, B., Bergb, B., Schramm-Kleinc H. and Foschtd, T. (2013), "The importance of retail brand equity and store accessibility for store loyalty in local competition", Journal of Retailing and Consumer Services, 20, pp.251-263.

Szymigin, I. y Carrigan, M. (2001), "Wherefore customer loyalty”, Journal of Financial Services Marketing, 6, pp.6-8.

Tauber, E.M. (1972), “Why do people shop?”, Journal of Marketing, 36, pp. 46-49.

Tax, S.S., Brown, S.W. and Chandrashekaran, M. (1998), "Customer Evaluations of Service Complaint Experiences: Implications for Relationship Marketing”, Journal of Marketing, vol. 62, pp. 60-76.

Taylor, S.A. y Baker,T.L. (1994), “An antecedent of the relationship between service quality and customer satisfaction in the formation of consumers' purchase intentions", Journal of Retailing, $\mathrm{n}^{\mathrm{o}} 70$, pp. 163-178.

Teas, K. and Agarwal, S. (2000), “The effects of extrinsic product cues on consumers' perceptions of quality, sacrifice and value", Journal of the Academy of Marketing Science, 28, pp. 278-291. 
Teas, R.K. (1993), "Expectations, performance evaluation, and customer perceptions of quality", Journal of Marketing, 57, pp. 18-34.

Terblanche, N. and Boshoff, C. (2006), "The relationship between a satisfactory in-store shopping experience and retailer loyalty", South Africa Journal of Business Management, vol. 37, $\mathrm{n}^{\mathrm{o}} .2$, pp.33-43.

Theron, E. and N.S. Terblanche (2010), "Dimensions of relationship marketing in business-to-business financial services”, Int. J. Market Res., 52: pp.373-392.

Thibaut, J.W. and Kelley, H.H. (1959). The social psychology of groups, Wiley, New York.

Thorelli, H.B. (1986), Networks: Between Markets and Hierarchies, Strategic Management Journal, vol. 7, nº 1, pp. 37-51.

Treacy, M. and Wiersema, F. (1993), Customer intimacy and other value disciplines, Harvard Business Review, vol. enero/febrero, pp. 84-93.

Trespalacios, A. J. (1993), Hacia un nuevo concepto de marketing. Del marketing como intercambio al marketing de relaciones, Anales de Economía y Administración de Empresas, pp. 114-128.

Tucker, W. T. (1964), “The Development of Brand Loyalty”, Journal of Marketing Research, vol. agosto, pp. 32-35.

Ulaga, W. and Eggert, A. (2003), Developing a Standard Scale of Relationship Value in Business Markets: Development of a Measurement Scale, Working Paper 2/2003. Working Paper Series. Institute for the Study of Business Markets (ISBM) at the Penn State University, University Park.

Uncles, M. y Laurent, G. (1997), Editorial, special Issue on loyalty. International Journal of Research in Marketing, $\mathrm{n}^{\mathrm{o}}$ 14, pp. 399-404

Uncles, M.D., Dowling, G.R. y Hammond, K. (2003), “Customer loyalty and customer loyalty programs", The Journal of Consumer Marketing, vol. 20, nº.4, pp.294-316.

Uncles, M.D., Hammond, K.A. y Ehrenberg, A.S.C. (1995), "Patterns of buyer behavior: regularities, models and extensions, part 2", Marketing Science, vol. 14, no.3, pp.7178.

Uriel, E. y Aldás, J. (2005), Análisis multivariante aplicado, Madrid: Thomson. 
Van Heerde, H.J.and Bijmolt, T.H.A. (2005), "Decomposing the Promotional Revenue Bump for Loyalty Program Members Versus Nonmembers”, Journal of Marketing Research, vol. 42, $n^{\circ}$ 4, pp. 443-457.

Vázquez-Carrasco, R. and Foxall, G. R. (2006), "Influence of personality traits on satisfaction, perception of relational benefits, and loyalty in a personal service context”, Journal of Retailing and Consumer Services, nº 13, pp. 205-219.

Verlegh, P.W.J., Steenkamp, J.B.E.M. and Meulenberg, M. (2005), "Country-of-origin effects in consumer processing of advertising claims", International Journal of Research in Marketing, vol. 22, nº 2, pp. 127-139.

Wagner, T., Hennig-Thurau, T. and Rudolph, T. (2009), "Does customer demotion jeopardize loyalty?", Journal of Marketing, vol.73, nº 3, pp. 69-75.

Wakefield, K.L. and Baker, J., (1998), "Excitement at the mall: determinants and effects on shopping response", Journal of Retailing 74 (3), 515-540.

Wallace, D. W., Giese, J.L. and Johnson, J.L. (2004), “Customer Retailer Loyalty in the Context of Multiple Channel Strategies”, Journal of Retailing, vol. 80, n 4, pp. 249263.

Walters, D. and Lancaster, G. (1999), "Value and information - concepts and issues for management”, Management Decision, 37, pp. 643-656.

Wang, H. and Wang, S. (2010), "Predicting mobile hotel reservation adoption: Insight from a perceived value standpoint", International Journal of Hospitality Management, 29, pp. 598-608.

Wang, W.H., Liang, C.J. y Wu, Y.D. (2006), "Relationship bonding tactics, , relationship quality and behavioral loyalty-behavioral sequence in Taiwan's information services industry", Journal of Services Research, vol. 6, nº 1, pp. 31-57.

Wang, X., Kim, T. and Lee, D. (2016), “Cognitive diversity and team creativity: Effects of team intrinsic motivation and transformational leadership", Journal of Business Research, 69, pp. 3231-3239.

Webster, F.E. (1992), “The changing role of marketing in the corporation”, The Journal of Marketing, vol. 56, $\mathrm{n}^{\mathrm{o}} .4$, pp. 1-17 
Weinstein, R. y Johnson, W.C. (1999), Designing and delivering superior customer value: concepts, cases, and applications, Boca Raton, Fla. St. Lucie Press, Londres.

Weitz, B.A.y Jap, S.D. (1995), "Relationship marketing and distribution channels", Journal of the Academy of Marketing Science,vol. 23, n 4, pp. 305-320.

Westbrook, R. and Black, W. (1985), “A motivation-based shopper typology”, Journal of Retailing, 61, pp. 78-103.

White, R. W. (1959). "Motivation reconsidered”, Psychological Review, 66, pp. 297333.

Wicker, F.W., Lambert, F.B.,Richardson,F.C. and Kahler,J. (1984), "Categorical goal hierarchies and classification of human motives", Journal of Personality, Vol. 52(2), pp. 285-305.

Williams, S. (2004). Tourism: Critical concepts in the social sciences. Routledge.

Williamson, O. (1975), Markets and Hierarchies: Analysis and Antitrust Implications, New York, Free Press.

Williamson, O. (1985), The Economics Institutions of Capitalism, New York, Free Press Williamson, O. (1993), “Calculativeness, trust, and economic organization”, The Journal of Law \& Economics, vol. 36, $\mathrm{n}^{\circ} 1$, pp. 487-500.

Wilson, D.T. (1995), "An integrated model of buyer-seller relationships", Journal of the Academy of Marketing Science, vol. 23, n $n^{\circ}$ 4, pp. 335-345.

Wong, A. y Sohal, A. (2002), "An examination of the relationship betwen trust, commitment and relationship quality", International Journal of Reailing \& Distribution Management, vol. 30, $\mathrm{n}^{\mathrm{o}}$ 1, pp. 34-50.

Woodall, T. (2003), "Conceptualising value for the customer: An attributional, structural and dispositional analysis", Academy of Marketing Science Review, n 12, pp. 142.

Woodruff, R.B. (1997), "Customer value: The next source of competitive advantage", Journal of the Academy of Marketing Science, 25, pp. 139-153.

Woodworth, R.S. (1918). Dynamic Psychology. New York: Columbia University Press.

Wright, P. (1973), “The Cognitive Processes Mediating Acceptance of Advertising”, Journal of Marketing Research, vol. 10, pp. 53-62. 
Wu, L., Kang, M. and Yang, S.B. (2015), "What makes users buy paid smartphone applications? Examining app, personal, and social influences", Journal of Internet Banking and Commerce, 20, pp. 1-22.

Yang, Z. and Peterson, R. (2004), "Customer perceived value, satisfaction, and loyalty: the role of switching costs", Psychol. Mark., 21 (10), pp. 799-822

Yau, J., Lee, R., Chow, L. and Tse, A. (2000), "Relationship marketing: the Chinese way", Business Horizons, 43, pp. 16-24.

Yi, Y. (1990), A critical review of consumer satisfaction, en V. Zeithaml (ed.) Review of Marketing, AMA, Chicago.

Yi, Y. and Jeon, H. (2003), "Effects of Loyalty Programs on Value Perception, Program Loyalty, and Brand Loyalty", Journal of the Academy of Marketing Science, vol.31, $\mathrm{n}^{\mathrm{o}} 3$, pp. 229-240.

Yi, Y., and La, S. (2004), "What influences the relationship between customer satisfactions and repurchase intention? Investigating the effects of adjusted expectations and customer loyalty", Psychology and Marketing, vol. 21, n5, pp. 351-373.

Yoganathan, D., Jebarajakirthy, C. and Traichon, P. (2015), "The influence of relationship marketing orientation on brand equity in banks", Journal of Retailing and Consumer Services, 26, pp. 14-22.

Yoon, Y. and Uysal, M. (2005), "An Examination of the Effects of Motivation and Satisfaction on Destination Loyalty: A Structural Model.” Tourism Management, 26, pp. 45-56.

Yoon, Y., Lee, J. and Lee, C. (2010), "Measuring festival quality and value affecting visitors' satisfaction and loyalty using structural approach”, International Journal of Hospitality Management, 29, pp. 335-342.

Yuping, L. and Yang, R. (2009), "Competing loyalty programs: Impact of market saturation, market share, and category expandability", Journal of Marketing, vol. 73, pp. 93-108. 
Zablah, A.R., Johnston, W.J. and Bellenger, D.N. (2005), "Transforming partner relationships through technological innovation”, Journal of Business \& Industrial Marketing, vol. 20, $\mathrm{n}^{\mathrm{o}}$ 7, pp. 335-363.

Zaltman, G. and Wallendorf, M. (1983), Consumer Behavior, Wiley, New York.

Zuluaga, G. (2014). Establecimiento de procesos de Marketing Relacional en empresa Retail: Establecimiento de procesos de marketing relacional en los almacenes del Comité de Cafeteros del Quindío. Eae edito 
